\author{
UNIVERSIDADE DE SÃO PAULO \\ ESCOLA DE ENGENHARIA DE SÃO CARLOS \\ DEPARTAMENTO DE ENGENHARIA MECÂNICA
}

\title{
DIAGRAMAS DE LIMITE DE CONFORMAÇÃO APLICADOS À ANÁLISE POR ELEMENTOS FINITOS DE UM PROCESSO DE ESTAMPAGEM EM CHAPAS METÁLICAS
}

Eng $^{0}$ Sérgio Henrique Evangelista

Dissertação apresentada à Escola de Engenharia de São Carlos da Universidade de São Paulo, como parte dos requisitos para obtenção do título de Mestre em Engenharia Mecânica

ORIENTADOR: Prof. Dr. João Lirani

São Carlos

2000 
Aos meus pais Esmeraldo e Lúcia, aos meus irmãos Paulo, Daniel, André e Carlos

à Norma, ao Agostinho e ao Tóti,

e à Rita . 


\section{Agradecimentos}

Ao Professor João Lirani, pela dedicação, orientação e amizade .

Aos Professores João Lirani, Reginaldo Teixeira Coelho, Sérgio Persival Baroncini Proença e Hazim Ali Al-Qureshi pelas valiosas contribuições dadas a este trabalho .

Aos amigos Mariano e Neilor pelas discussões e sugestões .

Aos amigos do grupo CAD-CAE, César e Giovanni .

Aos amigos Godoy, Volnei, Rodrigo, Alexandre, Gi, Kelen, Carlos, Zé Croce, Ana Lúcia, Fabiana, Luciana, Hubinger, Torres, Geraldo, Klaus, Cuca e Canto.

Às secretárias da pós-graduação Beth e Ana Paula, pela eficiência na resolução de questões burocráticas .

Aos colegas, professores e funcionários do departamento de Engenharia Mecânica .

Às demais pessoas que contribuíram direta ou indiretamente na realização deste trabalho.

À CAPES - Fundação Coordenação de Aperfeiçoamento de Pessoal de Nível Superior, pela bolsa de estudo, sem a qual seria impossível a realização deste trabalho . 
Sumário

Lista de figuras. iv

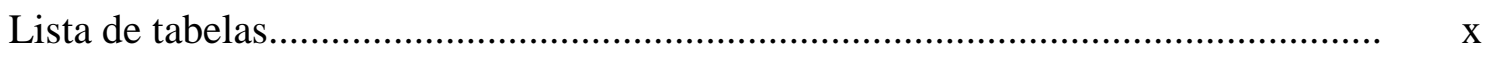

Lista de abreviaturas e siglas........................................................................ $\quad$ xi

Lista de símbolos....................................................................................... xii

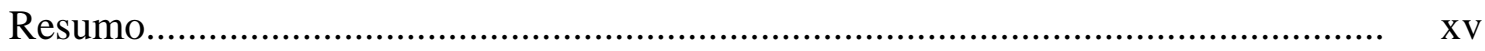

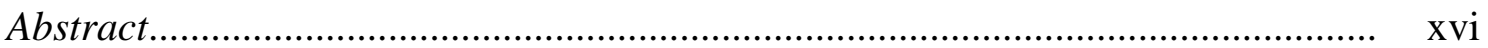

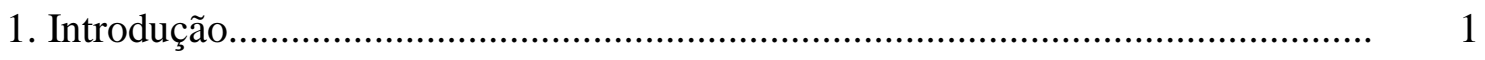

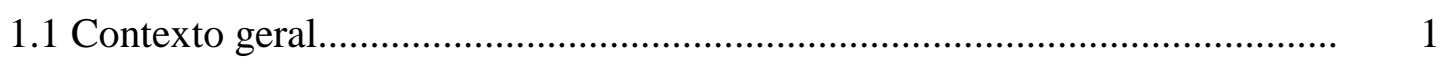

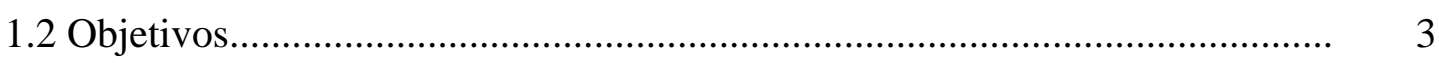

1.3 Conteúdo deste trabalho..............................................................................

2. Uma introdução à análise de conformação de chapas............................................ 5

2.1 Conformação de chapas metálicas.................................................................. 5

2.2 Análise de processos de conformação de chapas............................................ 7

2.3 Tópicos da teoria da plasticidade aplicada à conformação de chapas.............. 9

2.4 Procedimentos de análise pelo Método de Elementos Finitos......................... 23

2.4.1 Aplicação do método dos Elementos Finitos a processos de conformação de metais...................................................................... 26

2.4.2 Dificuldades para simulação do processo de conformação...................... 27

2.4.3 Equacionamento de problemas estruturais mecânicos............................ 28

2.4.4 Resolução numérica de problemas não-lineares : abordagem estática implícita. 
2.4.5 Resolução numérica de problemas não-lineares: integração no tempo e a abordagem dinâmica explícita.

3. Diagramas de limite de conformação. 43

3.1 Aspectos de conformabilidade de chapas metálicas. 43

3.2 A presença de defeitos na chapa. 46

3.3 Ensaios de conformabilidade. 50

3.4 A representação gráfica do limite de conformabilidade. 52

3.5 Determinação teórica dos limites de conformabilidade. 55

3.5.1 Tensões uniaxiais em um corpo de prova perfeito. 56

3.5.2 Tensões uniaxiais em um corpo de prova imperfeito... 58

3.5.3 Tensões uniaxiais em um material sensível à taxa de deformação 60

3.5.4 O conceito de estricção em chapas contínuas. 62

3.5.5 Uma condição para a estricção local. 63

3.5.6 Estricção em tensões biaxiais. 70

3.6 Métodos gerais para cálculo dos diagramas. 75

4. Cálculo de diagramas de limite de conformação por elementos finitos 80

4.1 Considerações gerais.

4.2 Determinação por Elementos Finitos de diagramas de limite de conformação.

4.2.1 Modelo $M K$ analisado de modo alternativo.

4.2.2 Implementação por Elementos Finitos 84

4.3 Discussões sobre as curvas obtidas. 88

5. Análise de estampagem por diagramas de limite de conformação. 96

5.1 Metodologia proposta. 96

5.2 Análise por Elementos Finitos de problemas de estampagem. 100

5.2.1 Pré-processamento. 100

5.2.2 Solução. 109 
5.2.3 Pós-processamento.

5.3 Avaliação dos casos de estampagem em relação aos diagramas de limite de conformação obtidos.

5.3.1 Avaliação do caso 1

5.3.2 Avaliação do caso 2.

5.3.3 Considerações para o diagrama de limite de tensões de conformação..... 124

5.4 Variáveis para otimização do projeto de estampos

126

6. Conclusões e sugestões para trabalhos futuros.

7. Referências bibliográficas

Apêndice I. 


\section{Lista de figuras}

FIGURA 1.1.1 : Elementos diversos na tecnologia moderna de conformação de chapas, por LANGE (1997)............................................................ 2

FIGURA 2.1.1 : Composição básica de uma ferramenta de estampagem

FIGURA 2.2.1 : Principais variáveis no processo de conformação de chapas metálicas e suas inter-relações (KOBAYASHI et al. 1989)

FIGURA 2.2.2 : Diagrama de blocos para o projeto e controle do processo em conformação de metais (KOBAYASHI et al., 1989)

FIGURA 2.3.1 : Tração uniaxial. (a) Corpo de prova; (b) Curvas tensãodeformação (KOBAYASHI et al., 1989)...................................................

FIGURA 2.3.2 : Tensões, deformações e taxa de deformações............................. 11

FIGURA 2.3.3 : Representação geométrica de um estado de tensões plástico no espaço $\left(\sigma_{1}, \sigma_{2}, \sigma_{3}\right)$, (KOBAYASHI et al.,1989).

FIGURA 2.3.4 : Yield locii no plano $\pi$ para os critérios de máxima tensão de cisalhamento e energia de distorção, (KOBAYASHI et al., 1989).........

FIGURA 2.3.5 : Modelos matemáticos para a representação do comportamento com encruamento, (OWEN, 1986).

FIGURA 2.4.1 : Processo de análise por Elementos Finitos, (BATHE,1996)...

FIGURA 2.4.2 : Corpo tridimensional genérico com um elemento de 8 nós, (BATHE, 1996).

FIGURA 2.4.3 : Movimento de um corpo em um sistema de coordenadas Cartesiano, (BATHE, 1996)

FIGURA 2.4.4 : Corpos em contato no tempo $t$, (BATHE,1996).

FIGURA 2.4.5 : Aproximações sucessivas para obtenção da solução $u$. 38

FIGURA 2.4.6 : Método de Newton Raphson para o cálculo de $u$. 
FIGURA 2.4.7 : Método de Newton Raphson modificado

FIGURA 3.2.1 : Alguns defeitos presentes em chapas conformadas

(KOBAYASHI et al,1989)

FIGURA 3.4.1 : Representação dos possíveis defeitos na chapa em um diagrama $\left(\varepsilon_{1}, \varepsilon_{2}\right)$

FIGURA 3.4.2 : Diagrama de limite de conformação determinado através de estricção e/ou fratura

FIGURA 3.4.3 : Teste do punção esférico, conforme norma ABNT - MB $362 / 79$

FIGURA 3.4.4 : Modelo de corpo de prova para o estiramento biaxial, conforme FERRON \& MAKINDE (1988).

FIGURA 3.5.1 : Porção de um corpo de prova perfeito.

FIGURA 3.5.2 : Encruamento adimensional versus deformação para um material recozido.

FIGURA 3.5.3 : Carga versus a) elongação e b) deformação para um corpo de prova perfeito

FIGURA 3.5.4 : Porção de um corpo de prova imperfeito.

FIGURA 3.5.5 : Carga versus deformação para regiões uniforme e imperfeita..

FIGURA 3.5.6 : Diagrama carga x elongação para um corpo de prova imperfeito.

FIGURA 3.5.7 : Carga x deformação para um teste com taxa constante de deformação.

FIGURA 3.5.8 (a) : Tensão x taxa de deformação e área nas regiões uniforme e imperfeita; (b) : Diferenças nas taxas de deformação para materiais diferentes

FIGURA 3.5.9 : Diferentes taxas de crescimento em imperfeições com diferentes valores $m$

FIGURA 3.5.10 : Perturbação em uma casca esférica através de estricção difusa

FIGURA 3.5.11 : Forças específicas, $T_{1}$ e $T_{2}$ em uma chapa por um processo dito proporcional ( $T_{1}$ e $T_{2}$ são forças por unidade de comprimento).... 
FIGURA 3.5.12 : Valores de deformação por diferentes caminhos de carregamentos e para tensões máximas, em que o material obedeça a $\sigma_{f}=K \cdot \varepsilon^{n}$

FIGURA 3.5.13 : Uma imperfeição que é difusa em relação à espessura da chapa, mas que é localizada na superfície.

FIGURA 3.5.14 : Necking local em uma região uniformemente deformada e orientada de $\theta$ em relação à maior tensão principal

FIGURA 3.5.15 : Círculo de Mohr para deformações incrementais, mostrandose a orientação da linha cuja deformação é nula..

FIGURA (3.5.16) : Aumento observado experimentalmente em deformações estáveis além da tensão máxima e no estiramento biaxial, $0<\beta<1$, segundo MARCINIAK \& DUNCAN (1992)

FIGURA 3.5.17 : Imperfeição $B$ em uma região $A$ sujeita a deformações uniformes

FIGURA 3.5.18 : O estado de tensões na região uniforme $\mathrm{A}_{0}$ e na imperfeição $\mathrm{B}_{0}$ no início das deformações plásticas

FIGURA 3.5.19 : Giro do vetor de deformações quando se move em torno da superfície de tensões de escoamento

FIGURA 3.5.20 : Estado de tensões na região uniforme $A$ e no rebaixo $B$ após o primeiro incremento de deformações.

FIGURA 3.5.21 : Trajetória de um ponto representando o estado de tensões no rebaixo $B$ tendendo ao estado plano de deformações, onde $\alpha=1 / 2 \ldots$.

FIGURA 3.5.22 : Trajetória para deformações no rebaixo $B$ e na região uniforme A.

FIGURA 3.5.23 : Diagrama de limite de conformação representando as deformações finais $\left(\varepsilon_{2 A}, \varepsilon_{1 A}\right)$ na região uniforme $A$ para diversas trajetórias de deformações $\beta$.

FIGURA (3.6.1) : Curvas limites para solicitação biaxial, GHOSH \& LAUKONIS (1976).

FIGURA (3.6.2) : Curvas limites para solicitação uniaxial, GHOSH \& LAUKONIS (1976)

FIGURA 3.6.3 : Diagramas FLSD para tensões (STOUGHTON , 2000). 78 
FIGURA 3.6.4 : Modelo $M K$ e a imperfeição rotacionada de $\theta$

FIGURA 4.2.1 : Imperfeição $B$ em uma região $A$ sujeita a deformações uniformes, conforme $M K$

FIGURA 4.2.2 : Algoritmo de cálculo para a estricção, implementado com o método dos Elementos Finitos.

FIGURA 4.2.3 : Comportamento de material no defeito do trecho de chapa analisado.

FIGURA (4.2.4) : Malha, vinculações, carregamentos e direções principais de análise

FIGURA 4.3.1 : Distribuição de deslocamentos na direção $x$ para um valor genérico de $\alpha$.

FIGURA 4.3.2 : Distribuição das deformações plásticas principais na direção 1 para um valor genérico de $\alpha$

FIGURA 4.3.3 : Distribuição das deformações plásticas principais na direção 2 para um valor genérico de $\alpha$

FIGURA 4.3.4 : Distribuição das deformações plásticas principais na direção 3 para um valor genérico de $\alpha$

FIGURA 4.3.5 : Distribuição das tensões principais na direção 1 para um valor genérico de $\alpha$

FIGURA 4.3.6 : Estricção na chapa para um valor genérico de $\alpha$.

FIGURA 4.3.7 : Comparação de curvas de limite de conformação diversas

$$
(n=0.22 \text { e } m=0.012)
$$

FIGURA 4.3.8 : Influência do parâmetro $n$ nas curvas limite, para $m=0.012 \ldots$.

FIGURA 4.3.9 : Influência do parâmetro $m$ nas curvas limite, para $n=0.19 \ldots \ldots .93$

FIGURA 4.3.10 : Influência do parâmetro $m$ nas curvas limite, para $n=0.22 \ldots$.

FIGURA 4.3.11 : Diagrama de limite de conformação para o estudo conjunto com estampagem

FIGURA 4.3.12 : Diagrama de limite de tensões de conformação.

FIGURA 5.1.1 : Metodologia proposta

FIGURA 5.2.1-a : Cotas parametrizadas para a modelagem geométrica da estampagem 
FIGURA 5.2.1-b : Cotas parametrizadas para a modelagem geométrica da estampagem.

FIGURA 5.2.2 : Curvas de material

FIGURA (5.2.3) : Malhas : a) Chapa ; b) Prensa-chapas.

FIGURA (5.2.4) : Malhas (vista em perspectiva) : a) Punção ; b) Matriz

FIGURA (5.2.5) : Malhas para o conjunto das peças consideradas no caso 1..... 104

FIGURA (5.2.6) : Malhas : a) Chapa ; b) Prensa-chapas................................ 105

FIGURA (5.2.7) : Malhas (vista em perspectiva): a) Punção ; b) Matriz........... 105

FIGURA (5.2.8) : Malhas para o conjunto das peças consideradas no caso 2.... 105

FIGURA 5.2.9 : Condições de contorno impostas à chapa, Caso 1: (a)

Restrições de deslocamento (em azul) e rotação (em vermelho). (b)

Vista do modelo completo com as condições de contorno aplicadas à chapa.

FIGURA 5.2.10 : Condições de contorno impostas à chapa, Caso 2: (a)

Restrições de deslocamento (em azul) e rotação (em vermelho). (b)

Vista do modelo completo com as condições de contorno aplicadas à chapa.

FIGURA 5.2.11 : Deformações totais na direção principal 1 (radial)....

FIGURA 5.2.12 : Deformações totais na direção principal 2 (circunferencial)...

FIGURA 5.2.13 : Deformações totais efetivas.....

FIGURA 5.2.14 : Deformações totais na direção principal 1

FIGURA 5.2.15 : Deformações totais na direção principal 2

FIGURA 5.2.16 : Deformações totais efetivas

FIGURA 5.3.1 : Numeração de nós para análise do caso 1

FIGURA 5.3.2 : Mapa de deformações para o caso 1 , passo 99.

FIGURA 5.3.3 : Mapa de deformações para o caso 1 , passo 76.

FIGURA 5.3.4 : Deformações totais na direção principal 1

FIGURA 5.3.5 : Deformações totais na direção principal 2

FIGURA 5.3.6 : Deformações totais na direção principal 3 (espessura da chapa).....

FIGURA 5.3.7 : Variação da deformação na direção principal 3 (espessura da chapa). 
FIGURA 5.3.8 : Variação da espessura da chapa na direção principal 3............ 118

FIGURA 5.3.9 : Numeração de nós para análise do caso 2 .............................. 119

FIGURA 5.3.10 : Mapa de deformações para o caso 2, passo 99....................... 120

FIGURA 5.3.11 : Mapa de deformações para o caso 2, passo 58....................... 120

FIGURA 5.3.12 : Deformações totais na direção principal 1 ............................. 121

FIGURA 5.3.13 : Deformações totais na direção principal 2 ............................ 121

FIGURA 5.3.14 : Deformações totais na direção principal 3............................. 122

FIGURA 5.3.15 : Variação da deformação na direção principal 3 (espessura da

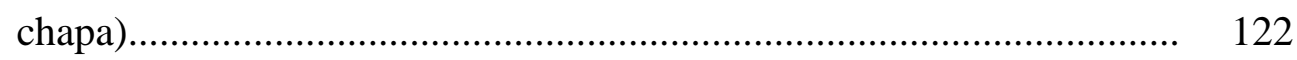

FIGURA 5.3.16 : Variação da espessura da chapa na direção principal 3.......... 123

FIGURA 5.3.17 : Comparação da variação da espessura da chapa na direção principal 3, casos 1 e 2 ................................................................. 124

FIGURA 5.3.18 : Diagrama de tensões de conformação, curva limite e paths,

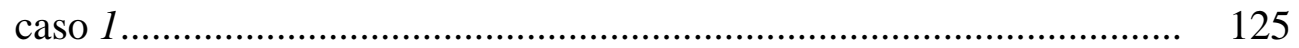

FIGURA 5.3.19 : Diagrama de tensões de von Mises , caso 1 .......................... 125

FIGURA I-1 : Elemento SOLID45 ............................................................. 133

FIGURA I-2 : Elemento SHELL163 ....................................................... 134 


\section{Lista de tabelas}

TABELA 4.2.1 : Curvas de material conforme parâmetros $n, m$ e $f \ldots \ldots \ldots \ldots \ldots \ldots . . . . \quad 85$

TABELA 5.2.1 : Valores para a geometria do problema de estampagem............ 101

TABELA 5.2.2 : Distribuição dos tipos de elementos na modelagem................. 103 


\section{Lista de abreviaturas e siglas}

$\begin{array}{ll}\text { CAD } & \text { - Computer Aided Design } \\ \text { CAE } & \text { - Computer Aided Engineering } \\ \text { DLC } & \text { - Diagrama de Limite de Conformação } \\ \text { EDO'S } & \text { - Equações Diferenciais Ordinárias } \\ \text { FEM } & \text { - Finite Element Method } \\ \text { FLD } & \text { - Forming Limit Diagram } \\ \text { FLSD } & \text { - Forming Limit Stress Diagram } \\ \text { MEF } & \text { - Método dos Elementos Finitos } \\ \text { PDV } & \text { - Princípio dos Deslocamentos Virtuais }\end{array}$




\section{Lista de Símbolos}

A - Área transversal do corpo de provas após aplicação de carga por um tempo $t$ $\left[\mathrm{m}^{2}\right]$

$A_{0} \quad$ - Área transversal inicial do corpo de provas $\left[\mathrm{m}^{2}\right]$

$B \quad$ - Constante de material

a - Expoente para os critérios de escoamento

$c \quad$ - Velocidade do som no meio material $[\mathrm{m} / \mathrm{s}]$

$e \quad$ - Deformação em engenharia

E - Módulo de Young $\left[\mathrm{N} / \mathrm{m}^{2}\right]$

$f^{\text {B }} \quad-$ Vetor forças de campo $\left[\mathrm{N} / \mathrm{m}^{3}\right]$

$f^{C} \quad$ - Forças de contato $\left[\mathrm{N} / \mathrm{m}^{2}\right]$

$f^{\mathrm{S}} \quad$ - Vetor forças de superfície $\left[\mathrm{N} / \mathrm{m}^{2}\right]$

$f($ ) - Função de escoamento

$g$ ( ) - Função escalar dos invariantes de tensão desviadora

H - Parâmetro de anisotropia

$h($ ) - Função escalar dos invariantes de tensão desviadora

$I_{1} \quad$ - Invariante do tensor de tensões

$I_{2} \quad$ - Invariante do tensor de tensões

$I_{3} \quad$ - Invariante do tensor de tensões

$J_{2} \quad$ - Invariante do tensor de tensões desviadoras

$J_{3} \quad$ - Invariante do tensor de tensões desviadoras

$K \quad$ - Matriz de rigidez

$K, k$ - Coeficiente de resistência do material $\left[\mathrm{N} / \mathrm{m}^{2}\right]$

$k_{m} \quad$ - Coeficiente de proporcionalidade

Ls - Comprimento característico do elemento 
$l$ - Comprimento do corpo de provas após aplicação de carga por um tempo $t$ $[\mathrm{m}]$

$l_{0} \quad$ - Comprimento inicial do corpo de provas [m]

M - Matriz de massa

$m$ - Expoente de sensibilidade à taxa de deformação

$m \quad$ - Expoente de Graf-Hosford

$n \quad$ - Coeficiente de encruamento

$P \quad$ - Carregamento aplicado ao CP $[\mathrm{N}]$

$p_{11} \quad$ - Componente do tensor não simétrico (primeiro) de Piola Kirchhoff [N/m $\left.{ }^{2}\right]$

$r \quad$ - $r$-value ou fator de anisotropia

$R \quad$ - Trabalho virtual externo $[\mathrm{Nm}]$

$R_{C} \quad$ - Carregamentos concentrados [N]

$r_{m} \quad$ - Anisotropia normal média

$S_{C} \quad$ - Área efetiva de contato entre dois corpos $\left[\mathrm{m}^{2}\right]$

$S_{f} \quad$ - Superfície sobre a qual são prescritas componentes de tração $\left[\mathrm{m}^{2}\right]$

$S_{u} \quad$ - Superfície sobre a qual são prescritas condições de deslocamento [m²]

$t \quad$ - Tempo [s]

$\mathrm{t} \quad$ - Espessura de chapa [m]

$u \quad$ - Vetor de deslocamentos nodais

$U \quad$ - Vetor de deslocamentos

$\bar{U} \quad$ - Vetor deslocamentos virtuais

$\mathrm{V} \quad$ - Velocidade $[\mathrm{m} / \mathrm{s}]$

$V \quad$ - Volume $\left[\mathrm{m}^{3}\right]$

W - Largura [m]

$W_{p} \quad$ - Trabalho plástico total [Nm]

$X \quad$ - Posição de referência da partícula [m]

$x \quad$ - Posição de uma partícula no tempo $t$ [m]

$Y \quad$ - Tensão de início de escoamento $\left[\mathrm{N} / \mathrm{m}^{2}\right]$

$\alpha \quad$ - Constante de proporcionalidade para tensões

$\beta \quad$ - Constante de proporcionalidade para deformações

$\Delta r \quad$ - Anisotropia planar

$\Delta t \quad$ - Incremento de tempo [s] 


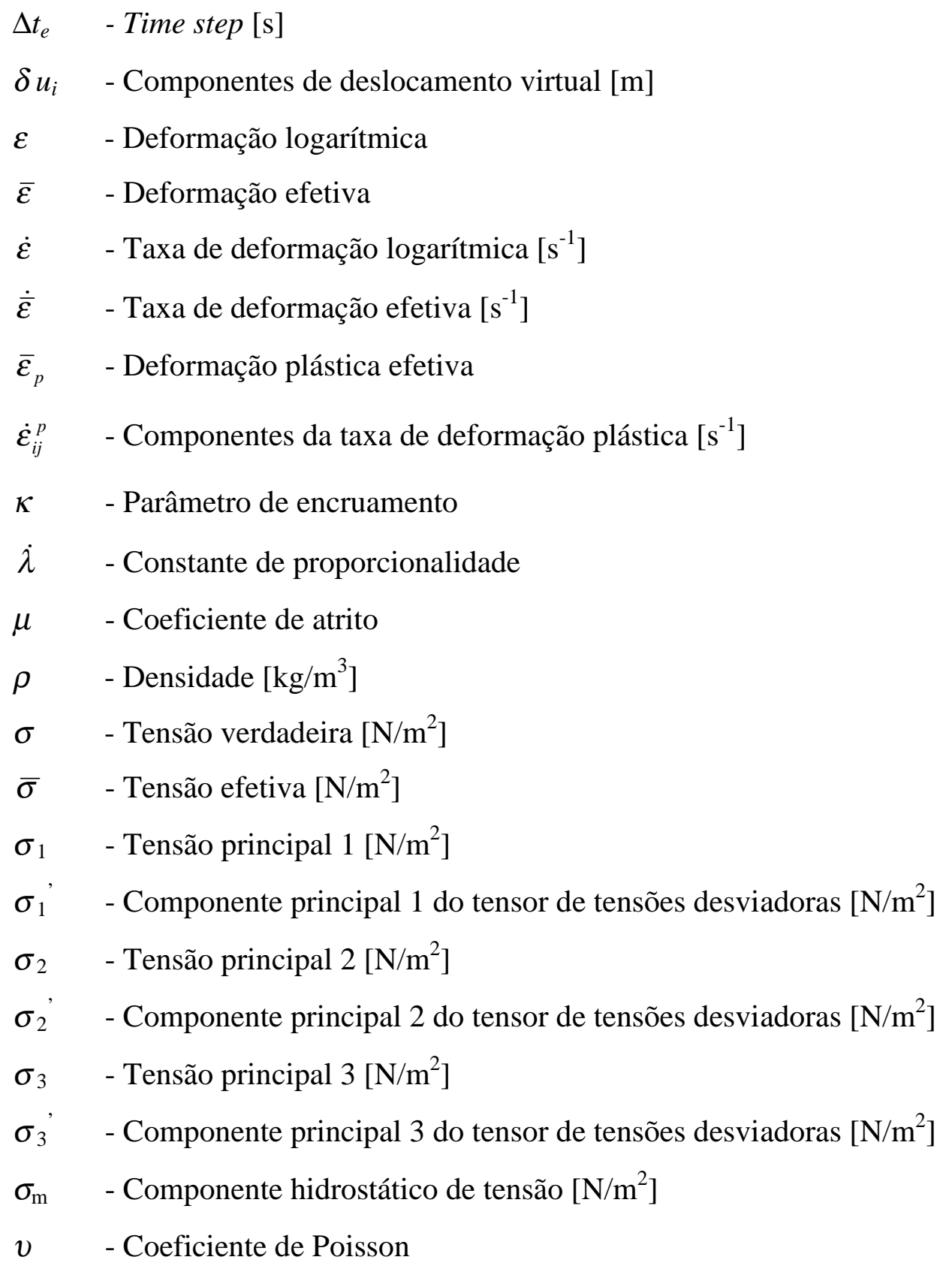




\section{Resumo}

EVANGELISTA, S. H. (2000). Diagramas de limite de conformação aplicados à análise por elementos finitos de um processo de estampagem em chapas metálicas. São Carlos. 135p. Dissertação (Mestrado) - Escola de Engenharia de São Carlos , Universidade de São Paulo .

Entre os processos de fabricação mecânicos atuais destacam-se os processos de conformação de chapas metálicas devido à sua produtividade e confiabilidade e a seus baixos custos de produção, baixo consumo de material e produtos nos formatos bem próximos dos esperados nas fases de projeto. Isto só é possível se todas as variáveis do projeto e do processo estiverem conforme as especificações prévias, exigidas principalmente em setores da indústria tais como o aeronáutico e o automobilístico. Um recurso útil para se alcançar estas expectativas é o estudo da estricção e da conformabilidade em chapas metálicas, representadas em diagramas de limite de conformação (DLC), os quais, aliados à análise numérica através do Método dos Elementos Finitos, permitem predições a respeito das variáveis de projeto. Este trabalho tem como objetivos rever e aplicar conceitos relativos a estes aspectos. O objetivo principal deste trabalho é de dispor uma metodologia de avaliação e otimização para o processo de estampagem, utilizando-se elementos finitos e DLC. Uma modificação no método de Marciniak-Kuczynski é utilizada para a obtenção do DLC. Busca-se com isto uma contribuição para a redução de custos em aplicações industriais com o uso desta metodologia através da diminuição das fases de tentativas e erros em projeto e reforma de estampos (try-outs).

Palavras-chave : Conformação de chapas metálicas, Método dos Elementos Finitos, Diagramas de Limite de Conformação, Estricção . 


\begin{abstract}
EVANGELISTA, S. H. (2000). Forming limit diagrams applied to finite element analysis of deep drawing of sheet metals. São Carlos. 135p. Dissertação (Mestrado) - Escola de Engenharia de São Carlos, Universidade de São Paulo .
\end{abstract}

Nowadays, sheet metal forming processes have an important role amongst the mechanical manufacturing processes, because they are characterized by high productivity and reliability at low cost, low material waste and near net shapes from design. This is achieved by controlling the design and process parameters according to initial constraints. This scenario is common at aeronautic and at automobilistic productions. These results are obtained by studies of necking and formability in sheet metals and by the use of forming limit diagrams (FLD) and finite element numerical analysis to predict design parameters. This work reviews these concepts and presents a methodology for optimization of deep drawing processes, by using finite element method and FLD. A modification of the Marciniak-Kuczynski method has been introduced to obtain the FLD. Once this methodology has been performed, it can be possible to reduce try-outs in sheet metal dies and costs reduction can also be obtained.

Keywords : Sheet metal forming, Finite Element Method, Forming Limit Diagrams, Necking . 


\section{Introdução}

\subsection{Contexto geral}

Os processos de conformação de chapas podem ser caracterizados através de modificações específicas feitas na geometria de uma chapa metálica ou em um blank (peça-obra), pelo controle do fluxo de material no estado plástico de deformações e pela avaliação de qualidade da peça final através da presença ou não dos diversos tipos de defeitos. Estes processos podem alcançar elevada produtividade nos parques industriais quando suas variáveis são bem combinadas, obtendo-se baixos custos de produção, baixo consumo de material e produtos nos formatos bem próximos dos esperados nas fases de projeto. Nestes processos predominam as tensões de tração e as deformações finais podem ser alcançadas em um ou mais estágios limitados pelo início da instabilidade plástica, dada pela formação de defeitos como estricção de espessura (necking) ou por enrugamentos (wrinkling).

A arte e a ciência dos processos de conformação de chapas consistem em obter-se as peças desejadas conforme os requisitos de projeto e de fabricação, ponderando-se com uma razoável margem de segurança as variações de propriedades de material e condições de processo que estejam fora dos padrões especificados. Genericamente, seus diversos fatores influentes podem ser agrupados conforme visto na fig. 1.1.1 . Muitas peças conformadas são vendidas a baixo custo e em mercados altamente competitivos. O custo do material pode ter uma fração elevada no custo total da peça, de modo que uma otimização no formato do blank se faz necessária. Para uma boa competitividade, a margem de segurança deve ser minimizada, como é visto em setores de conformação industrial de alto nível. Nesta situação, pequenas diferenças nas propriedades de material, condições de ferramentas e lubrificação podem causar mudanças consideráveis no andamento do processo, demandando 
experiência e habilidade sobre a análise de falhas e o diagnóstico na conformação. Entre os vários processos de conformação de chapas, cita-se o processo de estampagem profunda por apresentar maior complexidade de análise em termos de deformações ou de tensões.

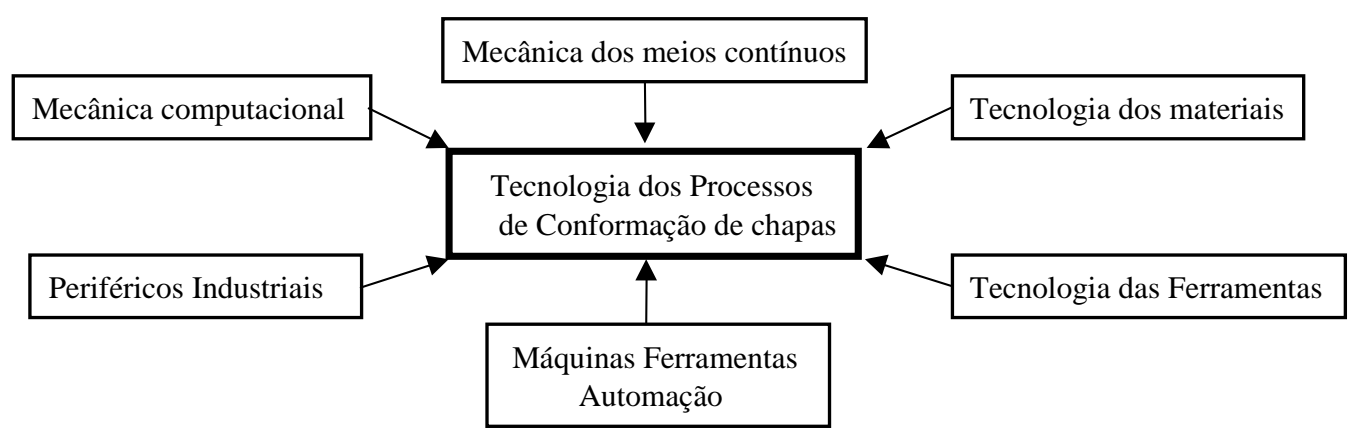

FIGURA 1.1.1 : Elementos diversos na tecnologia moderna de conformação de chapas, (LANGE 1997) .

Dentre os diversos fatores vistos na fig. 1.1.1, destacam-se as teorias da mecânica dos meios contínuos e da mecânica computacional pelos avanços recentes disponíveis na literatura que possibilitaram novos pontos de vista para a tecnologia nesta área. Na mecânica dos meios contínuos, além da teoria clássica da plasticidade, destaca-se o enfoque experimental dado aos limites de formabilidade da chapa como em KEELER \& BACKHOFEN (1964) apud STOUGHTON (2000) e GOODWIN (1968) apud STOUGHTON (2000), com a representação dos FLDs (forming limit diagrams) ou diagramas de limite de conformação. Representando os limites no andamento de processo em termos de deformações, estas ferramentas de análise possibilitaram uma primeira forma de otimização, quando aliadas aos testes de formabilidade e a todo aparato técnico disponível tanto na indústria como em laboratórios.

Nesta linha, diversos autores apresentaram considerações teóricas acerca dos limites aceitáveis de deformação no processo. Modelos matemáticos foram criados para representar de modo macroscópico alguns defeitos presentes, uma vez que estes são as causas dos limites do processo. Isto foi considerado no modelo $M K$, de MARCINIAK \& KUCZYNSKI (1967) apud GRAF \& HOSFORD (1990), também descrito em MARCINIAK \& DUNCAN (1992). 
Estes aspectos trouxeram o desafio de se prever o comportamento do blank durante e no fim do processo, visando otimizações e redução de custos. A formabilidade da chapa pôde ser descrita, definida em geral pela distribuição uniforme de deformações, pelo alcance de maiores níveis de deformação sem ocorrência de afinamentos ou fraturas, pela manutenção de tensões de compressão no plano das deformações, evitando-se o enrugamento, pela manutenção do cisalhamento no plano de deformações, sem a ocorrência de fraturas, pela manutenção da forma após a remoção da matriz e enfim pela apresentação de superfície com textura suavisada, sem danificações.

Contribuindo para estes progressos tem-se o método dos elementos finitos, atuando como um elo entre a mecânica dos meios contínuos e a mecânica computacional. Com este método analisa-se um processo de conformação numericamente, a partir de seu modelamento, cujos resultados validam-se através de dados experimentais.

Este trabalho revê os aspectos relacionados aos $F L D s$ e à sua predição teórica, discutindo os pontos mais importantes e visando a escolha de um método relevante para implementação de algoritmos de cálculo destes diagramas. Além disto, busca-se analisar um processo de conformação de chapa metálica, com enfoque principal dado ao caso de estampagem profunda, pelo método dos elementos finitos $(M E F)$ implementado no software ANSYS / LS DYNA .

\subsection{Objetivos}

Este trabalho tem como objetivos rever e aplicar conceitos relativos ao método dos elementos finitos, aos processos de conformação de chapas e aos diagramas de limite de conformação. O objetivo principal deste trabalho é de dispor uma metodologia de avaliação e otimização para o processo de estampagem, utilizando-se elementos finitos e diagramas de limite de conformação.

Busca-se com isto uma contribuição para a redução de custos em aplicações industriais com o uso desta ferramenta de análise através da diminuição das fases de tentativas e erros em projeto e reforma de estampos (try-outs). 


\subsection{Conteúdo deste trabalho}

Os principais capítulos além deste são estruturados conforme a descrição a seguir:

CAPÍTULO 2 - Uma introdução à análise de conformação de chapas : Apresentase uma revisão bibliográfica abordando o tema conformação de chapas metálicas, destacando-se os aspectos para análise dos processos relacionados. Para isto faz-se a apresentação dos principais tópicos da teoria plasticidade, do método dos elementos finitos e de sua aplicação à conformação mecânica.

CAPÍTULO 3 - Diagramas de limite de conformação : Na segunda parte da revisão introduzem-se conceitos acerca da conformabilidade da chapa, da sua predição e de sua representação em diagramas. Após isto, apresenta-se um modelo relevante para determinação teórica dos diagramas de limite de conformação. A seguir são estabelecidadas algumas relações entre os métodos de cálculos pesquisados, em que destaca-se um algorítimo baseado em GRAF \& HOSFORD (1990).

CAPÍTULO 4 - Cálculo de diagramas de limite de conformação por elementos finitos : Com os conceitos sobre as curvas limite disponíveis, realiza-se uma implementação do fenômeno de estricção (necking) na chapa através do método dos elementos finitos. Assim obtem-se diagramas para as deformações principais no plano da chapa, sendo discutidos conforme algumas considerações impostas.

CAPÍTULO 5 - Aplicação de diagramas de limite de conformação à análise de estampagem : Neste item implementa-se uma análise por elementos finitos para dois casos de estampagem. Seus resultados são então avaliados em relação a um diagrama de limite de conformação escolhido no capítulo 4, conforme a metodologia proposta .

CAPÍTULO 6 - Conclusões e sugestões para trabalhos futuros : Apresentam-se as conclusões e sugestões de novas considerações a respeito deste trabalho.

CAPÍTULO 7 - Referências bibliográficas : Listam-se as obras consultadas e referenciadas neste trabalho.

Apêndice I: Apresenta uma breve descrição sobre os tipos de elementos utilizados nos enfoques estático implícito e dinâmico explícito . 


\section{Uma introdução à análise de conformação de chapas}

\subsection{Conformação de chapas metálicas}

Nos processos de conformação de chapas, uma chapa inicial (blank) é deformada plasticamente na matriz para obtenção da configuração final. Assim, podem-se obter formatos complexos, nos quais o processo impõe a geometria desejada pela aplicação de pressões sobre o material através da interface materialferramenta.

Os processos de conformação de chapas metálicas dividem-se basicamente em (KOBAYASHI et al., 1989) :

- Repuxo (deep drawing), estampagem, fig. (2.1.1)

- Dobramento de chapas e calandragem

- Estiramento de chapas

- Estiramento no plano da chapa

- Hidroconformação (hydroforming) e conformação por elastômeros

- Conformação a vácuo, eletromagnética, por explosão

- outros.

Suas características básicas são :

- A peça trabalhada é uma chapa ou uma peça fabricada a partir de uma chapa metálica.

- As deformações usualmente causam mudanças significativas no formato mas não nas secções transversais da chapa. 
- Em alguns casos, as magnitudes das deformações plástica e elástica recuperável são comparáveis; em outros casos o retorno elástico (springback) pode ser significante.

- Suas diferenças baseiam-se no modo como as deformações se compõem, ou seja, pela predominância de deformações de tração ou de compressão ou combinações.

Um processo de conformação é viável quando a geometria dos componentes é moderadamente complexa e o volume de produção é grande, de modo a amortizar os custos do ferramental, como por exemplo em peças da indústria automobilística. Além disto, aplicam-se também a casos em que as propriedades e integridade metalúrgica dos componentes são extremamente importantes, como por exemplo em peças de aeronaves de carga, de motores a jato e de turbinas.

Dentre os vários processos citados anteriormente, destaca-se a estampagem, a qual pode ser classificada conforme a profundidade alcançada no processo em estampagem leve, média ou profunda. Este processo será enfocado no decorrer deste trabalho e o termo estampagem será tratado de forma genérica.

Tal processo é empregado na produção de componentes com formatos cilíndrico ou prismático, a partir de um ou mais estágios, em prensas mecânicas ou hidráulicas. Para o material das peças pode-se empregar aços carbono e ligas, ligas de alumínio e titânio, superligas de ferro, níquel e cobalto, ligas de molibdênio, nióbio e tungstênio.

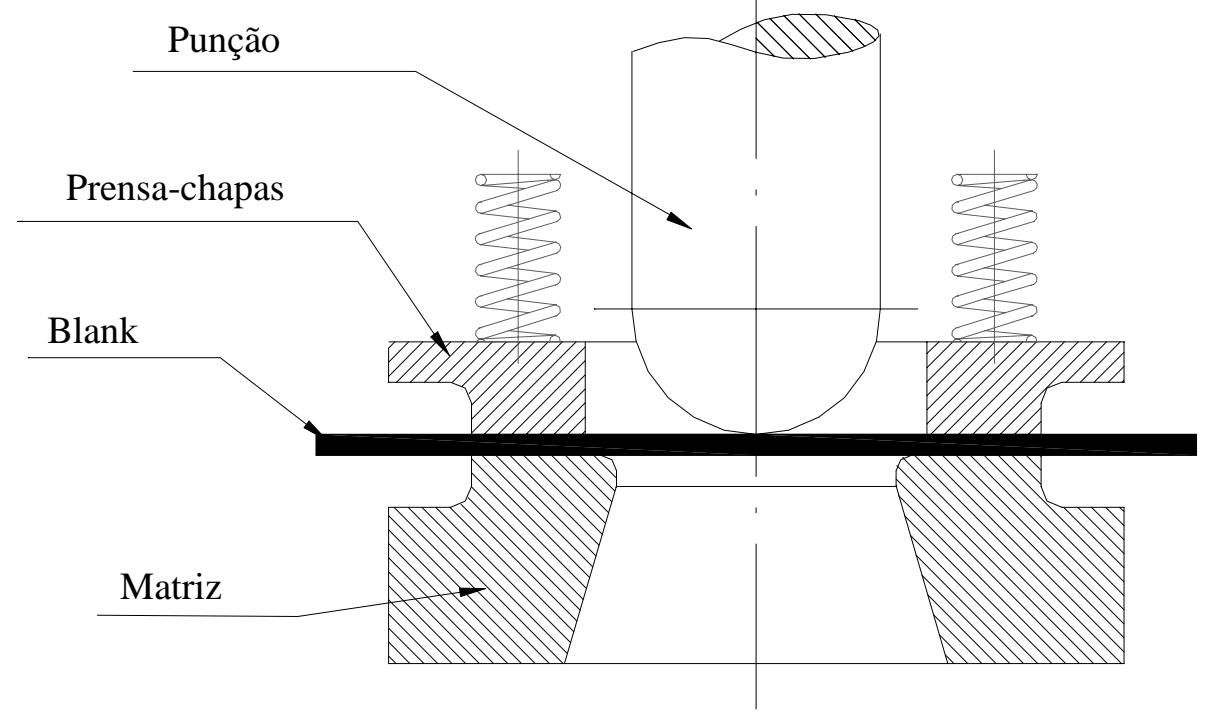

FIGURA (2.1.1) : Composição básica de uma ferramenta de estampagem 


\subsection{Análise de processos de conformação de chapas}

Segundo KOBAYASHI et al. (1989), em uma operação de conformação mecânica, o projeto consiste essencialmente de:

- Estabelecer as relações cinemáticas (forma, velocidades, taxas de deformação e deformações) entre a parte não deformada (blank) e a parte deformada;

- Estabelecer os limites de conformabilidade, isto é, determinar se é possível executar a operação de conformação sem causar algum defeito de superfície ou interno (afinamentos, enrugamentos, fraturas, etc.);

- Prever as forças e tensões necessárias para executar a operação de conformação. Esta informação é necessária para o projeto da ferramenta e para selecionar o equipamento apropriado, com força adequada e capacidade de energia para executar a operação de conformação.

A fig. (2.2.1) mostra as principais variáveis no processo de conformação de chapas metálicas e suas inter-relações. O processo requer a especificação das leis de escoamento do metal, tensões, transferência de calor, condições de lubrificação, técnicas de aquecimento e resfriamento, manuseio do material, projeto da matriz e equipamento de conformação.

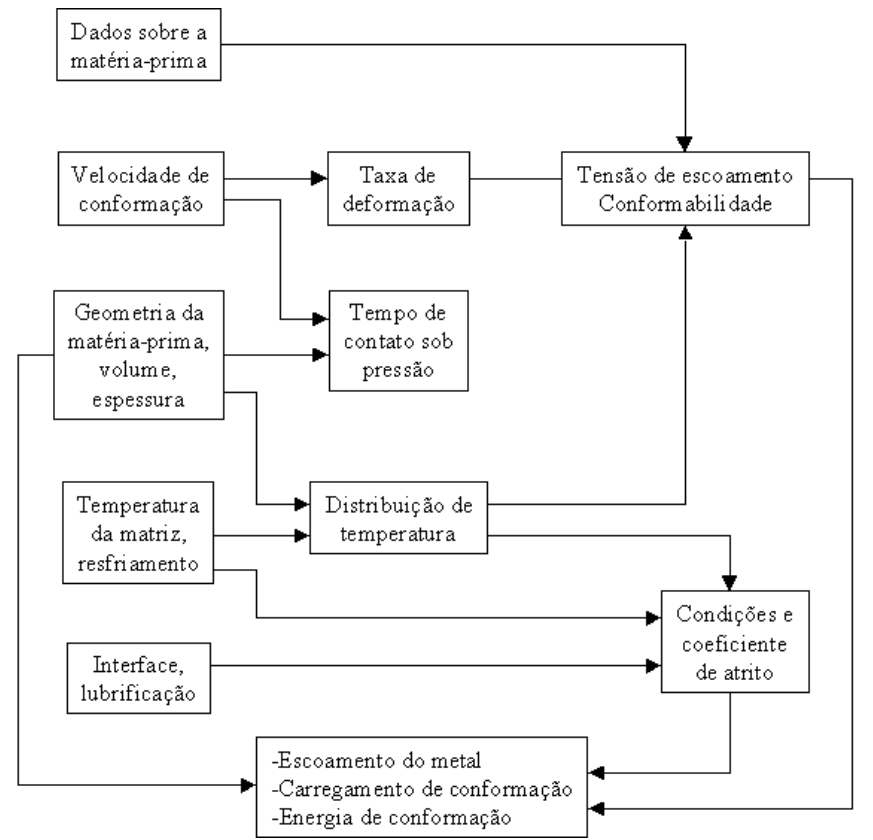

FIGURA 2.2.1 : Principais variáveis no processo de conformação de chapas metálicas e suas inter-relações (KOBAYASHI et al., 1989) 
Sem o conhecimento da influência de variáveis tais como condições de atrito, propriedades de material e geometria da peça na mecânica do processo, não seria possível projetar as matrizes e equipamentos necessários adequadamente ou prever e prevenir o surgimento de defeitos. Logo, a modelagem do processo para simulação computacional tem sido uma grande preocupação na tecnologia de conformação metálica moderna. A fig. (2.2.2) indica o papel da modelagem do processo com alguns detalhes.

Um grande número de métodos aproximados de análise têm sido desenvolvidos e aplicados a vários processos de conformação. Os métodos mais conhecidos são o slab method, o slip-line field method, o visioplasticity method, upper- (e lower-) bound techniques, o método de Hill e mais recentemente o Método dos Elementos Finitos (KOBAYASHI et al., 1989), cujo desenvolvimento e aplicação possibilitou um dos mais significativos avanços em análise e simulação de processos de conformação de metais nos últimos anos. Esta tecnologia possibilita uma análise do comportamento do material ao longo do processo com grande acuracidade, justificando seu emprego.

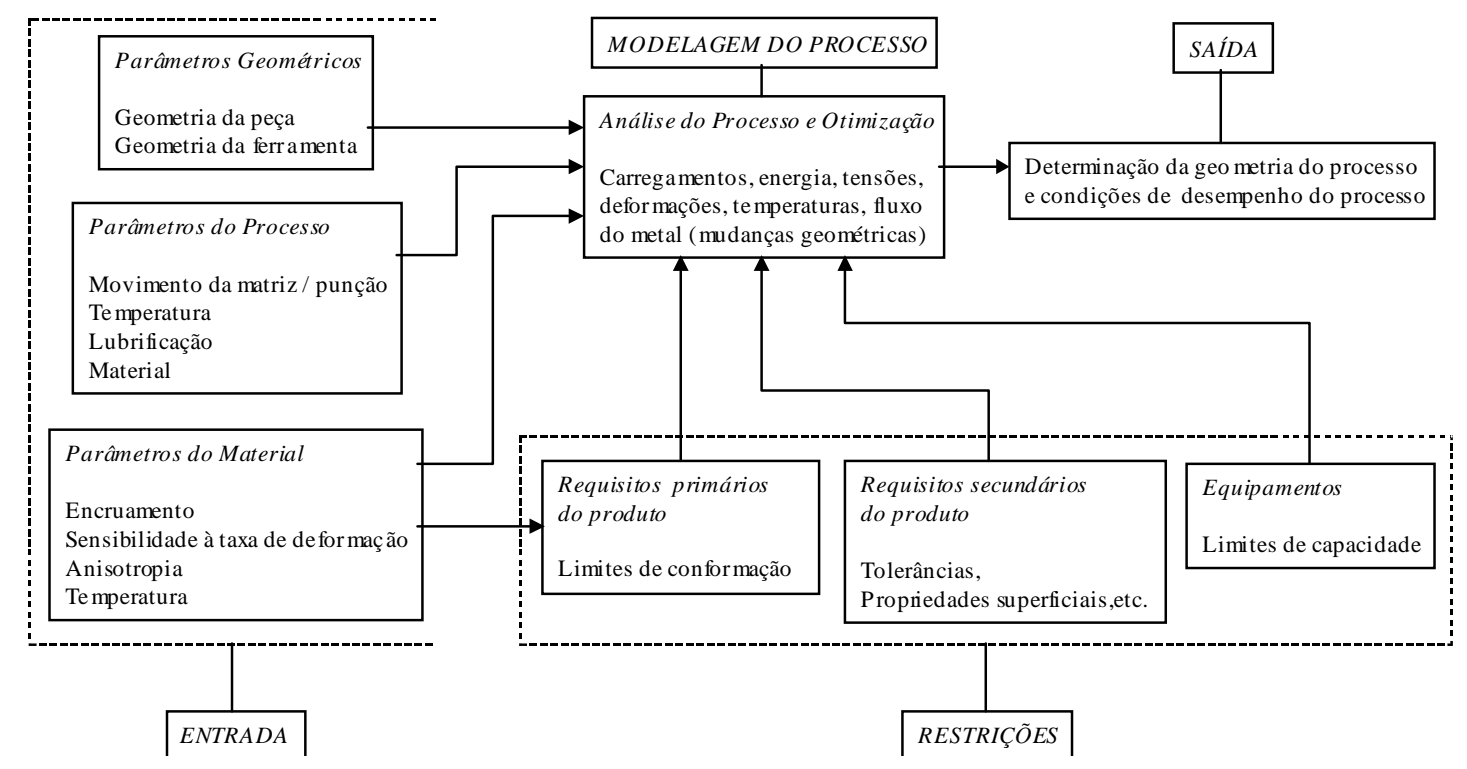

FIGURA 2.2.2 : Diagrama de blocos para o projeto e controle do processo em conformação de metais (KOBAYASHI et al., 1989) 
Neste trabalho serão considerados aspectos gerais do item conformabilidade relacionada à estampagem de chapas, como visto nas figs. (2.2.1) e (2.2.2) . Pelas figs. vêem-se que suas variáveis influentes são os dados sobre o material, a taxa de deformação, a tensão de escoamento e a distribuição da temperatura. A combinação destes fatores, conforme o esquema mostrado, interfere diretamente no comportamento do escoamento do material, no carregamento e na energia da conformação aplicada.

\subsection{Tópicos da teoria da plasticidade aplicada à conformação de chapas}

As grandezas que podem ser utilizadas para descrever o mecanismo de deformação de um corpo, passando de uma configuração para outra por meio da aplicação de um carregamento externo, são a tensão, deformação e taxa de deformação (KOBAYASHI et al., 1989).

Considere-se o teste uniaxial de tração de um corpo de prova cilíndrico de comprimento inicial $l_{0}$ e seção de área $A_{0}$ conforme a fig. (2.3.1). O corpo de prova é tracionado axialmente por uma força $P$ até o comprimento $l$ e área $A$, no tempo $t$. Da resposta do material obtém-se curvas tensão-deformação :

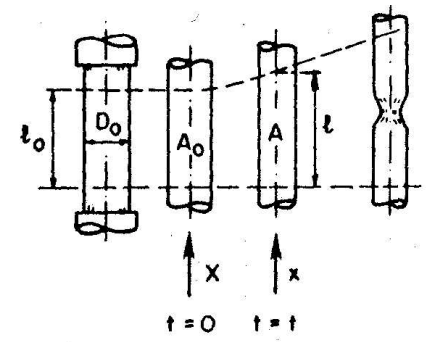

(a)
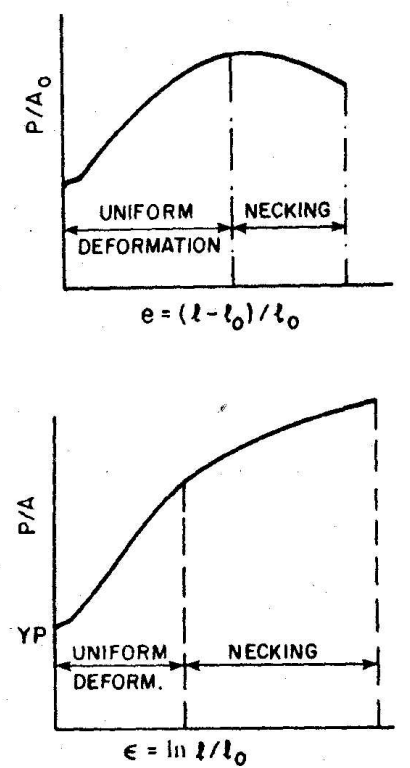

(b)

FIGURA 2.3.1 : Tração uniaxial. (a) Corpo de prova; (b) Curvas tensão-deformação (KOBAYASHI et al., 1989) 
Há dois modos de se descrever a deformação do contínuo : a Lagrangiana e a Euleriana. A descrição Lagrangiana emprega as coordenadas $X_{i}$ de uma partícula no estado de referência (não deformada) como variável independente, enquanto na descrição Euleriana as variáveis independentes são as coordenadas $x_{i}$ de um ponto material no estado deformado. Quando a deformação é infinitesimal, em que os produtos de derivadas dos deslocamentos podem ser desconsiderados, não se necessita fazer distinção entre ambas. Na teoria da deformação infinitesimal, as tensões e taxas de deformação (ou deformações infinitesimais) são expressas em relação a um sistema de coordenadas fixo na configuração do material no tempo em consideração. No caso de tração uniaxial:

$$
\sigma=\frac{P}{A}
$$

em que $\sigma$ é a tensão nominal na direção da carga $P$.

$$
\dot{\varepsilon}=\frac{i}{l}
$$

para a taxa de deformação, em que o ponto indica derivada em relação ao tempo para a deformação $\varepsilon$ e :

$$
d \varepsilon=\frac{d l}{l}
$$

para a deformação de engenharia.

A tensão definida na eq. (2.3.1) é chamada tensão verdadeira ou tensão de Cauchy. A deformação total é medida integrando-se a deformação infinitesimal:

$$
\varepsilon=\int_{l_{0}}^{l} d \varepsilon=\ln \left(\frac{l}{l_{0}}\right)
$$


é chamada deformação verdadeira, logarítmica ou natural.

Em um caso generalizado, tem-se que para tensões, deformações e taxas de deformações, considerando-se um pequeno elemento da chapa na fig. (2.3.2) :

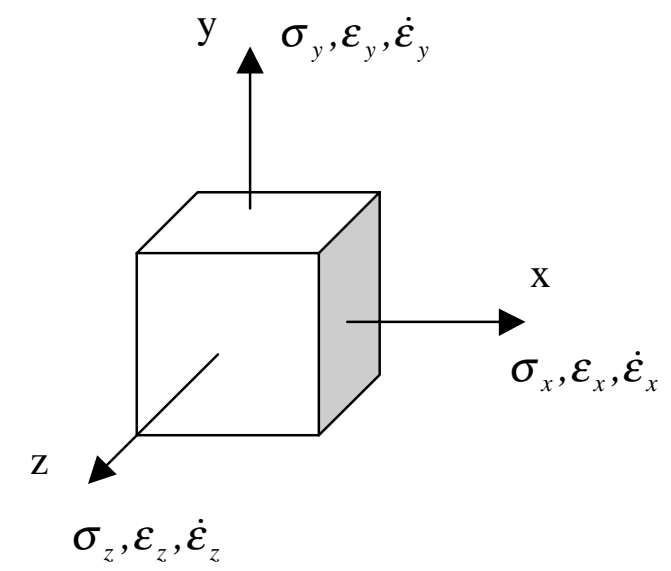

FIGURA 2.3.2 : Tensões, deformações e taxa de deformações

Serão vistas a seguir as expressões referentes à formulação para as deformações infinitesimais do material. Detalhes acerca da formulação Lagrangiana são encontrados em KOBAYASHI et al. (1989) .

Tensor de taxa de deformação e tensor de tensão

O tensor de taxa de deformação [ $\dot{\boldsymbol{\varepsilon}}_{i j}$ ], em que $i, j=x, y, z$, é simétrico e seus componentes são definidos simbolicamente por:

$$
\dot{\varepsilon}_{i j}=\frac{1}{2}\left(u_{i, j}+u_{j, i}\right)
$$

em que a vírgula significa derivada em relação à coordenada $u$ de deslocamentos de um ponto considerado. O tensor de tensões de Cauchy $\left[\sigma_{i j}\right]$, em que $i, j=x, y, z$, é também simétrico e é representado por:

$$
\left[\sigma_{i j}\right]=\left[\begin{array}{lll}
\sigma_{x} & \tau_{y x} & \tau_{z x} \\
\tau_{x y} & \sigma_{y} & \tau_{z y} \\
\tau_{x z} & \tau_{y z} & \sigma_{z}
\end{array}\right]
$$


No caso em que $\tau_{i j}=0 \quad$ com $\quad i \neq j$, vem que para $i=j$ tais que sejam 1,2 ou 3, obtém-se as tensões principais representadas por :

$$
\left[\sigma_{i j}\right]=\left[\begin{array}{ccc}
\sigma_{1} & 0 & 0 \\
0 & \sigma_{2} & 0 \\
0 & 0 & \sigma_{3}
\end{array}\right]
$$

Do tensor de tensões extraem-se $I_{1}, I_{2}, I_{3}$, que são quantidades independentes das direções dos eixos escolhidos e chamadas de invariantes do tensor de tensões $\sigma_{i j}$.

$$
\begin{aligned}
& I_{1}=\sigma_{x}+\sigma_{y}+\sigma_{z}=\sigma_{1}+\sigma_{2}+\sigma_{3} \\
& I_{2}=-\left(\sigma_{x} \sigma_{y}+\sigma_{y} \sigma_{z}+\sigma_{z} \sigma_{x}\right)+\tau_{x y}^{2}+\tau_{y z}^{2}+\tau_{z x}^{2}=-\left(\sigma_{1} \sigma_{2}+\sigma_{2} \sigma_{3}+\sigma_{3} \sigma_{1}\right) \\
& I_{3}=\sigma_{x} \sigma_{y} \sigma_{z}+2 \tau_{x y} \tau_{y z} \tau_{z x}-\sigma_{x} \tau_{y z}^{2}-\sigma_{y} \tau_{z x}^{2}-\sigma_{z} \tau_{x y}^{2}=\sigma_{1} \sigma_{2} \sigma_{3}
\end{aligned}
$$

\section{Critérios de Escoamento isotrópicos}

Um critério de escoamento é uma lei definindo um limite de elasticidade sob qualquer combinação de tensões possível. É expresso por:

$$
f\left(\sigma_{i j}\right)=C(\text { const })
$$

A função de tensões $f\left(\sigma_{i j}\right)$ é chamada função de escoamento. Para materiais isotrópicos, o escoamento plástico pode ser expresso como:

$$
f\left(I_{1}, I_{2}, I_{3}\right)=C
$$

A partir de dados experimentais (KOBAYASHI et al.,1989) considera-se que o escoamento do material não é, em primeira aproximação, afetado por uma pressão hidrostática moderada, representada graficamente na fig. (2.3.3) pelo vetor $\overline{P S}$.

Portanto, o escoamento depende somente dos três componentes principais do tensor de tensões desviatórias $\left(\sigma_{1}{ }^{\prime}, \sigma_{2}{ }^{\prime}, \sigma_{3}{ }^{\prime}\right)$ tais que : 


$$
\sigma_{i j}=\sigma_{i j}^{\prime}+\delta_{i j} \sigma_{m}
$$

em que $\sigma_{m}=\left(\sigma_{1}+\sigma_{2}+\sigma_{3}\right) / 3$ é o componente hidrostático da tensão e $\delta_{i j}$ é o delta de Kronecker. Os três componentes principais do tensor de tensões desviatórias não são independentes, uma vez que $\sigma_{1}{ }^{\prime}+\sigma_{2}{ }^{\prime}+\sigma_{3}{ }^{\prime}$ é igual a zero.

Assim, o critério de escoamento isotrópico pode ser escrito da forma:

$$
f\left(J_{2}, J_{3}\right)=C
$$

em que:

$$
\begin{aligned}
& J_{2}=-\left(\sigma_{1}^{\prime} \sigma_{2}^{\prime}+\sigma_{2}^{\prime} \sigma_{3}^{\prime}+\sigma_{3}^{\prime} \sigma_{1}^{\prime}\right) \\
& J_{3}=\sigma_{1}{ }^{\prime} \sigma_{2}^{\prime} \sigma_{3},
\end{aligned}
$$

Dois critérios têm sido amplamente utilizados em análise de deformação de metais. O critério de Tresca, de 1864, cuja contribuição histórica foi importante para outros critérios posteriores, estabelece que o escoamento do material inicia-se quando a tensão de cisalhamento atinge um valor máximo $\left|\tau_{\text {máx }}\right|=$ valor crítico, a partir do que, conforme uma análise conveniente do círculo das tensões de Mohr, obtem-se :

$$
\sigma_{1}-\sigma_{3}=\text { const com } \sigma_{1} \geq \sigma_{2} \geq \sigma_{3}
$$

O critério de von Mises estabelece que o escoamento ocorre quando $J_{2}$ atinge um valor crítico, ou, em outras palavras, que a função de escoamento $f$ da eq. (2.3.9) não envolva $J_{3}$. O critério pode ser escrito como:

$$
\begin{aligned}
& J_{2}=\frac{1}{2}\left(\sigma_{1}^{\prime 2}+\sigma_{2}^{\prime 2}+\sigma_{3}^{\prime 2}\right)=\frac{1}{2} \sigma_{i j}^{\prime} \sigma_{i j}^{\prime}=k^{2} \\
& \left(\sigma_{1}-\sigma_{2}\right)^{2}+\left(\sigma_{2}-\sigma_{3}\right)^{2}+\left(\sigma_{3}-\sigma_{1}\right)^{2}=6 k^{2} \\
& \left(\sigma_{x}-\sigma_{y}\right)^{2}+\left(\sigma_{y}-\sigma_{z}\right)^{2}+\left(\sigma_{z}-\sigma_{x}\right)^{2}+6\left(\tau_{x y}^{2}+\tau_{y z}^{2}+\tau_{z x}^{2}\right)=6 k^{2}
\end{aligned}
$$


em que $k$ é um parâmetro que regula a escala de tensão e dependência das propriedades de material.

As constantes nas equações (2.3.14) e (2.3.15) podem ser determinadas a partir de um estado simples, como em tensão uniaxial. No escoamento em tração simples, $\sigma_{1}=Y$ e $\sigma_{2}=\sigma_{3}=0$. Assim, pode-se escrever (2.3.14) e (2.3.15) como

$$
\begin{aligned}
& \sigma_{1}-\sigma_{3}=Y \\
& \left(\sigma_{1}-\sigma_{2}\right)^{2}+\left(\sigma_{2}-\sigma_{3}\right)^{2}+\left(\sigma_{3}-\sigma_{1}\right)^{2}=2 Y^{2}
\end{aligned}
$$

respectivamente. $\mathrm{O}$ parâmetro $k$ pode ser identificado como tensão de escoamento a cisalhamento e $\mathrm{k}=\mathrm{Y} / \sqrt{3}$, comparando-se (2.3.19) com (2.3.17).

Deve-se notar que o critério de escoamento definido pela eq. (2.3.19) deve depender do processo de deformação plástica (encruamento). Caso assuma-se que o encruamento ocorra se e somente se trabalho plástico é feito, então a hipótese de que o critério de escoamento é independente do componente hidrostático implica que não há mudança de volume durante a deformação plástica. Um estado de tensões é completamente especificado pelos valores dos três componentes principais. Então, cada estado de tensões pode ser representado por um vetor no espaço tridimensional de tensões, em que as tensões principais são tomadas como sendo as coordenadas cartesianas. Na fig. (2.3.3), $\overline{O S}$ é o vetor $\left(\sigma_{1}, \sigma_{2}, \sigma_{3}\right)$ e seu componente $\overline{O P}$, é o vetor representando a tensão desviatória $\left(\sigma_{1}{ }^{\prime}, \sigma_{2}{ }^{\prime}, \sigma_{3}{ }^{\prime}\right) . \overline{O P}$ sempre reside sobre o plano $\pi$ cuja equação é $\sigma_{1}+\sigma_{2}+\sigma_{3}=0$. O componente hidrostático $\left(\sigma_{m}, \sigma_{m}, \sigma_{m}\right)$ da tensão é representado por $\overline{P S}$, que é perpendicular ao plano $\pi$. 


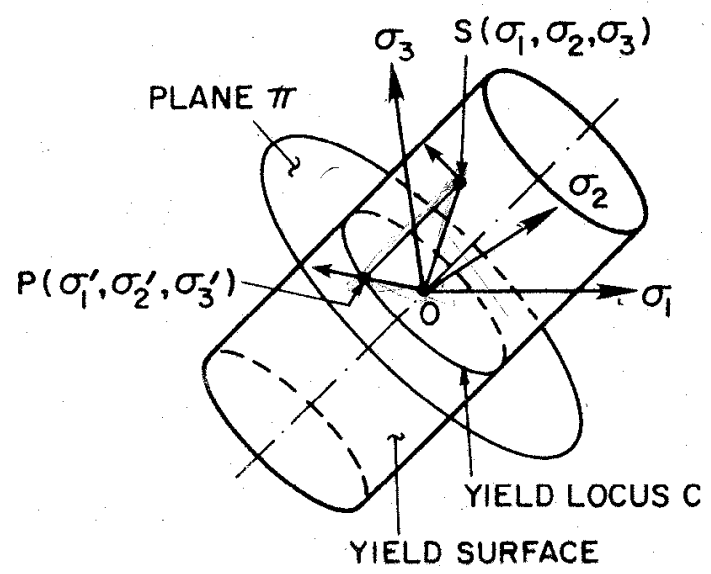

FIGURA 2.3.3 : Representação geométrica de um estado de tensões plástico no espaço

$$
\left(\sigma_{1}, \sigma_{2}, \sigma_{3}\right),(\text { KOBAYASHI et al.,1989) }
$$

Um critério de escoamento, que seja independente do componente hidrostático de tensão, é representado por uma curva $\mathrm{C}$ no plano $\pi$. O yield locus correspondente ao critério de tensão de cisalhamento e de distorção de energia são respectivamente o hexágono regular e o círculo mostrado na fig. (2.3.4).

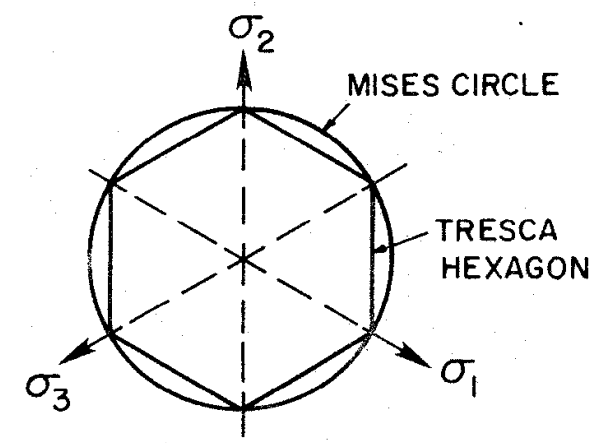

FIGURA 2.3.4 : Yield locii no plano $\pi$ para os critérios de máxima tensão de cisalhamento e energia de distorção, (KOBAYASHI et al., 1989)

Potencial plástico e regra de fluxo (Lévy-mises)

Quando o regime de deformação estende-se à faixa plástica, as relações de tensão e deformação plástica são deduzidas utilizando-se o conceito de potencial plástico. 
As razões dos componentes da taxa de deformação plástica $\dot{\varepsilon}_{i j}^{p}$ (ou deformação plástica infinitesimal $d \varepsilon_{i j}^{p}$ ) são definidas por:

$$
\dot{\varepsilon}_{i j}^{p}=h \frac{\partial g}{\partial \sigma_{i j}} \dot{f} \quad \text { ou } \quad d \varepsilon_{i j}^{p}=h \frac{\partial g}{\partial \sigma_{i j}} d f
$$

em que $g$ e $h$ são funções escalares dos invariantes de tensão desviatória e $f$ é a função de escoamento (se $\dot{f}=0$, carregamento neutro e $\dot{f}<0$, descarregamento). A função $g\left(\sigma_{i j}\right)$ é denominada potencial plástico. Embora a eq. (2.3.20) esteja escrita na forma de uma taxa, as relações entre tensão e deformação são independentes do tempo.

Assumindo-se uma simples relação $g=f$, a eq. (2.3.20) torna-se:

$$
\dot{\varepsilon}_{i j}^{p}=\frac{\partial f}{\partial \sigma_{i j}} \dot{\lambda} \quad \text { ou } \quad d \varepsilon_{i j}^{p}=\frac{\partial f}{\partial \sigma_{i j}} d \lambda
$$

em que $\dot{\lambda}$ ou $d \lambda$ é uma constante de proporcionalidade positiva, sendo igual a $h \dot{f}$ ou $h d f$. A eq. (2.3.21) é a regra de fluxo associada à função de escoamento $f\left(\sigma_{i j}\right)$.

\section{Encruamento}

Após o escoamento inicial, o estado de tensões no qual ocorre deformação plástica pode ser dependente do grau de deformação plástica atual. Tal fenômeno é chamado de encruamento. Portanto, a superfície de escoamento irá variar a cada estágio da deformação plástica, com as superfícies de escoamento subseqüentes sendo de algum modo dependentes das deformações plásticas precedentes. Alguns modelos que descrevem o encruamento em um material são ilustrados na fig. (2.3.5). Em (a) mostra-se um material perfeitamente plástico, em que o grau da tensão de escoamento independe do grau de plastificação. 


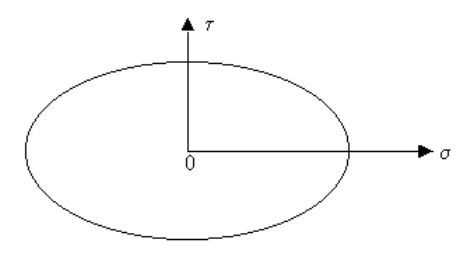

(a) Perfeitămente plástico

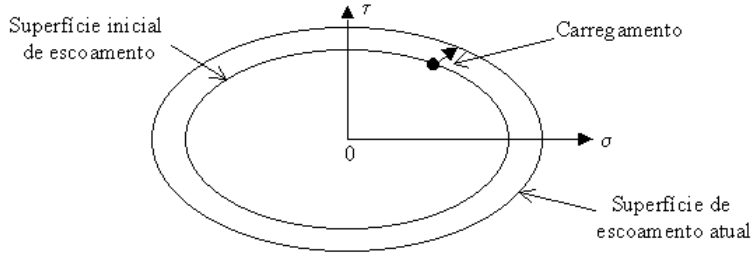

(b) Encruamento isotrópico

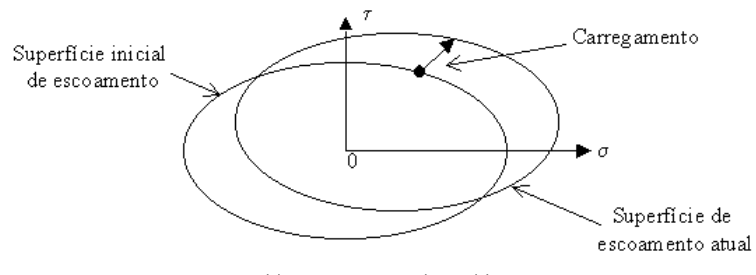

(c) encruamento cinemático

FIGURA 2.3.5 : Modelos matemáticos para a representação do comportamento com encruamento, (OWEN, 1986)

Se as superfícies de escoamento subseqüentes forem uma expansão uniforme da curva de escoamento original, sem translação, como mostrado em (b), o modelo de encruamento é dito isotrópico. Por outro lado, se as superfícies de escoamento subseqüentes preservarem suas formas e orientações mas transladarem no espaço das tensões como um corpo rígido, como mostrado em (c) o encruamento é dito cinemático. Tal modelo de encruamento representa o efeito Bauschinger observado experimentalmente no carregamento cíclico (OWEN, 1986).

O desenvolvimento progressivo da superfície de escoamento pode ser definido relacionando-se a tensão de escoamento à deformação plástica por meio do parâmetro de encruamento $\kappa$. Isto pode ser feito de dois modos. Primeiramente, o grau de encruamento pode ser postulado como sendo uma função apenas do trabalho plástico total, $W_{p}$ (work hardening). Então

$$
\kappa=W_{p} \quad \text { em que } \quad W_{p}=\int \sigma_{i j}\left(d \varepsilon_{i j}\right)_{p}
$$


em que $\left(d \varepsilon_{i j}\right)_{p}$ são os componentes de deformação plástica ocorrendo durante um incremento de deformação. Alternativamente, $\kappa$ pode ser relacionado a uma medida de deformação plástica total chamada de deformação plástica efetiva ou equivalente, a qual é definida incrementalmente como

$$
d \bar{\varepsilon}_{p}=\sqrt{\left(\frac{2}{3}\right)}\left\{\left(d \varepsilon_{i j}\right)_{p}\left(d \varepsilon_{i j}\right)_{p}\right\}^{/ 2}
$$

Para situações em que a hipótese de que o escoamento independe de qualquer tensão hidrostática é válida, $\left(d \varepsilon_{i i}\right)_{p}=0$ e consequentemente $\left(d \varepsilon_{i j}^{\prime}\right)_{p}=\left(d \varepsilon_{i j}\right)_{p}$. Consequentemente, (2.3.23) pode ser reescrita como

$$
d \bar{\varepsilon}_{p}=\sqrt{\left(\frac{2}{3}\right)}\left\{\left(d \varepsilon_{i j}^{\prime}\right)_{p}\left(d \varepsilon_{i j}^{\prime}\right)_{p}\right\}^{/ 2}
$$

Então o parâmetro de encruamento $\kappa$ é assumido como sendo definido por

$$
\kappa=\bar{\varepsilon}_{p}
$$

em que $\bar{\varepsilon}_{p}$ é o resultado da integração de $d \bar{\varepsilon}$ ao longo do caminho da deformação. Este comportamento é chamado encruamento por deformação (strain hardening).

Estados de tensão em que $f=\kappa$ representam estados plásticos enquanto comportamento elástico é caracterizado por $f<\kappa$. Em um estado plástico, $f=\kappa$, a mudança incremental na função de escoamento devido a uma mudança incremental de tensão é

$$
d f=\frac{\partial f}{\partial \sigma_{i j}} d \sigma
$$

\section{Então se:}


$\mathrm{d} f<0$, descarregamento elástico ocorre (comportamento elástico) e o ponto de tensão retorna para dentro de superfície de escoamento.

$\mathrm{d} f=0$, carregamento neutro (comportamento plástico para um material perfeitamente plástico) e o ponto de tensão permanece sobre a superfície de escoamento.

$\mathrm{d} f>0$, carregamento plástico (comportamento plástico para um material com encruamento) e o ponto de tensão permanece sobre a superfície de escoamento em expansão.

\section{Anisotropia plástica}

Freqüentemente, a anisotropia de materiais é representada pelas razões de deformação, conhecidas como r-values (razão de deformação plástica) ou fator de anisotropia, que é obtido pela razão entre a deformação verdadeira na largura e a deformação verdadeira na espessura na região de alongamento uniforme em um corpo de prova submetido a um ensaio de tração (TAYLOR ,1988). O valor $r$ é dado por :

$$
r=\frac{\varepsilon_{w}}{\varepsilon_{t}}=\frac{\ln \left(\frac{w}{w_{0}}\right)}{\ln \left(\frac{t}{t_{0}}\right)}
$$

em que $w$ é um parâmetro para largura do material, $t$ a espessura e $\varepsilon$ a deformação respectiva.

O r-value é uma medida da capacidade do material de resistir à perda excessiva na espessura. Maiores considerações são dadas em HILL (1950) onde se encontram deduções específicas para o critério geral de anisotropia de Hill, considerando-se os $r$-values.

Nas operações de estampagem, o material no flange é estirado radialmente e comprimido circunferencialmente. Um elevado valor de $r$ indica que o material tem boas propriedades de estampagem.

É comum medir-se o $r$-value médio ou a anisotropia normal média, $r_{m}$, e a anisotropia planar, $\Delta r$. 
Definem-se $r_{m}=\frac{r_{0}+2 r_{45}+r_{90}}{4}$ e $\Delta r=\frac{r_{0}-2 r_{45}+r_{90}}{2}$ em que os índices subscritos referem-se ao ângulo entre a linha de centro do corpo de prova e a direção de laminação.

O valor $r_{m}$ influencia a profundidade média possível de ser obtida em uma operação de estampagem profunda (deep drawing). O valor de $\Delta r$ mede a variação de $r$ no plano da chapa, determinando a extensão do fenômeno de earing. Uma estampagem ótima é obtida pela combinação de um elevado valor de $r_{m}$ e um baixo valor de $\Delta r$.

Nos trabalhos de STOUGHTON (2000) encontram-se sistematizados vários critérios de escoamento anisotrópico, convenientes conforme o caso em estudo. Para os cálculos realizados em algorítimos para processos de conformação de chapas, considera-se que :

$$
\sigma_{3}=0 \text { para os casos de tensão plana }
$$

obtendo-se:

Potencial plástico quadrático normal anisotrópico de Hill :

$$
\begin{aligned}
& \bar{\sigma}^{a}=\frac{1}{r+1} \cdot\left[\sigma_{1}^{a}+\sigma_{2}^{a}+r \cdot\left(\sigma_{1}-\sigma_{2}\right)^{a}\right] \\
& \text { com } a=2 .
\end{aligned}
$$

Potencial plástico não-quadrático normal anisotrópico de Hill :

$$
\bar{\sigma}^{m}=\frac{1}{2(1+r)} \cdot\left[\left|\sigma_{1}+\sigma_{2}\right|^{m}+(1+2 . r) \cdot\left|\sigma_{1}-\sigma_{2}\right|^{m}\right]
$$

com $m \neq 2$. 
Potencial plástico não-quadrático normal anisotrópico de Hosford:

$$
\begin{aligned}
& \bar{\sigma}^{a}=\frac{1}{(1+r)} \cdot\left[\left|\sigma_{1}\right|^{a}+\left|\sigma_{2}\right|^{a}+r \cdot\left|\sigma_{1}-\sigma_{2}\right|^{a}\right] \\
& \operatorname{com} 6<a<8 .
\end{aligned}
$$

Potencial plástico quadrático anisotrópico generalizado de Hill :

$$
\begin{aligned}
& \bar{\sigma}=\sqrt{H \cdot\left(\frac{1+r_{0}}{r_{0}} \cdot \sigma_{x x}{ }^{2}+\frac{1+r_{90}}{r_{90}} \cdot \sigma_{y y}{ }^{2}-2 \cdot \sigma_{x x} \cdot \sigma_{y y}+\frac{r_{0}+r_{90}}{r_{0} \cdot r_{90}} \cdot\left(1+2 \cdot r_{45}\right) \cdot \sigma_{x y}{ }^{2}\right)} \\
& H=\frac{r_{0}}{1+r_{0}} \\
& \sigma_{x x}+\sigma_{y y}=\sigma_{1}+\sigma_{2} \\
& \sigma_{x x} \cdot \sigma_{y y}-\sigma_{x y}{ }^{2}=\sigma_{1} \cdot \sigma_{2} \\
& \dot{\bar{\varepsilon}}=\sqrt{\frac{1}{H} \cdot\left(\frac{r_{0} \cdot r_{90}}{1+r_{0}+r_{90}} \cdot\left(\frac{1+r_{90}}{r_{90}} \cdot \dot{\varepsilon}_{x x}{ }^{2}+\frac{1+r_{0}}{r_{0}} \cdot \dot{\varepsilon}_{y y}{ }^{2}+2 \cdot \dot{\varepsilon}_{x x} \cdot \dot{\varepsilon}_{y y}\right)+\frac{4 \cdot r_{0} \cdot r_{90}}{\left(r_{0}+r_{90}\right) \cdot\left(1+2 . r_{45}\right)} \cdot \dot{\varepsilon}_{x y}{ }^{2}\right)}
\end{aligned}
$$

E tendo sido considerado nos critérios anteriores :

$r_{0}=r_{45}=r_{90}=r$

Leis de potência para o comportamento do material

As leis de potência empregadas dependem do material considerado, o qual é referenciado nas expressões por três parâmetros : 
- Valor $n$ : Índice de encruamento

- Valor $m$ : Sensibilidade à taxa de deformação

- Valor $K$ : Constante de resistência do material

Com isto, os modelos de plasticidade são descritos por :

$$
\bar{\sigma}=K \cdot \bar{\varepsilon}^{n}
$$

(Hollomon)

ou de forma incremental

$$
\bar{\sigma}=K .\left(\bar{\varepsilon}_{0}+\bar{\varepsilon}\right)^{n} \quad \quad(\text { Swift })
$$

ou considerando-se a taxa de deformação específica

$$
\bar{\sigma}=K \cdot \dot{\bar{\varepsilon}}^{m} \cdot(\bar{\varepsilon}+\Delta \bar{\varepsilon})^{n} \quad \text { (Ramburgh-Osgood) }
$$

ou para materiais dúteis como o alumínio

$$
\bar{\sigma}=B-(B-A) \cdot \exp \left(-n_{0} \cdot \bar{\varepsilon}^{n}\right) \quad(\text { Voce })
$$

em que $\bar{\sigma}$ é a tensão efetiva, $\dot{\bar{\varepsilon}}$ é a taxa efetiva de deformação e $(\bar{\varepsilon}+\Delta \bar{\varepsilon})$ compreende a deformação efetiva de modo incremental. 


\subsection{Procedimentos de análise pelo Método de Elementos Finitos}

Para prever-se o desempenho de componentes mecânicos, o projetista dispõe hoje de uma série de ferramentas matemáticas que podem ser aplicadas. Soluções analíticas podem ser usadas em certos casos, mas sua aplicação é limitada a situações específicas em que uma solução matemática da estrutura pode ser encontrada. Uma maneira mais abrangente de tratar problemas estruturais consiste no uso de métodos numéricos de análise. Apesar de tais métodos fornecerem soluções aproximadas, em muitos casos é a única maneira de que os projetistas dispõem para encontrar as respostas que procuram.

O Método dos Elementos Finitos considera a região de solução do problema formada por pequenos elementos interconectados entre si. A região em estudo é analiticamente modelada ou aproximada por um conjunto de elementos discretos prédefinidos. Uma vez que estes elementos possam ser colocados juntos em um número incontável de diferentes configurações, têm-se formas geométricas bastante complexas modeladas. Além disso, possibilita que o projetista tenha boas possibilidades no modo de aplicação de cargas e condições de contorno, o que torna este método o mais amplamente utilizado em análises estruturais nos dias atuais.

O Método dos Elementos Finitos é aplicável a uma grande faixa de problemas de valores de contorno em engenharia. Em um problema de valor de contorno, uma solução é procurada na região do corpo (domínio), enquanto nos contornos desta região os valores das variáveis dependentes (ou suas derivadas) são conhecidos.

O processo de análise por Elementos Finitos é esquematizado na fig. (2.4.1) (BATHE, 1996). Idealizando um problema físico por um modelo matemático requerem-se hipóteses que conduzem a um conjunto de equações diferenciais que governam este modelo. Sendo o método dos Elementos Finitos também um conjunto de procedimentos baseados em métodos numéricos, é necessário considerar-se a acuracidade da solução. 


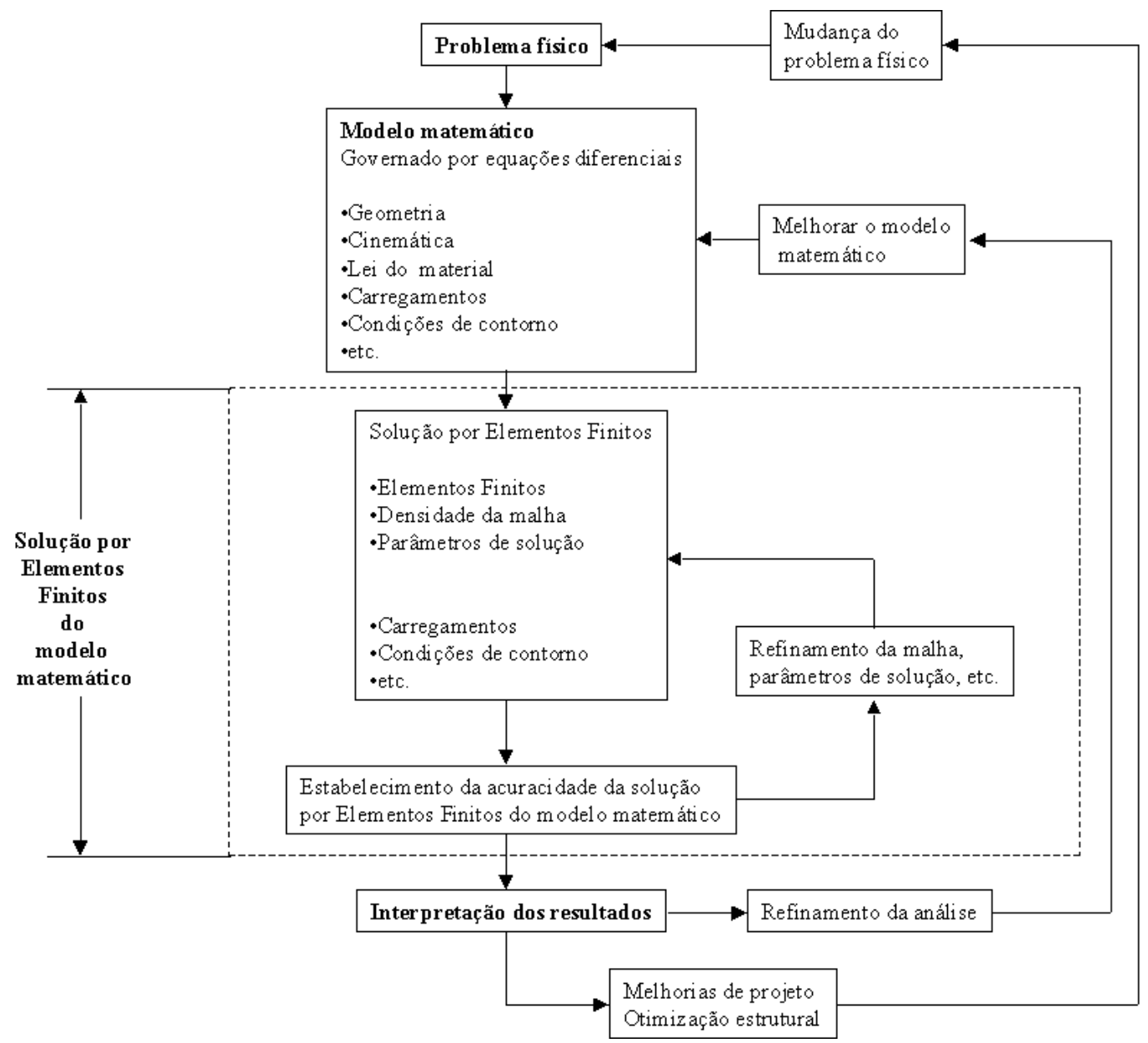

FIGURA 2.4.1 : Processo de análise por Elementos Finitos, (BATHE,1996)

De acordo com HUEBNER (1982) o método pode ser sumarizado basicamente em 3 etapas: pré-processamento, solução e pós-processamento :

\section{Pré-Processamento (preprocessing)}

É a etapa de preparação do problema para posteriormente solucioná-lo. É nesta fase que se faz a modelagem do fenômeno, assumindo-se hipóteses, condições iniciais, condições de contorno e carregamentos, assim como a escolha do elemento, das propriedades dos materiais e da geometria que representará a forma do componente a ser analisado. 
Solução (solver)

A solução do problema tem como ponto de partida o modelo configurado na etapa anterior. Portanto, a acuracidade das respostas depende basicamente da capacidade do engenheiro em abstrair o fenômeno. A solução é baseada em um algoritmo numérico que visa solucionar da maneira mais rápida e acurada uma equação diferencial com condições de contorno e/ou condições iniciais impostas pelo modelo.

Pós-Processamento (postprocessing)

Esta é a última etapa. Nela analisam-se os casos vindos das necessidades do engenheiro que modela o problema. Ou seja, ela é o conjunto solução da equação diferencial que descreve o fenômeno em estudo, sendo que em problemas mecânicos pode ser apresentada por:

- Deslocamentos nodais;

- Deformações da geometria;

- Gradientes de tensão ;

- Gradientes de temperatura;

- Deslocamentos nodais ao longo do tempo;

- Frequiências naturais e modos de vibrar da estrutura.

Esses recursos implementados computacionalmente permitem estimar a solução de um problema complexo em um tempo relativamente pequeno, fazendo com que se otimize o tempo de desenvolvimento de projetos de materiais isotrópicos ou anisotrópicos sujeitos a carregamentos estáticos, térmicos, dinâmicos e outros. 


\subsubsection{Aplicação do método dos Elementos Finitos a processos de conformação de metais}

Em processos práticos de conformação mecânica, um número de operações (pré-formação) é necessário para transformar uma geometria "simples" inicial em uma geometria "complexa", mantendo-se as propriedades e tolerâncias desejadas. Para isso, um método de análise que pode tratar das condições de contorno de matrizes é necessário para aproveitar completamente as vantagens do método dos Elementos Finitos na análise de conformação.

MAKINOUCHI (1996) fornece uma breve descrição dos principais métodos de análise existentes :

\section{Método dos Elementos Finitos com formulação de material Rígido-Plástica ou} Rígido-Viscoplástica: a condição assumida de formulação de material rígido-plástica ou rígido-viscoplástica implica no fato de a tensão de escoamento ser uma função da deformação, taxa de deformação e temperatura e na resposta elástica do material ser desprezada. Esta condição é bem razoável na análise dos problemas de conformação, pois a porção elástica da deformação é desprezada na maioria das vezes. A formulação rígida-viscoplástica tem vantagens práticas significativas: primeiro, ela reduz o esforço e tempo computacional exigidos para a simulação de escoamento de material; segundo, ela estima as tensões $\sigma$, deformações $\varepsilon$, taxas de deformação $\partial \varepsilon$, velocidades $V$ e temperaturas $T$ com acuracidade suficiente para propósitos práticos. Devido à desconsideração da região elástica do material, não é possível calcular a deformação inicial da chapa na face da matriz devido ao seu peso e o efeito springback após a conformação.

\section{Método dos Elementos Finitos com formulação de material Elasto-Plástica :}

Abordagem estática implícita : considerando-se que o processo de estampagem não é realmente um processo de impacto, assume-se um equilíbrio quase estático para o processo. O esquema estático implícito de integração no tempo satisfaz este requerimento, desde que as condições de equilíbrio sejam asseguradas em cada passo de integração no tempo. Contudo, há que avaliar-se o tempo de convergência, devido 
principalmente à mudança do estado de atrito e contato entre a ferramenta e a chapa durante a iteração.

Abordagem estática explícita : de modo a solucionar a questão da convergência, resolvem-se as equações da matriz de rigidez sem iterações em cada passo de integração no tempo, limitando-se o tamanho de cada passo de modo a ser muito pequeno. Um grande número de incrementos é necessário para completar todo o processo de conformação sem acúmulo de erro devido ao desprezo dos termos de ordem elevada na integração no tempo.

Abordagem dinâmica explícita : neste tipo de abordagem, as equações de equilíbrio dinâmico são a base da formulação. Tem-se a grande vantagem de não ser necessária a montagem e solução da matriz de rigidez, obtendo-se a solução para um time step mais rapidamente que em uma abordagem estática. Para obter-se a solução neste tipo de abordagem, o incremento de tempo deve ser limitado de maneira que a onda de dilatação não ultrapasse nenhum elemento. É comum utilizar-se step times de $10^{-6}$ segundos. Para reduzir o tempo de cálculo, a simulação é feita com o punção em velocidade aumentada, chegando-se a 100 vezes a velocidade real, o que pode conduzir a resultados não realísticos (MAMALIS et al , 1996) .

\subsubsection{Dificuldades para simulação do processo de conformação}

O desenvolvimento de métodos confiáveis para simular o processo de deformação de metais têm como obstáculo o comportamento não linear do material, que ocorre devido às deformações de caráter inelástico, além de outros problemas, como a natureza transitória deste tipo de processo, a presença de grandes deslocamentos, grandes rotações, deformações finitas e os efeitos derivados do contato e atrito entre a chapa e a matriz. Tais características tornam o processo tão complexo que requerem o uso de sofisticados algoritmos numéricos e necessidades de grandes recursos computacionais.

Autores como BATHE (1996) e AGELET DE SARACIBAR e OÑATE (1991) atribuem o comportamento não linear a três causas principalmente: 
- Comportamento não linear do tipo cinemático devido a grandes deslocamentos, rotações e deformações que ocorrem no processo;

- Comportamento linear do tipo constitutivo, devido ao caráter inelástico (plástico, viscoplástico, degradação) que caracteriza as deformações do material;

- $\quad$ Caráter não linear das condições de contorno devido à interação (contato e atrito) que se produz entre os sólidos que atuam no processo (lâmina, matriz, moldes) ao longo de uma superfície de contato que não é conhecida a priori e que varia ao longo do processo.

No contexto da análise por Elementos Finitos de processos de conformação de metais, pode-se considerar duas formas de abordar o problema: a formulação de sólido ou formulação de fluxo. A formulação de sólido é o caso mais geral, em que a porção elástica da deformação não é desprezada. Na formulação de fluxo estabelecese a hipótese de que as deformações elásticas são desprezíveis frente as deformações inelásticas. É um caso particular da formulação de sólido, no entanto, é aplicável em muitos processos de conformação de metais. Do ponto de vista de análise computacional, a formulação de fluxo é muito mais econômica que a de sólido.

\subsubsection{Equacionamento de problemas estruturais mecânicos}

Assume-se aqui por simplicidade que todos os componentes de deslocamento estão prescritos sobre $S_{u}$ (área do domínio onde ocorrem os deslocamentos), e todos os componentes de tração estão prescritos sobre $S_{f}$ (área do domínio onde atuam as forças externas), tal que $S_{u} \cup S_{f}=S$ e $S_{u} \cap S_{f}=0$, fig. (2.4.2). Analisando-se o equilíbrio de um corpo tridimensional em equilíbrio, sendo dados:

- Geometria do corpo

- Carregamentos aplicados

- Condições de contorno em $S_{u}$

- Lei de tensão x deformação do material

- Estado inicial de tensões no corpo 
Deve-se calcular os deslocamentos $u$ do corpo e correspondentes deformações $(\varepsilon)$ e tensões $(\tau)$. Para calcular-se a resposta do corpo, estabelece-se a equação diferencial governante do equilíbrio, resolvendo-se então para as condições de contorno aplicadas.

Princípio dos deslocamentos virtuais (trabalhos virtuais)

A base da solução por Elementos Finitos em problemas baseados no deslocamento é o princípio dos deslocamentos virtuais $(P D V)$. Este princípio estabelece que o equilíbrio do corpo na fig. (2.4.2) requer que, para qualquer pequeno deslocamento imposto sobre o estado de equilíbrio do corpo, o trabalho virtual interno total seja igual ao trabalho virtual externo total.

Trabalho virtual Trabalho virtual externo $\mathrm{R}$

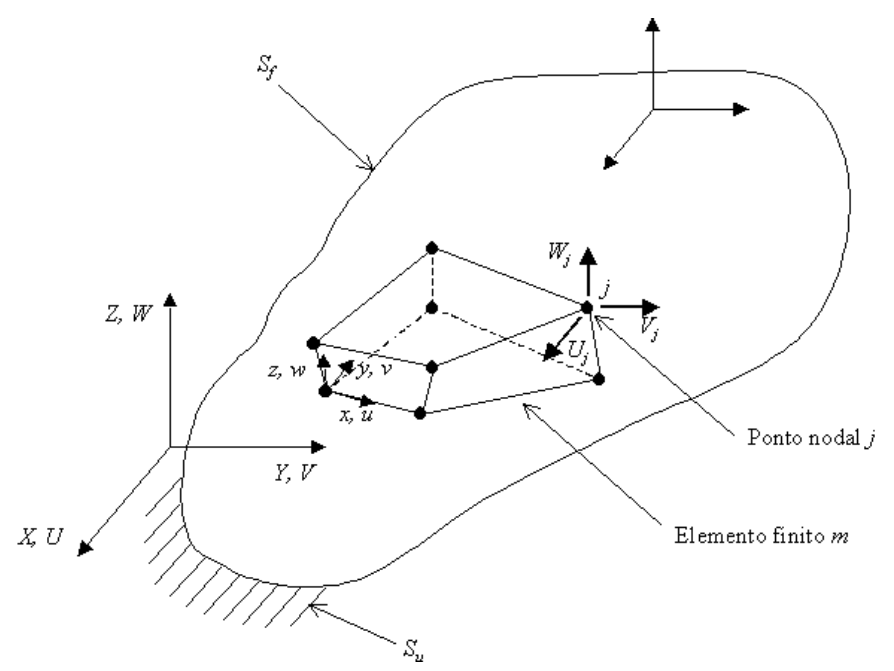

FIGURA 2.4.2 : Corpo tridimensional genérico com um elemento de 8 nós, (BATHE,1996)

Enfatizam-se aqui que: 
- As tensões $\tau$ são assumidas como conhecidas e únicas tal que o balanço de carregamentos é exato.

- As deformações virtuais $\varepsilon$ são calculadas por diferenciações feitas a partir dos deslocamentos virtuais assumidos, $U$

- Os deslocamentos virtuais devem representar um campo contínuo de deslocamento, permitindo a avaliação de $\varepsilon$, com $U$ igual a zero em que são prescritas condições de contorno, $S_{u}$.

- Todas as integrações são executadas sobre o volume original e a área superficial do corpo, não afetados pelos deslocamentos virtuais impostos.

Quando o PDV é satisfeito para todos os deslocamentos virtuais admissíveis, também são satisfeitos os requisitos fundamentais da mecânica:

- Equilíbrio: o PDV é uma expressão de equilíbrio.

- Compatibilidade: os deslocamentos $U$ são contínuos e satisfazem as condições de contorno.

- Lei de Tensão / Deformação: assegurada devido às tensões serem calculadas utilizando-se as relações constitutivas para as deformações $\varepsilon$ (que são avaliadas para os deslocamentos $U$ ).

Assume-se que existam condições de suporte suficientes para uma solução de deslocamento única.

Em uma análise não linear, o equilíbrio de um corpo deve ser considerado na configuração corrente. Para o desenvolvimento a seguir considera-se o movimento de um corpo genérico em um sistema de coordenadas cartesiano estacionário, como mostrado na fig. (2.4.3), e assume-se que o corpo possa sofrer grandes deslocamentos, grandes deformações e uma resposta constitutiva não linear. 


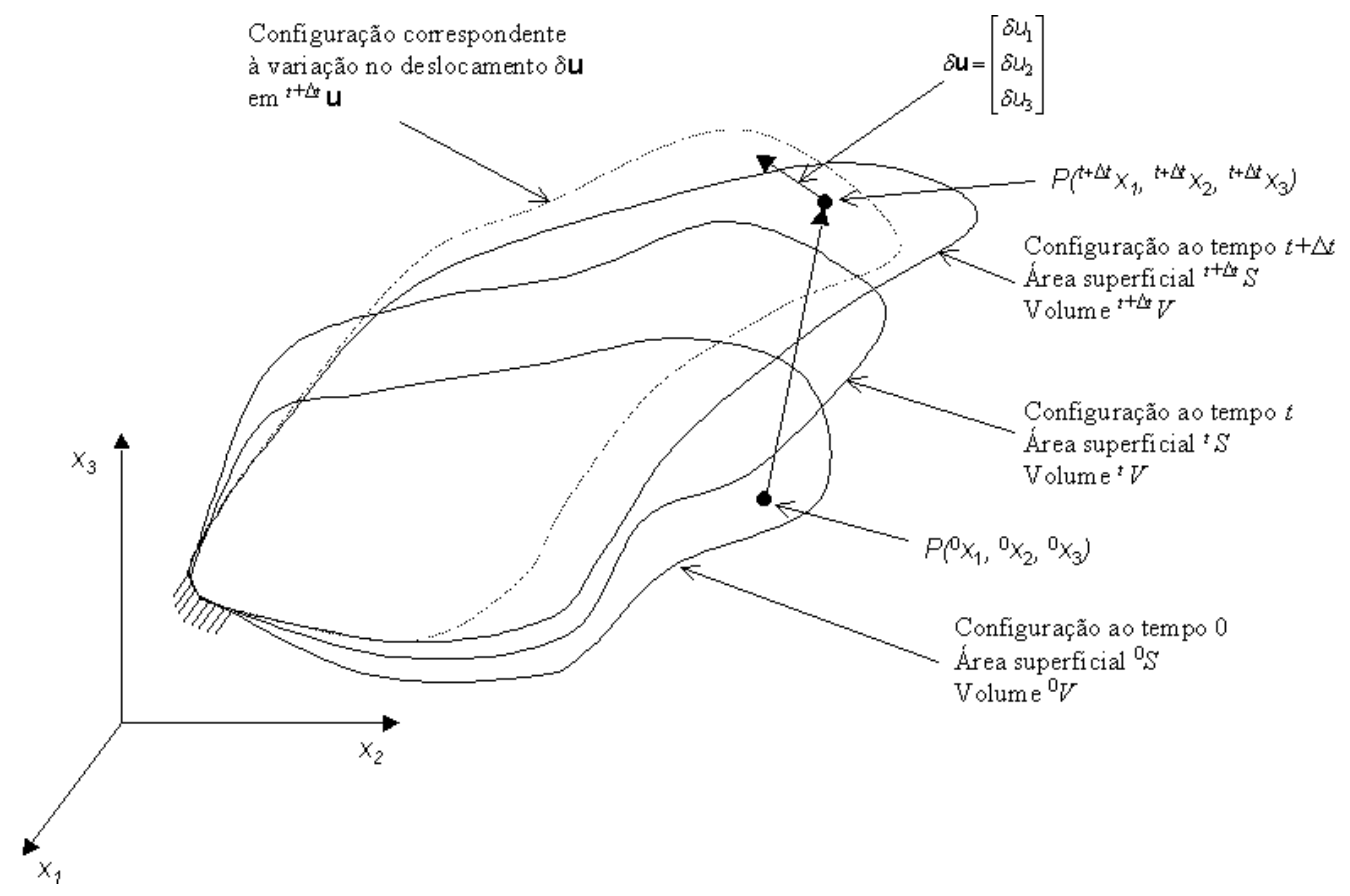

FIGURA 2.4.3 : Movimento de um corpo em um sistema de coordenadas Cartesiano,

(BATHE,1996)

Para considerar-se a possibilidade de o corpo sofrer grandes deslocamentos e rotações e grandes deformações bem como uma relação tensão / deformação não linear, pode-se aplicar o PDV conforme demonstrado a seguir.

Utilizando-se uma formulação Lagrangiana, expressa-se o equilíbrio do corpo no tempo $t+\Delta t$ através do PDV. Em notação tensorial:

$$
\int_{t+\Delta t}{ }^{t+\Delta t} \tau_{i j} \delta_{t+\Delta t} e_{i j} d^{t+\Delta t} V={ }^{t+\Delta t} R
$$

em que:

${ }^{\mathrm{t}+\Delta t} \tau_{\mathrm{ij}}$ : componentes cartesianas do tensor de tensões de Cauchy.

$\delta_{t+\Delta t} e_{i j}=\frac{1}{2}\left(\frac{\partial \delta u_{i}}{\partial^{t+\Delta t} x_{j}}+\frac{\partial \delta u_{j}}{\partial^{t+\Delta t} x_{i}}\right)$ : tensor de deformação correspondente aos deslocamentos virtuais.

$\delta \mathrm{u}_{\mathrm{i}}$ : componentes de deslocamento virtual impostos sobre a configuração corrente no tempo $t+\Delta t$, como função de ${ }^{\mathrm{t}+\Delta \mathrm{t}} \mathrm{x}_{\mathrm{j}}, j=1,2,3$ 
${ }^{\mathrm{t}+\Delta \mathrm{t}} \mathrm{X}_{\mathrm{i}}$ : coordenadas Cartesianas de um ponto material no tempo $t+\Delta t$.

${ }^{\mathrm{t}+\Delta \mathrm{t}} \mathrm{V}$ : volume no tempo $t+\Delta t$.

$\mathrm{e}$

$$
{ }^{t+\Delta t} R=\int_{{ }^{t+\Delta t} V}{ }^{t+\Delta t} f_{i}^{B} \delta u_{i} d^{t+\Delta t} V+\int_{{ }^{t+\Delta t} S_{f}}{ }^{t+\Delta t} f_{i}^{S} \delta u_{i}^{S} d^{t+\Delta t} S
$$

em que:

${ }^{t+\Delta t} f_{i}^{B}$ : componente de forças externamente aplicadas por unidade de volume no tempo $t+\Delta t$.

${ }^{t+\Delta t} f_{i}^{S}$ : componentes de tração aplicados externamente por unidade de área no tempo $t+\Delta t$.

${ }^{t+\Delta t} \mathrm{~S}_{\mathrm{f}}$ : superfície à qual as trações externas são aplicadas no tempo $t+\Delta t$.

$\delta \mathrm{u}_{\mathrm{i}}^{\mathrm{S}}=\delta \mathrm{u}_{\mathrm{i}}$ : avaliado na superfície ${ }^{\mathrm{t}+\Delta \mathrm{t}} \mathrm{s}_{\mathrm{f}}$ (os componentes $\delta u_{i}$ são zero, para a superfície $^{t+\Delta t} s_{u}$, em que os deslocamentos são prescritos como condições de contorno).

\section{Condições de contato}

Um comportamento não linear particularmente difícil de analisar é o contato entre dois ou mais sólidos. A faixa de problemas de contato envolve desde o contato sem atrito em pequenos deslocamentos até o contato com atrito em condições de grandes deformações inelásticas. A não linearidade do problema é dada não somente por não linearidades geométrica ou de material mas também por condições de contorno. 


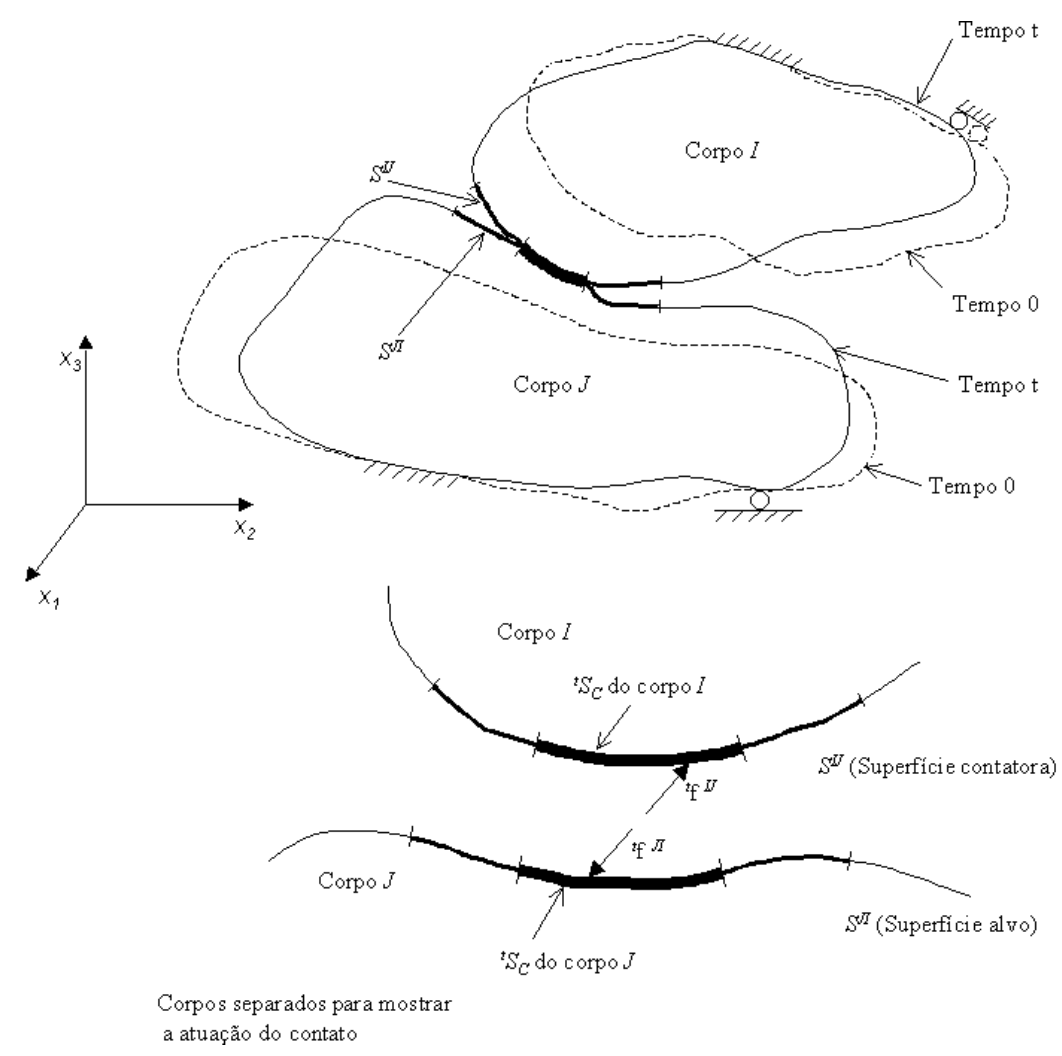

FIGURA 2.4.4 : Corpos em contato no tempo $t$, (BATHE,1996)

Considerem-se $N$ corpos que estão em contato no tempo $t$. Seja ${ }^{t} S_{C}$ a área completa de contato para cada corpo $L, L=1, \ldots, N$. O princípio dos trabalhos virtuais para $N$ corpos, no tempo $t$ fornece:

$$
\sum_{\mathrm{L}=1}^{N}\left\{\int_{{ }_{\mathrm{t}}}{ }^{\mathrm{t}} \tau_{\mathrm{ij}} \delta_{\mathrm{t}} \mathrm{e}_{\mathrm{ij}} \mathrm{d}^{\mathrm{t}} \mathrm{V}\right\}=\sum_{\mathrm{L}=1}^{\mathrm{N}}\left\{\int_{{ }_{\mathrm{t}} \mathrm{V}} \delta \mathrm{u}_{\mathrm{i}}{ }^{\mathrm{t}} \mathrm{f}_{\mathrm{i}}^{\mathrm{B}} \mathrm{d}^{\mathrm{t}} \mathrm{V}+\int_{{ }^{\mathrm{T}} \mathrm{S}_{\mathrm{f}}} \delta \mathrm{u}_{\mathrm{i}}{ }^{\mathrm{s}} \mathrm{f}_{\mathrm{i}}^{\mathrm{S}} \mathrm{d}^{\mathrm{t}} \mathrm{S}\right\}+\sum_{\mathrm{L}=1}^{\mathrm{N}} \int_{{ }^{S_{\mathrm{C}}}} \delta \mathrm{u}_{\mathrm{i}}{ }^{\mathrm{C}} \mathrm{t}_{\mathrm{i}} \mathrm{f}^{\mathrm{C}} \mathrm{d}^{\mathrm{t}} \mathrm{S}
$$

em que os termos entre chaves correspondem aos termos usuais e o último somatório corresponde à contribuição das forças de contato. O efeito das forças de contato é incluído como uma contribuição às forças de tração aplicadas externamente.

Seja ${ }^{t} f^{I J}$ o vetor contendo as forças de tração devido ao contato no corpo $I$ causado pelo corpo $J$, e ${ }^{t} f^{I J}=-{ }^{t} f^{J I}$, conforme notação utilizada na fig. (2.4.4). O trabalho virtual devido às trações de contato pode ser escrito como: 


$$
\int_{S^{I J}} \delta u_{i}^{I t} f_{i}^{I J} d S^{I J}+\int_{S^{I I}} \delta u_{i}^{J t} f_{i}^{J I} d S^{J I}=\int_{s^{J}} \delta u_{i}^{I J} d S^{I J}
$$

em que $\delta u_{i}^{I}$ e $\delta u_{i}^{J}$ são os componentes de deslocamento virtual sobre as superfícies de contato dos corpos $I$ e $J$ respectivamente, e

$$
\delta u_{i}^{I J}=\delta u_{i}^{I}-\delta u_{i}^{J}
$$

Pode-se chamar o par de superfícies $S^{I J}$ e $S^{J I}$ de par de superfícies em contato e estas superfícies não têm necessariamente o mesmo tamanho. Contudo, a atual área de contato em um tempo $t$ para os corpos $I$ e $J$ é ${ }^{t} S_{C}$, e em cada caso esta área é parte de $S^{I J}$ e $S^{J I}$, respectivamente chamadas de "superfície contatora" e "superfície alvo". O lado direito da eq. (2.4.5) pode ser interpretado como o trabalho virtual que as forças de contato produzem sobre o deslocamento virtual relativo do par de superfícies em contato.

O caráter não linear das condições de contato superficiais permite que apenas alguns problemas sejam resolvidos analiticamente. Os aspectos não lineares, devido às condições de contorno, têm um papel muito importante na simulação computacional deste tipo de processo. A análise se faz de forma geral em $2 \mathrm{D} / 3 \mathrm{D}$, tanto para contato generalizado como para contato unilateral. No primeiro caso, ocorre a interação de entre sólidos deformáveis e no segundo, entre sólidos deformáveis e sólidos rígidos. Do ponto de vista computacional, de acordo com AGELET DE SARACIBAR \& OÑATE (1991), um dos aspectos mais importantes é a otimização dos algorítmos e procedimentos de busca e detecção dos contatos, para que se possa introduzir a formulação do problema de contato no contexto geral de análise por Elementos Finitos, de modo a verificar as condições de compatibilidade cinemática impostas pelas restrições de contato, assegurando-se que não haja penetrações entre os sólidos que interagem.

Existem dois métodos bem estabelecidos na literatura e softwares comerciais de Elementos Finitos para considerar o problema de contato entre sólidos (AGELET DE SARACIBAR \& OÑATE, 1991). O primeiro é o método dos multiplicadores de Lagrange, no qual se obriga a que as restrições de contato se verifiquem de forma 
exata através dos multiplicadores de Lagrange. Como inconveniente, apresenta o aumento do número de incógnitas e o aparecimento de zeros na diagonal principal da matriz de rigidez associada aos multiplicadores de Lagrange. O segundo, é o método da penalização, o qual requer que as condições de contato se verifiquem de forma aproximada, por meio do fator de penalização. Este método não conduz a um aumento do número de incógnitas, mas leva a um mal condicionamento da matriz de rigidez.

Atrito

Em processos de conformação, o escoamento de material é causado pela pressão transmitida pela matriz para a peça conformada. Portanto, as condições de atrito na interface matriz/material têm influência no escoamento do metal, formação de defeitos superficiais e internos, tensões e forças atuantes no processo. Tais condições dependem basicamente do tipo de lubrificação adotada [ALTAN et al (1983), KOBAYASHI et al. (1989)].

Sob condições a seco, nenhum lubrificante é utilizado na interface e somente as camadas de óxido presentes na matriz e na matéria prima estão presentes. Neste caso, o atrito é alto, situação desejável apenas em pequeno número de operações de conformação.

Condições hidrodinâmicas existem quando uma espessa camada de lubrificante está presente entre as matrizes e a peça. Neste caso, as condições de atrito são governadas pela viscosidade do lubrificante e pela velocidade relativa entra matriz e peça. Em operações de conformação em alta velocidade, a condição hidrodinâmica existe somente dentro de um certo regime de velocidades, em que a temperatura nas interfaces são relativamente baixas.

Uso de filme lubrificante (Boundary lubrication) é a situação mais comum encontrada em conformação de metais. $\mathrm{O}$ aumento de temperatura na interface e as elevadas pressões de contato normalmente não possibilitam a presença da condição hidrodinâmica em regime. Uso de filmes de lubrificante, por outro lado, não possibilita uma análise confiável. Conseqüentemente, muito do conhecimento de 
lubrificação em conformação é empírico, com poucas informações baseadas em formulação adequada do problema.

Existem dois modelos básicos de simular o problema de atrito entre sólidos (AGELET DE SARACIBAR e OÑATE, 1991): o modelo de atrito cinemático e o modelo de atrito de Coulomb. No modelo cinemático, as forças de atrito são independentes da pressão de contato. No modelo de Coulomb, se produz um deslizamento relativo entre sólidos quando as tensões tangenciais alcançam um certo limite, que é proporcional à pressão de contato e que $\mu$ é o coeficiente de atrito. Esta hipótese significa que os efeitos de atrito são incluídos de modo muito simplificado.

\subsubsection{Resolução numérica de problemas não-lineares : abordagem estática implícita}

Em problemas estruturais não lineares discretiza-se o domínio e considerando-se a atuação das forças externas, obtem-se a partir de (2.4.4) :

$$
[K(u)]\{u\}=-\{f\}
$$

em que:

$[\mathrm{K}]=$ matriz de rigidez global

$\{\mathrm{u}\}=$ vetor de incógnitas (por exemplo, deslocamentos nodais)

$\{\mathrm{f}\}=$ vetor de forças externas

Quando os valores de $\mathrm{K}_{\mathrm{ij}}$ dependem dos valores do vetor incógnita $\{\mathrm{x}\}$, ou de suas derivadas, o problema é não linear. Então para encontrar a solução do sistema, utilizam-se métodos iterativos. Para solução destes tipos de problemas têm-se os métodos numéricos da iteração direta, o método de Newton-Raphson, o método da rigidez tangencial e o método da rigidez inicial (OWEN \& HINTON, 1986).

Os problemas de análises não lineares podem, segundo ZIENKIEWICZ (1977), ser divididos conforme:

- Não linearidade de material independente do tempo; 
- Não linearidade de material dependente do tempo ;

- Problemas de campo não lineares.

Demonstra-se a seguir o procedimento geral para resolução de problemas não lineares discretos envolvendo a não linearidade de material independente do tempo .

Um sistema não linear discretizado pode ser escrito genericamente pelo seguinte conjunto de equações:

$$
[K(u)]\{u\}+f=0
$$

em que $u$ descreve a aproximação para a função ou funções desconhecidas.

A forma mais apropriada da equação acima depende do problema e do método de discretização como por exemplo resíduos ponderados e princípios variacionais em HUEBNER (1982). Para resolução deste sistema de equações é necessário o uso de métodos iterativos, nos quais o problema seja resolvido repetidamente como um sistema linear até que se obtenha a convergência. A seguir são apresentados os métodos iterativos mais utilizados para este caso segundo ZIENKIEWICZ (1977) :

Método da iteração direta :

Seja:

$$
\mathrm{K} u+\mathrm{f}=0
$$

em que $\mathrm{K}=\mathrm{K}(u)$.

Inicialmente assume-se o valor de $u$ como $u^{0}$, resultando:

$$
u^{1}=-\left(\mathrm{K}^{0}\right)^{-1} \mathrm{f} \quad \text { em que } \mathrm{K}^{0}=\mathrm{K}\left(u^{0}\right)
$$

Generalizando, tem-se : 


$$
u^{\mathrm{n}}=-\left(\mathrm{K}^{\mathrm{n}-1}\right)^{-1} \mathrm{f}
$$

O erro é estimado por: e $=u^{\mathrm{n}}-u^{\mathrm{n}-1}$, até que seja suficientemente pequeno.

Graficamente tem-se:

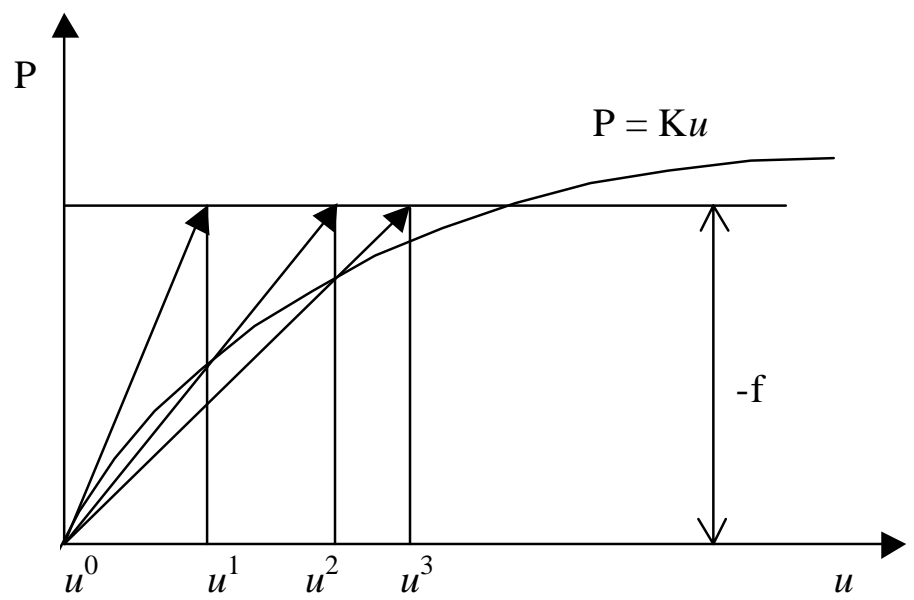

FIGURA 2.4.5 : Aproximações sucessivas para obtenção da solução $u$.

Método de Newton-Raphson :

Se uma solução aproximada $u=u^{\mathrm{n}}$ é obtida, pode-se escrever uma solução melhorada utilizando-se uma expansão de Taylor abreviada:

$$
\Psi\left(\mathrm{u}^{\mathrm{n}+1}\right) \equiv \Psi\left(\mathrm{u}^{\mathrm{n}}\right)+\left(\frac{\mathrm{d} \Psi}{\mathrm{du}}\right)_{\mathrm{n}} \Delta \mathrm{u}^{\mathrm{n}}=0
$$

com $u^{\mathrm{n}+1}=u^{\mathrm{n}}+\Delta u^{\mathrm{n}}$

Assim: $\frac{\mathrm{d} \Psi}{\mathrm{du}} \equiv \frac{\mathrm{dP}}{\mathrm{du}} \equiv \mathrm{K}_{\mathrm{T}}(\mathrm{u}), \quad$ o que representa uma matriz tangencial.

O novo valor de $u^{\mathrm{n}+1}$ pode ser obtido por:

$$
\Delta u^{\mathrm{n}}=-\left(\mathrm{K}^{\mathrm{n}}\right)^{-1} \Psi^{\mathrm{n}}=-\left(\mathrm{K}^{\mathrm{n}} \mathrm{T}\right)^{-1}\left(\mathrm{P}^{\mathrm{n}}+\mathrm{f}\right)
$$

Graficamente: 


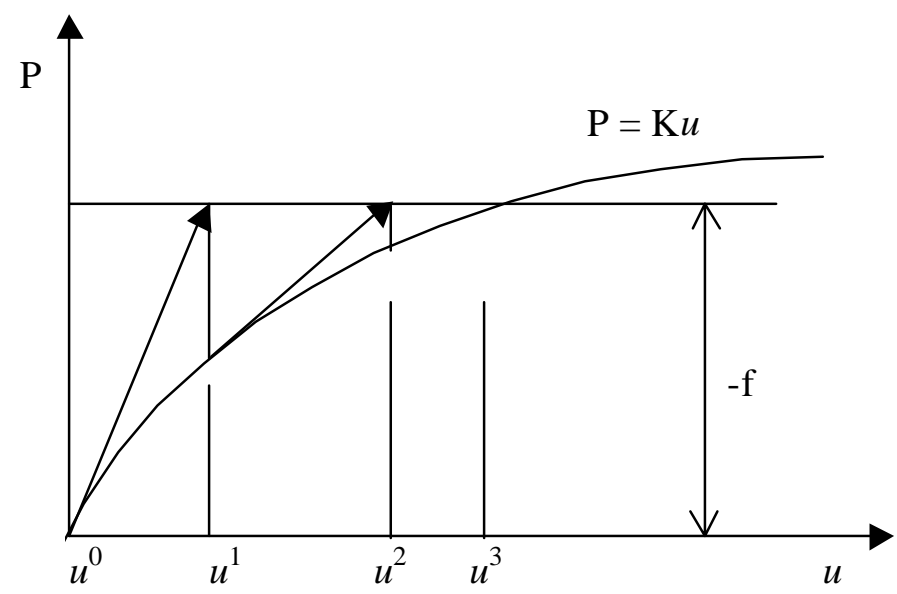

FIGURA 2.4.6 : Método de Newton Raphson para o cálculo de $u$.

\section{Método de Newton-Raphson modificado}

Esta modificação é as vezes utilizada porque no método de Newton-Raphson, a cada iteração, deve-se resolver um sistema completamente novo. Freqüentemente, pode ser feita a aproximação:

$$
\mathrm{K}_{\mathrm{T}}^{\mathrm{n}}=\mathrm{K}_{\mathrm{T}}^{0}
$$

O algorítimo torna-se:

$$
\Delta a^{\mathrm{n}}=-\left(\mathrm{K}_{\mathrm{T}}^{0}\right)^{-1}\left(\mathrm{P}^{\mathrm{n}}+\mathrm{f}\right)
$$

Este sistema é mais econômico a cada passo, mas a convergência é mais demorada.

Graficamente: 


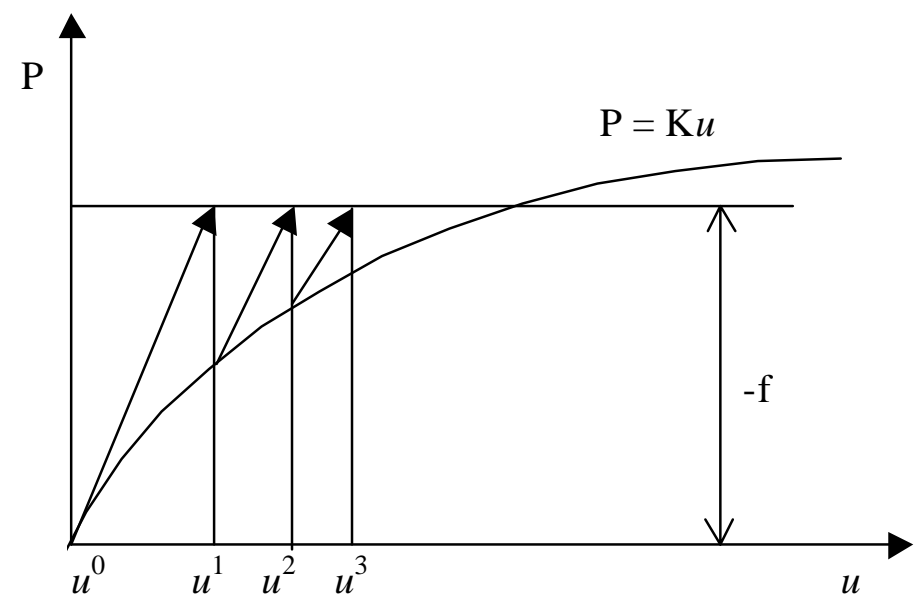

FIGURA 2.4.7 : Método de Newton Raphson modificado.

\subsubsection{Resolução numérica de problemas não-lineares: integração no tempo e a abordagem dinâmica explícita}

Neste tipo de abordagem, o conjunto de equações diferenciais não lineares a ser resolvido para estimar os delocamentos nodais é (MAMALIS et al ,1996):

$$
\begin{aligned}
& {[\mathrm{M}]\{\ddot{\mathrm{u}}(\mathrm{t})\}+[\mathrm{C}]\{\dot{\mathrm{u}}(\mathrm{t})\}+[\mathrm{K}(\mathrm{u}(\mathrm{t})]\{\mathrm{u}(\mathrm{t})\}=\{\mathrm{F}(\mathrm{t})\}} \\
& \text { Desprezando-se o amortecimento },[\mathrm{C}]: \\
& M \ddot{u}(t)=f^{e x t}(t)-f^{\text {int }}(t)
\end{aligned}
$$

em que $M$ é a matriz de massa, $u$ é o vetor desconhecido de deslocamentos nodais, $f$ ext $(t)$ é o vetor carregamento externo dependente do tempo e $f^{i n t}(t)$ é o vetor de forças internas provenientes de tensões existentes nos elementos.

Para solução de (2.4.16) cita-se como o método das diferenças centrais, descrito brevemente a seguir.

O método das diferenças centrais requer que todas as quantidades em $t_{n}$ sejam conhecidas para avançar a solução para o tempo $t_{n+1}$ utilizando-se a equação (2.4.17). Para avaliar-se $\ddot{u}(t)$ a partir de eq. (2.4.17) utiliza-se uma aproximação de massa nodal agrupada sendo, portanto, a matriz $M$ diagonal. A eq. (2.4.17) pode ser 
resolvida facilmente desde que os termos do lado direito da equação sejam conhecidos. Assume-se que:

$$
\begin{aligned}
& \ddot{u}\left(t_{n}\right)=\left(1 / \Delta t^{2}\right)\left[u\left(t_{n-1}\right)-2 u\left(t_{n}\right)+u\left(t_{n+1}\right)\right] \\
& \dot{u}\left(t_{n}\right)=(1 / 2 \Delta t)\left[-u\left(t_{n-1}\right)+u\left(t_{n+1}\right)\right]
\end{aligned}
$$

em que $u$, $\dot{u}$, e $\ddot{u}$ são respectivamente os vetores de deslocamento, velocidade e aceleração dependentes do tempo. $\Delta t$ é o intervalo de tempo no qual eq. (2.4.17) deve ser satisfeita.

$$
\Delta t=t_{n+1}-t_{n}
$$

As variáveis cinemáticas são conhecidas em $t_{n+1}$ desde que tenham sido obtidas nas equações. (2.4.18) e (2.4.19) a partir dos valores de tempo anterior. O vetor de forças externas dependentes do tempo $f^{\text {ext }}\left(t_{n+1}\right)$ também é definido desde que os carregamentos externos são usualmente funções do tempo predefinidas. $\mathrm{O}$ volume de cálculos dentro de um time step está relacionado ao cálculo das forças internas $f^{\text {int }}\left(t_{n+1}\right)$. A obtenção de $f^{i n t}\left(t_{n+1}\right)$ começa com os cálculos da taxa de deformação $d\left(t_{n+1}\right)$ :

$$
\left.\left.d\left(t_{n+1 / 2}\right)=(1 / 2) \mid \nabla \dot{u}\left(t_{n+1 / 2}\right)+\left(\nabla \dot{u}\left(t_{n+1 / 2}\right)\right)\right)^{T}\right\rfloor=B \dot{u}\left(t_{n+1 / 2}\right)
$$

em que $\nabla \dot{u}$ é o gradiente de velocidade em relação à geometria no instante $t_{n+1}$ e $B$ é o 'operador de velocidade de deformação'. Usando-se a taxa de deformação $d\left(t_{n+1 / 2}\right)$ e as variáveis de história do material, a função resposta de tensão $\sigma$ pode ser calculada como:

$$
\sigma\left(t_{n+1}\right)=\sigma\left(t_{n}\right)+\int_{t_{n}}^{t_{n+1}} \sigma d t
$$


Esta formulação incremental facilmente acomoda as não-linearidades de material. $\mathrm{O}$ vetor resultante de forças internas para um elemento $e$, é:

$$
f^{\mathrm{int}, e}\left(t_{n+1}\right)=\int_{\Omega^{e}} B^{T} \sigma\left(t_{n+1}\right) d \Omega^{e}
$$

e o vetor global de forças $f^{\text {int }}\left(t_{n+1}\right)$ é encontrado através da montagem da contribuição de todos os elementos.

O método de integração requer que o time step seja menor que o valor crítico $\Delta t_{c r}$, que é sugerido ser proporcional ao tamanho do menor elemento na malha gerada. Para o problema de grandes deformações ou comportamento não linear, o fator limitante do tamanho do time-step varia durante a análise; contudo o algoritmo de definição do time-step o mantém abaixo de um valor limite, de modo a assegurar a estabilidade e minimizar o custo da análise.

Para elementos SHELL, a serem utilizados no capítulo 5, os time steps são calculados através de :

$$
\Delta \mathrm{t}_{\mathrm{e}}=\frac{\mathrm{L}_{\mathrm{s}}}{\mathrm{c}}
$$

sendo $L s$ um diagonal representativa no elemento e $c$ igual à velocidade do som no meio material considerado e :

$$
c=\sqrt{\frac{E}{\rho\left(1-v^{2}\right)}}
$$

com módulo de Young $E$, densidade do material $\rho$ e coeficiente de Poisson $v$.

Outras considerações para os time steps são encontradas em HALLQUIST (1993). 


\section{Diagramas de limite de conformação}

Neste item são revistos vários aspectos relacionados à conformabilidade de chapas, os quais contribuirão para a elaboração de uma metodologia de análise de processos de conformação como o repuxo junto ao método dos elementos finitos. $\mathrm{O}$ principal objetivo deste tópico é de fornecer conceitos matemáticos para a definição da estricção local durante a fase plástica para o cálculo dos valores de limite em diagramas, a ser feito no capítulo 4.

\subsection{Aspectos de conformabilidade de chapas metálicas}

As propriedades físicas das chapas metálicas variam consideravelmente, dependendo do material e ligas empregadas, seu processamento, tratamentos térmicos e grau de encruamento. Busca-se na seleção do material um compromisso entre requisitos funcionais da peça e as propriedades de conformação nos materiais disponíveis quando requer-se bom desempenho. Para isto, analisam-se os fatores influentes na conformabilidade da chapa, que é definida pela sua capacidade de submeter-se ao processo de conformação escolhido conforme :

- distribuição uniforme de deformações;

- alcance de elevados níveis de deformação sem estricções exageradas;

- fixação das tensões de compressão no plano das deformações, evitando-se o enrugamento;

- fixação das tensões de cisalhamento no plano de deformações, sem a ocorrência de fraturas;

- manutenção da forma após a remoção da matriz e

- apresentação de superfície com textura suavisada, sem danificações. 
Estes fatores por sua vez são influenciados por diversas propriedades do material:

\section{Distribuição de deformações}

Três propriedades de material influenciam na distribuição de deformações durante uma operação de conformação :

- Módulo de elasticidade de Young E e coeficiente de Poisson v ;

- Coeficiente de encruamento ou valor $n$

- Sensibilidade à taxa de deformação ou valor $m$

- Razão de deformações plásticas ou fator de anisotropia ou valor $r$

A distribuição uniforme de deformações depende dos valores de $m$ e de $n$. O alcance de valores de deformação mais elevados depende de muitos fatores tais como o material empregado e suas ligas, tratamentos térmicos, os valores $m$, $n$, e $r$, a espessura da chapa, uniformidade além de quantidade de defeitos e inclusões presentes.

\section{Máximos níveis de tensão alcançados}

Cada tipo de material em chapa como aço ou alumínio pode ser deformado até um certo limite de tensões, antes da ocorrência de estricções (neckings) ou fraturas. Este limite depende principalmente de combinações de deformações impostas, ou seja, da relação entre as deformações máximas e mínimas. O limite inferior de tensões ocorre em pontos próximos ao caso de deformação plana, isto é, quando a menor deformação é nula. Em geral pode-se afirmar que o nível de tensões máximas aceitáveis aumenta quando aumenta-se a complexidade do estado de deformações do material. As propriedades do chapa que permitem este aumento são os parâmetros $m$ e $n$. 
Propriedades de material e enrugamentos

O efeito das propriedades do material na formação de enrugamentos é assunto bastante considerado na literatura. Em operações de estampagem profunda, TAYLOR (1988) afirma que, em experimentos feitos com copos cônicos e cilíndricos, os valores altos de $r_{m}$ e baixos de $\Delta r$ reduzem os enrugamentos de flange e de parede. Soma-se a isto o fato de uma razão baixa entre tensão de escoamento e módulo de elasticidade $\left(\sigma_{f} / E\right)$ diminuem os enrugamentos de parede. O valor $n$ tem uma influência indireta. Quando a força do prensa-chapas é mantida constante, o valor $n$ não tem efeito. Entretanto, valores altos para $n$ exigem que a força no prensa-chapas seja aumentada, reduzindo-se os enrugamentos de parede.

Propriedades de material e resistência ao cisalhamento

Fraturas por cisalhamento devido a tensões de cisalhamento no plano prevalecem em materiais de alta resistência e trabalhados a frio, sobretudo quando os defeitos internos como inclusões estão presentes. Neste caso, a falha do material ocorre em regiões próximas a $\varepsilon_{1}= \pm \varepsilon_{2}$, antes do início do necking. Este tipo de fratura depende do material, tratamentos térmicos e presença de encruamento.

Propriedades de material e recuo elástico (springback)

Os parâmetros do material que influem no springback após uma operação de conformação são :

- Módulo de elasticidade, $E$;

- Tensão de escoamento, $\sigma_{y} \mathrm{e}$

- Tangente da curva Tensão verdadeira x deformações, tangente $d \sigma_{T} / d \varepsilon$.

Na peça final, o recuo elástico é determinado por interações complexas entre as tensões elásticas internas e residuais, sujeitas a restrições pela geometria da peça. 


\section{Qualidade superficial}

As condições citadas previamente que ocasionam as texturas superficiais indesejáveis podem ser minimizadas ou prevenidas. Por exemplo a formação de "casca de laranja" em regiões que sofreram deformações drásticas pode ser diminuída pelo emprego de refinamento de grãos no material.

\section{Efeito da temperatura na formabilidade}

Uma modificação na temperatura externa ao sistema ou de forma localizada altera, em geral, as propriedades do material, afetando a conformabilidade de modo global ou local, respectivamente. Em aplicações específicas como em superplasticidade têm-se a presença de temperaturas elevadas, exigindo-se baixas taxas de deformação. Nas aplicações mais comuns ocorrem aquecimentos devidos aos atritos nos contatos e às deformações efetuadas. Neste caso, estes aspectos quando intensificados tornam-se prejudiciais porque reduzem a tensão de escoamento em regiões mais solicitadas, tendendo a dificultar a distribuição uniforme de deformações.

\subsection{A presença de defeitos na chapa}

Nos processo de conformação de metais, os esforços requeridos para se deformar o blank são transmitidos através chapa, havendo a formação de alguns tipos de defeitos em caso de sobrecargas. Para isto analisa-se o comportamento dos estados de tensões e deformações, obtendo-se uma avaliação dos processos de conformação de metais. Os fenômenos decorrentes de concentração de deformações são estudados sem razoável consenso a respeito de seus mecanismos, pois alguns aspectos das falhas do material podem ser considerados como parcialmente explorados (MARCINIAK \& DUNCAN, 1992). O desenvolvimento das falhas depende da geometria da peça, das forças em questão, das propriedades do material e do grau de homogeneidade inicial da chapa. 
Os defeitos mais comuns encontrados durante um processo de conformação de chapas são listados, sendo possíveis quaisquer combinações destes :

\section{Estricção e fraturas}

Ocorrem quando a chapa é submetida a tensões que excedam aos limites aceitáveis do material, para um dado histórico de deformações e seu estado atual, taxa de deformações e temperatura de trabalho. Eventualmente em algum ponto desta área ocorre uma concentração de deformações, ou seja, uma banda de afinamento na espessura da chapa conhecido como estricção (necking), que no final ocasiona a fratura. A deformação do necking é geralmente considerada como falha do blank porque produz um defeito visível e um enfraquecimento estrutural. A estricção pode ser local ou difusa e no decorrer deste trabalho serão detalhados alguns aspectos para a sua descrição.

\section{Enrugamentos (de flange ou de parede)}

Nas conformações típicas de chapas, o punção entra em contato com a chapa, estira-a e força-a através do anel do prensa-chapas. As bordas da chapa são puxadas para uma região cujo perímetro é cada vez menor. Isto produz tensões de compressão na direção circunferencial e no limite, dependendo do material e de sua espessura, surgem pequenas ondulações (buckles). Estas, por sua vez, desenvolvem-se para ondas mais pronunciadas (wrinkles) se a pressão do prensa-chapas não for suficientemente alta. Estes enrugamentos podem ocorrer em outras partes da peça como nas regiões de mudança abrupta de seção ou em regiões em que o metal recebe suporte ou contato por apenas uma de suas faces da espessura. Em casos extremos podem ocorrer dobras duplas ou triplas em regiões específicas da chapa. Citam-se como soluções usuais a este problema o bloqueio parcial ou total do fluxo do metal em regiões específicas da chapa ou um aumento conveniente da pressão no prensachapas. 


\section{Distorção de forma}

Nos processos em questão, o metal é deformado de modo elástico e plástico através de forças aplicadas. Com a remoção destas, relaxam-se as tensões elásticas internas. Em algumas regiões pode haver uma relaxação total destas tensões, com uma modificação pouco significante nas dimensões da peça. Entretanto, em áreas sujeitas ao dobramento ocorrem gradientes de tensões elásticas ao longo da espessura. Se estas tensões internas não forem restringidas ou bloqueadas quanto à sua propagação à geometria da peça, a relaxação destas causará uma distorção de forma, definida como recuo elástico (springback). Tal problema pode ser compensado nas etapas do projeto da peça e do ferramental, mas pode complicar-se em caso de grandes variações de um blank para outro nas propriedades do material ou do processo em si.

\section{Porção não deformada do material}

É indesejável para a peça final pois é defletida facilmente. É um fenômeno comum em latas de óleo, em que uma mesma área específica sendo côncava ou convexa pode ser encontrada. Em estampagens com duas ou mais dobras de raio pequeno e com mesma orientação, esta tendência existe para o material entre as dobras. Isto deve-se à dificuldade que o material possui em ter seu fluxo através de porções cujo raio é pequeno. Pode-se evitar isto garantindo-se que o metal não esteja em contato simultâneo com estas duas linhas de dobra. Assim, algum estiramento ocorrerá antes do contato com a segunda linha de dobra. Esta tendência mostra-se também no centro de porções repuxadas através de punções cuja base seja ampla e reta ou pouco abaulada. Obtem-se melhoria através do aumento das forças de restrição nas bordas da chapa. 
Texturas superfíciais indesejáveis (“casca de laranja”, spangles, e outras)

Em chapas fortemente deformadas, especialmente naquelas em que o aspecto metalográfico é dado por grãos maiores, geralmente é desenvolvida uma textura superfícial definida como "casca de laranja" (orange peel). Isto é usualmente inaceitável em peças visíveis nos equipamentos. Outros problemas ocorrem em metais que possuem uma distensão pronunciada no ponto de escoamento, ou seja, em materiais que estiram-se de um alto percentual sem um aumento relativo na carga após o escoamento. Nestes metais, deformações pequenas concentram-se em bandas irregulares tidas como linhas de Lüders. Estes defeitos desaparecem em níveis crescentes de deformações. Porém quase todas as peças possuem alguma região com baixo grau de deformação. Tais defeitos são invisíveis, não sendo pois detectados por algum tipo de marcador líquido. São encontrados em bordas de aços envelhecidos e em algumas ligas de alumínio-magnésio. Em alguns casos, aços galvanizados exibem defeitos superficiais conhecidos como spangles. Isto ocorre em peças trabalhadas a quente em que os grãos grosseiros são visualisados através da camada superficial de zinco. Corrige-se este problema estando ainda no processo de recobrimento. Citam-se ainda defeitos como riscos causados por pequenas partículas estranhas no processo, pelo mau acabamento superficial das ferramentas em contato com o blank e pela lubrificação inadequada no processo.

Alguns tipos de defeitos são mostrados na fig. (3.2.1) : 


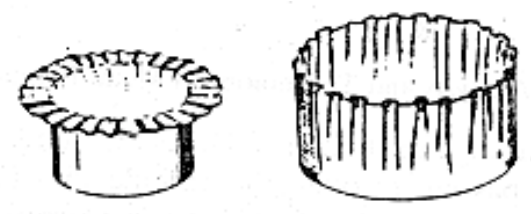

WRINKLES
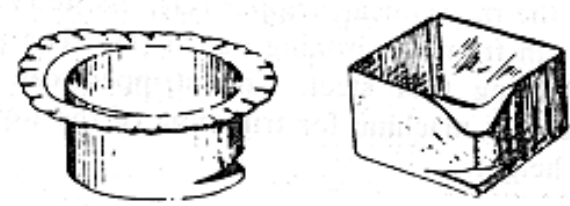

FRACTURE
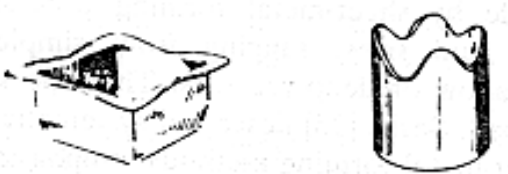

EARING

FIGURA 3.2.1 : Alguns defeitos presentes em chapas conformadas (KOBAYASHI et al,1989)

\subsection{Ensaios de conformabilidade}

Com o objetivo de se avaliar o comportamento de um processo de conformação são utilizados vários ensaios de conformabilidade. Os testes de conformabilidade são ensaios mecânicos para avaliação do comportamento do material no andamento do processo e nos seus limites, com predição para possíveis defeitos, em termos de forças, deslocamentos, tensões e deformações. No caso de chapas metálicas, eles podem ser classificados em basicamente dois tipos : intrínsecos e simulativos (TAYLOR, 1988). Os testes intrínsecos medem as características básicas que definem as propriedades dos materiais. Os testes simulativos sujeitam o material a um processo de deformações bem semelhante ao que ocorre em uma determinada operação de conformação.

\section{Testes intrínsecos}

Estes testes fornecem informações independentes da espessura e das condições superficiais do material. O teste mais importante e mais usado neste caso é 
o teste uniaxial de tração, que fornece valores de várias propriedades do material para uma ampla variedade de operações. Exemplos :

- Teste uniaxial de tensão

- Teste de tensão sob deformação plana

- Teste de estiramento Marciniak / teste de estiramento biaxial

- Teste de torção em chapas

- Teste de empenamento por pressão hidráulica

- Teste de cisalhamento Miyauchi

- Teste de dureza

\section{Testes simulativos}

Estes testes fornecem informações específicas e limitadas que são normalmente influenciadas pela espessura do blank, pelas condições superficiais, pela lubrificação e pela geometria e tipo do ferramental. Abaixo têm-se listados vários tipos de ensaios, sendo que entre parênteses está a nomenclatura usual :

- Testes de dobramento

- Teste de dobramento-estiramento

- Teste do punção esférico (Erichsen, Olsen)

- Teste de punção abaulado médio

- Teste de punção abaulado

- Teste de expansão de furo

- Teste rápido de copo (Swift)

- Teste rápido de copo, com perfil arredondado de punção

- Teste de copo cônico (Fukui)

- Teste de enrugamento por copo cônico

- Teste de flambagem (Yoshida)

- Teste de springback 


\subsection{A representação gráfica do limite de conformabilidade}

Pode-se associar conjuntos de pontos $\left(\varepsilon_{1}, \varepsilon_{2}\right)$ de uma chapa sob conformação mecânica com tipos de defeitos possíveis em um diagrama geral (MARCINIAK \& DUNCAN , 1992) :

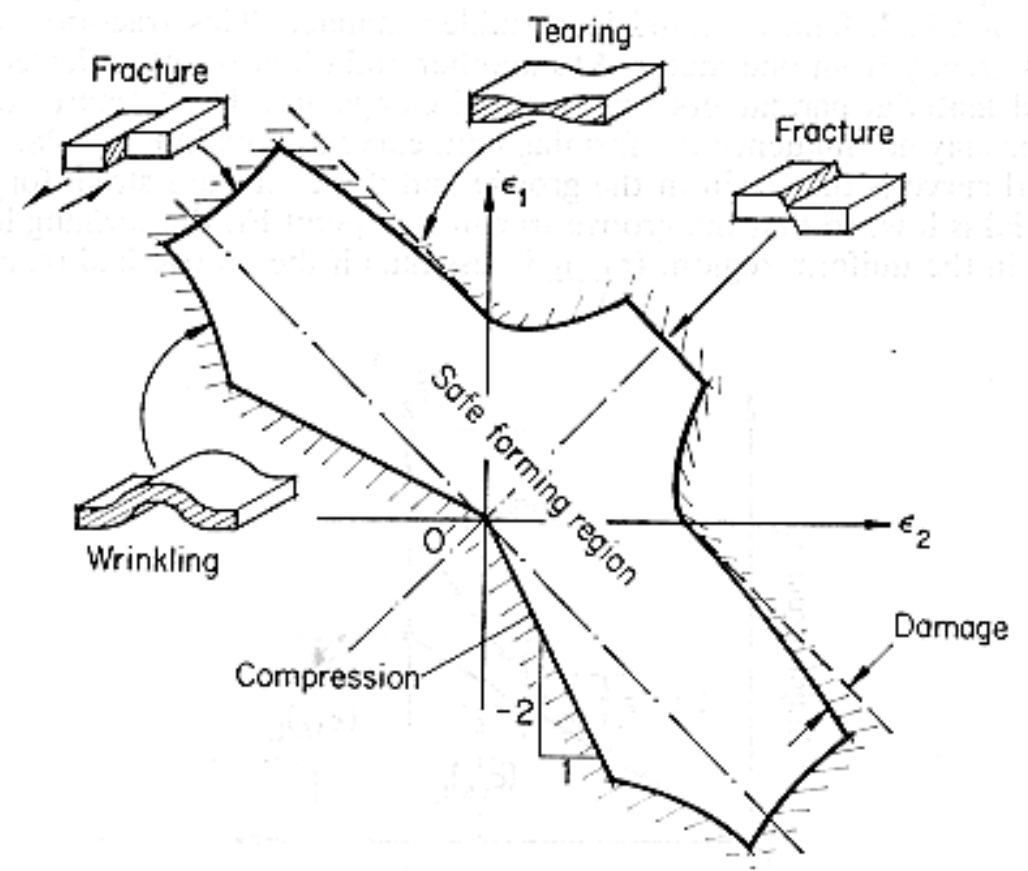

FIGURA 3.4.1 : Representação dos possíveis defeitos na chapa em um diagrama $\left(\varepsilon_{1}, \varepsilon_{2}\right)$

Os pontos deste diagrama podem ser determinados experimentalmente conforme alguns dos ensaios citados no tópico anterior. São chamados diagramas de limite de conformação (forming limit diagram ou FLD) e indicam as deformações no limite em que as chapas metálicas podem sustentar em um processo de conformação específico. Estes diagramas são ferramentas importantes para "visualizarem-se" os aspectos da conformabilidade de uma chapa. Sua construção é baseada na obtenção de pontos do corpo de prova com deformações principais $\left(\varepsilon_{1}, \varepsilon_{2}\right)$ que estejam sob estricção ou ruptura ou outros tipos de defeitos, conforme o critério escolhido.

$\mathrm{Na}$ determinação experimental da estricção e/ou fratura imprime-se uma grade de círculos na chapa para análise, a qual, deformada após alguma operação mecânica crítica, poderá apresentar uma série de elipses cujo perímetro esteja aberto ou não . Nas elipses "abertas" vêem-se distorções de forma que possibilitarão o 
cálculo das deformações principais em seu interior. Os ensaios são feitos para vários corpos de prova com impressão dos círculos, obtendo-se experimentalmente uma curva com o aspecto da fig. (3.4.2) .

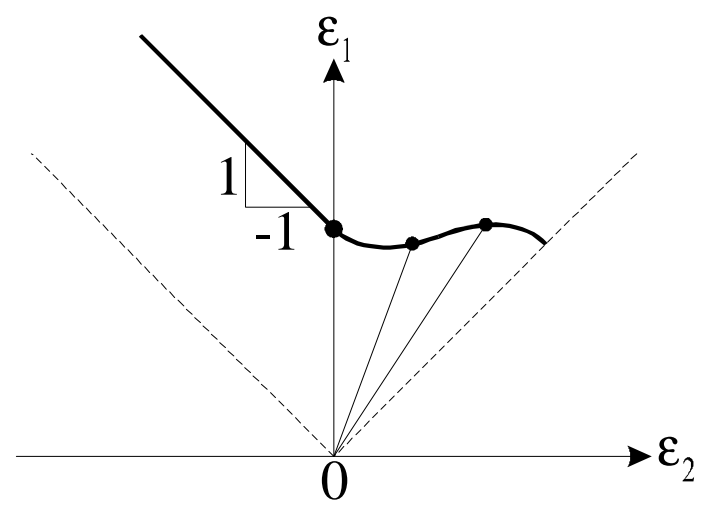

FIGURA 3.4.2 : Diagrama de limite de conformação determinado através de estricção e/ou fratura

Dois grandes grupos de testes são efetuados para determinação destes diagramas. O primeiro grupo de testes abrange o estiramento de corpos de prova através de um punção, por pressão hidráulica, como exemplo o método do punção esférico. Neste caso produzem-se deformações fora do plano de trabalho e com o uso do punção tem-se também os efeitos do atrito. O segundo grupo de testes produz somente deformações no plano e não envolve algum tipo de contato entre o blank e os medidores. O primeiro tipo de teste é mais usado que o segundo e fornece resultados razoavelmente diferentes (TAYLOR, 1988).

\section{Determinação pelo método do punção hemisférico}

Para construção dos diagramas imprimem-se círculos no blank de teste, procedimento tratado como circle grid analysis (análise por grade de círculos) . Assim, trava-se o blank no prensa-chapas, sendo o mesmo posteriomente estirado por um punção de aço de determinado diâmetro até a iminência de fraturas. As deformações são medidas nos círculos deformados, por dentro e por fora das regiões com neckings visíveis e fraturas. A curva limite então é desenhada com valores de deformações $\left(\varepsilon_{1}, \varepsilon_{2}\right)$ nas regiões que sofreram o defeito. 


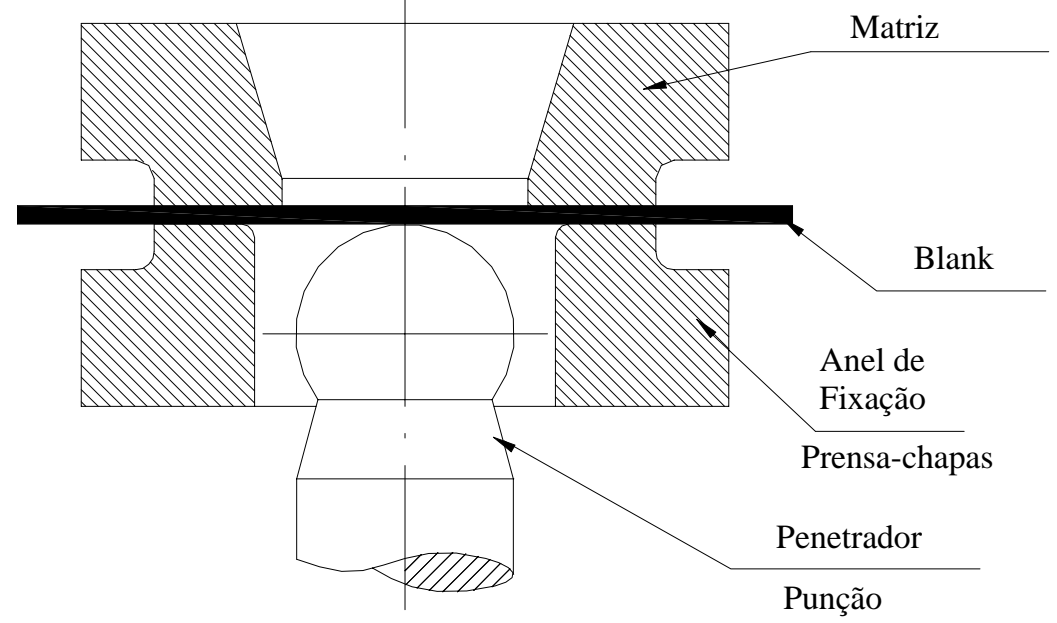

FIGURA 3.4.3 : Teste do punção esférico, conforme norma ABNT - MB - 362/79

\section{Determinação no plano}

Neste caso obtém-se os limites de conformação pelo teste uniaxial de tração, pelo teste de tensão aplicado a chapas retangulares ou pelo teste de estiramento biaxial visto na fig. (3.4.4) . A curva limite é então obtida em uma ampla faixa de razão de deformações, desconsiderando-se as deformações fora do plano de trabalho.

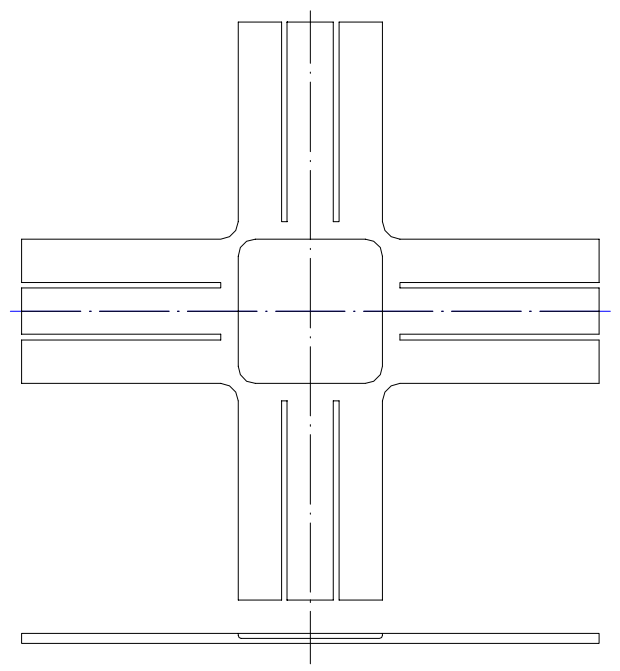

FIGURA 3.4.4 : Modelo de corpo de prova para o estiramento biaxial,

Baseado em FERRON \& MAKINDE (1988) 


\subsection{Determinação teórica dos limites de conformabilidade}

A determinação teórica dos limites de conformabilidade contribui para a redução de custos de predição do comportamento dos materiais utilizados e desempenho do processo mecânico estudado, uma vez que dispõe da rapidez e praticidade dos métodos de análise existentes.

Dentre os métodos existentes, citam-se o enfoque da análise clássica de bifurcações que incorpora a teoria de deformações " $J 2$ "; o enfoque que define o início da falha como condição para a ocorrência da instabilidade plástica e enfim o enfoque baseado no desenvolvimento da estricção a partir de regiões com uma nãohomogeneidade inicial e localizada na chapa .

Com o objetivo de construir-se o diagrama de limite de conformação através de cálculos matemáticos que venham representar os fenômenos de falha do material, revisou-se a respeito de alguns métodos disponíveis, cuja base teórica é descrita a seguir, segundo o enfoque da estricção na chapa a partir da não homogeneidade prévia.

MARCINIAK \& KUCZYNSKI (1967), na citação de autores como GRAF \& HOSFORD (1990) e STOUGHTON (2000), com detalhamentos em MARCINIAK \& DUNCAN (1992), apresentou um modelo que orientou os métodos de cálculo, denominado modelo $M K$. Neste item serão vistos os tópicos relativos a este modelo.

Em síntese este modelo representa o ensaio de estiramento biaxial plano e em que as imperfeições contidas no material tais como distribuição irregular da microestrutura e diferenças na espessura são representadas por um artifício geométrico imposto na chapa. Com isto busca-se estudar os defeitos de estricção (necking) e estabelecer condições matemáticas para sua ocorrência.

Estabelecem-se inicialmente as condições matemáticas para a estricção no caso unidimensional, sendo que posteriormente extendem-se os conceitos para o caso bidimensional. Os tópicos seguintes foram baseados em MARCINIAK \& DUNCAN (1992). 


\subsubsection{Tensões uniaxiais em um corpo de prova perfeito}

Considera-se uma porção de um corpo de prova perfeito de secção transversal de área $A$ conforme a fig. (3.5.1) tracionado axialmente . Com a carga axial, têm-se as seguintes relações :

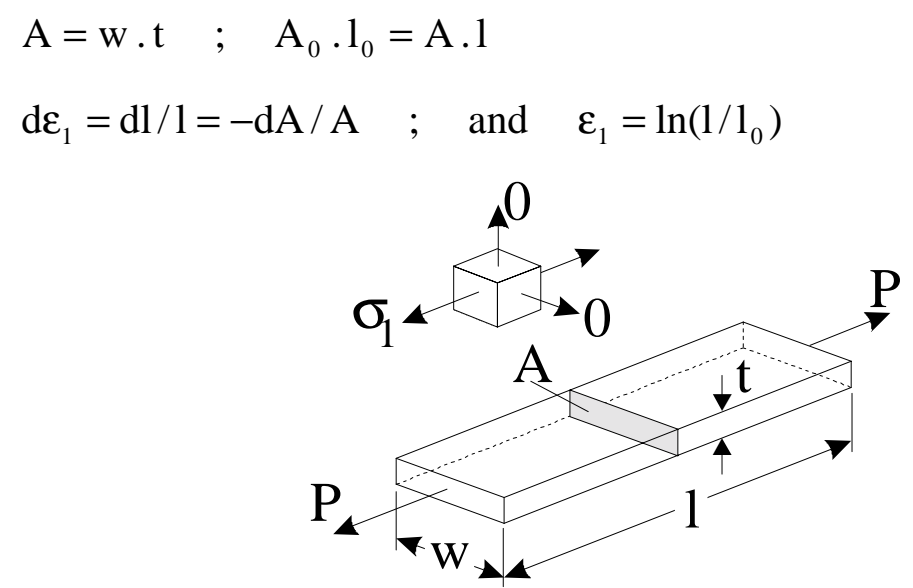

FIGURA 3.5.1 : Porção de um corpo de prova perfeito

A carga é dada por :

$$
\mathrm{P}=\sigma_{1} \cdot \mathrm{A}=\sigma_{1} \cdot \mathrm{A}_{0} \cdot\left(1_{0} / 1\right)
$$

e se o material comportar-se conforme uma relação tensão-deformação dada por:

$$
\sigma_{1}=\mathrm{f}\left(\varepsilon_{1}\right)
$$

então a equação (3.5.2) é diferenciada e dividindo-se pela própria eq. (3.5.2), com

$$
\mathrm{dP} / \mathrm{P}=\mathrm{d} \sigma_{1} / \sigma_{1}+\mathrm{dA} / \mathrm{A}=\mathrm{d} \sigma_{1} / \sigma_{1}-\mathrm{d} \varepsilon_{1}
$$

sendo $d \sigma_{l} / \sigma_{1}$ um valor positivo e gradualmente decrescente, enquanto que $d A / A$ é negativo devido à diminuição da área transversal ao longo do processo. Na carga máxima, $d P=0$ e então :

$$
\left(1 / \sigma_{1}\right) \cdot\left(\mathrm{d} \sigma_{1} / \mathrm{d} \varepsilon_{1}\right)=1
$$


Tal expressão define uma característica do material, dada como encruamento adimensional. No caso em que utiliza-se a lei dada em que a equação (3.5.3) tenha a forma da equação de Hollomon, (2.3.38) :

$$
\sigma_{1}=\mathrm{K} \cdot \varepsilon_{1}{ }^{\mathrm{n}}
$$

o encruamento adimensional obedeça a :

$$
\left(1 / \sigma_{1}\right) \cdot\left(\mathrm{d} \sigma_{1} / \mathrm{d} \varepsilon_{1}\right)=\mathrm{n} / \varepsilon_{1}
$$

como mostrado na fig. (3.5.2) ou seja, na carga máxima, a deformação limite é dada por :

$$
\varepsilon_{1}^{*}=\mathrm{n}
$$

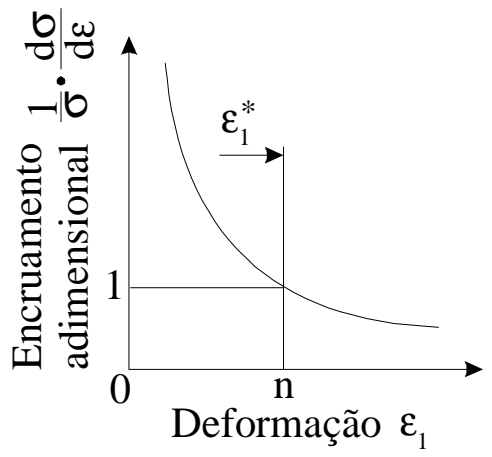

FIGURA 3.5.2 : Encruamento adimensional versus deformação para um material recozido

Para o mesmo material, a carga pode ser expressa por :

$$
\begin{aligned}
& \mathrm{P}=\mathrm{A}_{0} \cdot \mathrm{K} \cdot\left\{\ln \left(1 / 1_{0}\right)\right\}^{\mathrm{n}} \cdot\left(1 / 1_{0}\right) \\
& \mathrm{P}=\mathrm{A}_{0} \cdot \mathrm{K} \cdot \varepsilon_{1}{ }^{\mathrm{n}} \cdot \exp \left(-\varepsilon_{1}\right)
\end{aligned}
$$

Estas relações são mostradas nas fig. (3.5.3a) e (3.5.3b). Nota-se que a fig. (3.5.3) assemelha-se a um diagrama típico de ensaio de tração, com deformações uniformes para um corpo de prova perfeito, embora haja nas curvas reais uma queda mais acentuada de carga após seu valor máximo. 


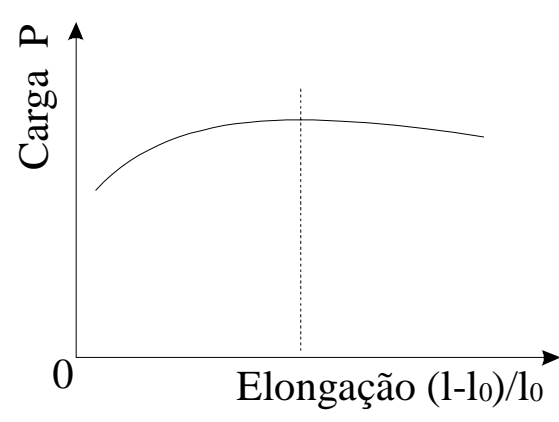

a)

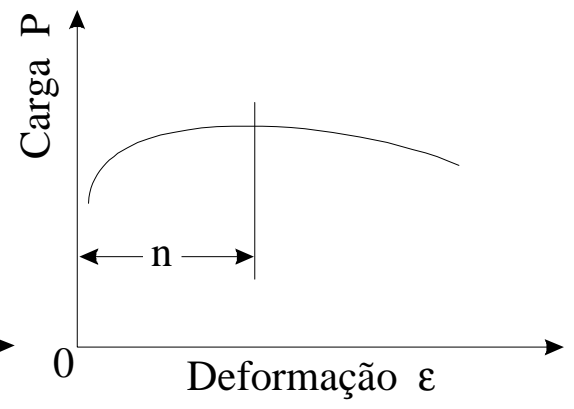

b)

FIGURA 3.5.3 : Carga versus a) elongação e b) deformação para um corpo de prova perfeito

\subsubsection{Tensões uniaxiais em um corpo de prova imperfeito}

Se o corpo de prova tiver inicialmente uma pequena região em que sua área transversal seja $A_{0}+d A_{0}$, com $d A_{0}$ sendo um valor pequeno e negativo, então em qualquer instante durante as deformações esta área, a tensão e a deformação na imperfeição serão diferentes do valores observados na região uniforme do corpo, através de $d A, d \sigma$ e $d \varepsilon$ como visto na fig. (3.5.4). Apesar disto, a carga transmitida ao longo das seções será a mesma, obedecendo-se à equação (3.5.11) :

$$
\mathrm{P}=\mathrm{A}_{0} \cdot \mathrm{K} \cdot \varepsilon^{\mathrm{n}} \cdot \exp (-\varepsilon)=\left(\mathrm{A}_{0}+\delta \mathrm{A}_{0}\right) \cdot \mathrm{K} \cdot \varepsilon_{\mathrm{i}}{ }^{\mathrm{n}} \cdot \exp \left(-\varepsilon_{\mathrm{i}}\right)
$$

com o índice i referente à imperfeição : $\varepsilon_{i}=\varepsilon+d \varepsilon$. Estas curvas são mostradas juntas na fig. (3.5.5), em que observa-se o ponto de máxima carga para o caso da imperfeição .

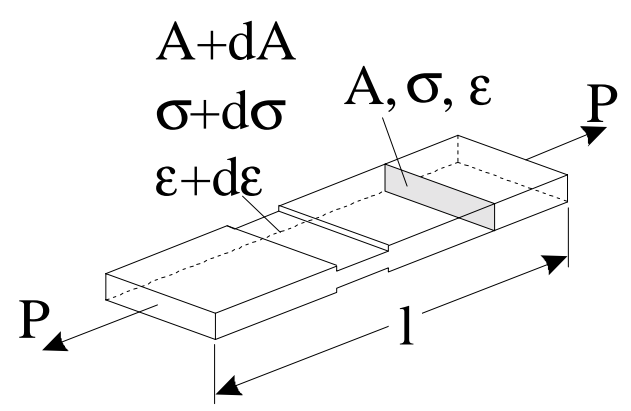

FIGURA 3.5.4 : Porção de um corpo de prova imperfeito 


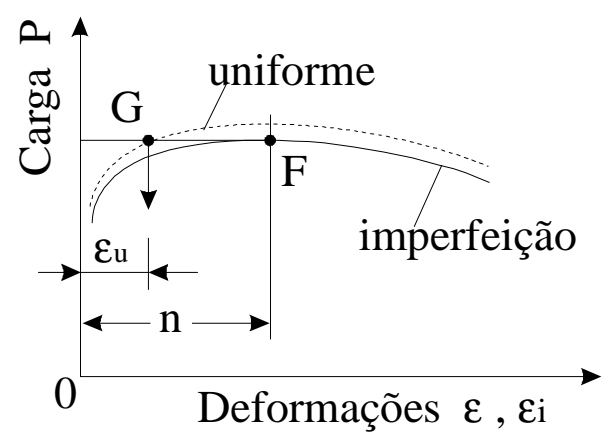

FIGURA 3.5.5 : Carga versus deformação para regiões uniforme e imperfeita

Como cada região transmite a mesma carga, a deformação na região uniforme recua-se em relação à região imperfeita de um valor inicialmente pequeno, mas que cresce com o andamento do processo. Com a deformação na imperfeição atingindo o valor $n$, alcança-se um máximo de carga e com o carregamento, distende-se rapidamente até a ruptura. Porém, a região uniforme não alcança um máximo e daí irá descarregar elasticamente. A imperfeição neste caso é definida como uma estricção difusa e tendo a deformação uniforme máxima como $e_{u}$, vem que, da equação (3.5.11) :

$$
\varepsilon_{\mathrm{u}}{ }^{\mathrm{n}} \cdot \exp \left(-\varepsilon_{\mathrm{u}}\right)=\left[1+\left(\delta \mathrm{A}_{0} / \mathrm{A}_{0}\right)\right] \cdot \mathrm{n}^{\mathrm{n}} \cdot \exp (-\mathrm{n})
$$

e como $n-e_{u}$ e $d A_{0} / A_{0}$ são ambos $\ll<$, obtem-se, pela aplicação da função logarítimica em ambos os lados e pela extração dos termos de primeira ordem das séries de Taylor correspondentes :

$$
\mathrm{n}-\varepsilon_{\mathrm{u}} \cong\left\{-\left(\delta \mathrm{A}_{0} / \mathrm{A}_{0}\right) \cdot \mathrm{n}\right\}^{1 / 2}
$$

Assim, a deformação uniforme máxima é menor que a também chamada deformação de Considére, $\varepsilon_{1}^{*}=n$, com a diferença dependendo de $n$ e da imperfeição inicial.

Considerando-se um diagrama carga $x$ elongação e assumindo que a imperfeição seja pequena em relação a $l_{0}$, então a curva para o corpo de prova imperfeito será similar àquela da corpo de prova ilustrado na fig. (3.5.6) . Quando a 
imperfeição alcança o seu valor máximo, a deformação na porção uniforme é aproximadamente igual a $e_{u}$, como na fig. (3.5.5). Além deste máximo, as deformações concentram-se na imperfeição mas como esta é uma região bem pequena, sua contribuição para a elongação total da peça também o é, e então a carga cai rapidamente. Na carga máxima, a deformação depende do encruamento e da não homogeneidade do material, enquanto que além deste ponto depende-se das características da taxa de deformação no necking (estricção), como será visto nos próximos ítens.

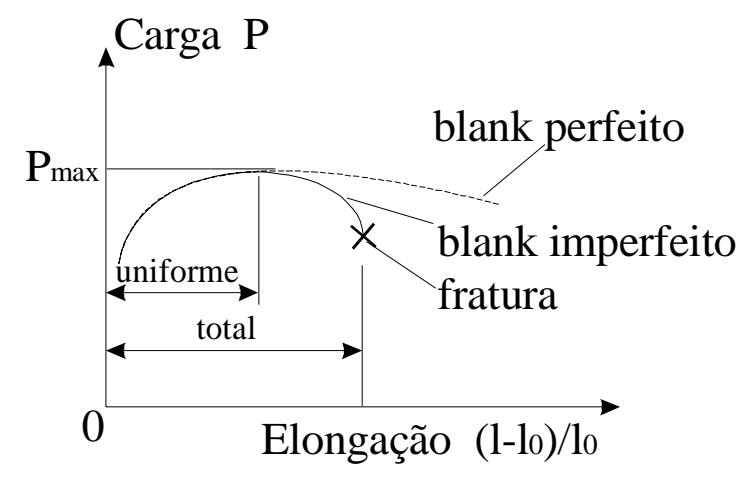

FIGURA 3.5.6 : Diagrama carga x elongação para um corpo de prova imperfeito

\subsubsection{Tensões uniaxiais em um material sensível à taxa de deformação}

Após a estricção, a deformação é concentrada na pequena região que contém a imperfeição. Se a taxa de deformação externa à imperfeição for constante, implica que em seu interior esta taxa tem que aumentar de forma significativa. Assumiu-se no item anterior que o comportamento do material fosse independente da taxa de deformação para efeito de modelagem. Entretanto a maioria dos materiais realmente possuem alguma sensibilidade às taxas de deformação. Considerando-se um material ideal que não sofra o encruamento, mas que seja sensível a estas taxas, vem que :

$$
\sigma_{\mathrm{f}}=\mathrm{B} \cdot \dot{\varepsilon}^{\mathrm{m}}
$$

em que $m$ é o expoente de sensibilidade à taxa de deformação, sendo esta dada por

$$
\dot{\varepsilon}=\mathrm{d} \varepsilon / \mathrm{dt}=(\mathrm{dl} / \mathrm{dt}) / 1=-(\mathrm{dA} / \mathrm{dt}) / \mathrm{A}
$$


e $t$ é a variável de tempo.

Consideram-se as deformações em um corpo de prova imperfeito como da fig. (3.5.4), efetuadas de forma que a taxa de deformação na seção uniforme seja mantida constante. Se não existisse a imperfeição, a carga na peça seria :

$$
\mathrm{P}=\mathrm{A}_{0} \cdot \mathrm{B} \cdot \dot{\varepsilon}_{0}{ }^{\mathrm{m}} \cdot \exp (-\varepsilon)=\mathrm{P}_{0} \cdot \exp \left(-\dot{\varepsilon}_{0} \cdot \mathrm{t}\right)
$$

Em que $P_{0}$ é a carga inicial, $\mathrm{A}_{0} \cdot \mathrm{B} \cdot \dot{\varepsilon}_{0}{ }^{\mathrm{m}}$, e $\dot{\varepsilon}_{0}$ é a taxa de deformação constante. Isto é mostrado na fig. (3.5.7) . Com a presença da imperfeição, vê-se que da fig. (3.5.8a) há uma diferença $\delta \dot{\varepsilon}$ na taxa de deformação entre as regiões. A condição de equilíbrio fornece :

$$
\begin{aligned}
& \sigma \cdot A=(\sigma+d \sigma) \cdot(A+d A) \quad \text { ou } \\
& \delta \sigma / \sigma=-\delta A / A
\end{aligned}
$$

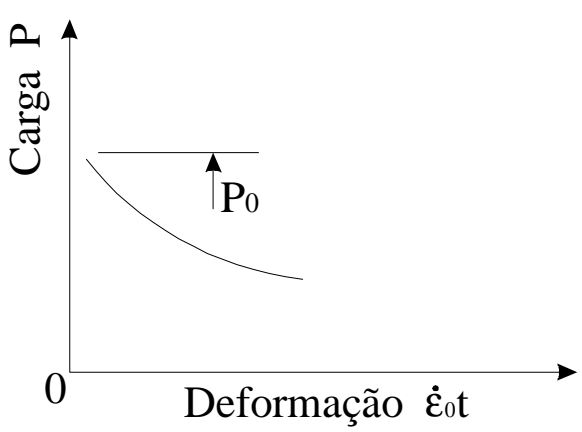

FIGURA 3.5.7 : Carga x deformação para um teste com taxa constante de deformação

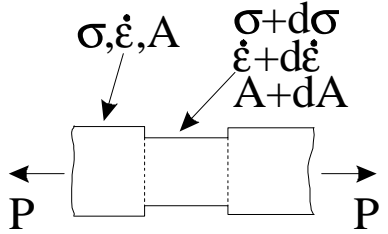

(a)

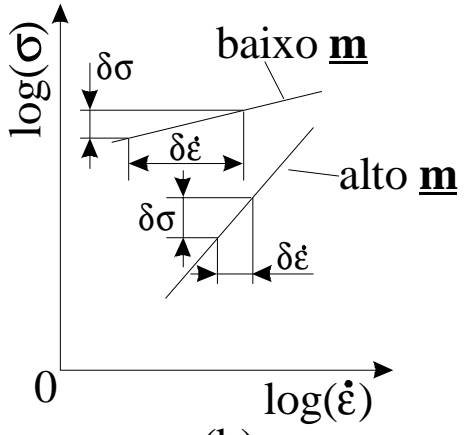

(b)

FIGURA 3.5.8 (a) : Tensão x taxa de deformação e área nas regiões uniforme e imperfeita;

(b) : Diferenças nas taxas de deformação para materiais diferentes 
A diferença na taxa de deformação, $\delta \dot{\varepsilon}$, associa-se à diferença de tensões $\delta \sigma$ conforme as propriedades do material. Se o valor $m$ é baixo, $\delta \dot{\varepsilon}$ é alto para um mesmo acréscimo nas tensões como visto na fig. (3.5.8b) ; isto é , a diferença na taxa de deformações é alta e a imperfeição cresce rapidamente. Se o valor $m$ é alto como na caso de polímeros viscosos e ligas superplásticas, $\delta \dot{\varepsilon}$ é pequeno e ambas as regiões se deformam à mesma velocidade. A equação de equilíbrio para uma barra imperfeita pode ser dada por :

$$
\varepsilon^{\mathrm{m}} \cdot \exp (-\varepsilon)=\left[1+\left(\delta \mathrm{A}_{0} / \mathrm{A}_{0}\right)\right] \cdot \varepsilon_{\mathrm{i}}^{\mathrm{m}} \cdot \exp \left(-\varepsilon_{\mathrm{i}}\right)
$$

Em que o índice $i$ refere-se à imperfeição. Isto pode ser resolvido numericamente e no caso de $\dot{\varepsilon}=\dot{\varepsilon}_{0}$ ser mantido constante, vêem-se os resultados na fig. (3.5.9) . Se o valor $m$ é pequeno, a deformação na imperfeição acelera-se e pouca deformação é acumulada na região uniforme. Se o valor $m$ é alto, ambas as regiões deformam-se simultaneamente por um período considerável, até que eventualmente a deformação na imperfeição se acelere.

Isto significa que uma alta deformação final indica um alto valor $m$ para o material.

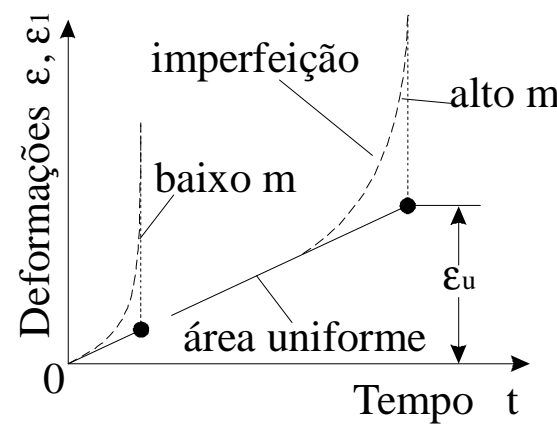

FIGURA 3.5.9 : Diferentes taxas de crescimento em imperfeições com diferentes valores $m$

\subsubsection{O conceito de estricção em chapas contínuas}

Nos testes de tração, o bloqueio exercido por alguma região sobre a estricção difusa em um corpo de prova não é significativo. Isto não se aplica em chapas contínuas, como visto na fig. (3.5.10). Se a deformação em alguma região $D$ 
acelera-se como uma estricção difusa, então ela pode estar associada a um aumento em sua área superficial. Para acomodar este aumento, esta região deve mover-se para fora do formato esférico da casca, conforme as linhas tracejadas mostradas. Este evento é fisicamente improvável nos processos de conformação de chapas em geral. Porém , a distribuição de deformações na região uniforme deve ser compatível com os formatos do ferramental. As acelerações locais na deformação como em uma estricção difusa nos testes de tração serão, no caso de chapas contínuas, associadas com mudanças do estado global de tensões de forma que seja mantida a compatibilidade de deformações em relação ao ferramental.

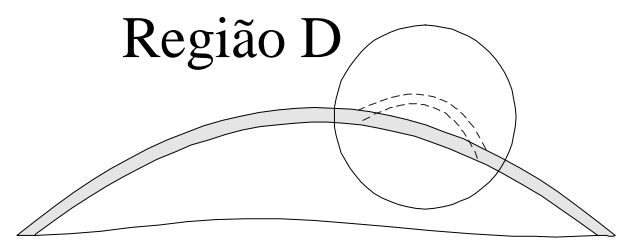

FIGURA 3.5.10 : Perturbação em uma casca esférica através de estricção difusa

Entretanto a estricção (necking) é possível em chapas contínuas se for localizada e de modo que não influencie a distribuição global de deformações. Estes neckings são difusos em relação à chapa quando sua largura é da ordem da espessura da chapa de forma que as tensões normais à superfície não se modifiquem demasiadamente. Por outro lado, as estricções (neckings) são localizadas quando sua largura é pequena quando comparada à espessura da chapa.

\subsubsection{Uma condição para a estricção local}

Conforme MARCINIAK \& DUNCAN (1992), considera-se uma região da chapa sob carregamentos no plano e em que as forças específicas são uniformes de acordo com a fig. (3.5.11). Definem-se como forças específicas aquelas transmitidas através da chapa :

$$
\mathrm{T}_{1}=\sigma_{1} \cdot \mathrm{t} \quad ; \quad \mathrm{T}_{2}=\sigma_{2} \cdot \mathrm{t}
$$


Supondo-se que a estricção localizada não interfira nas condições de contorno, uma condição necessária para esta ocorra é que uma ou mais forças específicas alcancem um valor máximo. Certos fenômenos de fratura dos materiais podem ocasionar falhas sob forças crescentes ( MARCINIAK \& DUNCAN , 1992), mas enfocando este caso em questão, tem-se que para a estricção, segundo o conceito de diferencial total de uma função $T=T\left(T_{1}, T_{2}\right)$ :

$$
\mathrm{dT} \leq 0
$$

Para a região da chapa mostrada na fig. (3.5.11), têm-se as tensões principais e os incrementos de deformações :

$$
\begin{aligned}
& \sigma_{1} \quad ; \quad \sigma_{2}=\alpha \cdot \sigma_{1} \quad ; \quad \sigma_{3}=0 \\
& \mathrm{~d} \varepsilon_{1} \quad ; \quad \mathrm{d} \varepsilon_{2}=\beta . \mathrm{d} \varepsilon_{1} \quad ; \quad \mathrm{d} \varepsilon_{3}=-(1+\beta) \cdot \mathrm{d} \varepsilon_{1}
\end{aligned}
$$
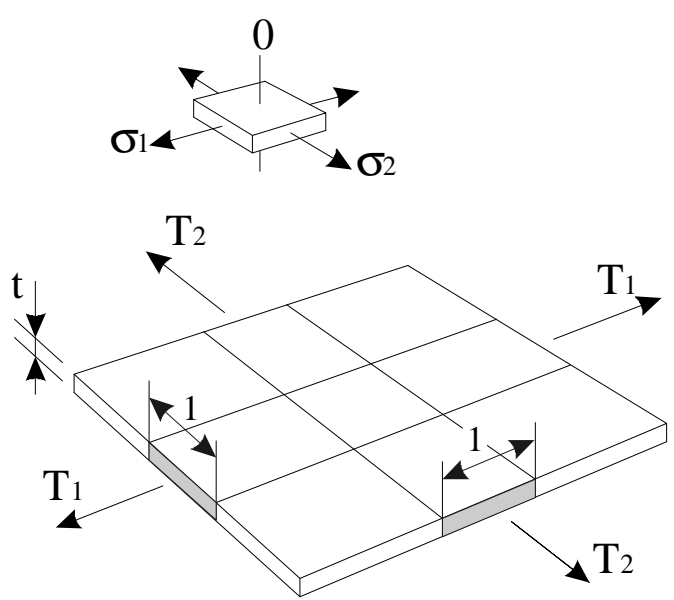

FIGURA 3.5.11 : Forças específicas, $T_{1}$ e $T_{2}$ em uma chapa por um processo dito proporcional ( $T_{1}$ e $T_{2}$ são forças por unidade de comprimento).

Se e somente se $\alpha$ e $\beta$ são constantes, ou seja, com a condição de carregamento proporcional nas duas direções do plano, a equação (3.5.21) pode ser diferenciada e dividindo-a pela mesma eq. (3.5.21), obtem-se :

$$
\frac{1}{\sigma_{1}} \cdot\left(\frac{\mathrm{d} \sigma_{1}}{\mathrm{~d} \varepsilon_{1}}\right)=1+\beta
$$


Se o material da chapa obedecer à equação de Hollomon, (2.3.38) :

$$
\sigma_{\mathrm{f}}=K \cdot \varepsilon^{\mathrm{n}}
$$

para algum processo com deformações proporcionais e

$$
\begin{aligned}
& \sigma_{1}=\mathrm{K}^{\prime} \cdot \varepsilon_{1}{ }^{\mathrm{n}} \quad \mathrm{com} \\
& \mathrm{K}^{\prime}=\mathrm{K} \cdot \mathrm{f}(\beta, \mathrm{n})
\end{aligned}
$$

Diferenciando-se a equação (3.5.26), obtem-se :

$$
\frac{1}{\sigma_{1}} \cdot\left(\frac{d \sigma_{1}}{d \varepsilon_{1}}\right)=\frac{n}{\varepsilon_{1}}
$$

e quando $T_{1}$ alcança um máximo, pelas equações (3.5.24) e (3.5.28) vem que :

$$
\begin{aligned}
& \varepsilon_{1}^{*}=\frac{\mathrm{n}}{(1+\beta)} \quad \varepsilon_{2}^{*}=\frac{\beta \cdot \mathrm{n}}{(1+\beta)} \quad \text { ou } \\
& \varepsilon_{1}^{*}+\varepsilon_{2}^{*}=\mathrm{n}
\end{aligned}
$$

A expressão (3.5.30) representa a ocorrência da estricção localizada na chapa através de equação de uma reta no diagrama $\left(\varepsilon_{1}, \varepsilon_{2}\right)$.

Pode-se aplicar o mesmo raciocínio se a equação (3.5.25) for substituída por :

$$
\sigma_{\mathrm{f}}=\mathrm{K} \cdot \varepsilon^{\mathrm{n}} \cdot \dot{\varepsilon}^{\mathrm{m}}
$$

Supõem-se analogamente :

$$
\begin{aligned}
& \sigma_{1}=\mathrm{K}^{\prime} \cdot \varepsilon_{1}{ }^{\mathrm{n}} \cdot \dot{\varepsilon}_{1}{ }^{\mathrm{m}} \\
& \mathrm{K}^{\prime}=\mathrm{K} \cdot \mathrm{f}(\beta, \mathrm{n}, \mathrm{m})
\end{aligned}
$$


Vem que :

$$
\frac{1}{\sigma_{1}} \cdot\left(\frac{\mathrm{d} \sigma_{1}}{\mathrm{~d} \varepsilon_{1}}\right)=\frac{\mathrm{n}}{\varepsilon_{1}}+\frac{\mathrm{m}}{\dot{\varepsilon}_{1}} \cdot \frac{\mathrm{d} \dot{\varepsilon}_{1}}{\mathrm{~d} \varepsilon_{1}}
$$

Com a hipótese adicional de $\mathrm{d} \dot{\varepsilon}_{1}=0$, anula-se a $2^{\mathrm{a}}$ parcela do lado direito de (3.5.34). Assim, obtem-se as expressões mostradas anteriormente em (3.5.29) e (3.5.30) .

Representando-se a equação (3.5.30) no espaço das deformações no plano, obtem-se a curva limite dada pela fig. (3.5.12) :

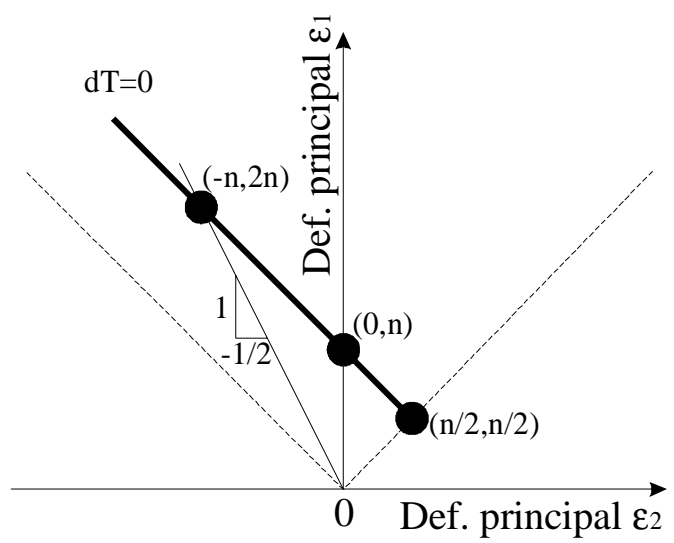

FIGURA 3.5.12 : Valores de deformação por diferentes caminhos de carregamentos e para tensões máximas, em que o material obedeça a $\sigma_{f}=K . \varepsilon^{n}$

Em uma trajetória de deformações equivalente ao estado de tensões simples, $\beta=-1 / 2$ e a deformação na tensão máxima é dada por $\varepsilon_{1}^{*}=2 n$, que é o dobro da deformação em carga máxima no teste de tração. Como na discussão sobre a estricção difusa no teste de tração, a hipótese da força unitária máxima foi assumida para indicar o início do necking em uma região em que um pequeno enfraquecimento existe. Se a chapa da fig. (3.5.11) fosse perfeita, seria esperado que esta continuasse a deformar-se uniformemente além deste ponto. Por analogia ao teste de tração, mas neste caso considerando uma seção da chapa na direção de $\sigma_{l}$ como na fig. (3.5.13), uma imperfeição $B$ poderia deformar-se de forma acelerada enquanto que a região uniforme $A$ poderia descarregar-se elasticamente. As deformações em $A$ poderiam ser bem menores que aquelas dadas na equação (3.5.30) se a imperfeição $\delta t_{0} / t_{0}$ fosse 
pequena mas não desprezível. Há duas situações importantes encontradas e que não se aplicam ao necking difuso de um corpo de prova :

- processo de deformação da estricção (definido por $\alpha$ ou $\beta$ ) deve manter-se inalterado, de modo a conseguir que $T_{1}$ tenha de fato um máximo conforme expressão (3.5.21) ;

- A deformação na região $A$ deve manter-se uniforme, garantindo que as condições de contorno na região da fig. (3.5.11) não se modifiquem durante a estricção .

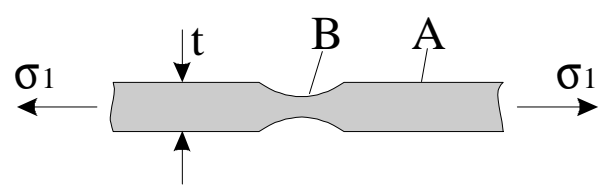

FIGURA 3.5.13 : Uma imperfeição que é difusa em relação à espessura da chapa, mas que é localizada na superfície.

A segunda condição confirma que o necking não cresce como uma bolha, vista na fig. (3.5.10). Pode ser mostrado que a única geometria para o neck desenvolver-se é na forma de uma faixa inclinada de um ângulo $\theta$ em relação à direção principal 1, como na fig. (3.5.14) . Este ângulo é determinado pela primeira condição . Se a região externa à estricção se descarrega e, desprezando-se as deformações elásticas, permanece rígida durante o crescimento do mesmo, então a compatibilidade requer que a deformação $\varepsilon_{y}$ ao longo do defeito seja também nula durante o processo. A primeira condição acima requer que o modo de deformação na região $B$ não se modifique durante o necking . Assim as deformações na direção $y$ antes do defeito também deverão ser nulas. De outra forma, o necking local irá desenvolver-se ao longo de uma linha de extensão nula. A direção desta linha pode ser determinada pelo círculo de Mohr para deformações incrementais, como na fig. (3.5.15) . O centro do círculo é o ponto

$$
\left\{[(1+\beta) / 2] . d \varepsilon_{1}, 0\right\}
$$

E o raio é dado por $(1-\beta) .{ }^{\mathrm{d}} \varepsilon_{1} / 2$, e então : 


$$
\cos 2 \theta=-\{(1+\beta) /(1-\beta)\}
$$

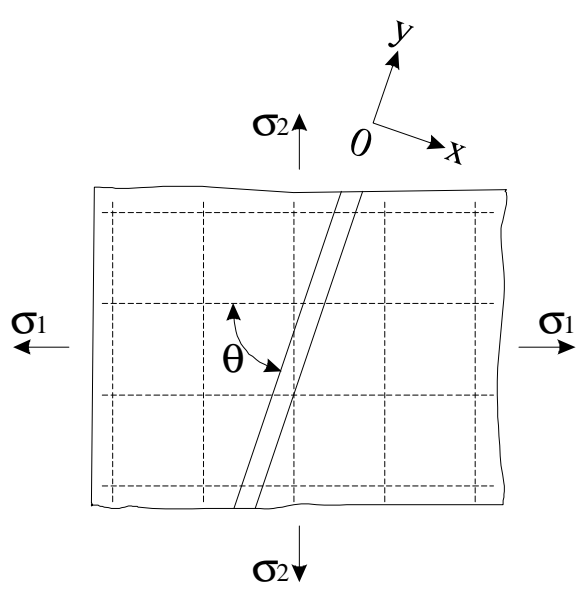

FIGURA 3.5.14 : Necking local em uma região uniformemente deformada e orientada de $\theta$ em relação à maior tensão principal

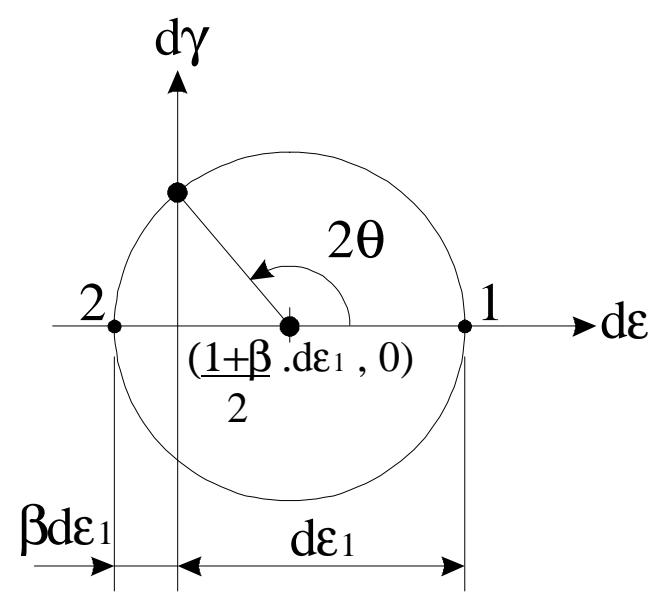

FIGURA 3.5.15 : Círculo de Mohr para deformações incrementais, mostrando-se a orientação da linha cuja deformação é nula

Para $\beta=-1 / 2, \theta=55^{\circ}$ e para $\beta=0$, deformações plana, $\theta=90^{\circ}$. Se entretanto $\beta>0$, não há solução para a equação (3.5.36) e portanto não há uma direção no plano da chapa que possua distensão nula.

Estes argumentos mostram que, assumindo-se que haja pequenas imperfeições, a condição de máxima tensão na chapa permite o desenvolvimento de estricções localizadas por sobre uma linha de extensão nula nesta chapa. Assim, para $\beta<0$, a linha na fig. (3.5.12) pode ser usada como limite local de necking como mostrado. Argumentos similares a estes para a estricção difusa confirmam que as imperfeições iniciais são significantes e que as deformações máximas na região 
uniforme serão menores que $\varepsilon_{1} *$ e $\varepsilon_{2} *$ de um valor proporcional à imperfeição inicial $\delta t_{0} / t_{0}$. Além do mais, se as imperfeições são orientadas de modo que as mais severas estão em direções diferentes daquela cuja distensão é nula, o defeito vai desenvolver-se na mesma direção. Entretanto, para imperfeições que são pequenas e distribuídas aleatoriamente em termos de magnitude e orientação, o desenvolvimento de uma faixa local ao longo de uma linha de extensão nula em tensão máxima, $d T=0$, é o mais provável modo de falha para carregamentos com $\beta \leq 0$.

Pode-se ver que se a chapa sofrer estiramento nas duas direções principais , isto é :

$$
0<\beta \leq 1
$$

então o necking local é observado em estados de deformação superiores àqueles notados em casos de máxima tensão, como na fig. (3.5.16), (MARCINIAK \& DUNCAN, 1992). Tais evidências sugerem que enquanto o critério de tensão máxima é uma condição necessária para o necking local, pode não ser uma condição suficiente quando o processo está no primeiro quadrante, que é o caso do estiramento biaxial da chapa. Há realmente alguns processos que atrasam o crescimento de estricções nesta região, como verificado no próximo item .

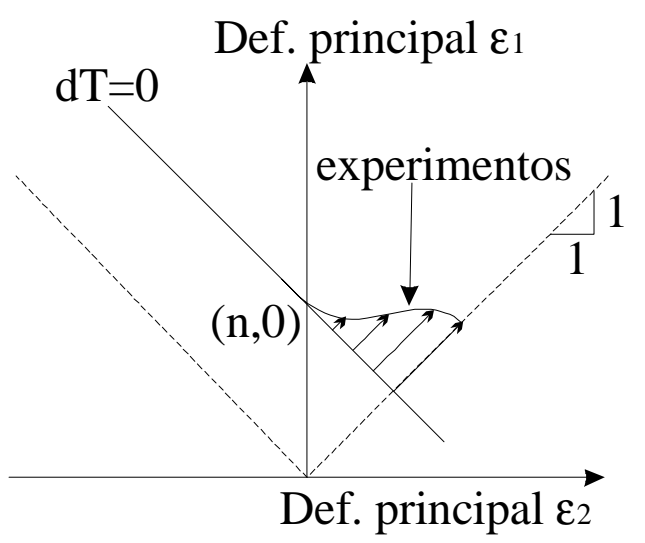

FIGURA (3.5.16) : Aumento observado experimentalmente em deformações estáveis além da tensão máxima e no estiramento biaxial, $0<\beta<1$, segundo MARCINIAK \& DUNCAN (1992) . 


\subsubsection{Estricção em tensões biaxiais}

Resumem-se abaixo os conceitos estabelecidos pelo método chamado " $M K$ ", o qual é base para o enfoque da estricção na chapa a partir da imperfeição inical prévia.

Em uma chapa sendo conformada num estado biaxial de tensões supõe-se uma imperfeição pré-existente $B$ na forma de um rebaixo perpendicular à maior tensão principal, como na fig. (3.5.17) . Pode-se representar esta imperfeição por :

$$
\mathrm{f}_{0}=\left(\mathrm{t}_{\mathrm{B}} / \mathrm{t}_{\mathrm{A}}\right)_{0}
$$

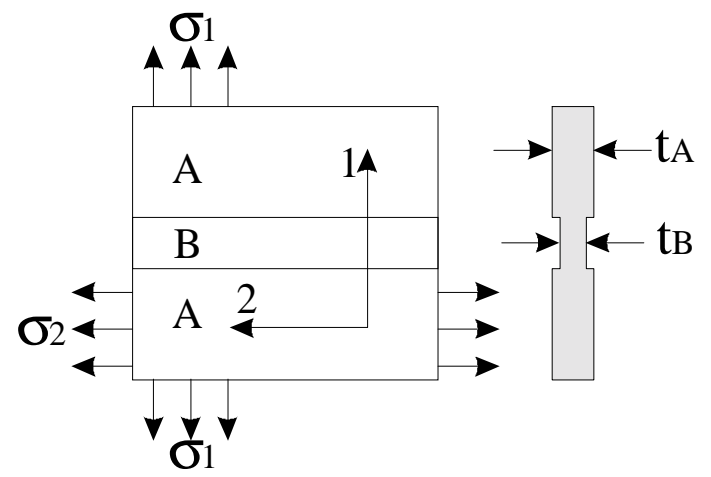

FIGURA 3.5.17 : Imperfeição $B$ em uma região $A$ sujeita a deformações uniformes

Exige-se que o processo de estricções não afete as condições de contorno externas. Tem-se que, exigindo-se uma compatibilidade de deslocamentos paralelos ao rebaixo :

$$
\left(\mathrm{d} \varepsilon_{2}\right)_{\mathrm{A}}=\left(\mathrm{d} \varepsilon_{2}\right)_{\mathrm{B}}
$$

Considerando-se um processo de conformação proporcional para a região $A$ tem-se :

$$
\begin{aligned}
& \sigma_{1 \mathrm{~A}} ; \quad \sigma_{2 \mathrm{~A}}=\alpha_{0} \cdot \sigma_{1 \mathrm{~A}} \quad ; \quad \sigma_{3 \mathrm{~A}}=0 \\
& \varepsilon_{1 \mathrm{~A}} \quad ; \quad \varepsilon_{2 \mathrm{~A}}=\beta_{0} \cdot \varepsilon_{1 \mathrm{~A}} \quad ; \quad \varepsilon_{3 \mathrm{~A}}=\left(1+\beta_{0}\right) \cdot \varepsilon_{1 \mathrm{~A}}
\end{aligned}
$$

Pelo equilíbrio de forças na direção principal 1 : 
$\mathrm{T}_{1}=\sigma_{1 \mathrm{~A}} \cdot \mathrm{t}_{\mathrm{A}}=\sigma_{1 \mathrm{~B}} \cdot \mathrm{t}_{\mathrm{B}}$

E considerando-se o comportamento do material pela equação :

$$
\sigma_{\mathrm{f}}=\mathrm{K} \cdot\left(\varepsilon_{0}+\varepsilon\right)^{\mathrm{n}}
$$

Investigam-se as deformações iniciais da região através do espaço de tensões na fig. (3.5.18). Como mostrado, a superfície de escoamento inicial de von Mises corresponde à relação de escoamento inicial dada por :

$$
\sigma_{\mathrm{f}}=\mathrm{K} \cdot \varepsilon_{0}{ }^{\mathrm{n}}
$$

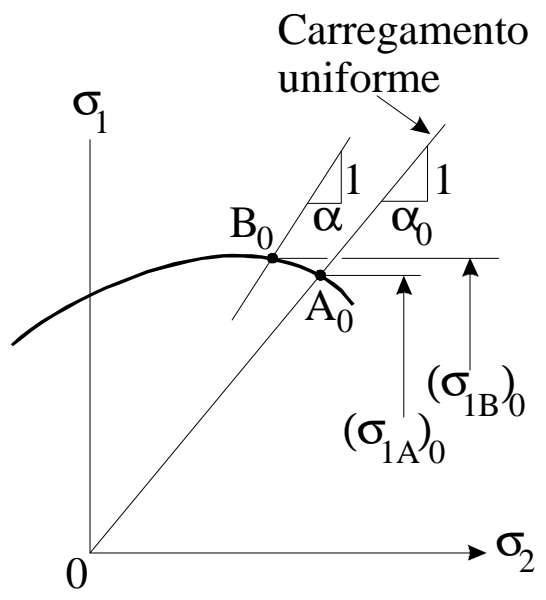

FIGURA 3.5.18 : O estado de tensões na região uniforme $\mathrm{A}_{0}$ e na imperfeição $\mathrm{B}_{0}$ no início das deformações plásticas

Supõe-se que as regiões $A$ sofram um carregamento dado por $O A_{0}$ nesta fig. com inclinação $1 / \alpha_{0}$. Para haver equilíbrio, tem-se que $\sigma_{B}$ é sempre maior que $\sigma_{A}$ :

$$
\left(\sigma_{1 \mathrm{~B}}\right)_{0}=\left(\sigma_{1 \mathrm{~A}}\right)_{0} / \mathrm{f}_{0}
$$

pois pela equação (3.5.38), $\mathrm{f}_{0}$ é menor que a unidade.

O rebaixo irá alcançar a superfície de escoamento primeiro. Entretanto, as deformações não ocorrem devido à imposição geométrica dada na equação (3.5.39) . As deformações ocorrerão somente quando o material nas regiões $A$ e $B$ alcançarem 
um estado de tensões de escoamento de modo que os incrementos de deformação paralelos ao rebaixo sejam iguais. Assim, no início do escoamento, a região $B$ movese em torno da superfície de escoamento, de forma que a relação de tensão seja :

$$
\left(\sigma_{2 \mathrm{~B}} / \sigma_{1 \mathrm{~B}}\right)_{0}=\alpha \quad \text { em que } \quad \alpha<\alpha_{0}
$$

Assim, diferentemente do caso do rebaixo ao longo de uma linha de deformações lineares nulas, a trajetória de tensões para um rebaixo no estado biaxial de tensões irá modificar-se durante as deformações. Ou seja, $\alpha$ e $\beta$ não serão constantes na região $\mathrm{B}$.

Consideram-se as deformações de cada região para pequenos incrementos, $d \varepsilon_{2 A}=d \varepsilon_{2 B}$. O vetor incremental de deformações, conforme a regra de fluxo de Lévy-Mises, é normal à superfície de escoamento e assim, da fig. (3.5.19), nota-se que para o rebaixo $\beta<\beta_{0}$. Daí, para incrementos iguais $d \varepsilon_{2}$, paralelos ao rebaixo, vem que :

$$
\mathrm{d} \varepsilon_{1 \mathrm{~B}}>\mathrm{d} \varepsilon_{1 \mathrm{~A}}
$$
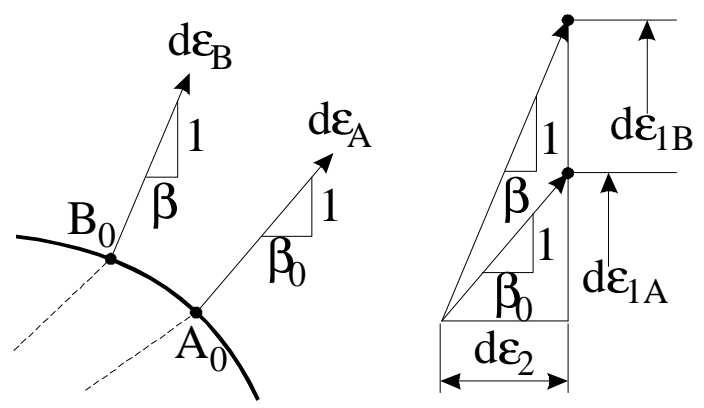

FIGURA 3.5.19 : Giro do vetor de deformações quando se move em torno da superfície de tensões de escoamento

No fim deste incremento, a deformação efetiva no rebaixo é maior que na região $A$ e a partir daí tem-se que cada região atua em diferentes superfícies de escoamento, como visto na fig. (3.5.20) . Tem-se também que :

$$
\left|\mathrm{d} \varepsilon_{3 \mathrm{~B}}\right|>\left|\mathrm{d} \varepsilon_{3 \mathrm{~A}}\right|
$$


ou seja, a profundidade do rebaixo aumenta e ainda que :

$$
\sigma_{1 \mathrm{~A}} / \sigma_{1 \mathrm{~B}}<\left(\sigma_{1 \mathrm{~A}} / \sigma_{1 \mathrm{~B}}\right)_{0}
$$

$\mathrm{ou}$

$$
\mathrm{t}_{\mathrm{B}} / \mathrm{t}_{\mathrm{A}}<\mathrm{f}_{0}
$$

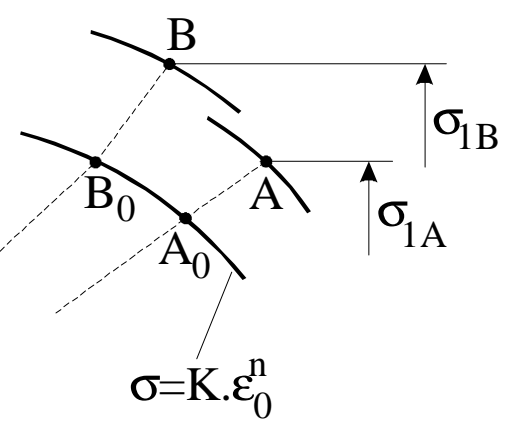

FIGURA 3.5.20 : Estado de tensões na região uniforme $A$ e no rebaixo $B$ após o primeiro incremento de deformações

Como a região $A$ deforma-se ao longo de uma trajetória fixa, o ponto que representa $B$ irá mover-se em torno da superfície de escoamento, à medida que suas deformações aumentam. Eventualmente, $B$ irá alcançar o ponto correspondente ao estado de deformações planas nesta superfície, como visto na fig. (3.5.21), em que :

$$
\mathrm{d} \varepsilon_{1 \mathrm{~B}} / \mathrm{d} \varepsilon_{2 \mathrm{~B}}=1 / \beta=\infty
$$

A partir deste ponto não há deformações posteriores em $A\left(d \varepsilon_{2 B}=d \varepsilon_{2 A}=0\right)$ e $\varepsilon_{l \mathrm{~B}}$ aumenta até que se alcance a falha do material. Isto é mostrado na fig. (3.5.22) . Na região uniforme $A$, a trajetória de deformações é linear, mas no rebaixo enquanto $d \varepsilon_{2 B}=d \varepsilon_{2 A}$, a deformação $d \varepsilon_{1 B}$ avança à frente de $d \varepsilon_{1 A}$ até que a deformação plana seja obtida e que a chapa falhe no rebaixo . A deformação na chapa após a formação desta falha no rebaixo é analisada do ponto de vista da região uniforme $A$. É o limite de conformação para a chapa e para uma trajetória particular de tensões $\alpha_{0}$, ou seja :

$$
\left(\varepsilon_{1 \mathrm{~A}}, \varepsilon_{2 \mathrm{~A}}\right)_{\varepsilon_{1 \mathrm{~B}} \rightarrow \infty}
$$


e esta é a maior deformação uniforme que pode ser imposta à chapa nesta trajetória de tensões e com análise conveniente, obtem-se então o Diagrama de Limite de Conformação conforme visto na fig. (3.5.23) :

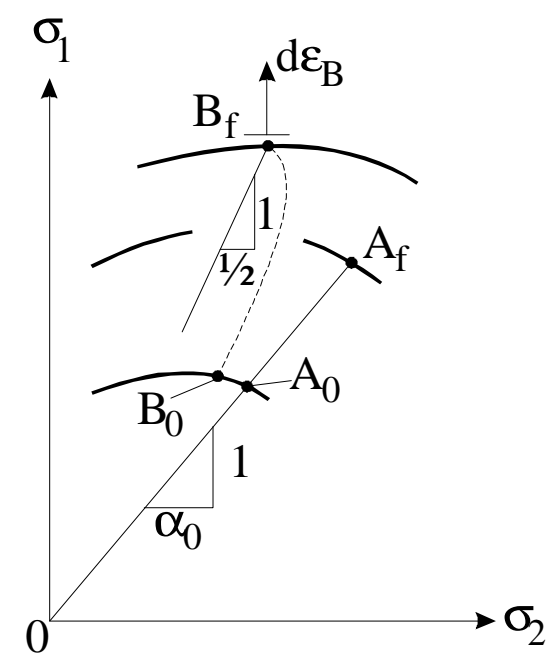

FIGURA 3.5.21 : Trajetória de um ponto representando o estado de tensões no rebaixo $B$ tendendo ao estado plano de deformações, onde $\alpha=1 / 2$

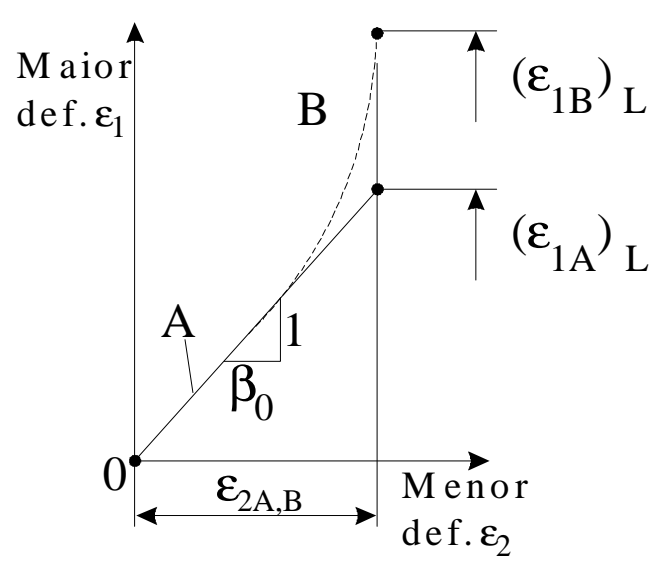

FIGURA 3.5.22 : Trajetória para deformações no rebaixo $B$ e na região uniforme A 


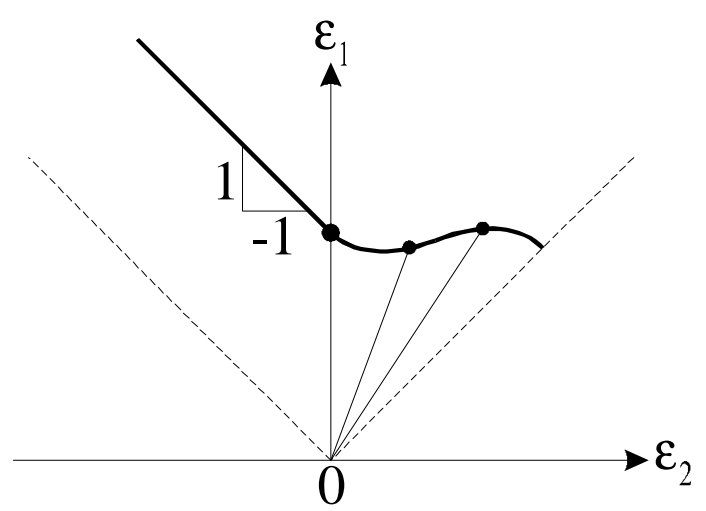

FIGURA 3.5.23 : Diagrama de limite de conformação representando as deformações finais $\left(\varepsilon_{2 A}, \varepsilon_{I A}\right)$ na região uniforme $A$ para diversas trajetórias de deformações $\beta$

Este tópico apresentou a modelagem de um tipo defeito comum nos processos de conformação de chapas que é a estricção. Vários autores adaptam novas considerações ao modelo estudado e alguns deles são revisados no próximo item.

\subsection{Métodos gerais para cálculo dos diagramas}

BANABIC (1999), utilizando o critério de escoamento de Hill (1993) apud BANABIC (1999), e baseado na condição de necking difuso de SWIFT (1952) apud BANABIC (1999), apresenta as deformações no início do defeito em diagramas construídos por expressões analíticas, partindo da equação de Hollomon (2.3.38) e do critério de escoamento de HILL (1993), op. cit..

Em outra linha de trabalho, GRAF \& HOSFORD (1990) seguem o modelo $M K$ descrito, partindo da equação de Swift (2.3.39) e dos critérios de escoamento não quadráticos de Hosford, equação (2.3.31), para o cálculo teórico dos diagramas de limite. Em seu trabalho apresenta-se um algorítimo de análise incremental, com cálculo de diagramas para vários materiais, destacando-se a influência da taxa de deformação (valor $m$ ) nos gráficos construídos. Em seu trabalho porém são encontradas definições alternativas a respeito da imperfeição inicial, neste caso apresentadas como sugestão de novo trabalho, e também alternativas a respeito da definição matemática da estricção na chapa. Estes aspectos serão detalhados no capítulo 4 . 
Uma característica importante das curvas nos diagramas é sua elevada dependência em relação ao modo de encruamento dos corpos de prova. GHOSH \& LAUKONIS (1976) apud STOUGHTON (2000) apresentam um estudo da influência do encruamento prévio na chapa , conforme um histórico de deformações ou strainpath. Nas figs. (3.6.1) e (3.6.2) vêem-se resultados experimentais (GHOSH \& LAUKONIS,1976, apud STOUGHTON, 2000) de dois tipos de ensaios em que o corpo de prova é uma chapa quadrada de aço dútil com solicitações no seu plano. Na fig. (3.6.1) tem-se a curva do ensaio de solicitação equi-biaxial para um aço laminado a frio. A linha cheia representa a curva para material padronizado e as linhas 1, 2, 3 representam materiais com pré-deformações de 0.031, 0.067 e 0.119 respectivamente (deformações verdadeiras) . Na fig. (3.6.2) têm-se as curvas para o caso em que o encruamento prévio é dado a partir de solicitações uniaxiais e para o mesmo material. A linha cheia é a mesma do caso anterior. As linhas 1, 2, 3 mostram os limites para pré-deformações de 0.068, 0.091 e 0.140 respectivamente, aplicando-se deformações sub-seqüentes paralelas ao eixo prévio de deformação principal. As linhas 4, 5, 6 representam os limites para as mesmas pré-deformações anteriores, porém com deformações posteriores perpendiculares ao eixo prévio de deformação principal.

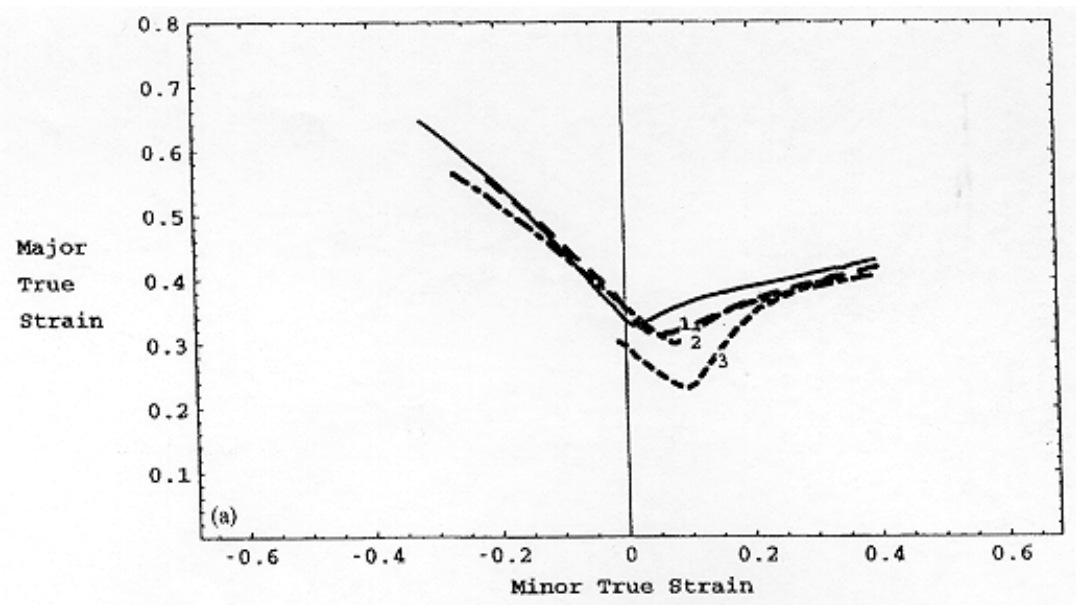

FIGURA (3.6.1) : Curvas limites para solicitação biaxial, GHOSH \& LAUKONIS (1976) 


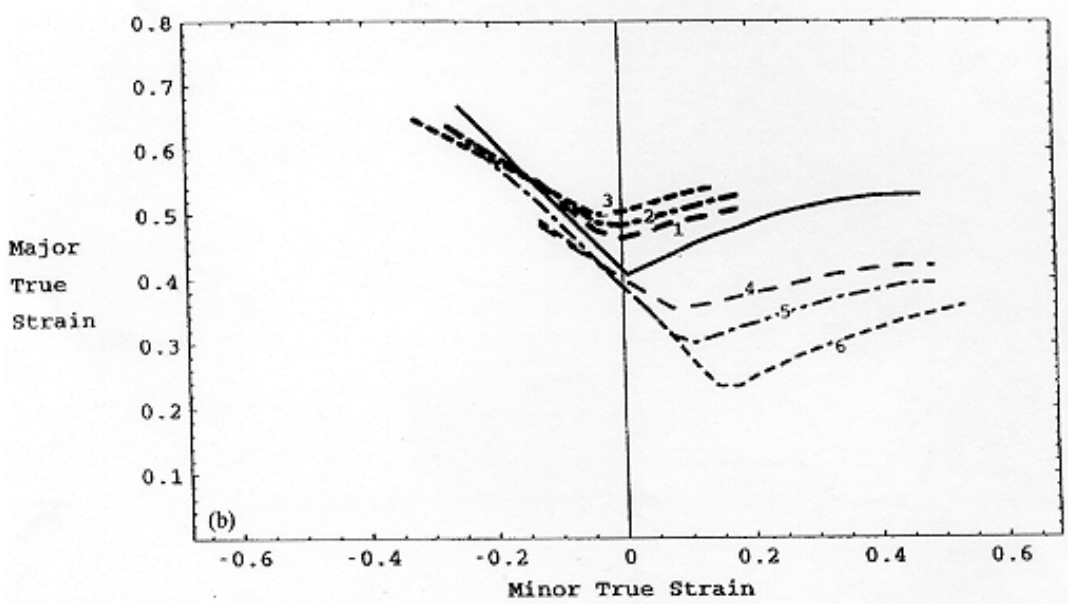

FIGURA (3.6.2) : Curvas limites para solicitação uniaxial, GHOSH \& LAUKONIS (1976)

Como a curva limite para deformações na chapa depende do encruamento ou de processos prévios aplicados ao blank, é necessário ponderar sua utilização na análise de conformações mecânicas que exibam estados de deformações complexos. Ainda em ZHAO et al. (1996) encontram-se verificações teóricas acerca desta influência.

Por outro lado, ARRIEUX et al. (1982) apud ARRIEUX et al. (1996) observaram que as tensões máximas na instabilidade do material não são muito afetadas pelo histórico de deformações efetuado, mesmo utilizando-se processos em mais de um estágio, como visto também em KLEEMOLA \& PELKKIKANGAS (1977) apud STOUGHTON (2000) . Considera-se que a curva limite no espaço de tensões, (forming limit stress diagrams ou "FLSD"), na fig. (3.6.3), depende da lei de potência e da função de potencial plástico empregadas, sendo que pequenas variações no nível de tensões em relação ao nível de deformações deve-se ao baixo expoente $n$ na lei de potência utilizada para materiais metálicos (STOUGHTON, 2000) . SOWERBY \& DUNCAN (1971) apud GRAF \& HOSFORD (1990) avaliam que a obtenção do estado de tensões restringe-se à superfície de escoamento e do correspondente critério de escoamento adotado, o que na expressão (2.3.31) significa uma escolha adequada do expoente $a$ e do fator $r$.

Um problema prático encontrado é dado pela dificuldade em se obter o estado de tensões no plano da chapa trabalhada. Citam-se como meios disponíveis a análise numérica do processo pelo método de elementos finitos ou a utilização de fórmulas 
de conversão de valores de deformações limites para tensões limites. STOUGHTON (2000) confirma as vantagens do uso do FLSD e apresenta as expressões de conversão necessárias entre os valores limites de deformação e tensão principais, conforme os vários critérios de escoamento citados. Alguns de seus resultados estão na fig. (3.6.3), em que os valores de deformações foram extraídos dos gráficos das figs. (3.6.1) e (3.6.2) . Com os gráficos $F L S D$ é possível uma melhor análise do processo aplicado a blanks que venham apresentar graus diferenciados de encruamento ou para processos realizados em mais de um estágio.

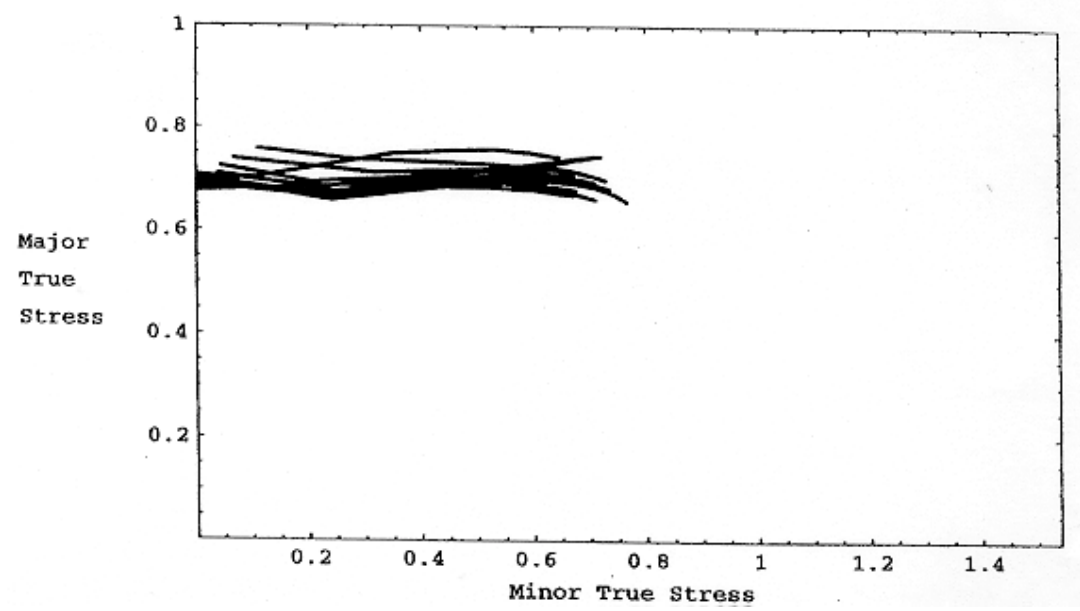

FIGURA 3.6.3 : Diagramas FLSD para tensões (STOUGHTON , 2000)

Neste mesmo ponto de vista, ZHAO et al. (1996) utilizam o algorítimo apresentado por GRAF \& HOSFORD (1990) para o cálculo de deformações no limite e com estes valores obtem as tensões limitantes na chapa. Verificou-se consistência com os estudos de ARRIEUX et al. (1982) apud ARRIEUX et al. (1996).

O modelo $M K$ a ser estudado mostra o defeito na chapa alinhado com um das direções principais de deformação. Pode-se considerar o caso de o defeito estar desalinhado de um ângulo $\theta$, fig. (3.6.4), levando à formulação de um modelo $M K$ mais complexo. O trabalho de VACHER et al. (1998) realiza um estudo com este modelo mais amplo, obtendo a construção de superfícies limitantes em diagramas 3D cujos eixos são deformações principais 1 e 2 e o terceiro eixo é dado pelo ângulo $\theta$. 


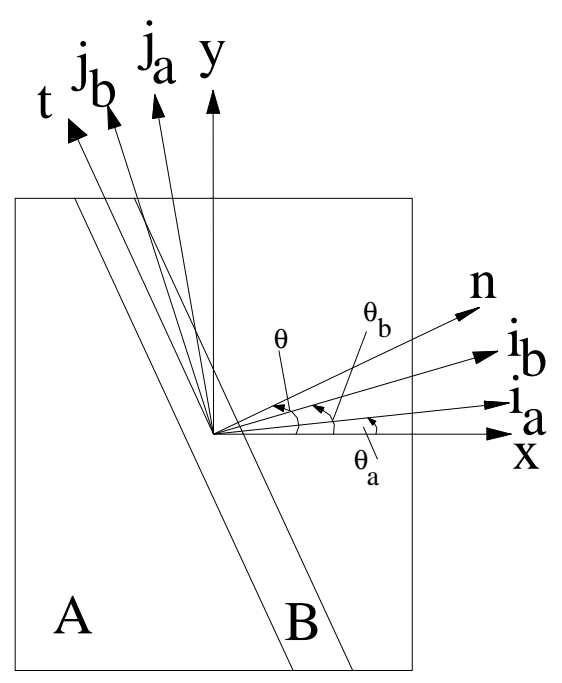

FIGURA 3.6.4 : Modelo $M K$ e a imperfeição rotacionada de $\theta$.

Seguindo processos análogos aos mostrados anteriormente, constroem-se diagramas 3D para as tensões principais no limite e o ângulo $\theta$. Com esta tendência, dispõe-se estes últimos gráficos para a análise pelo método de elementos finitos $(M E F)$, em que a otimização do ângulo $\theta$ é referência para melhor orientação de processo mecânico do material. Outras considerações sobre o modelo $M K$ são encontradas em ZHAO et al. (1996) sobre a orientação da imperfeição no modelo visto na fig. (3.6.4) na forma de rebaixo.

Uma limitação do modelo $M K$ é observada pelo fato de ele não simular as demais condições de processo tais como o atrito, a pressão normal à chapa e a curvatura do blank. Para isto, uma aplicação do MEF (Método dos Elementos Finitos) é mostrada em MAMALIS et al. (1997) com a apresentação de um algorítimo de avaliação de estricções conforme taxas de deformação elevadas e concentradas em algum ponto de uma tira metálica de teste. Neste caso analisa-se diretamente uma chapa sendo estirada pelo método do punção esférico. Este algorítimo é implementado junto ao software LS-DYNA3D, com determinação das tensões críticas no fim dos cálculos numéricos.

No próximo capítulo serão implementados por elementos finitos alguns procedimentos para o cálculo dos diagramas de limite de conformação, baseada principalmente nos trabalhos de GRAF \& HOSFORD (1990) e MARCINIAK \& DUNCAN (1992) . 


\section{Cálculo de diagramas de limite de conformação por elementos finitos}

\subsection{Considerações gerais}

Uma vez estabelecida a teoria básica do assunto, reunem-se as condições para a determinação dos diagramas. Entretanto, são necessárias algumas considerações no sentido de verificar-se como os diversos fatores influenciarão nos cálculos. Estas restrições são consideradas abaixo :

Quanto aos procedimentos de cálculo e verificação do diagrama

- Escolha do tipo de ensaio de conformabilidade a modelar : plano ou simulativo

- Modelos de análise disponíveis

- Cálculo por algorítimos ou por $M E F$

- Tipos de defeitos analisados : estricções ou fraturas

- Valores de cálculo verificados por experimentos ou por trabalhos da literatura

Quanto ao modelo de comportamento do material

- Escolha dos parâmetros $m, n, r$

- Lei de potência do material

- Isotropia ou anisotropia

- Critério de escoamento isotrópico ou anisotrópico

Baseado nestas restrições, escolheu-se para o cálculo dos diagramas o modelamento do ensaio plano de conformabilidade. Para o estudo utilizou-se o modelo de análise citado previamente como $M K$, o mesmo sendo estudado nesta 
etapa pelo Método dos Elementos Finitos. Como foi mostrado, o modelo $M K$ apresenta suas considerações baseadas na ocorrência de estricções na chapa, sendo que para os resultados serão feitas ponderações baseadas em dados disponíveis na literatura. Nos cálculos serão utilizados os parâmetros $m, n$ e outros para o caso de aços dúteis com respectivas leis de potência. Estudam-se os casos isotrópicos, sendo feitas algumas considerações para os casos anisotrópicos.

\subsection{Determinação por Elementos Finitos de diagramas de limite de conformação}

Neste tópico estuda-se o método $M K$ segundo a aplicação de GRAF \& HOSFORD (1990), com a inclusão de algumas modificações e implementado pelo método dos elementos finitos.Com os valores do limite, constroem-se os gráficos de deformações e tensões de pontos externos à região do defeito. Realizam-se cálculos para as circunstâncias descritas abaixo, escolhendo-se uma condição relevante para o estudo conjunto com um processo de estampagem, a ser visto no capítulo 5.

\subsubsection{Modelo $M K$ analisado de modo alternativo}

Até então considerou-se o defeito como uma região da chapa de menor espessura, ou

$$
\mathrm{f}_{0}=\left(\mathrm{t}_{\mathrm{B}} / \mathrm{t}_{\mathrm{A}}\right)_{0}
$$

Como alterações do modelo citado, considera-se o defeito conforme:

$$
\mathrm{f}_{0}=\left(\mathrm{K}_{\mathrm{B}} / \mathrm{K}_{\mathrm{A}}\right)_{0}
$$

ou seja, através de uma relação entre as constantes de resistência do material no instante inicial, cujo comportamento é dado por :

$$
\sigma_{\mathrm{A}}=\mathrm{K}_{\mathrm{A}} \cdot \dot{\bar{\varepsilon}}^{\mathrm{m}} \cdot \bar{\varepsilon}^{\mathrm{n}}
$$

para a região perfeita $\mathrm{e}$ 


$$
\sigma_{\mathrm{B}}=\mathrm{K}_{\mathrm{B}} \cdot \dot{\bar{\varepsilon}}^{\mathrm{m}} \cdot \bar{\varepsilon}^{\mathrm{n}}
$$

para o defeito. Nos limites para os cálculos de deformações, considerou-se anteriormente que

$$
\mathrm{d} \varepsilon_{1 \mathrm{~B}} / \mathrm{d} \varepsilon_{2 \mathrm{~B}}=1 / \beta=\infty
$$

com as curvas construídas para

$$
\left(\varepsilon_{1 \mathrm{~A}}, \varepsilon_{2 \mathrm{~A}}\right)_{\varepsilon_{1 \mathrm{~B}} \rightarrow \infty}
$$

No algorítimo apresentado por GRAF \& HOSFORD (1990), obtém-se incrementalmente os limites através do critério de parada :

$$
\Delta \varepsilon_{1 \mathrm{a}}<\Delta \varepsilon_{1 \mathrm{~b}} / 10
$$

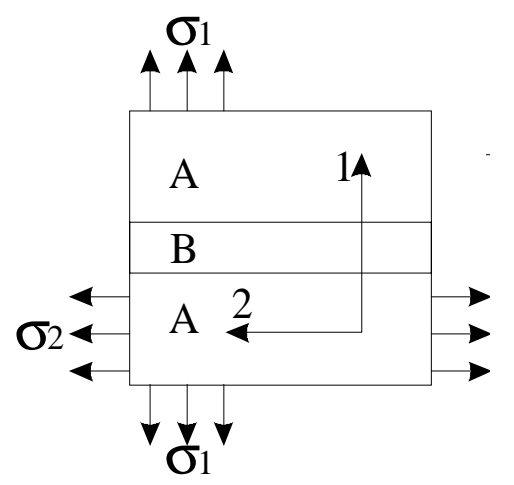

FIGURA 4.2.1 : Imperfeição $B$ em uma região $A$ sujeita a deformações uniformes, conforme $M K$.

Como critério de parada será utilizada a sugestão apresentada em por GRAF \& HOSFORD (1990), dada por :

$$
\varepsilon_{3 \mathrm{~A}}=0.8 \varepsilon_{3 \mathrm{~B}}
$$

Esta expressão é modificada conforme (4.2.9), de modo a abranger um intervalo de deformações convenientes e também uma adaptação ao algorítimo 
desenvolvido junto ao método dos Elementos Finitos . Ou seja, limitam-se as deformações de espessura na região perfeita dentro de uma faixa de valores relativos à deformação na região de estricção, a partir da convenção adotada pela expressão (4.2.8) . Isto significa que em qualquer região analisada onde haja eventuais defeitos, a deformação de espessura medida localmente seja da ordem de $20 \%$ a $30 \%$ maior em módulo do que na vizinhança.

$$
0.7 \varepsilon_{3 \mathrm{~B}} \leq \varepsilon_{3 \mathrm{~A}} \leq 0.8 \varepsilon_{3 \mathrm{~B}}
$$

A condição obtida em (4.2.9) é aplicável ao quadrante direito do diagrama de limite de conformação, ou seja, se durante o processo, de (3.5.23) :

$$
\mathrm{d} \varepsilon_{1} \quad ; \quad \mathrm{d} \varepsilon_{2}=\beta . \mathrm{d} \varepsilon_{1} \quad ; \quad \mathrm{d} \varepsilon_{3}=-(1+\beta) \cdot \mathrm{d} \varepsilon_{1}
$$

Vir que :

$$
0<\beta<1
$$

Para o quadrante esquerdo do diagrama, respeitam-se as condições matemáticas dadas de (3.5.22) a (3.5.30) e com a hipótese da taxa de deformação na direção principal 1 constante e nula, tem-se que :

$$
\begin{aligned}
& -1<\beta<0 \\
& \varepsilon_{1}^{*}+\varepsilon_{2} *=n
\end{aligned}
$$

Ressalta-se aqui a condição de estricção local para o quadrante esquerdo do diagrama, na qual as deformações de limite relacionam-se ao expoente de encruamento $n$ conforme a equação de reta (4.2.13) .

Com isto, a curva limite a ser proposta será a curva composta a partir das condições (4.2.9) para o quadrante direito e (4.2.13) para o quadrante esquerdo. 


\subsubsection{Implementação por Elementos Finitos}

O problema foi dividido seguindo-se as três etapas essenciais para a utilização do Método dos Elementos Finitos: etapas de pré-processamento e de solução e etapa final de pós-processamento, esquematizadas na fig. (2.4.1). Para isto utilizou-se o software ANSYS para a solução não linear pela abordagem estática implícita, verificada no tópico 2.4.4 . Porém, realizou-se este estudo a partir de um algorítimo incremental para as deformações na estricção, apresentado na fig. (4.2.2) e descrito a seguir .

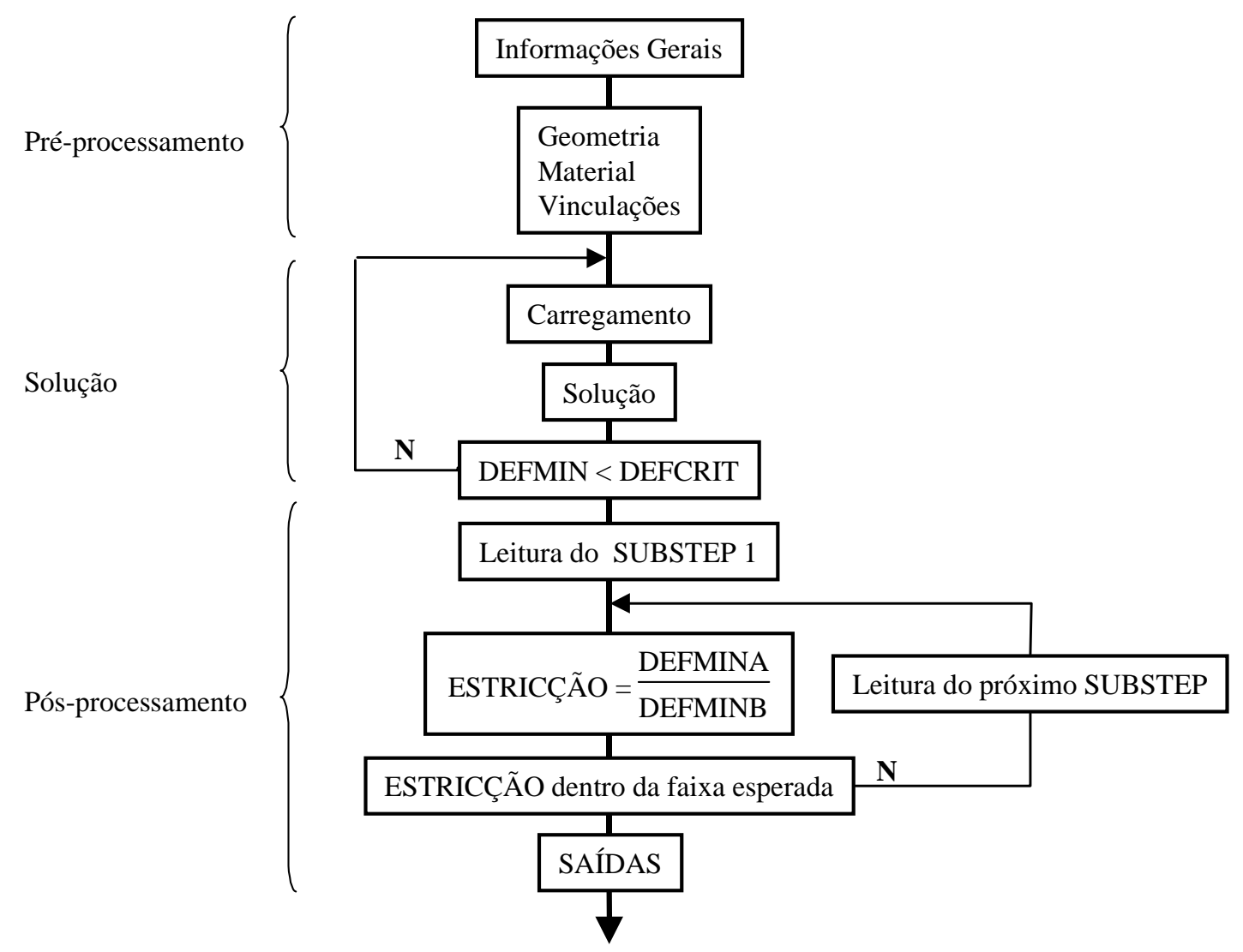

FIGURA 4.2.2 : Algorítimo de cálculo para a estricção, implementado com o método dos

Elementos Finitos.

$\mathrm{Na}$ etapa de pré-processamento obtém-se as informações gerais para a geometria, material e vinculações . Para a geometria estudou-se um trecho quadrado de chapa de 1,0 mm de espessura e 10,0 mm de lado, definida conforme a fig. (4.2.1). No caso de material, utilizaram-se cinco tipos usuais em estampagem, sendo 
todos sistematizados na tab. (4.2.1) . Estes valores foram baseados em GRAF \& OSFORD (1990) .

\begin{tabular}{|r|r|r|r|}
\hline Curva & n & m & f \\
\hline 1 & 0,19 & 0 & 0,905 \\
\hline 2 & 0,19 & 0,012 & 0,905 \\
\hline 3 & 0,22 & 0 & 0,905 \\
\hline 4 & 0,22 & 0,012 & 0,905 \\
\hline 5 & 0,19 & 0 & 0,895 \\
\hline
\end{tabular}

TABELA 4.2.1: Curvas de material conforme parâmetros $n, m$ e $f$.

Nesta tabela os parâmetros $n$ e $m$ são provenientes da lei de potência, expressão (4.2.3), com taxa de deformação constante de ensaio com valor 0.05 , e o parâmetro $f_{0}$ é o fator do defeito, definido na expressão (4.2.2). Fazem-se as análises com casos isotrópicos, ou seja, $r=1$.

Para a curva 2, definida na tab. (4.2.1), tem-se o seguinte gráfico :

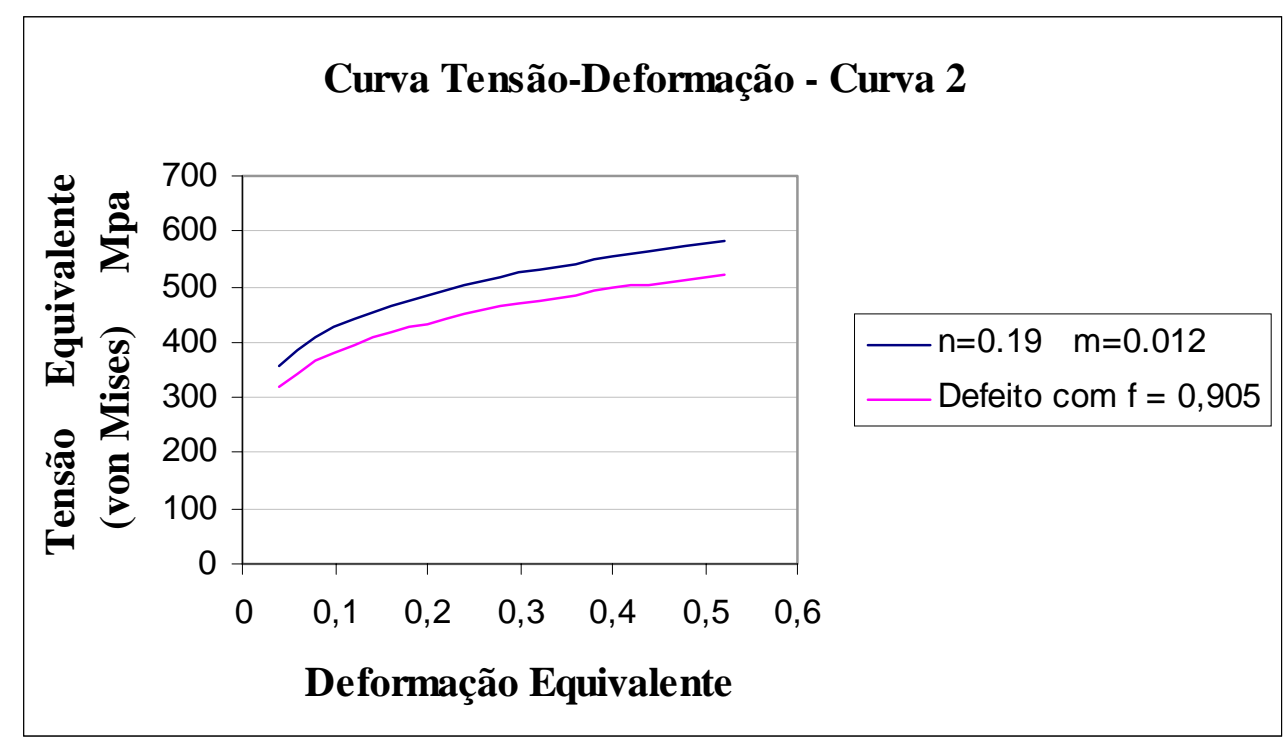

FIGURA 4.2.3 : Comportamento de material no defeito do trecho de chapa analisado .

Na fig. (4.2.4) apresentam-se a malha e as vinculações do trecho de chapa analisado. Nesta figura tem-se que o defeito é identificado pela faixa central cinza e as vinculações são marcadas pelos símbolos em azul. A característica principal deste modo de vinculações é de manter o trecho de chapa fixo em relação aos 
deslocamentos na direção 3 e de forma que os deslocamentos das bordas sejam simétricos, seja pelos deslocamentos da direção 1 bem como pelos deslocamentos da direção 2 .

A malha é composta por 35 elementos SOLID45, conforme fig. (4.2.4), para permitir-se o cálculo de valores de deformação e tensão em cada um de seus 8 nós.

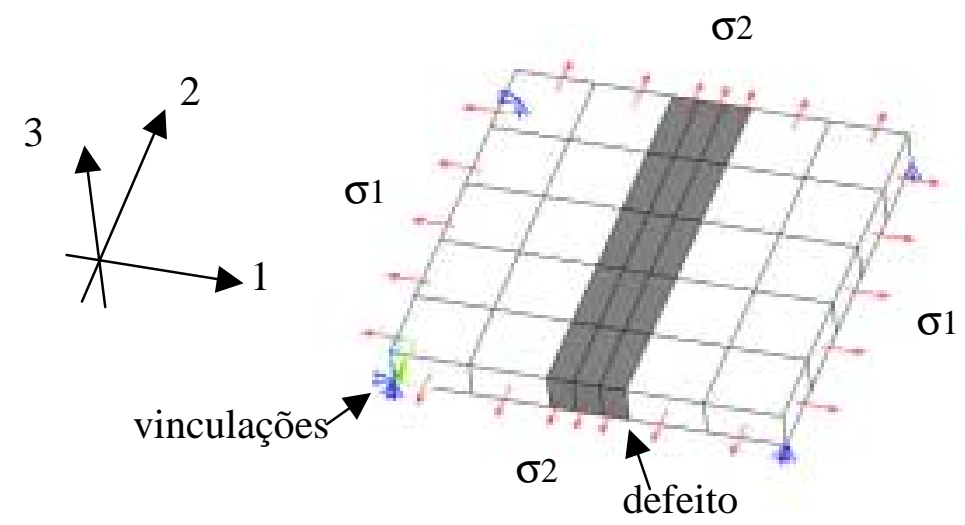

FIGURA (4.2.4) : Malha, vinculações, carregamentos e direções principais de análise.

O carregamento foi definido por combinações de pressão nas bordas do trecho de chapa, dada pela expressão (4.2.14) :

$$
\sigma_{2}=\alpha . \sigma_{1}
$$

sendo que para $\alpha$ utilizaram-se os valores $0,0.5,0.6,0.7,0.8,0.9$ e 1.0 (total de 7 pontos por curva). A obtenção de valores para $\alpha=0$ foi feita no sentido de compará-la com as deformações calculadas para o quadrante do diagrama com $\varepsilon_{2}<0$, apresentadas inicialmente por (4.2.12) e (4.2.13). Escolheram-se os limites inferiores para este quadrante para garantir-se maior margem de segurança no processo a ser estudado no capítulo 5 .

A solução do problema para cada valor $\alpha$ foi realizada em fases iterativas. Inicialmente define-se o carregamento nas bordas do trecho de chapa. A estricção pronuncia-se à medida que este carregamento é aumentado, respeitando-se a relação (4.2.14). Como critério de parada especifica-se que a mínima deformação na região do defeito seja alcançada conforme : 


$$
\text { DEFMIN }<\text { DEFCRIT }=-0.9
$$

ou seja, requer-se que a mínima deformação na direção 3 (na direção da espessura da chapa) e na região do defeito estabeleça-se abaixo de um valor de referência DEFCRIT =-0.9 . Isto significa uma imposição matemática para a estricção em função de carregamentos sucessivos na borda da chapa.

A partir deste ponto tem-se a etapa de pós-processamento em que são verificados os valores nodais de deformação e tensão. Assim são lidos todos os substeps do último acréscimo de carregamento. Como critério de parada define-se a variável

$$
\text { ESTRICÇÃO }=\frac{\text { DEFMINA }}{\text { DEFMINB }}
$$

em que DEFMINA é a deformação média de espessura (direção 3) na região $A$ (região perfeita) e DEFMINB é a deformação média de espessura (direção 3) na região $B$ (região do defeito, imperfeita) . Neste sentido requer-se que a variável ESTRICÇÃO esteja dentro de uma faixa de valores e a partir da expressão (4.2.9), sendo dividido ambos os lados por $\varepsilon_{3 \mathrm{~B}}$, obtem-se :

$$
0.7 \leq \text { ESTRICÇÃO } \leq 0.8
$$

Satisfeito este critério, obtem-se o substep da solução para a análise dos resultados . Os valores de saída a serem obtidos são

$$
\left(\bar{\varepsilon}_{1 \mathrm{~A}}, \bar{\varepsilon}_{2 \mathrm{~A}}\right)
$$

ou seja o par de deformações médias nas direções 1 e 2 na região perfeita da chapa.

Feito isto, utiliza-se um novo valor para $\alpha$ e obtem-se novos valores de saída e assim sucessivamente. 


\subsection{Discussões sobre as curvas obtidas}

Baseado no esquema de trabalho proposto no tópico anterior, especialmente nas condições de ensaio da tab. (4.2.1) e no algorítimo para determinação visto na fig. (4.2.2), foram obtidas as seguintes configurações para deslocamentos, deformações e tensões, apresentados para para um valor $\alpha$ genérico :

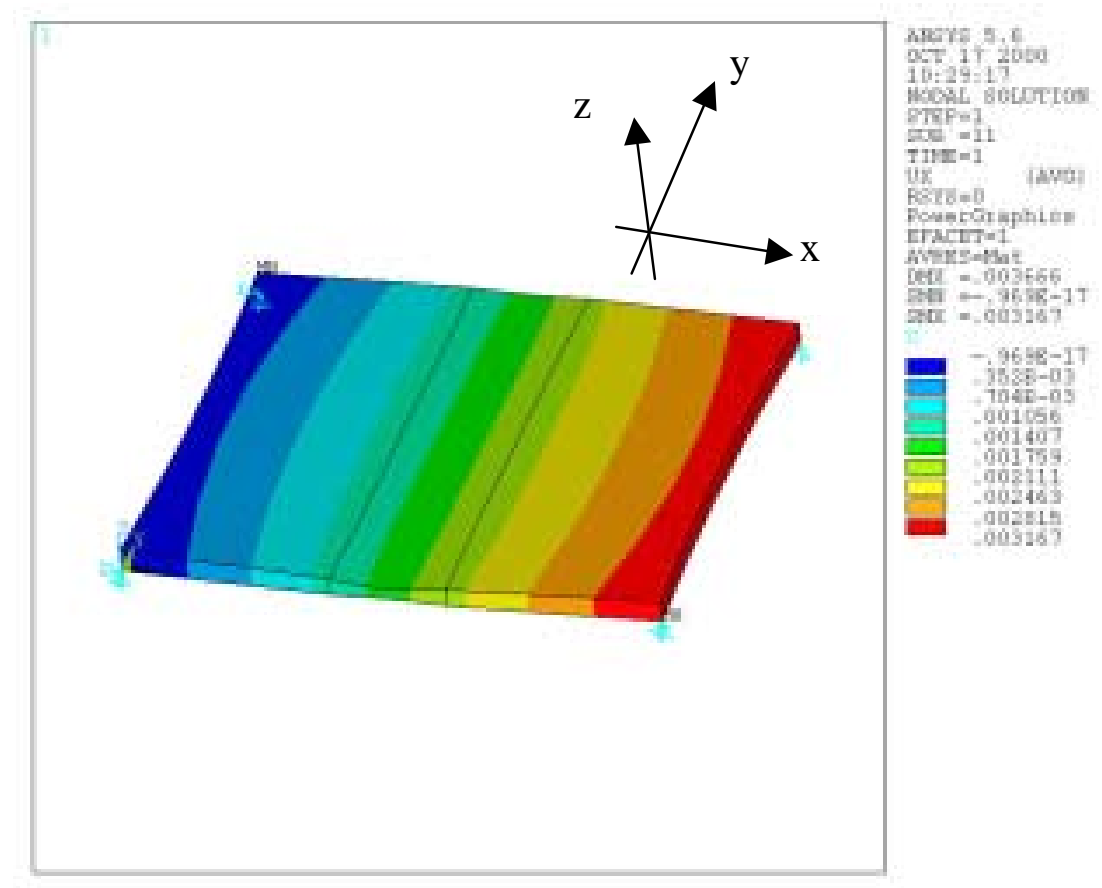

FIGURA 4.3.1 : Distribuição de deslocamentos na direção $x$ para um valor genérico de $\alpha$.

Pode-se observar nas figs. (4.3.1) a (4.3.6) o detalhe da estricção na porção central, bem como a distribuição regular das grandezas avaliadas nas direções transversal e longitudinal da chapa. Verificam-se que os maiores valores em módulo de deformação e tensão encontram-se na região do defeito.

$\mathrm{Na}$ fig. (4.3.6) enfoca-se a estricção de forma genérica e sua distribuição na espessura da chapa. Em todos os casos estudados encontrou-se esta distribuição em maior ou menor intensidade, dependendo do caso. Nota-se também nesta figura a posição inicial das faces da chapa em linhas tracejadas. 


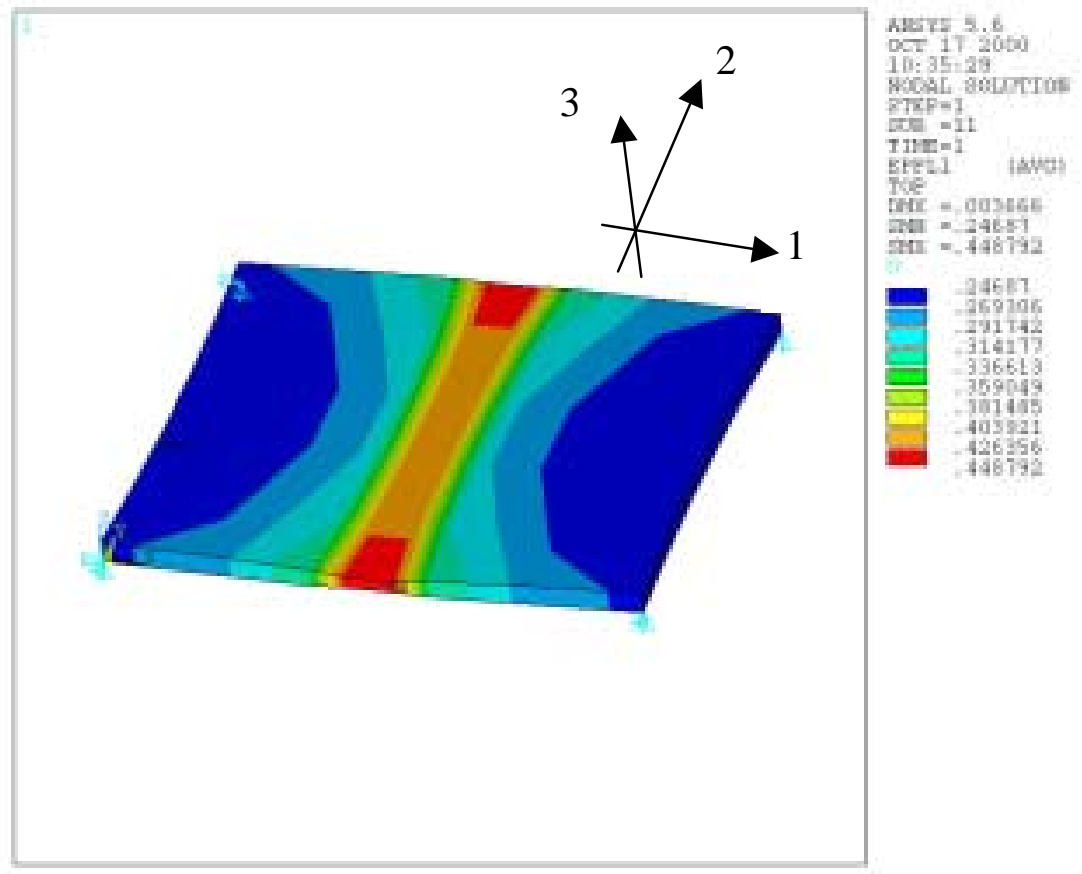

FIGURA 4.3.2 : Distribuição das deformações plásticas principais na direção 1 para um valor genérico de $\alpha$.

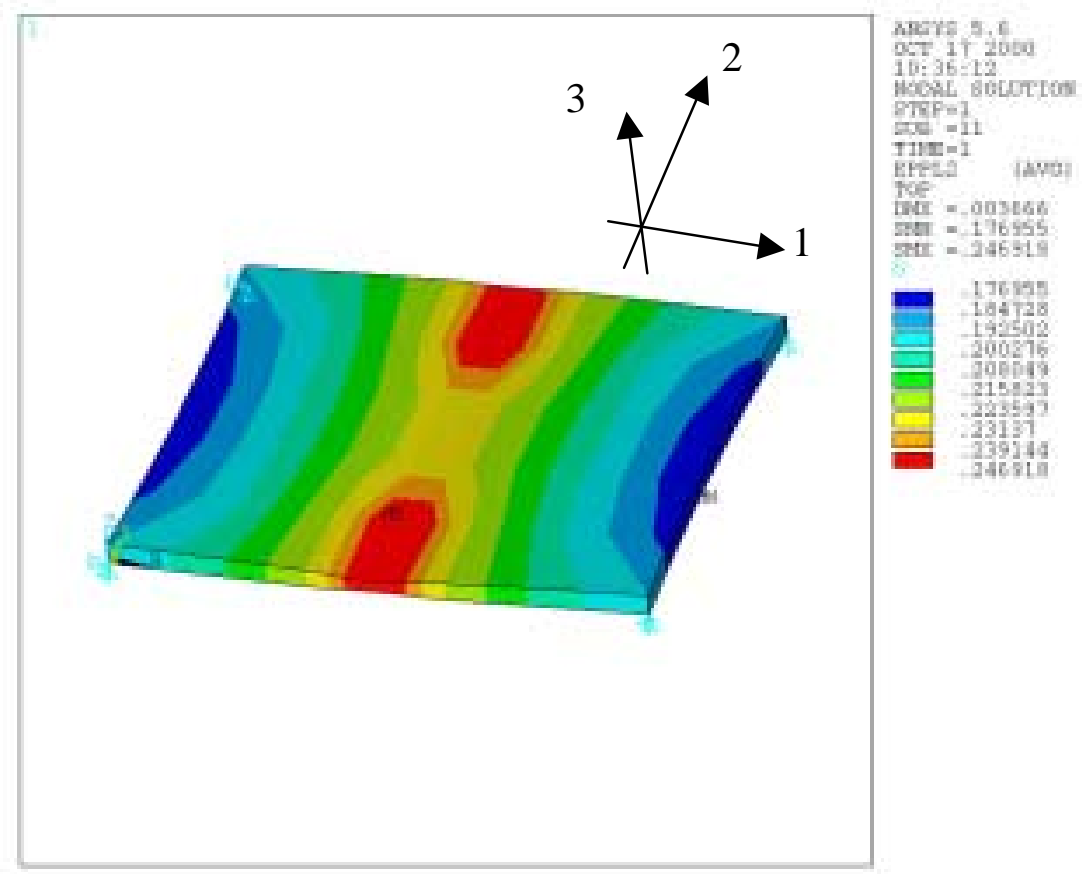

FIGURA 4.3.3 : Distribuição das deformações plásticas principais na direção 2 para um valor genérico de $\alpha$. 


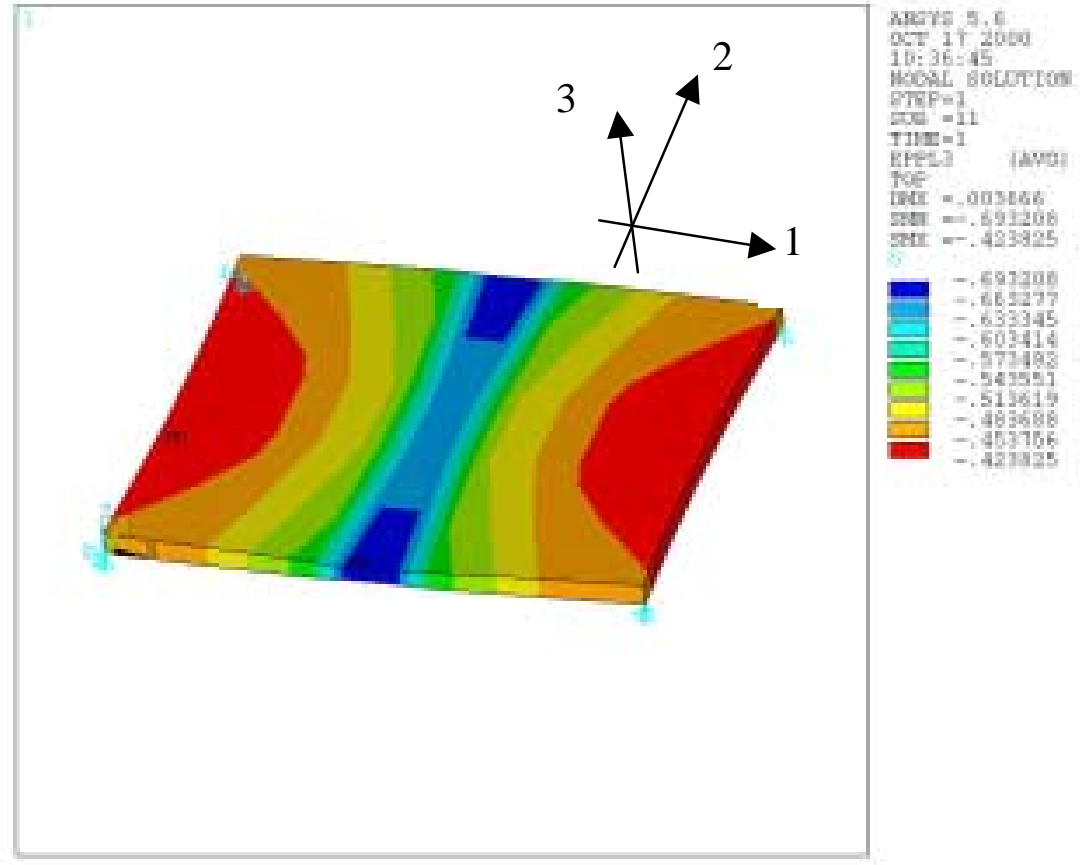

FIGURA 4.3.4 : Distribuição das deformações plásticas principais na direção 3 para um valor genérico de $\alpha$.

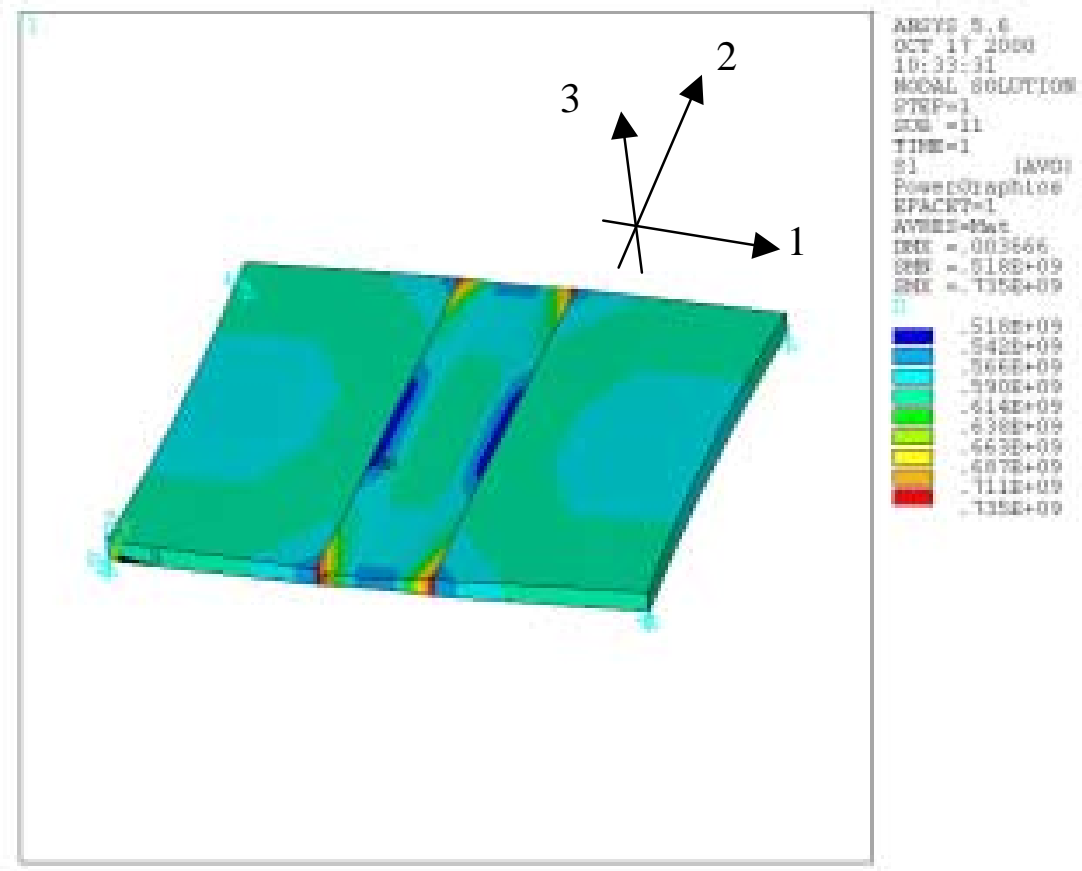

FIGURA 4.3.5 : Distribuição das tensões principais na direção 1 para um valor genérico de $\alpha$. 
FIGURA 4.3.6 : Estricção na chapa para um valor genérico de $\alpha$.

Conforme o algorítimo da fig. (4.2.2) obteve-se uma curva de deformações na estricção, sendo esta comparada com outras curvas encontradas na literatura :

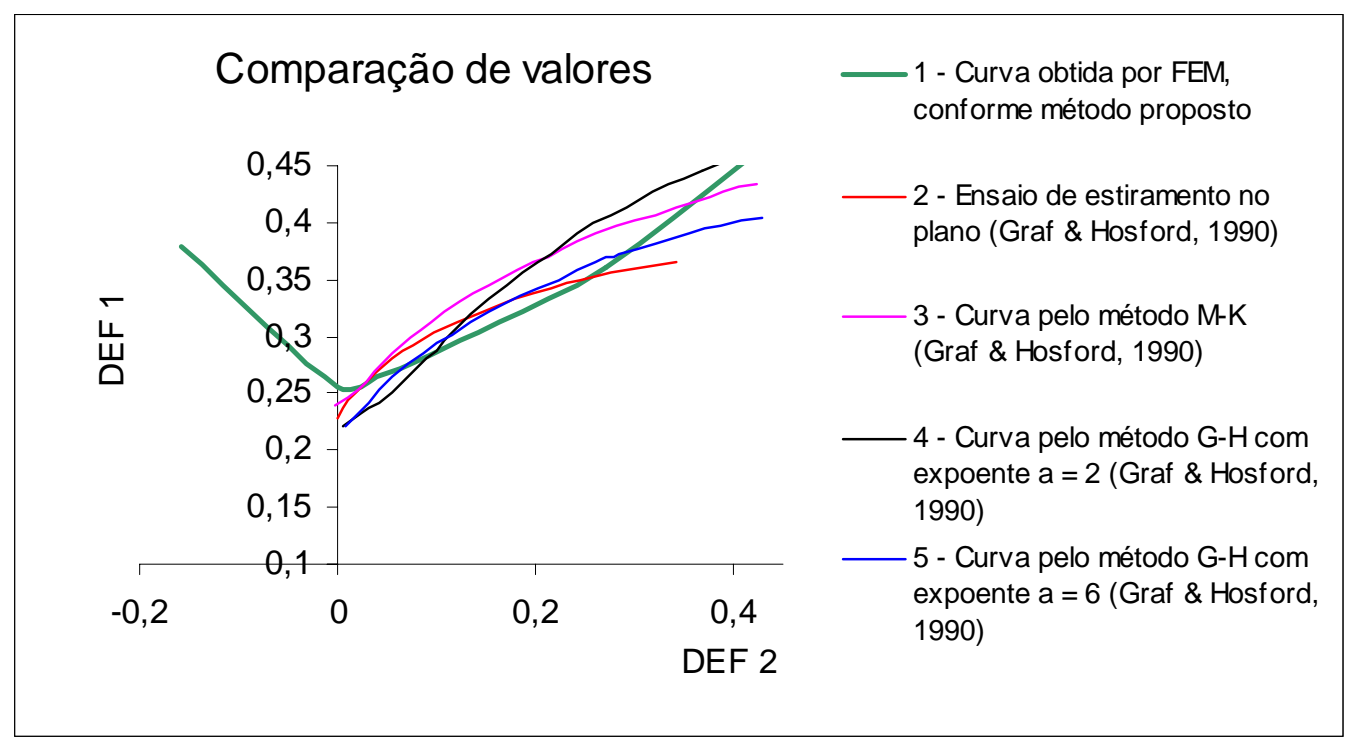

FIGURA 4.3.7 : Comparação de curvas de limite de conformação diversas ( $n=0.22$ e $m=0.012$ ).

Têm-se na fig. (4.3.7) algumas curvas para uma primeira comparação, sendo todas com os mesmos parâmetros $n=0.22$ e $m=0.012$. Discutem-se os aspectos referentes ao lado direito do gráfico, enquanto que para o lado esquerdo consideramse os resultados satisfatórios, conforme o que foi apresentado no tópico 3.5.5 sobre a condição para a estricção local.

A curva 1 foi obtida através do método proposto, sendo construída para todos os valores de $\alpha$ utilizados e com o parâmetro $f_{0}=0.905$. As curvas 2,3,4 e 5 foram extraídas de GRAF \& HOSFORD (1990). A curva 2 foi obtida a partir do ensaio de estiramento plano e torna-se uma referência para estas comparações. A curva 3 foi construída conforme o método $M K$ apresentado. As curvas 4 e 5 foram obtidas pelo método descrito como $G H$, pela utilização das expressões (2.3.29) com expoente $a=$ 
2 e (2.3.31) com expoente $a=6$, respectivamente. Nestes dois casos o valor empregou-se $r=1.5$ e $f_{0}=0.994$.

Pela figura tem-se que a curva 1 prediz satisfatoriamente o comportamento real do material definido pela curva 2 . Isto porque a curva 1 não superestima os limites reais como o fazem as curvas 3,4 e 5 na maior parte do trecho em análise, devido principalmente à sua concavidade invertida em relação às demais curvas. Esta concavidade invertida pode merecer novos estudos, uma vez que cabem refinamentos posteriores ao algorítimo apresentado.

Por este gráfico nada se conclui a respeito da relação entre o valor $f_{0}$, fator do defeito, utilizado para a curva $1\left(f_{0}=0.905\right)$ e o valor $f$ utilizados para as curvas $4 \mathrm{e}$ $5\left(f_{0}=0.994\right)$. Entretanto, a utilização de $f_{0}=0.905$ nos cálculos da curva 1 foi necessária para o ajuste adequado dos pontos próximos às curvas de comparação $2,3,4$ e 5 .

A questão dos expoentes 2 e 6 das curvas 4 e 5 respectivamente é descrita a seguir. Autores como GHOSH (1975) apud GRAF \& HOSFORD (1990) confirmam através de observações experimentais que a curva limite não é influenciada pelos valores $r$ de anisotropia . Porém, os cálculos obtidos para o caso de trações biaxiais superestimam as deformações no limite quando se utiliza o critério de escoamento de von Mises $(a=2)$. Para contornar este fato, ZHAO et al. (1996) bem como GRAF \& HOSFORD (1990) utilizam o expoente $a=6$ e obtem melhores aproximações para curvas reais. Na literatura encontram-se questões mais amplas acerca do formato da superfície de escoamento do material, porém a análise por elementos finitos aqui obtida pode ser considerada satisfatória em relação à curva 2 e pelo fato de não se considerar o comportamento anisotrópico do material.

Algumas curvas foram calculadas, baseado na tab. (4.2.1): 


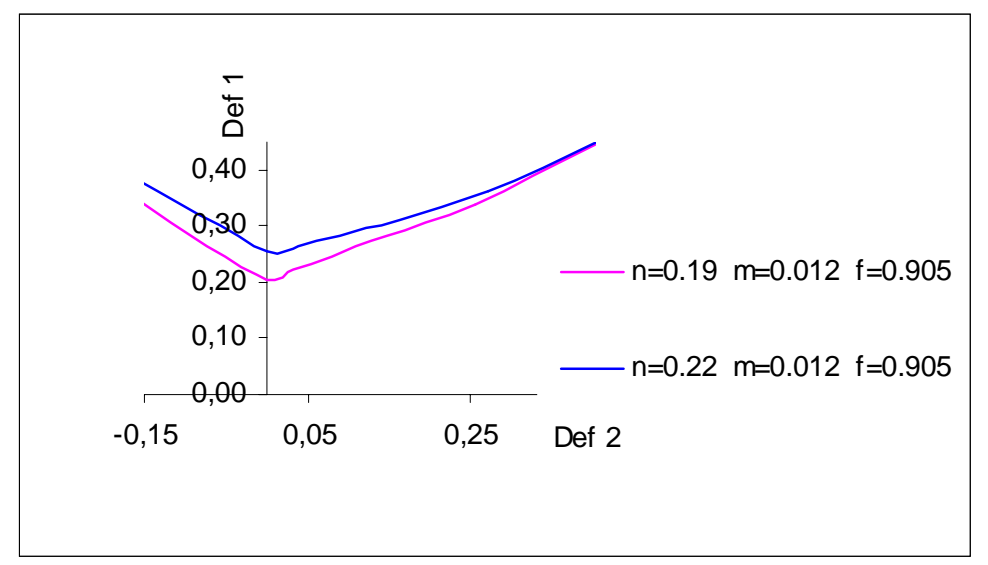

FIGURA 4.3.8 : Influência do parâmetro $n$ nas curvas limite, para $m=0.012$.

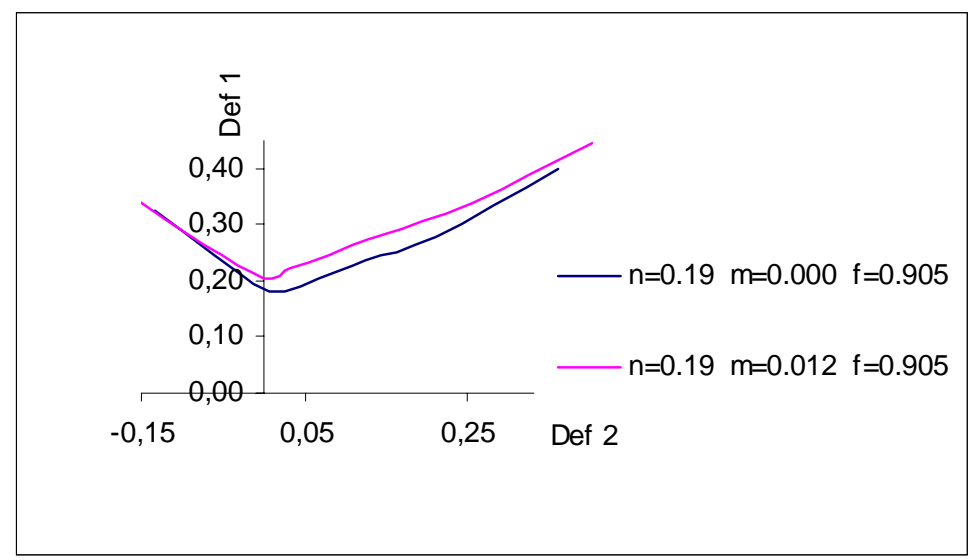

FIGURA 4.3.9 : Influência do parâmetro $m$ nas curvas limite, para $n=0.19$.

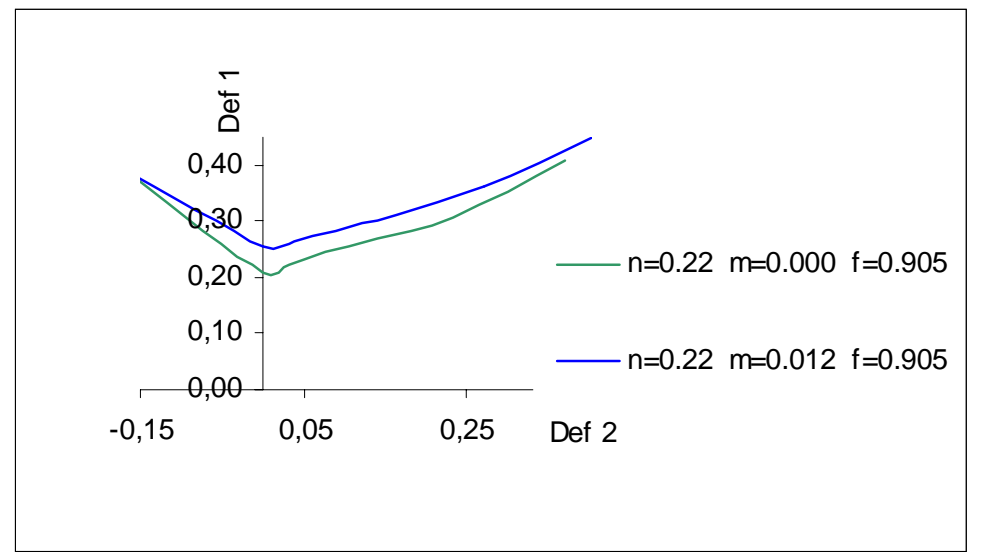

FIGURA 4.3.10 : Influência do parâmetro $m$ nas curvas limite, para $n=0.22$.

$\mathrm{Na}$ fig. (4.3.8) o aumento do expoente de encruamento $n$, de 0.19 para 0.22 , contribuiu para a elevação da curva limite no diagrama, mantido constante o parâmetro de sensibilidade à taxa de deformação, $m=0.012$. 
Na fig. (4.3.9) o aumento do parâmetro $m$, de 0.000 para 0.012, também contribuiu para o aumento dos valores da curva limite, mantido constante o expoente $n=0.19$. O mesmo raciocínio é empregado na fig. (4.3.10) para a mesma modificação no valor $m$, quando se mantém constante $n=0.22$.

Ratificando os estudos de autores como MARCINIAK \& DUNCAN (1992) bem como GRAF \& HOSFORD (1990), as observações nas figs. (4.3.8), (4.3.9) e (4.3.10) confirmam que em geral o aumento dos parâmetros $n$ e $m$ contribuem para um aumento nos valores de início da estricção pré-estabelecida .

Pelo exposto, considera-se o método empregado satisfatório conforme as condições iniciais a que se propôs. Porém, citam-se outros aspectos que podem ser considerados em novos trabalhos como por exemplo as influências de espessura da chapa, de taxa de deformação, do encruamento inicial e tratamentos mecânicos adicionais como através outros estágios de conformação além de outras considerações para a anisotropia e para o próprio fator de defeito , $f_{0}$.

Assim escolhe-se uma curva entre aquelas obtidas para um estudo conjunto com a estampagem a ser descrita no próximo capítulo. Com propriedades representativas de aços de estampagem usuais, similares a ABNT 1008/1010, a curva com os parâmetros $n=0.19$ e $m=0.012$ será utilizada no próximo estudo.

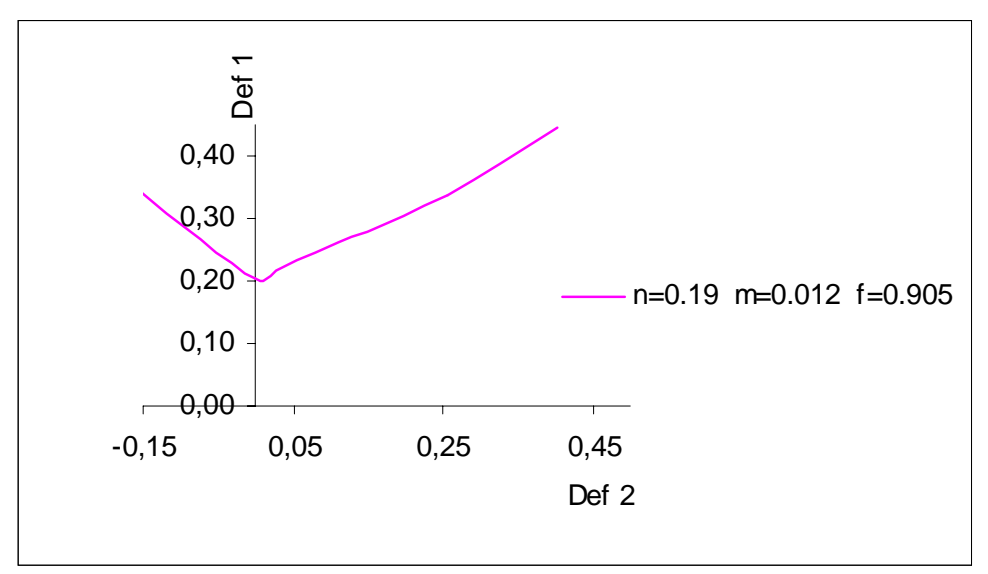

FIGURA 4.3.11 : Diagrama de limite de conformação para o estudo conjunto com estampagem .

Por outro lado pode-se obter as conversão dos valores finais de deformação no limite de estricção para tensões de limite de estricção. Os resultados obtidos são 
mostrados na fig. (4.3.12), em que as curvas são convencionadas conforme a tab. (4.2.1) .

Observa-se que os diversos pontos determinados anteriormente têm seus valores de tensões principais aproximadamente posicionados sobre uma reta com equação ajustada dada no diagrama de tensões e com coeficiente de correlação próximo da unidade. Ou seja, enquanto as deformações de estricção variam de caso a caso, conforme as propriedades de material, as tensões de estricção têm variação relativa muito baixa, para os mesmos casos considerados. Isto é confirmado em STOUGHTON (2000) e em ARRIEUX et al. (1982) apud ARRIEUX et al. (1996), embora o primeiro autor tenha trabalhado com fórmulas de conversão aplicadas às deformações de estricção verificadas experimentalmente.

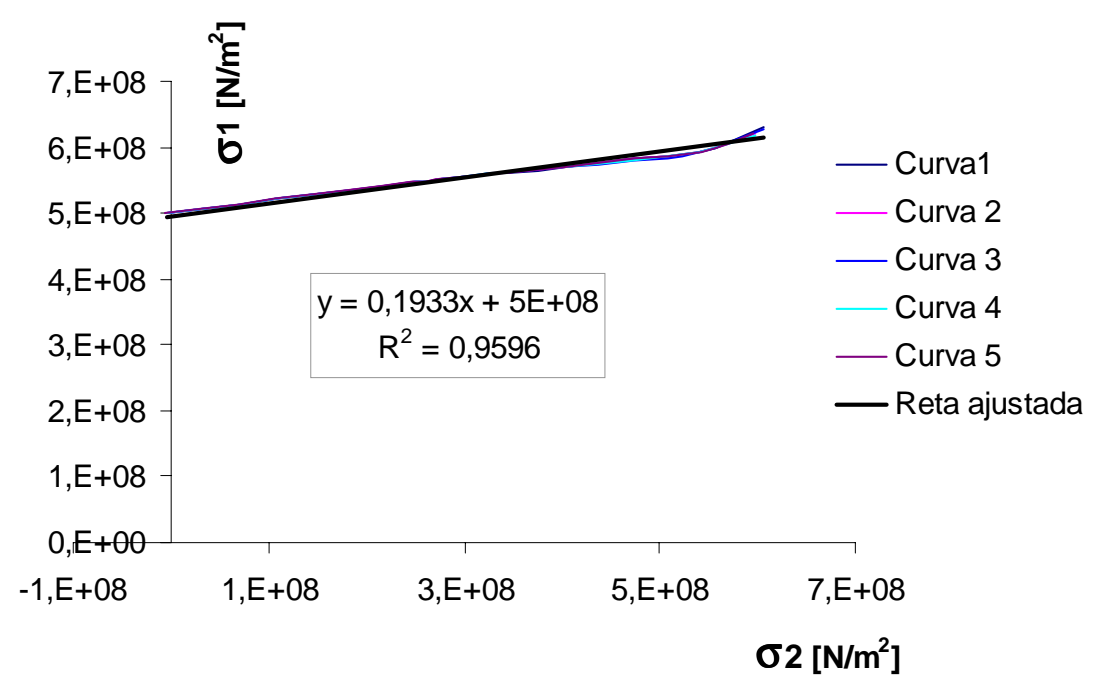

FIGURA 4.3.12 : Diagrama de limite de tensões de conformação 


\section{Análise de estampagem por diagramas de limite de conformação}

\subsection{Metodologia proposta}

Estabeleceu-se uma metodologia para trabalho cujo objetivo principal é de definir alguns procedimentos para o projeto ou para a reforma de estampos de repuxo existentes . Estes procedimentos são orientados para a avaliação e/ou a otimização de estampagem através dos diagramas de limite de conformação obtidos anteriormente. Tem-se esquematizado na fig. (5.1.1) a metodologia proposta, adaptada a partir da fig. (2.4.1), sendo descrita a seguir.

I - Obtenção do diagrama de limite de conformação para o material da chapa:

Baseado no capítulo 4 têm-se os procedimentos implementados para cálculo da curva limite, necessária para a utilização desta metodologia .

II - Abstração do problema de estampagem :

Esta etapa é caracterizada pelo modo com que o projetista do estampo de repuxo define seus interesses e sua estratégia de análise do problema. Nesta etapa reunem-se todas as informações disponíveis do problema real, as quais são trabalhadas para a busca de resultados finais satisfatórios no projeto ou na reforma do ferramental. Os aspectos de tempos de execução e custos finais são restrições importantes a serem obedecidas desde então.

III - Modelamento sólido e CAD :

Uma vez organizadas as informações primordiais do problema, inicia-se a fase do planejamento da ferramenta, utilizando-se o know-how acumulado e as diversas técnicas de projeto disponíveis. Feito isto, disponibilizam-se os valores 
iniciais de todas as dimensões do ferramental através da etapa de modelamento da geometria, valendo-se de conceitos tais como modelamento sólido atráves de $C A D$ (Computer Aided Design).

IV-Modelamento matemático :

Define-se nesta fase o modelo físico idealizado a partir do problema físico real, que envolve as leis matemáticas de comportamento de material (curvas de material e propriedades), o carregamento externo (força no prensa-chapas) e as condições de contorno (velocidade do punção) a serem aplicadas sobre as peças do estampo.

\section{$V$ - Método dos elementos finitos:}

A partir disto têm-se as condições para a discretização do domínio do problema e a associação do modelamento matemático e as superfícies de contato à malha obtida. Assim parte-se para a solução numérica do problema, executada conforme a descrição apresentada no tópico 2.4 . Verificam-se em um primeiro instante os resultados numéricos obtidos, de forma a estudar o refinamento da malha e a acuracidade da solução. Em relação a isto, pode-se ainda retornar às etapas anteriores para aperfeiçoamento do modelo geométrico ou do modelo matemático, se necessário.

VI-Avaliação e otimização do estampo :

Obtidos os resultados da análise numérica, inicia-se a fase de avaliação e otimização do estampo através do modelo implementado por elementos finitos. Os softwares comerciais como o ANSYS/LS DYNA possuem módulos de pósprocessamento dos resultados, sendo estes armazenados em arquivos específicos, os quais podem ser lidos em função de qualquer profundidade ou intervalo de tempo de duração da estampagem . Podem-se extrair deformações, tensões e deslocamentos nodais em qualquer substep e para qualquer nó . Com isto obtem-se gráficos tais como paths de tensões e deformações e mapa final de deformações. 
VII - Históricos ou trajetórias de deformações (paths) nodais :

São definidos como curvas com valores do par $\left(\varepsilon_{1}, \varepsilon_{2}\right)$ para um nó específico e ao longo da duração da estampagem. Analogamente pode-se obter paths de tensões $\left(\sigma_{1}, \sigma_{2}\right)$.

VIII - Mapa final de deformações e verificação da profundidade crítica de estampagem :

Superpõem-se no mesmo diagrama os paths lidos no pós-processamento e o diagrama de limite de conformação obtido conforme o exposto no capítulo 4 para a construção do mapa final de deformações. Pela observação de quais pontos dos paths estejam na curva limite deste diagrama, verificam-se quais os nós críticos e a partir de qual instante e qual profundidade ocorreu a estricção, segundo o critério utilizado.

IX-Outros gráficos :

Pode-se também analisar a variação da espessura ao longo de uma direção escolhida na chapa estampada. Este tipo de gráfico é voltado para a verificação da homogeneidade na distribuição de deformações na espessura, sendo útil para o controle direto da qualidade do processo.

X-Mudança do problema físico e variável de otimização :

Com os ítens VII, VIII e IX disponíveis, sugerem-se modificações na concepção do projeto ou no plano de reformas com a escolha da variável de otimização, através da redefinição de dimensões (geometria) ou de parâmetros físicos (modelamento matemático) . Repetem-se os procedimentos com a nova variável, sendo esta sucessivamente modificada até que os resultados esperados estejam dentro das espectativas previstas. 


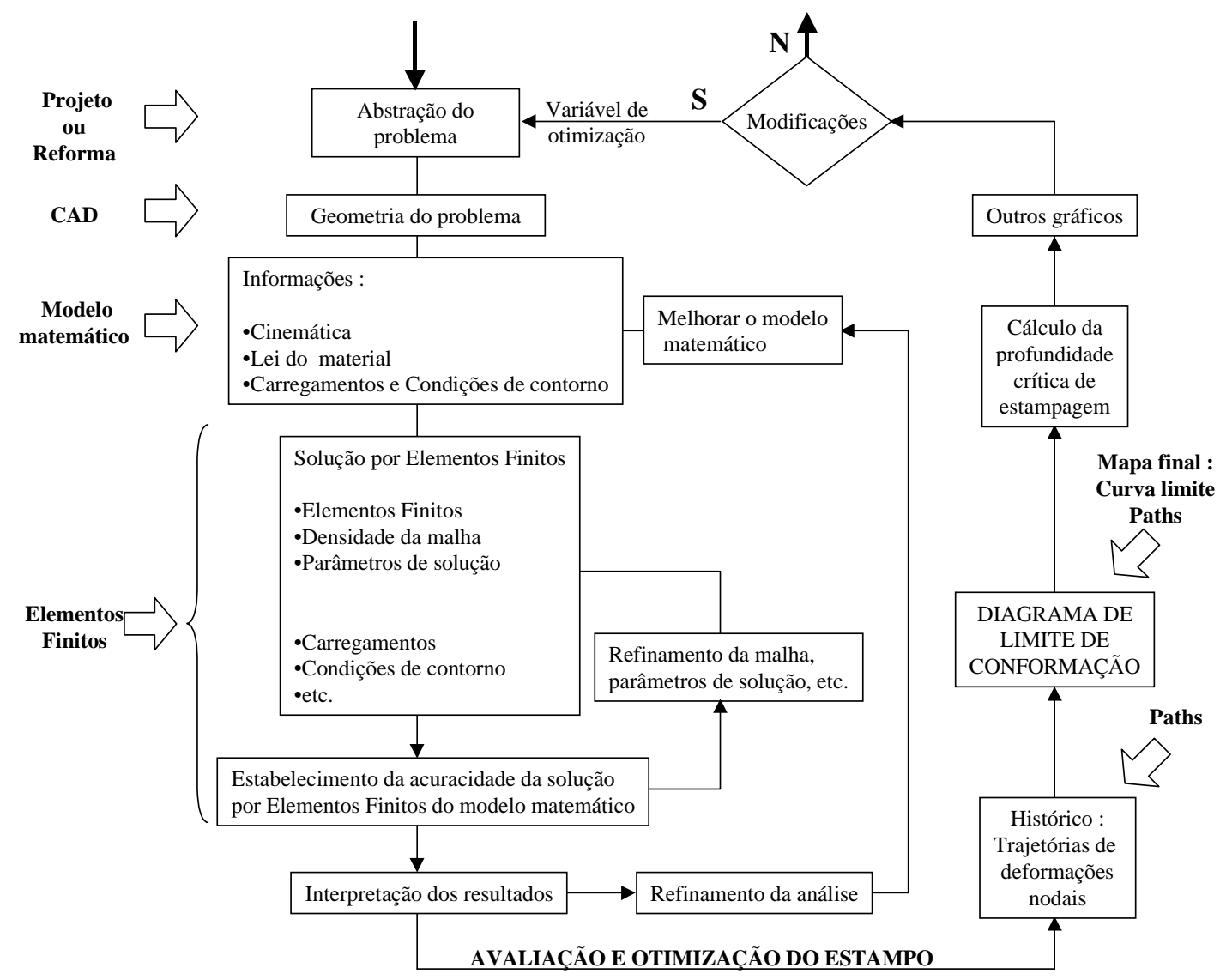

FIGURA 5.1.1 : Metodologia proposta .

Para o presente trabalho, considera-se um processo de estampagem de chapa fina de aço com propriedades mecânicas similares aos aços ABNT 1008/1010. Exige-se que o processo mecânico seja feito em um único estágio, ou seja, este estudo não se aplica a estampagens que impliquem em trocar a chapa de matriz após alguma estampagem prévia. $\mathrm{Na}$ análise completa, ressalva-se que, no que foi apresentado na fig. (2.2.1), modelam-se todas as variáveis relacionadas ao processo, com exceção da influência da temperatura, que foi desprezada.

No item 5.2 descrevem-se os aspectos relacionados à implementação de dois casos de estampagem em um software comercial de elementos finitos, segundo os ítens $I I I, I V$ e $V$ desta metodologia. No item 5.3 avaliam-se os resultados obtidos em relação ao diagrama calculado no capítulo 4. No item 5.5 listam-se algumas variáveis possíveis para otimização do estampo. 


\subsection{Análise por Elementos Finitos de problemas de estampagem}

De acordo com o que metodologia exposta no item (5.1), o problema foi dividido seguindo-se as etapas essenciais para a utilização do Método dos Elementos Finitos: etapas de modelamento de geometria, modelamento matemático e criação da malha (pré-processamento) e de solução e etapa final de pós-processamento. Nestas análises utilizou-se o software ANSYS/LS-Dyna3D, dado que o mesmo utiliza a abordagem Explícita Dinâmica, descrita anteriormente no item 2.4.5 .

\subsubsection{Pré-processamento}

\section{Construção da geometria}

As dimensões utilizadas para a análise numérica do problema de estampagem são especificadas conforme os parâmetros da fig. (5.2.1), com os seus respectivos valores definidos em casos numerados na tab. (5.2.1). A escolha destes valores baseou-se em dados similares encontrados na literatura para estampos com punção de diâmetro $50 \mathrm{~mm}$. A simplicidade da geometria bem como a utilização de $1 / 4$ do modelo contribuiu para poupar-se esforço computacional.

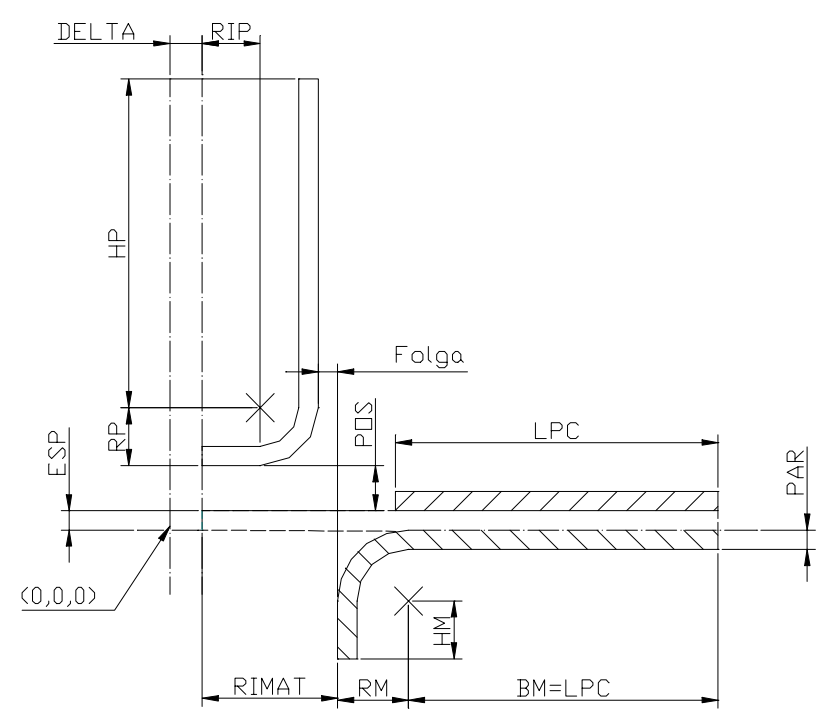

FIGURA 5.2.1-a : Cotas parametrizadas para a modelagem geométrica da estampagem. 


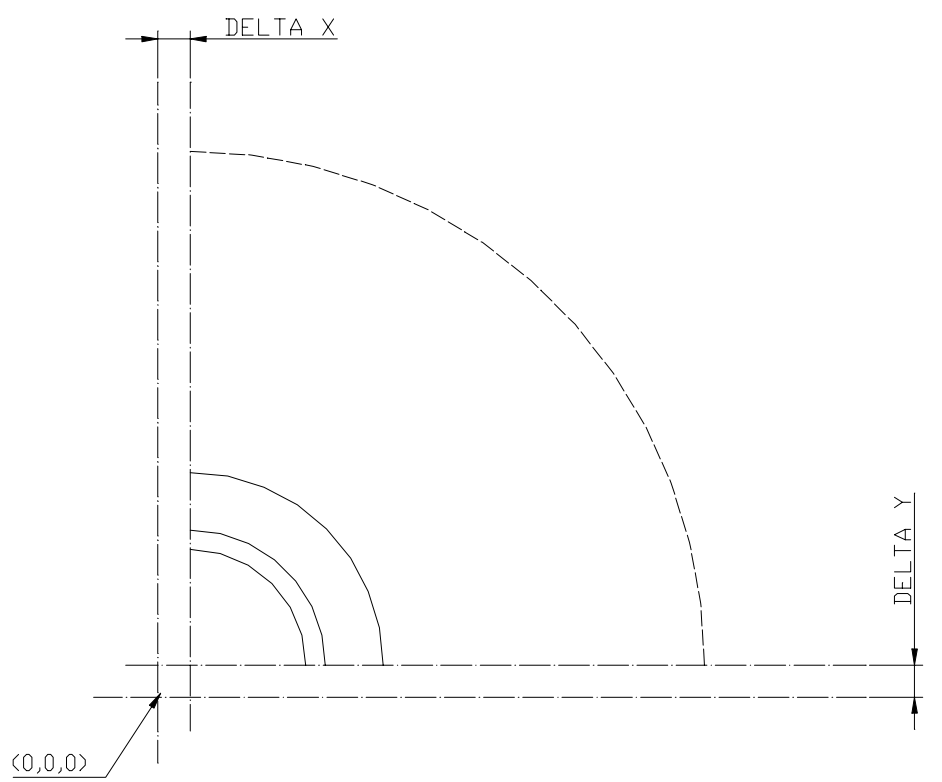

FIGURA 5.2.1-b : Cotas parametrizadas para a modelagem geométrica da estampagem.

\begin{tabular}{|c|c|c|c|}
\hline & \multirow[t]{3}{*}{\begin{tabular}{|l} 
LDR \\
\end{tabular}} & 2 & \\
\hline & & CASO 1 & CASO 2 \\
\hline & & Punção redondo & Punção quadrado \\
\hline \multirow{18}{*}{ 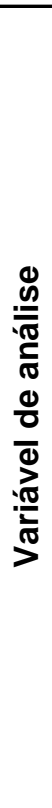 } & DELTAX & 0,0 & 15,0 \\
\hline & DELTAY & 0,0 & 15,0 \\
\hline & LRC & 50,0 & 35,0 \\
\hline & RIMAT & 26,5 & 11,5 \\
\hline & RIP & 21,0 & 6,0 \\
\hline & RIPC & 36,5 & 21,5 \\
\hline & BM & 13,5 & 13,5 \\
\hline & ESP & 1,0 & 1,0 \\
\hline & FOLGA & 1,5 & 1,5 \\
\hline & $\mathbf{H}$ & 29,0 & 29,0 \\
\hline & HM & 19,0 & 19,0 \\
\hline & HP & 25,0 & 25,0 \\
\hline & LPC & 13,5 & 13,5 \\
\hline & PAR & 2,0 & 2,0 \\
\hline & POS & 1,0 & 1,0 \\
\hline & RM & 10,0 & 10,0 \\
\hline & $\mathbf{R P}$ & 4,0 & 4,0 \\
\hline & \multicolumn{3}{|c|}{ Dimensões em mm } \\
\hline
\end{tabular}

TABELA 5.2.1 : Valores para a geometria do problema de estampagem 
Dados de materiais :

Para a chapa de aço com especificações próximas ao aço ABNT 1008/1010, usual em operações de estampagens, considerou-se a formulação de material isotrópico (expressão 2.3.19) , com lei de potência dada por (2.3.40) , $\bar{\sigma}=K \cdot \dot{\bar{\varepsilon}}^{m} \cdot(\bar{\varepsilon}+\Delta \bar{\varepsilon})^{n}$, sendo que seus parâmetros são dados por :

$K=660 \mathrm{E} 6 \mathrm{~N} / \mathrm{m}^{2} \quad$ Constante para a resistência do material

$\dot{\bar{\varepsilon}}=30.0 \quad$ Taxa média de deformação (aumentada em 100 vezes por exigência do enfoque dinâmico explícito para a redução do tempo de processamento) $m=0.012 \quad$ Expoente de sensibilidade à taxa de deformação

$n=0.19 \quad$ Expoente de encruamento

e demais parâmetros :

$E=2,1 \mathrm{E}+10 \mathrm{~N} / \mathrm{m}^{2} \quad$ Módulo de elasticidade de Young

$\rho=7850 \mathrm{Kg} / \mathrm{m}^{3} \quad$ Densidade do aço

$v=0,29 \quad$ Coeficiente de Poisson

$\mathrm{Na}$ fig. (5.2.2) observam-se as curvas para o material da chapa conforme os parâmetros $n, m$ e taxa média de deformação.

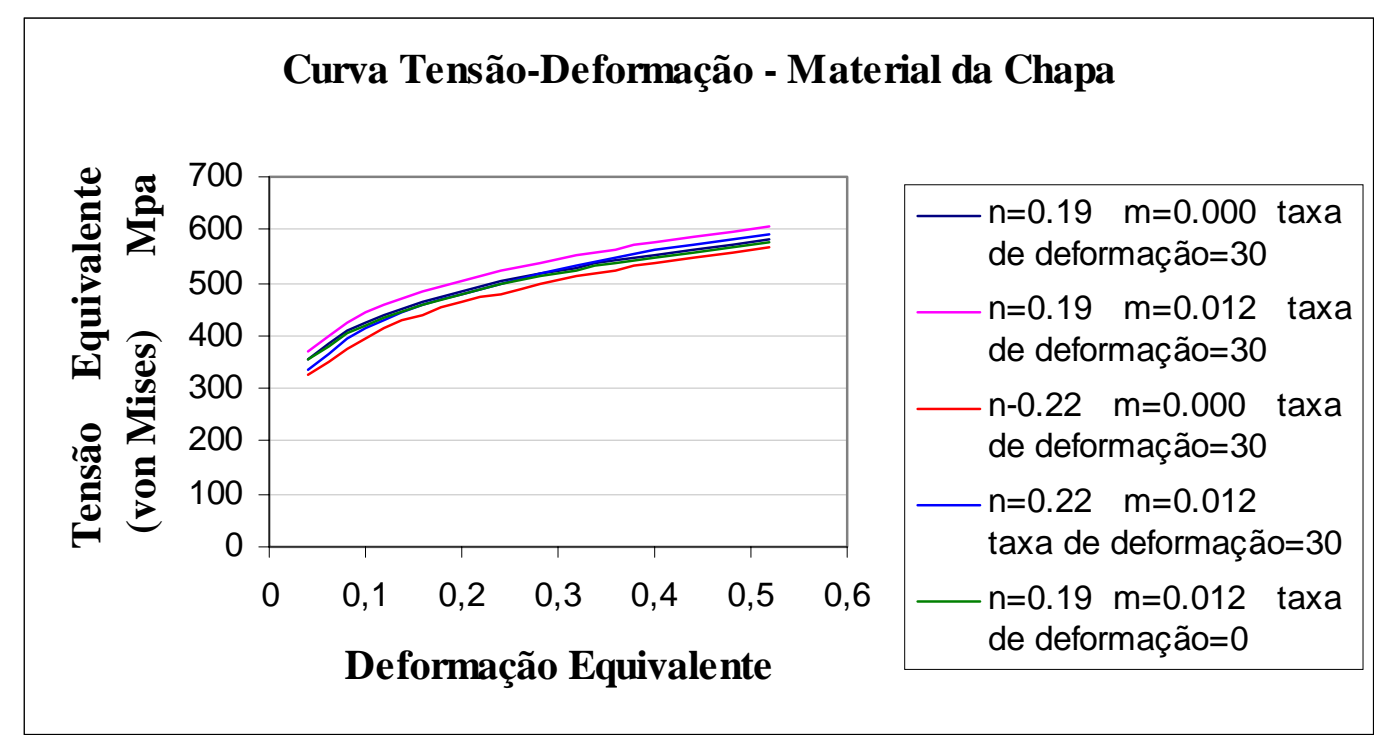

FIGURA 5.2.2 : Curvas de material 
Escolheu-se para a análise de estampagem o material com $n=0.19, m=0.012$ e taxa média de deformação = 30. Na fig. (5.2.2) observam-se os comportamentos de materiais com taxas 0 e 30, mantidas constantes as demais variáveis. Verifica-se um modificação nas tensões da ordem de $5 \%$ de um caso para o outro, devido ao fato de o parâmetro $m$ ter um valor pequeno.

O comportamento das demais peças (matriz, prensa-chapas e punção) foi adotado como rígido e portanto são avaliadas somente as propriedades mecânicas da chapa no decorrer da estampagem.

\section{Geração da malha}

Foram definidos 2 tipos de elementos para a construção da malha, sendo dados a seguir :

- Elemento Thin Shell-163, para a malha da chapa

- Elemento Solid-164, para a malha das demais peças

$\mathrm{Na}$ tab. (5.2.2) tem-se a quantidade de elementos usados na modelagem conforme os casos estudados :

\begin{tabular}{|l|l|r|r|}
\hline & \multicolumn{1}{|c|}{ CASO 1 } & \multicolumn{1}{|c|}{ CASO 2 } \\
\hline Peça & Tipo de Elemento & \\
\hline CHAPA & Shell 163 & $\mathbf{7 3 6}$ & $\mathbf{5 3 1}$ \\
\hline MATRIZ & Solid 164 & 432 & 486 \\
PRENSA-CHAPAS & Solid 164 & 112 & 126 \\
PUNÇÃO & Solid 164 & 384 & 369 \\
\hline \multicolumn{2}{|l|}{ Total } & 1664 & 1512 \\
\cline { 2 - 4 }
\end{tabular}

TABELA 5.2.2 : Distribuição dos tipos de elementos na modelagem

Nas figs. (5.2.3) e (5.2.4) têm-se as configurações da malha das peças, dadas conforme a distribuição da tab. (5.2.2) para o caso 1 . 
a)

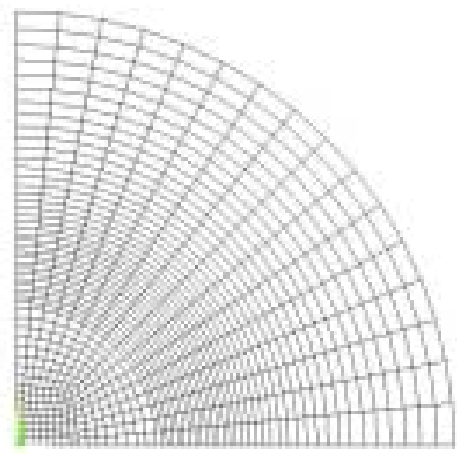

b)

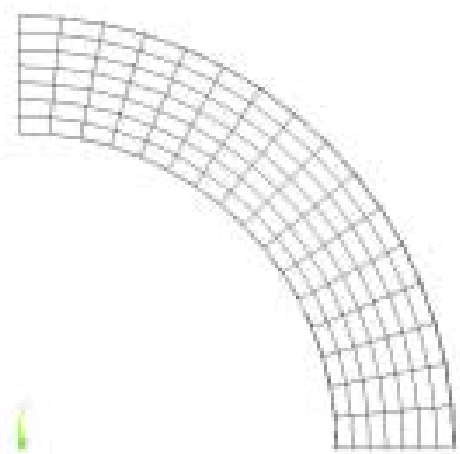

FIGURA (5.2.3) : Malhas

a) Chapa ; b) Prensa-chapas

a)

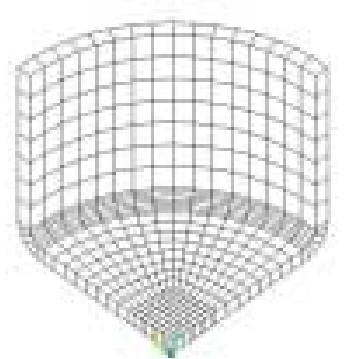

FIGURA (5.2.4) : Malhas (vista em perspectiva)

a) Punção ; b) Matriz

A configuração final do conjunto de peças do caso 1 é vista na fig. (5.2.5) :

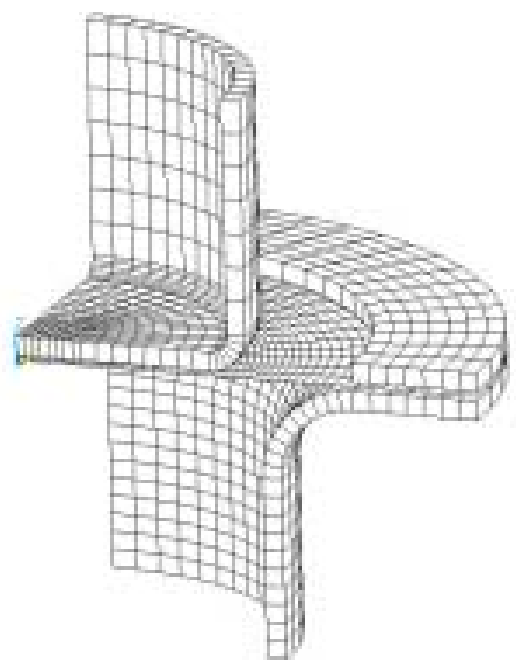

FIGURA (5.2.5) : Malhas para o conjunto das peças consideradas no caso 1.

Nas figs. (5.2.6) e (5.2.7) têm-se as configurações da malha das peças, dadas conforme a distribuição da tab. (5.2.2) para o caso 2 . 
a)

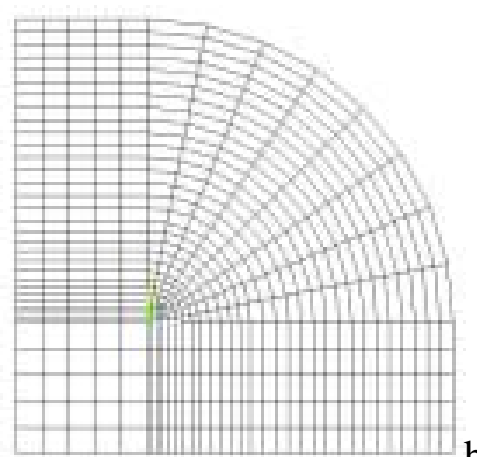

b)

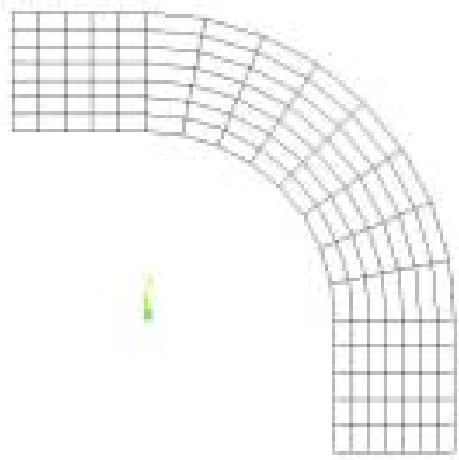

FIGURA (5.2.6) : Malhas

a) Chapa ; b) Prensa-chapas

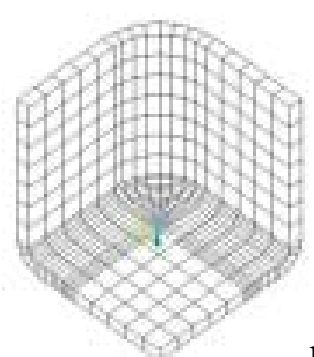

b)

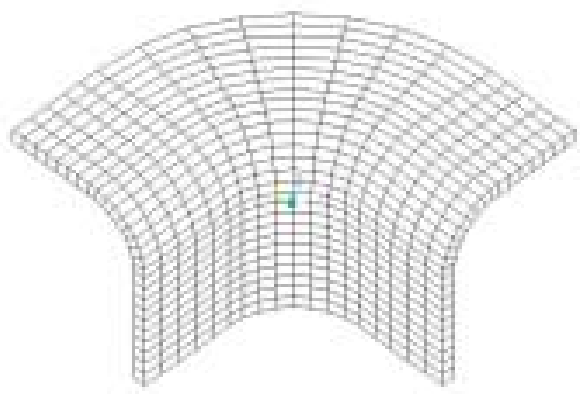

FIGURA (5.2.7) : Malhas (vista em perspectiva)

a) Punção ; b) Matriz

A configuração final do conjunto de peças do caso 2 é vista na fig. (5.2.8) :

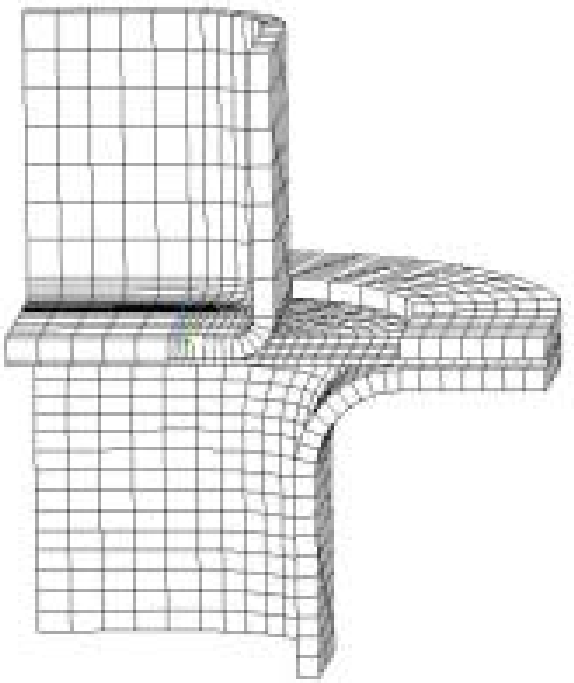

FIGURA (5.2.8) : Malhas para o conjunto das peças consideradas no caso 2. 


\section{Condições de contato entre as peças}

Uma vez gerado o modelo e a malha, é necessária a criação de componentes formados por nós para a definição das regiões em que ocorre contato entre os sólidos. Para tal foram criados os componentes para descrever as superfícies do punção, do prensa chapas, da matriz e das superfícies superior e inferior da chapa.

Segundo AGELET DE SARACIBAR e OÑATE (1991), a definição de contato deve ser feita definindo-se dois componentes, designados por master (principal) e slave (associado). Desta maneira, impõe-se que nenhum nó da superfície associada penetre a superfície principal. Deve-se notar que são permitidas penetrações dos nós da superfície principal na superfície associada. Uma mesma superfície pode pertencer a mais de um par de superfícies em contato, podendo também ser definida alternativamente como principal ou associada. Assim na modelagem do problema aqui tratado, os contatos foram duplicados, com as superfícies alternando o papel de principal e associada. A opção de contato utilizada no ANSYS/LS-Dyna3D foi automatic surface-to-surface contact, onde foram definidos os componentes que podem vir a entrar em contato. O programa, durante a simulação, faz a verificação e se necessário impõe as condições de contato. Assim, segundo HALLQUIST (1993), cada nó da superfície associada é verificado em relação à penetração na superfície principal. Se o nó associado não tiver penetrado a superfície principal, nada é feito. Caso contrário, é aplicada uma força entre o nó associado e seu ponto de contato, de magnitude proporcional ao valor da penetração.

Nas interfaces punção/chapa, prensa-chapas/chapa e chapa/matriz, foi assumido um valor constante de atrito de Coulomb , sendo o atrito estático $\mu_{\mathrm{e}}=0,1 \mathrm{e}$ atrito dinâmico $\mu_{\mathrm{d}}=0,04$.

\section{Ccondições de contorno}

Uma vez feita a modelagem de um quarto do problema, é necessária a aplicação de condições de contorno que traduzam a simetria do modelo.

Na modelagem da matriz, punção e prensa-chapas a opção de defini-los como corpos rígidos permite travar os graus de liberdade desejados, de modo que na matriz 
foram travados todos os graus de liberdade e no punção e prensa-chapas foi liberado apenas o deslocamento em $z$ (direção da profundidade de estampagem).

A chapa não pode ser considerada como corpo rígido, de modo que as restrições devem ser aplicadas a nós selecionados. Aos nós com coordenada $y=0$ foram travados os deslocamentos na direção $x$ e rotações em torno de $y$ e $z$. Aos nós com coordenada $x=0$ foram travados os deslocamentos na direção $y$ e rotações em torno de $x$ e $z$. Estas condições são mostradas nas figs. (5.2.9) para o caso 1 e (5.2.10) para o caso 2 . Desta maneira, estão consideradas as condições de simetria do modelo.
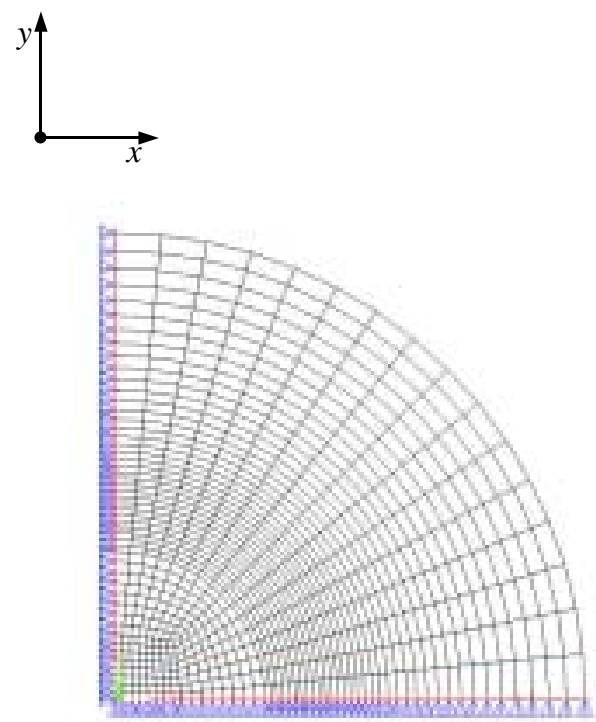

a)

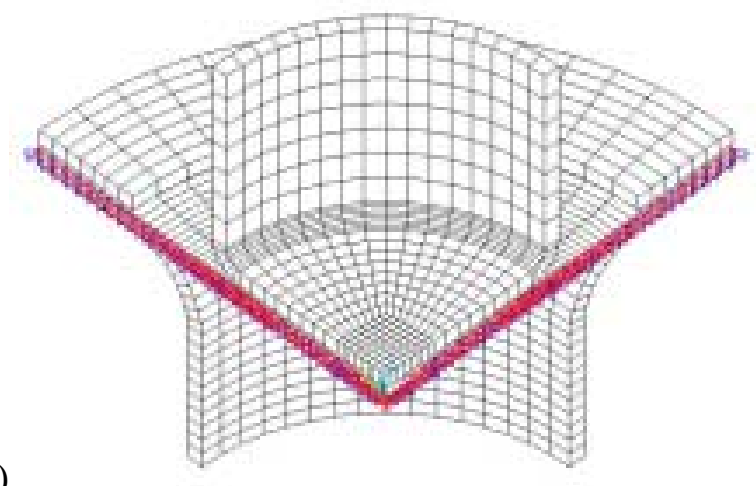

FIGURA 5.2.9 : Condições de contorno impostas à chapa, Caso 1: (a) Restrições de deslocamento (em azul) e rotação (em vermelho). (b) Vista do modelo completo com as condições de contorno aplicadas à chapa 
a)

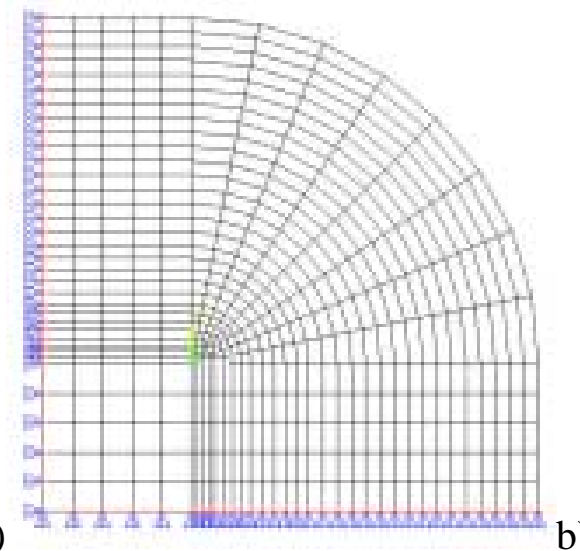

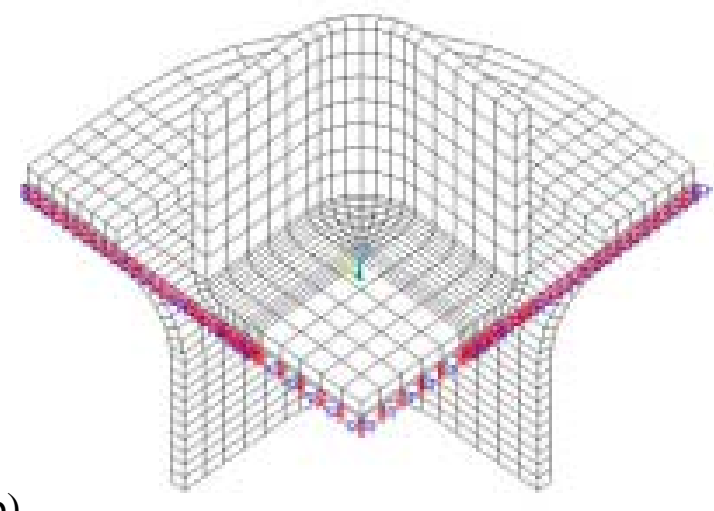

b)

FIGURA 5.2.10 : Condições de contorno impostas à chapa, Caso 2: (a) Restrições de deslocamento (em azul) e rotação (em vermelho). (b) Vista do modelo completo com as condições de contorno aplicadas à chapa

\section{Condições iniciais}

Como condição inicial foi aplicada uma velocidade inicial ao punção. Ao longo do experimento realizado por MAMALIS et al. (1996), a velocidade do punção foi constante com valor de $17 \mathrm{~mm} / \mathrm{s}$. No intuito de poupar-se esforço computacional, é comum neste tipo de análise utilizarem-se de velocidades até cem vezes maiores que a velocidade real [MAKINOUCHI (1996)]. Nos ensaios aqui apresentados foi utilizada uma velocidade inicial de $1.7 \mathrm{~m} / \mathrm{s}$ para o punção, mesmo valor utilizado por MAMALIS et al. (1996).

\section{Carregamentos}

A força no prensa-chapas foi considerada constante ao longo do processo com valor dado por (MARCINIAK \& DUNCAN, 1992) :

$$
\begin{aligned}
& \mathrm{B}=\lambda \cdot \sigma_{\mathrm{f}} \cdot \pi \cdot \mathrm{r}_{1}^{2} \cdot\left[\left(\mathrm{r}_{2} / \mathrm{r}_{1}\right)^{2}-1\right] \\
& 0.01<\lambda<0.02
\end{aligned}
$$

com 
$B=$ Força total aplicada pelo prensa-chapas [ N ]

$\lambda=$ Parâmetro para estimativa

$\sigma_{f}=$ Tensão de escoamento do material [ $\left.\mathrm{N} / \mathrm{m}^{2}\right]$

$r_{l}=$ Raio do punção $\left(r_{l}=R I P+R P\right.$, conforme a tab. 5.2.1)

$r_{2}=$ Raio externo da chapa $\left(r_{2}=L R C\right.$, conforme a tab. 5.2.1)

Com os dados disponíveis e utilizando-se $\lambda=0.02$, tem-se que $B=26 \mathrm{KN}$.

\subsubsection{Solução}

O tempo de $C P U$ para os casos estudados foi de aproximadamente 3 horas segundo todas as condições dadas . Em função destas condições, o time step médio para os cálculos foi da ordem de 1.0E-07 segundos.

A metodologia proposta foi obtida através de soluções por Elementos Finitos realizadas no laboratório CAD/CAE, Depto. de Engenharia Mecânica, Escola de Engenharia de São Carlos, sendo utilizada a infra-estrutura relacionada a seguir:

\section{Hardware}

- Workstations IBM Risk 6000

- Servidor IBM Netfinity 3000, 128Mb de memória RAM, processador Pentium II 400MHz e 4,0Gb de disco rígido.

- Microcomputador 32MB de memória RAM, processador Pentium I $133 \mathrm{MHz}$ e $8.0 \mathrm{~Gb}$ de disco rígido.

Software

-CAE (Computer Aided Engineer)

- Plataforma UNIX / AIX ANSYS/LS-Dyna3D

- Plataforma UNIX / AIX ANSYS High Option 


\subsubsection{Pós-processamento}

Os dados numéricos dos casos analisados foram armazenados para a verificação junto aos diagramas de limite de conformação. Para cada caso foram salvos 99 passos (substeps) de solução, de modo a permitir o monitoramento do histórico do processo como um todo. Feito isto, obtem-se gráficos com resultados de tensões e deformações em nós ou em elementos para qualquer passo intermediário da solução.

Apresentam-se abaixo os resultados gráficos para os casos estudados, com os valores especificados no último passo da solução.

\section{Caso 1:}

Nas figs. (5.2.11), (5.2.12), (5.2.13) têm-se as deformações principais na direção 1 (radial), direção 2 (circunferencial) e deformações efetivas, respectivamente, no passo 99, com profundidade máxima de 21,30 $\mathrm{mm}$.

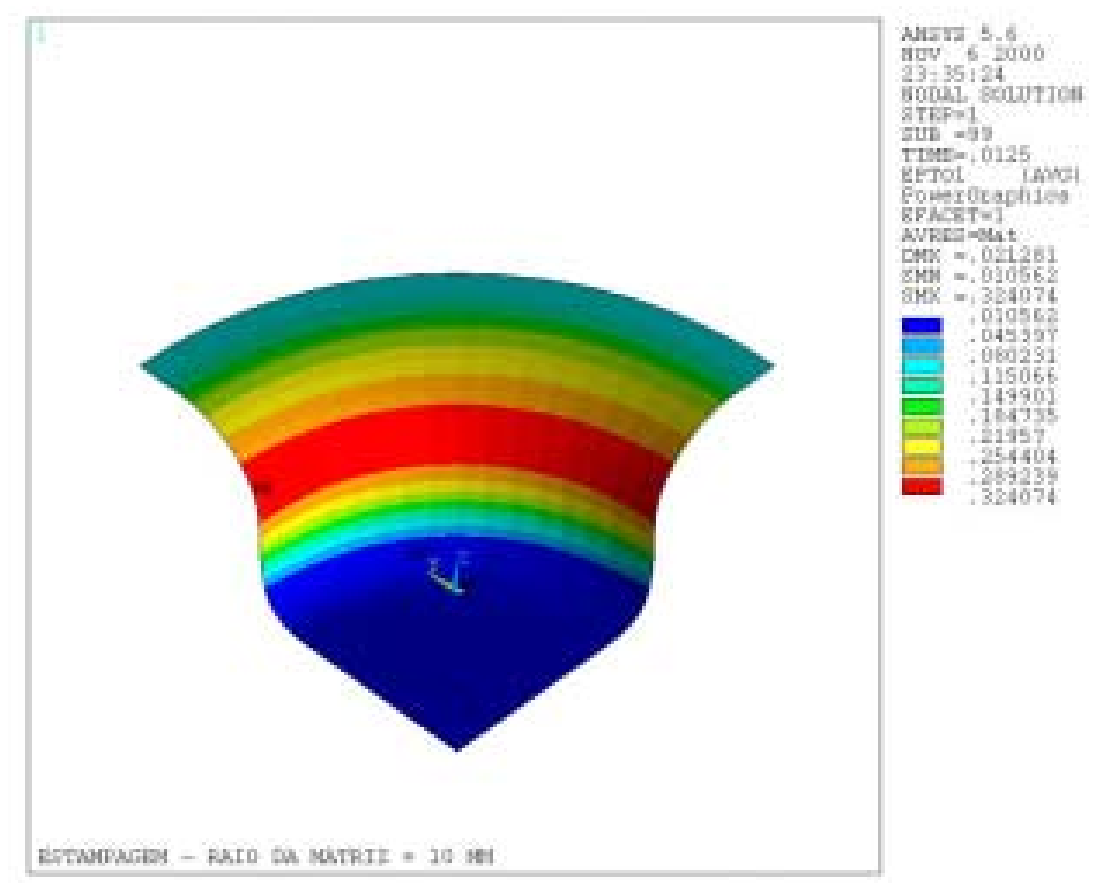

FIGURA 5.2.11 : Deformações totais na direção principal 1 (radial) 


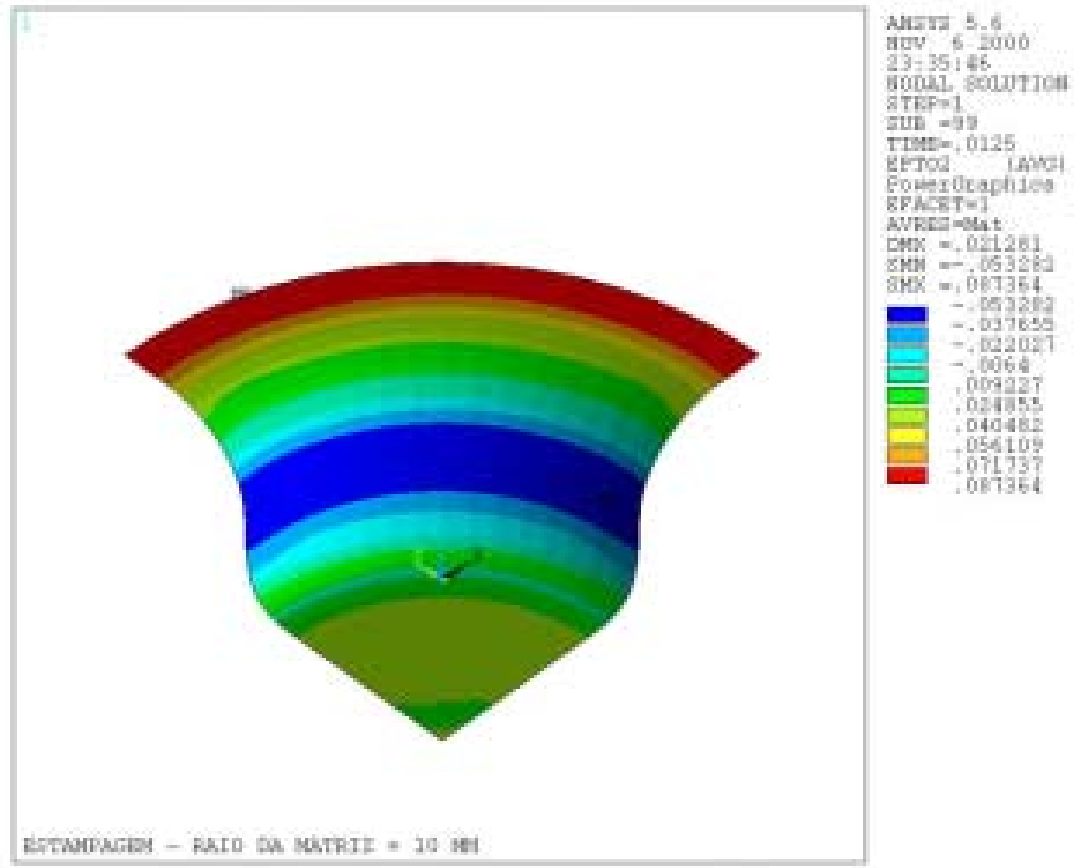

FIGURA 5.2.12 : Deformações totais na direção principal 2 (circunferencial)

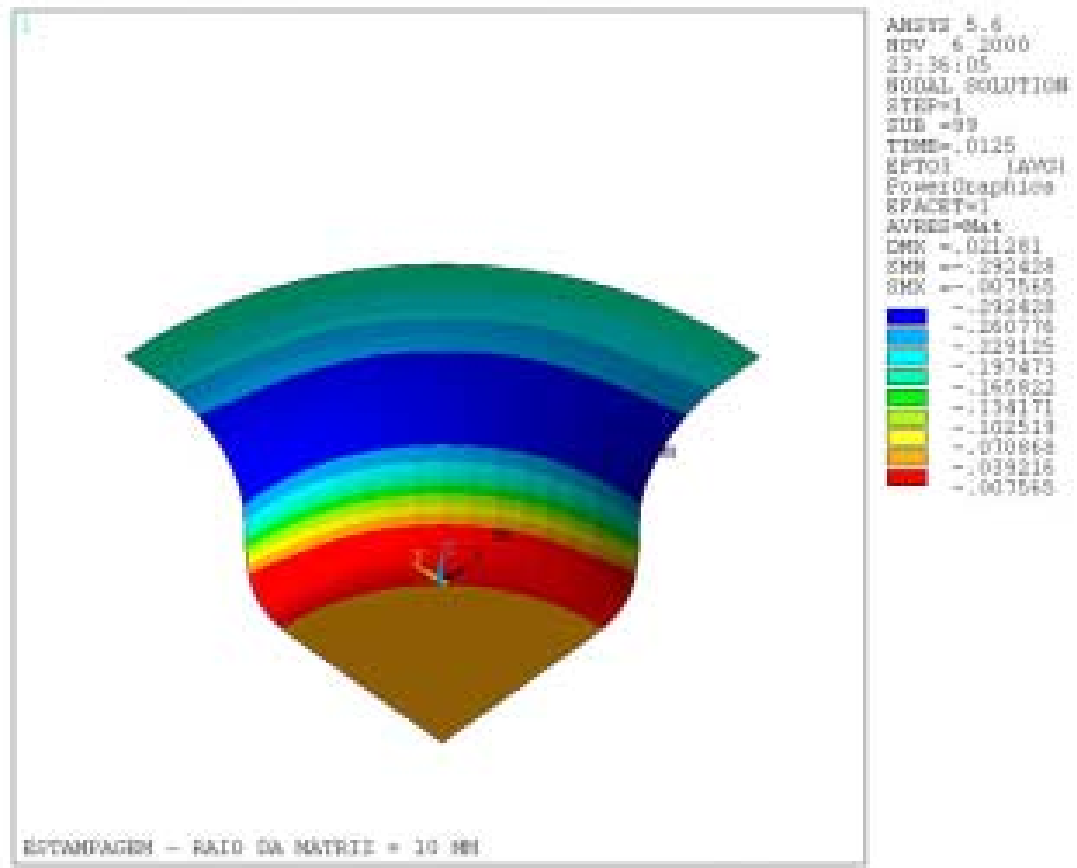

FIGURA 5.2.13 : Deformações totais efetivas . 
Caso 2 :

Nas figs. (5.2.14), (5.2.15), (5.2.16) têm-se as deformações principais na direção 1 , direção 2 e deformações efetivas, respectivamente, no passo 99, com profundidade máxima de 21,30 mm . Neste caso, as direções 1 e 2 são similares ao Caso 1.

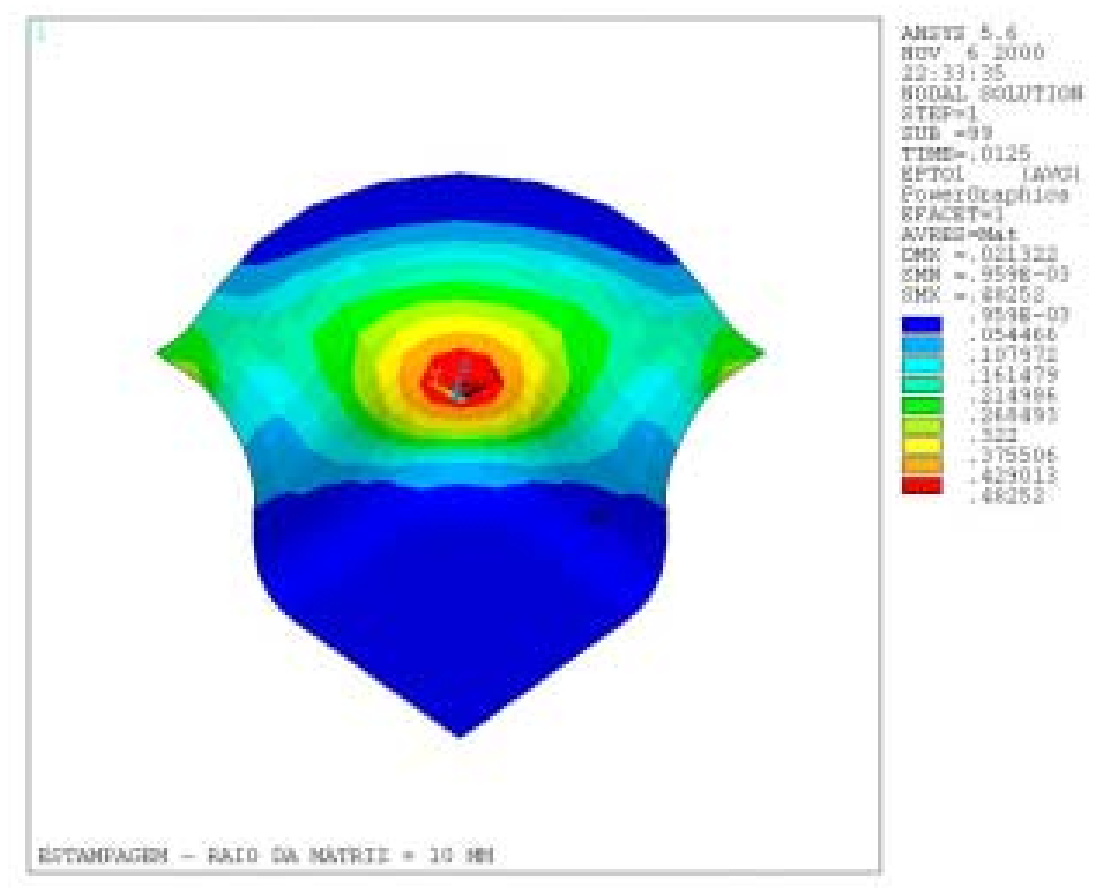

FIGURA 5.2.14 : Deformações totais na direção principal 1 .

Devido à geometria dos problemas tem-se que no caso 2 as deformações encontram-se concentradas no canto arredondado da peça, enquanto que no caso 1 houve uma distribuição axisimétrica das grandezas avaliadas (deformação principal 1 e deformação efetiva). Este fato relaciona-se às dificuldades de escoamento do material através de regiões com formatos mais complexos . 


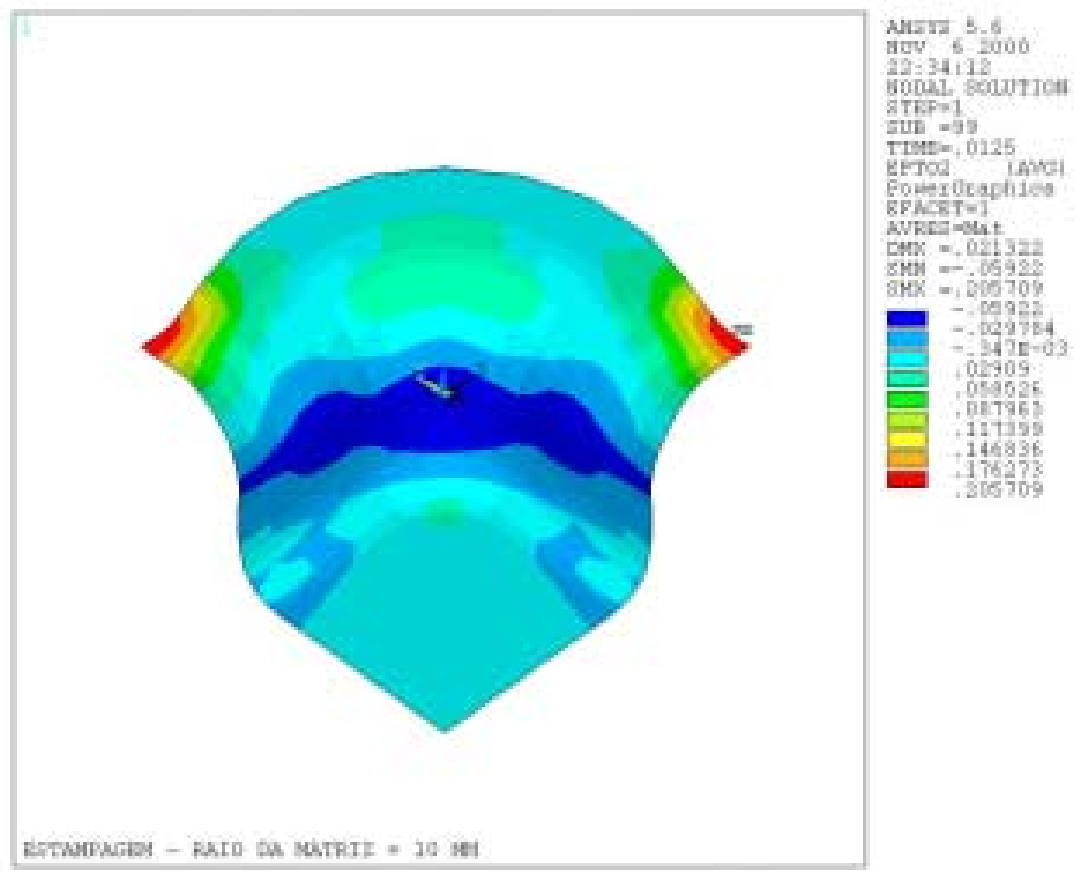

FIGURA 5.2.15 : Deformações totais na direção principal 2 .

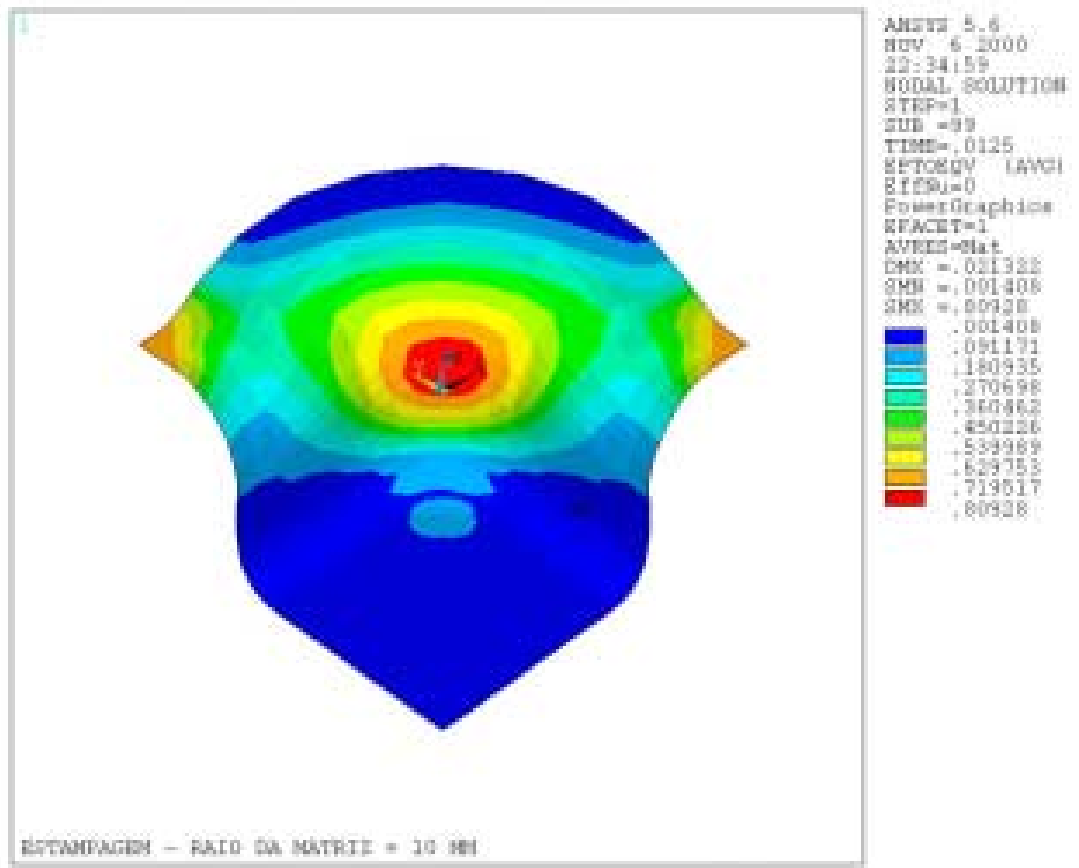

FIGURA 5.2.16 : Deformações totais efetivas . 


\subsection{Avaliação dos casos de estampagem em relação aos diagramas de limite de conformação obtidos}

\subsubsection{Avaliação do caso 1}

Para a análise, foram escolhidos alguns nós da malha construída na chapa, conforme a numeração do software na fig. (5.3.1) .

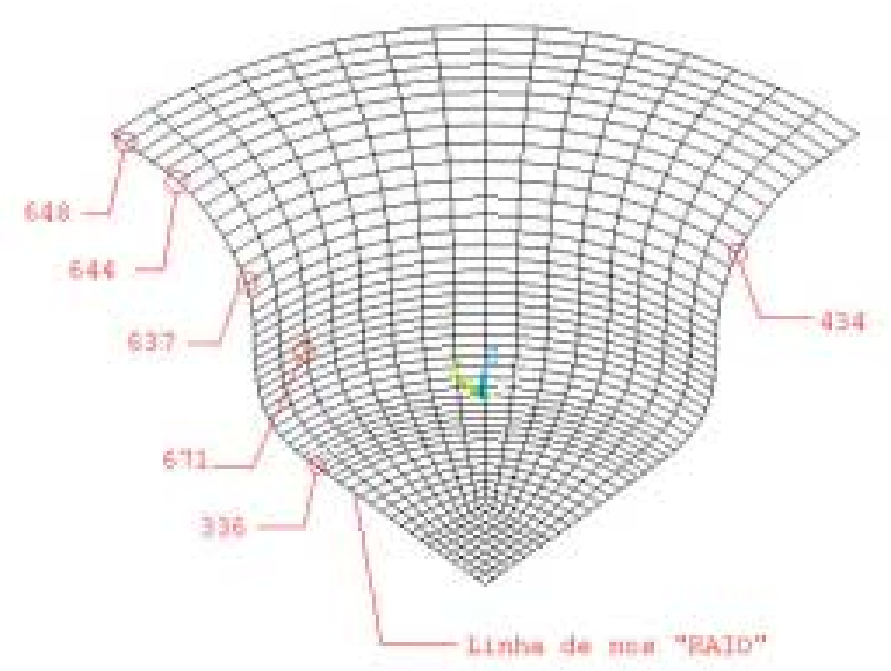

FIGURA 5.3.1 : Numeração de nós para análise do caso 1 .

Nesta figura determinou-se uma linha com direção radial denominada "RAIO”, junto à qual estão os nós escolhidos, com exceção do nó 434 . Para todos os nós desta linha foram obtidos os conjuntos de valores $\left(\varepsilon_{1}, \varepsilon_{2}\right)$ no último passo da solução . Na figura (5.3.2) tem-se o diagrama de limite de conformação escolhido no capítulo 4 comparado a estes valores, especificados como "pontos finais" na legenda. Para os nós escolhidos foram desenhados no mesmo diagrama os conjuntos de valores $\left(\varepsilon_{1}, \varepsilon_{2}\right)$ para estes nós e em todos os passos de solução . As linhas obtidas, definidas como trajetórias de deformações (paths), representam o andamento do processo no plano das deformações principais 1 e 2 . Para o início de estricção, no enfoque deste trabalho, limitam-se os paths na região de segurança abaixo da curva limite. 


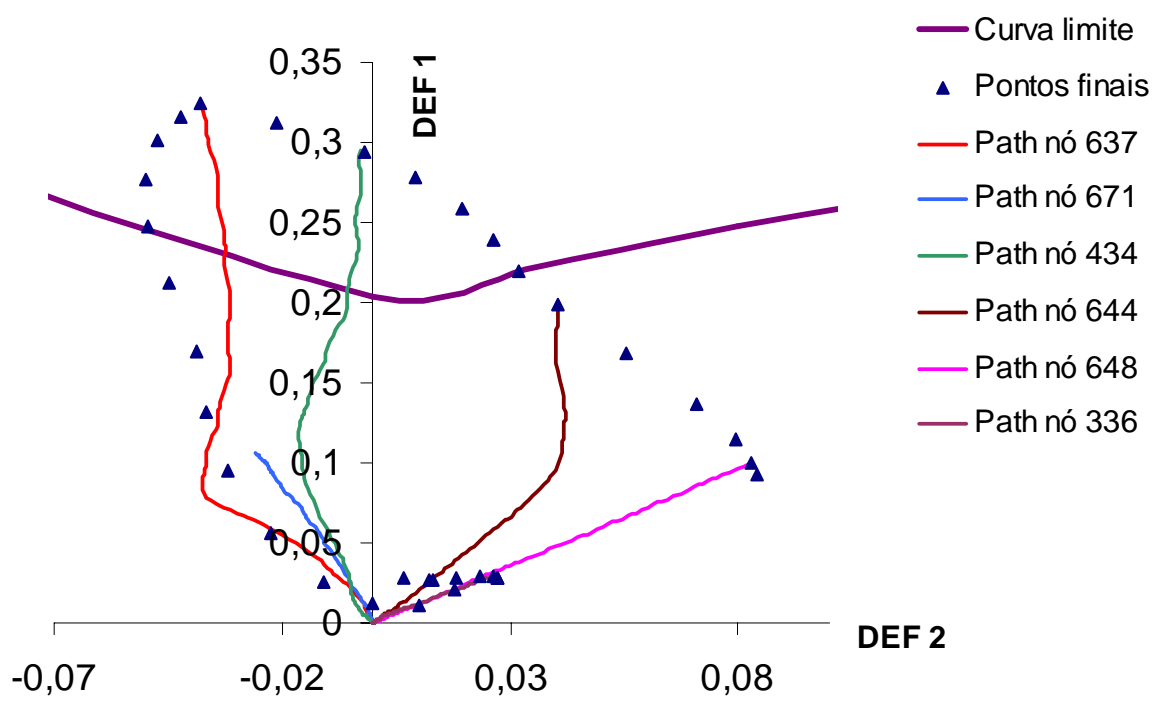

FIGURA 5.3.2 : Mapa de deformações para o caso 1 , passo 99.

Assim, observou-se que o nó 637 apresentou valores mais críticos do par $\left(\varepsilon_{1}, \varepsilon_{2}\right)$ e após uma verificação nos valores da trajetória de deformações deste nó em todos os passos, obteve-se que o substep crítico foi o de número 76. Com este dado, limitaram-se os paths dos demais nós escolhidos e foram obtidos novos valores $\left(\varepsilon_{1}, \varepsilon_{2}\right)$ para a linha de nós "RAIO" especificada na fig. (5.3.1). Os novos resultados são esquematizados no mapa da fig. (5.3.3) :

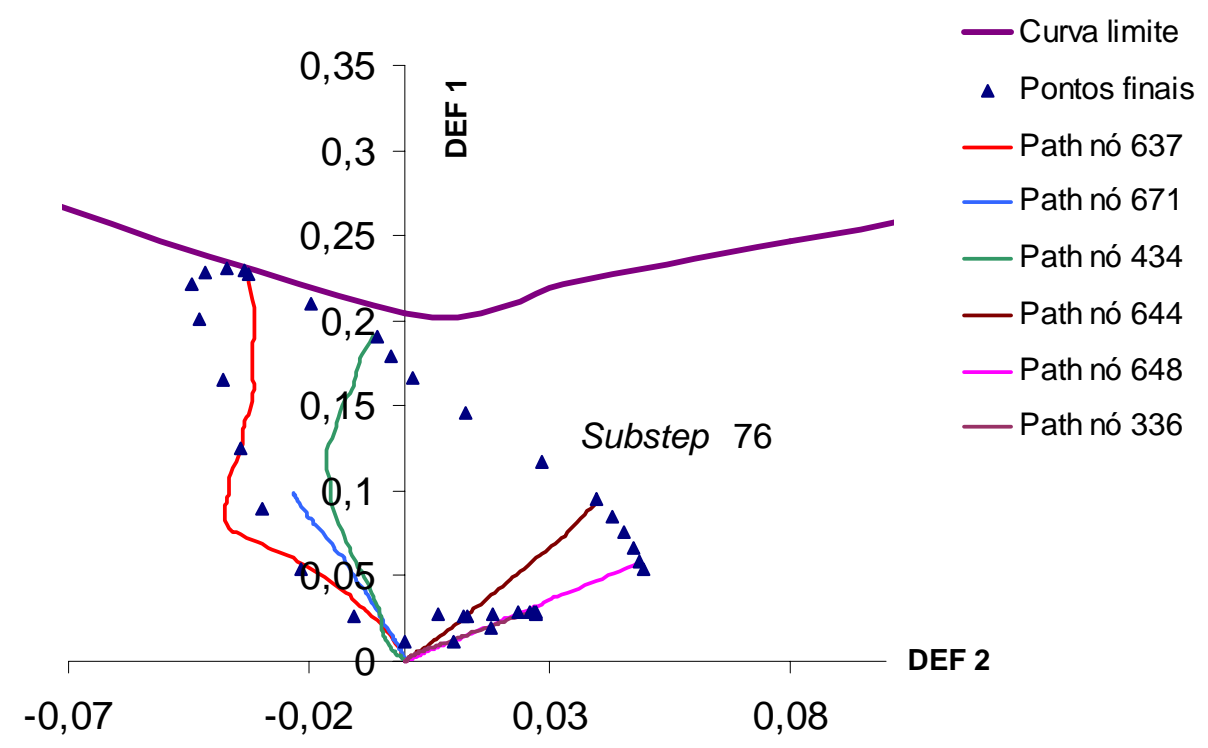

FIGURA 5.3.3 : Mapa de deformações para o caso 1 , passo 76. 
Com isto limitou-se o processo do caso 1 a partir da trajetória de deformações nó 637 desenhada até a curva limite de estricção . No passo 76 da solução têm-se novas representações para as deformações, as quais são coerentes com os resultados anteriores, devido à simetria, ao conjunto de valores menores do que no passo 99 e a concordância com os valores dos pontos finais do gráfico da fig. (5.3.3) . Assim :

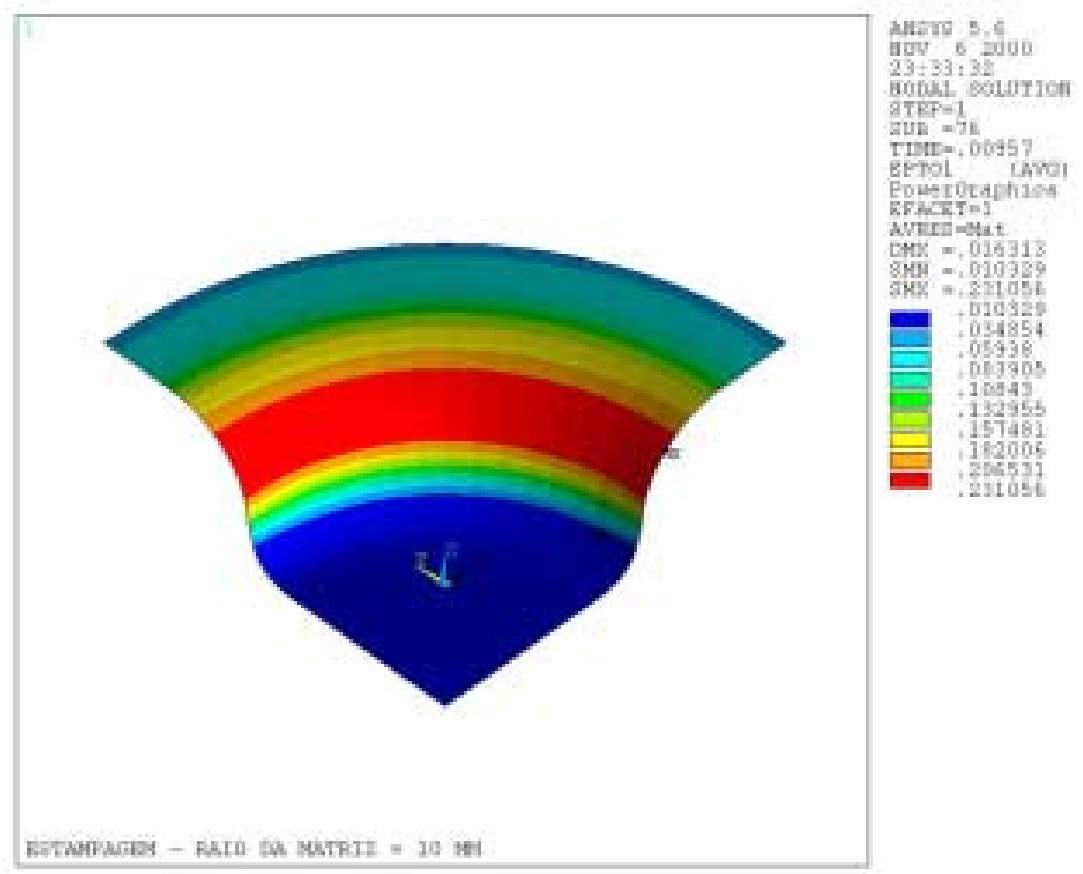

FIGURA 5.3.4 : Deformações totais na direção principal 1 .

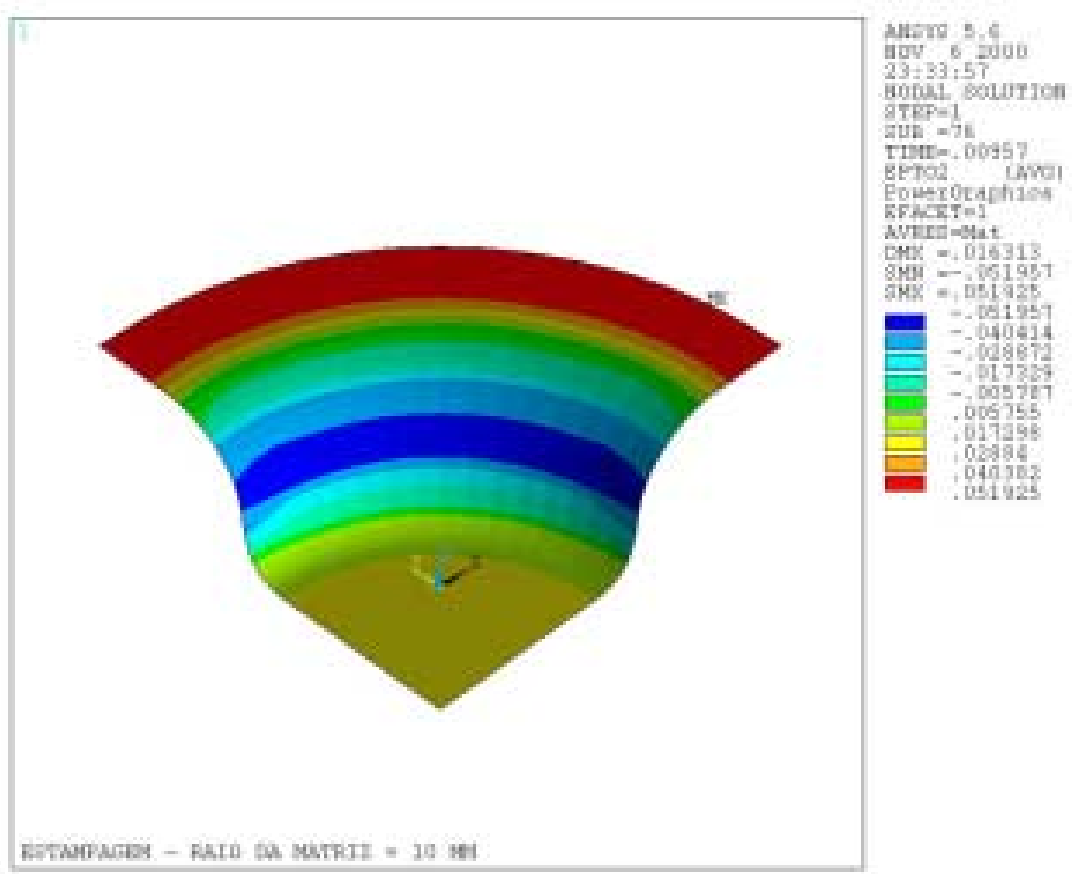

FIGURA 5.3.5 : Deformações totais na direção principal 2 . 


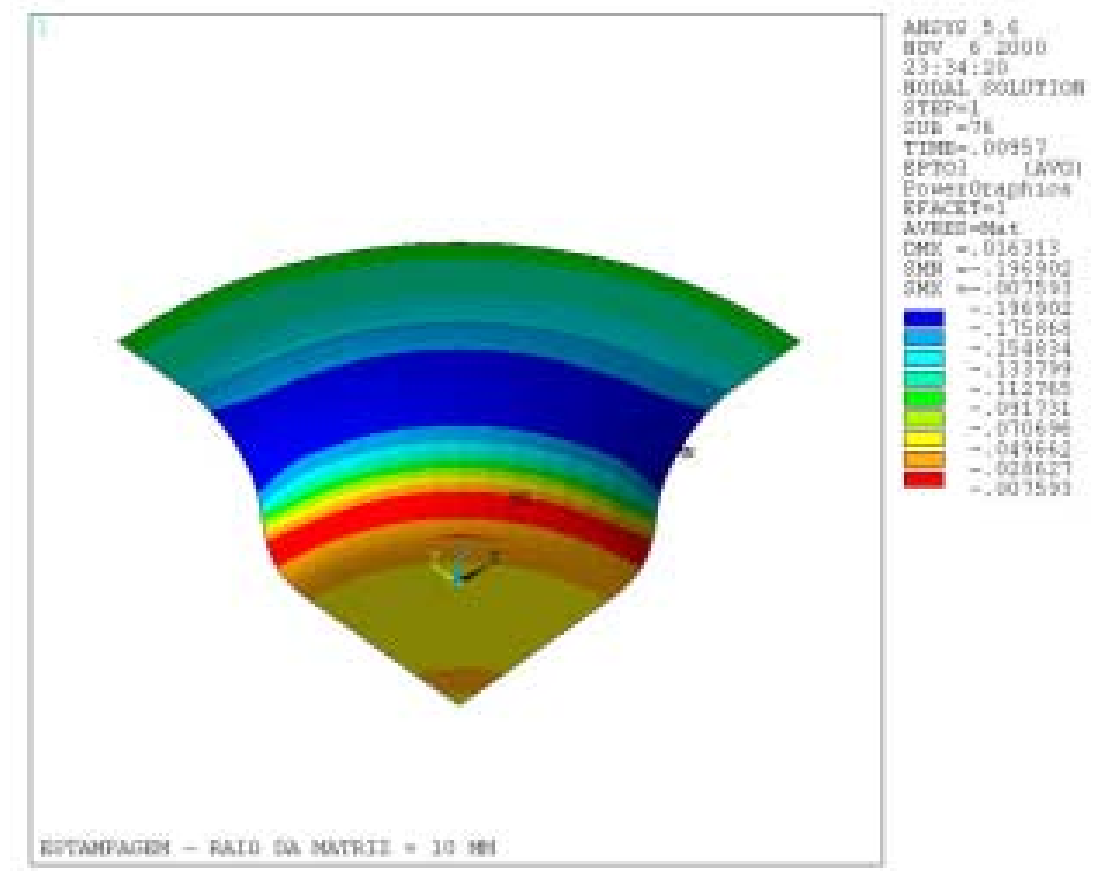

FIGURA 5.3.6 : Deformações totais na direção principal 3 (espessura da chapa) .

Desta forma, no passo 76 de solução a profundidade alcançada no processo é de $16,30 \mathrm{~mm}$.

Um aspecto importante é a variação das deformações de espessura ao longo da chapa estampada . Como o caso 1 é axissimétrico, uma linha radial é suficiente, de modo a partir do centro da chapa até limite na borda desta.

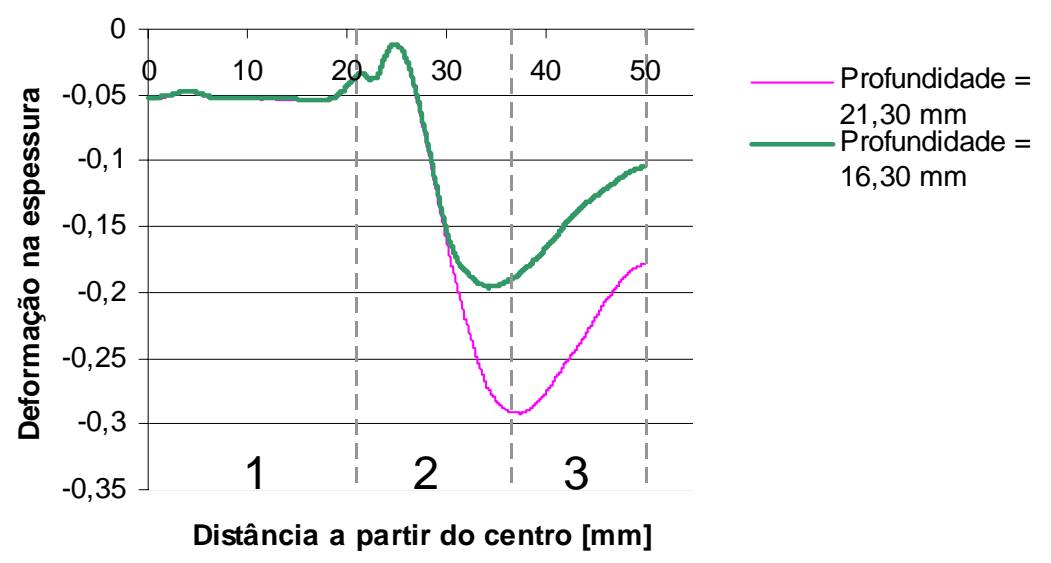

FIGURA 5.3.7 : Variação da deformação na direção principal 3 (espessura da chapa) .

Nesta figura há 3 regiões : 
Região 1 : Distância de 0 a 21,0 mm do centro da chapa, para o contato da face plana inferior do punção com a chapa ;

Região 2 : Distância de 21,0 a 36,5 mm, para a região de contato da chapa com os raios do punção e da matriz ;

Região 3 : Distância de 36,5 a mais de $50,0 \mathrm{~mm}$, para o contato da chapa com o prensa-chapas e a matriz .

Tem-se que pela redução da profundidade de estampagem em 5,00 mm (de 21,30 para $16,30 \mathrm{~mm}$ ou $-23,47 \%$ ) possibilitou-se uma redução de 33,3\% no módulo das deformações máximas de espessura. Isto permite uma estipulação prévia de tolerância na espessura da peça final, dentro das condições estudadas, conforme :

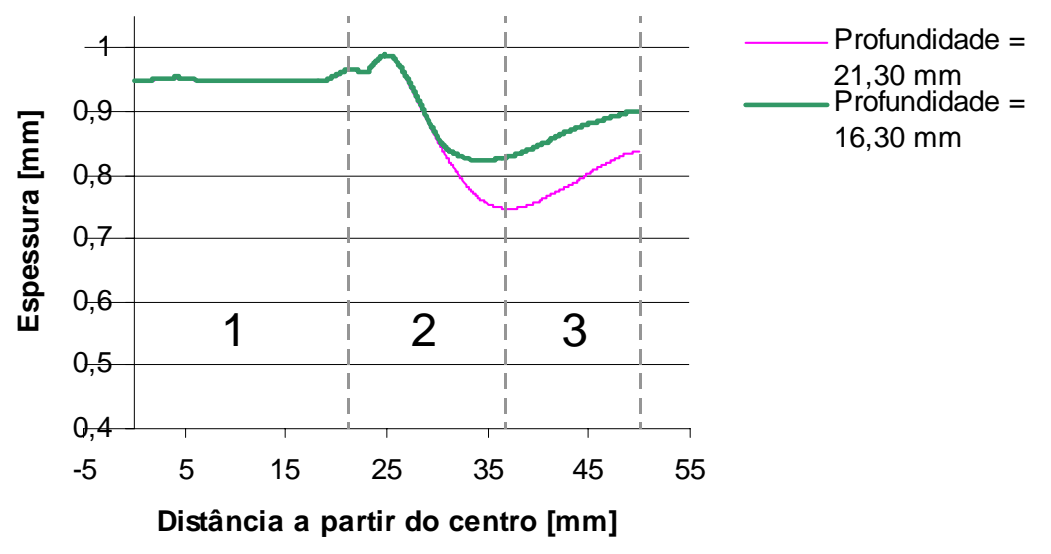

FIGURA 5.3.8 : Variação da espessura da chapa na direção principal 3.

Com estes procedimentos limita-se a variação na espessura da chapa de 0,20 mm (mínimo de 0,8 mm a 1,00 mm, com espessura inicial de 1,00 mm) .

\subsubsection{Avaliação do caso 2}

Para a análise deste caso, os nós da malha construída na chapa foram escolhidos conforme a numeração do software na fig. (5.3.9) . Neste caso há duas linhas de nós a serem consideradas : uma linha definida como "LADO" ou seja, uma linha de nós direcionados à borda reta da chapa e a outra definida como "RAIO", direcionada do centro até a borda arredondada da chapa . Em cada uma foram 
escolhidos alguns nós para a análise detalhada, sendo que os demais nós pertencentes a uma linha foram considerados em termos de seus pontos finais $\left(\varepsilon_{1}, \varepsilon_{2}\right)$ nos mapas de deformações, como visto anteriormente.

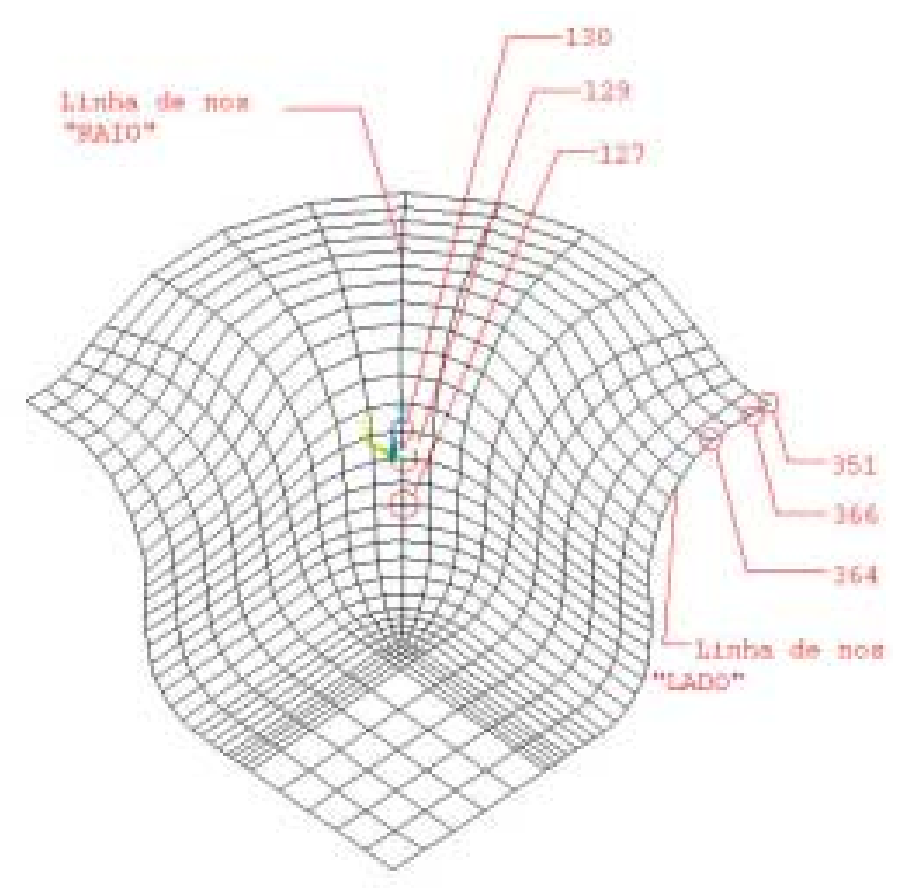

FIGURA 5.3.9 : Numeração de nós para análise do caso 2 .

Na figura (5.3.10) tem-se o diagrama de limite de conformação escolhido no capítulo 4 comparado a estes valores, especificados como "pontos finais" para o lado e para o raio, conforme a legenda. Para os nós escolhidos foram desenhados no mesmo diagrama os conjuntos de valores $\left(\varepsilon_{1}, \varepsilon_{2}\right)$ para estes nós e em todos os passos de solução . As linhas obtidas, definidas como trajetórias de deformações (paths), representam o andamento do processo no plano das deformações principais 1 e 2 . Para o início de estricção, no enfoque deste trabalho, limitam-se analogamente os paths na região de segurança abaixo da curva limite . 


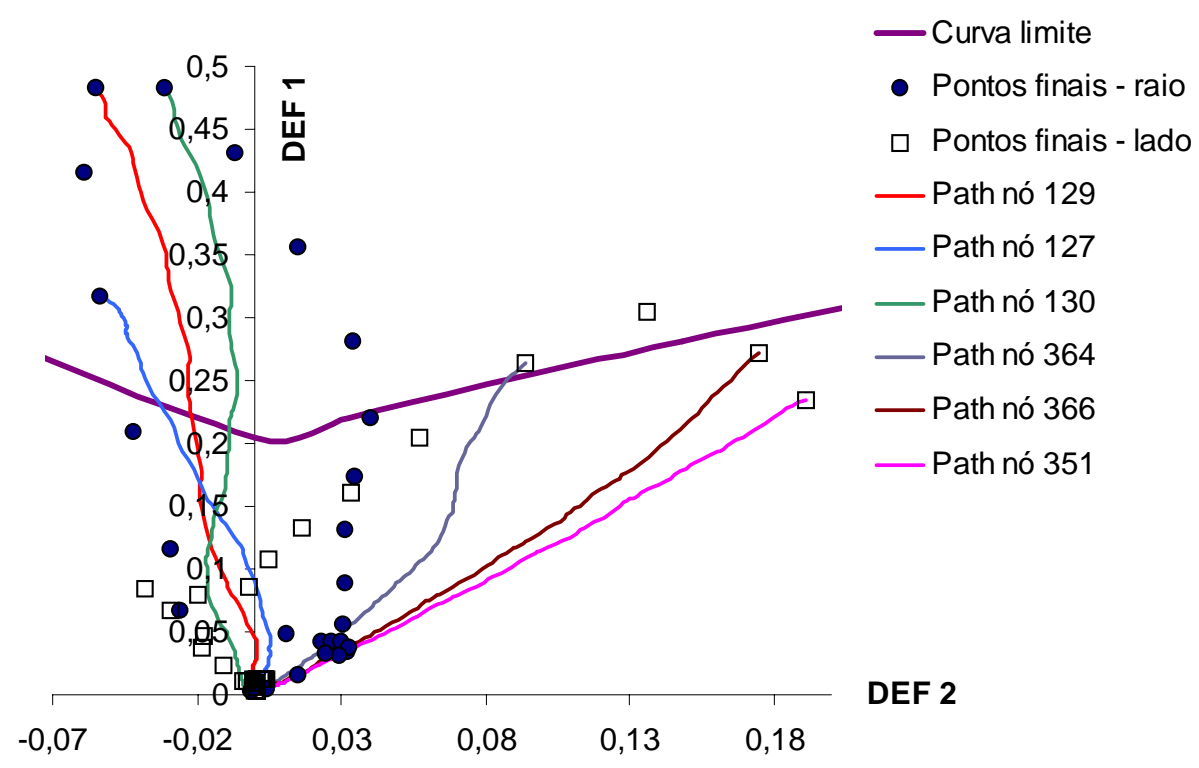

FIGURA 5.3.10 : Mapa de deformações para o caso 2, passo 99.

Assim, observou-se que o nó 129 apresentou valores mais críticos do par $\left(\varepsilon_{1}, \varepsilon_{2}\right)$ e após uma verificação nos valores da trajetória de deformações deste nó em todos os passos, obteve-se que o substep crítico foi o de número 58 . Com este dado, limitaram-se os paths dos demais nós escolhidos e foram obtidos novos valores $\left(\varepsilon_{1}, \varepsilon_{2}\right)$ para a linha de nós "RAIO" e para linha de nós "LADO" especificada na fig. (5.3.9). Os novos resultados são esquematizados no mapa da fig. (5.3.11) :

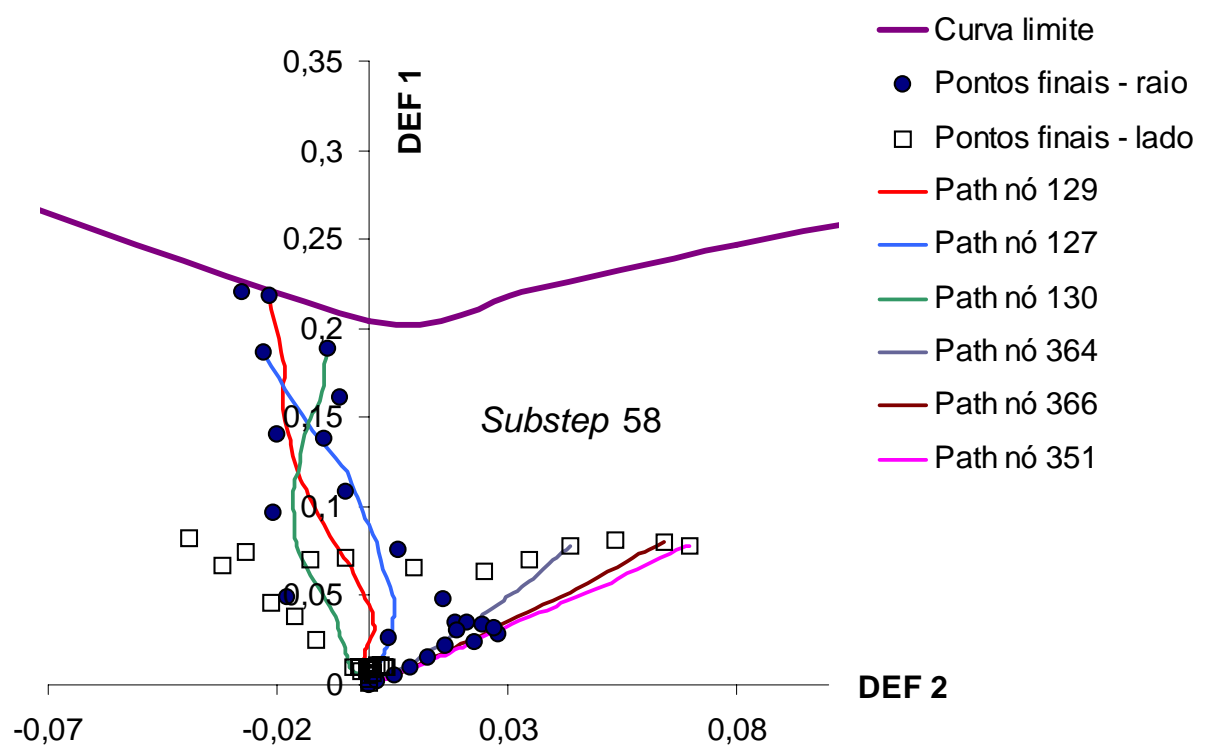

FIGURA 5.3.11 : Mapa de deformações para o caso 2, passo 58. 
Com isto limitou-se o processo do caso 2 a partir da trajetória de deformações do nó 129 desenhada até a curva limite de estricção . No passo 58 da solução têm-se novas representações para as deformações, coerentes com a fig. (5.3.11) e dadas por:

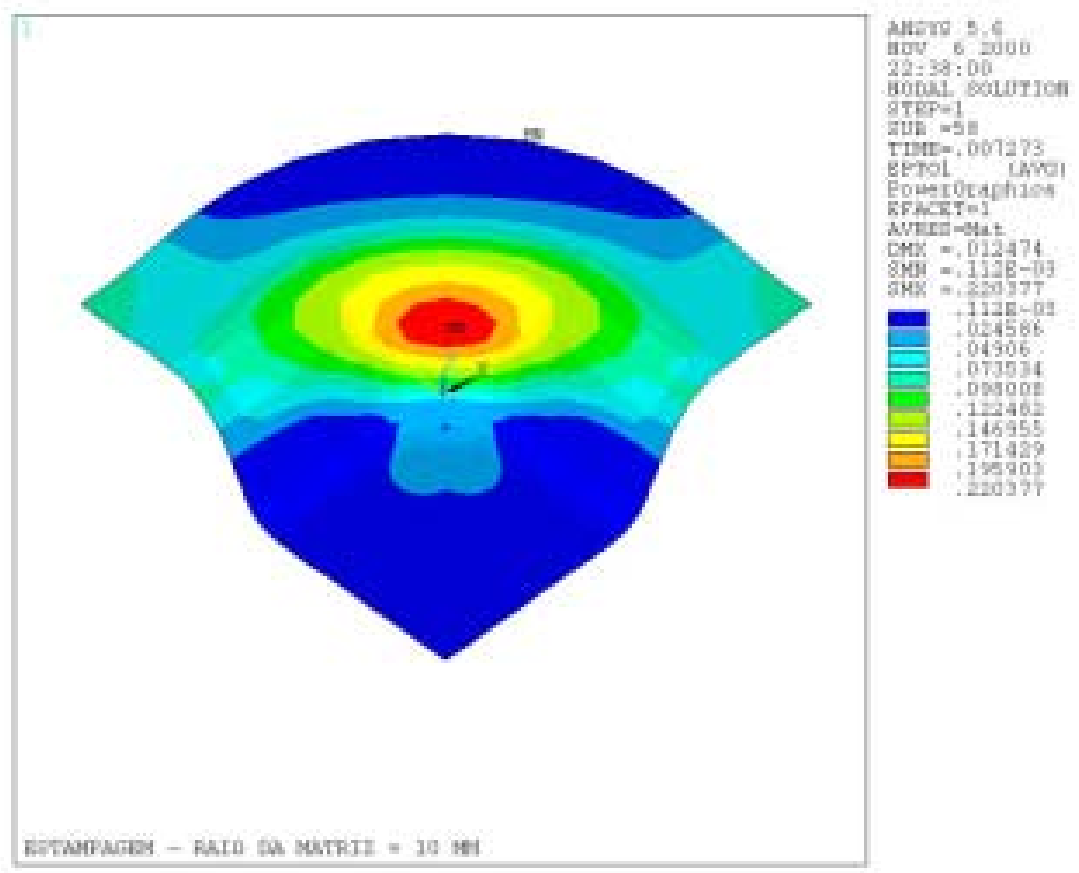

FIGURA 5.3.12 : Deformações totais na direção principal 1 .

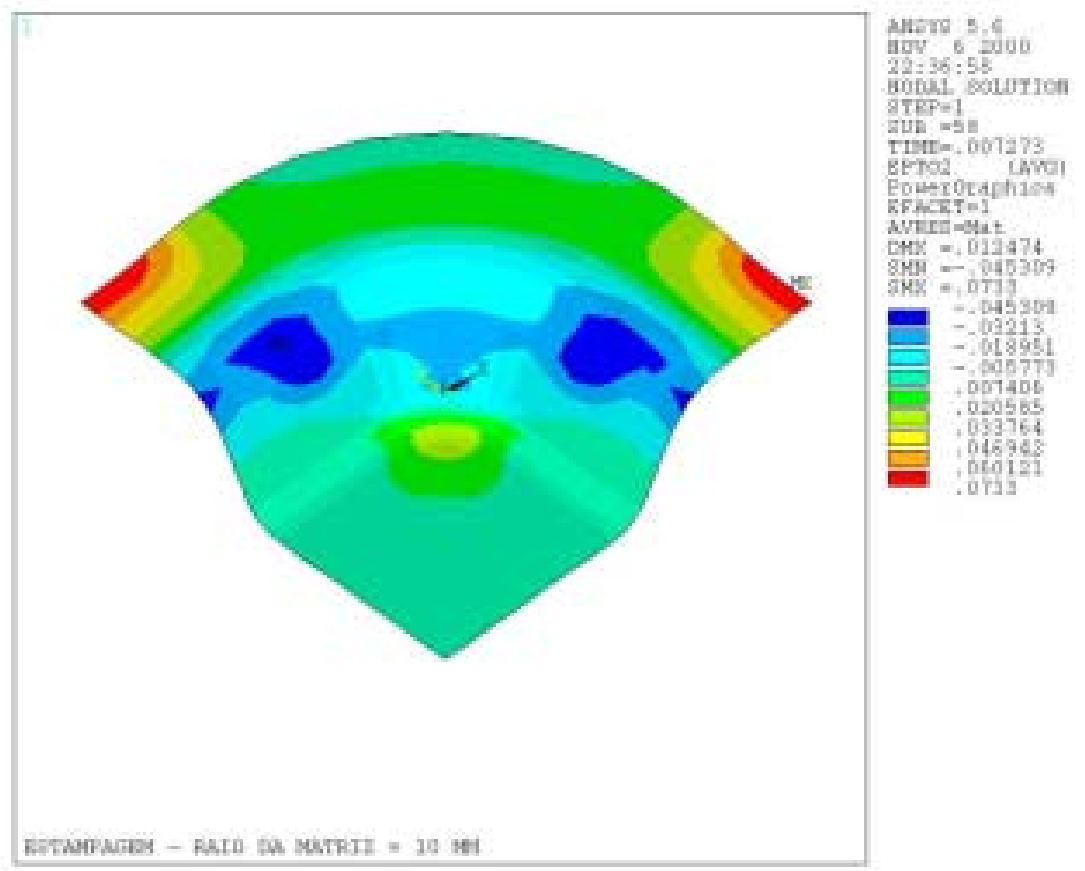

FIGURA 5.3.13 : Deformações totais na direção principal 2 . 


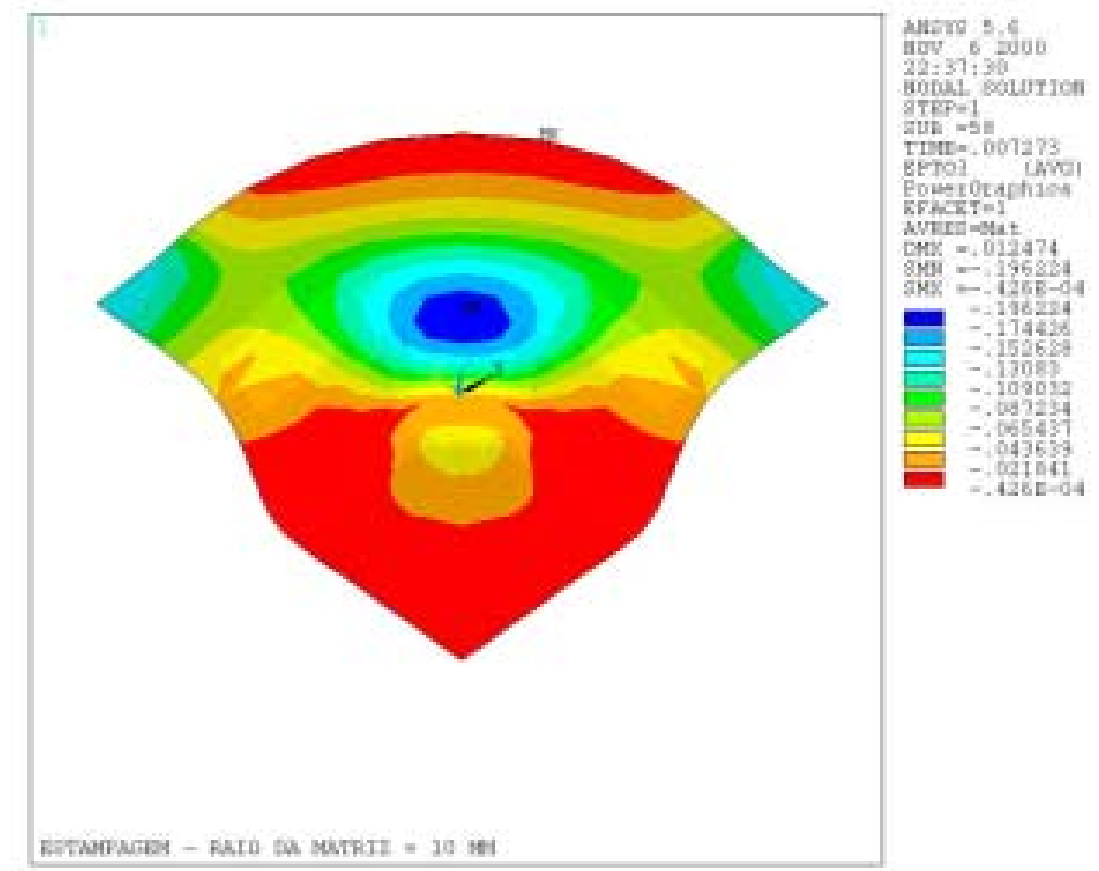

FIGURA 5.3.14 : Deformações totais na direção principal 3 .

Desta forma, no passo 58 de solução a profundidade alcançada no processo é de $12,50 \mathrm{~mm}$.

Para avaliar-se a deformação de espessura ao longo das duas linhas de nós escolhidos vem que :

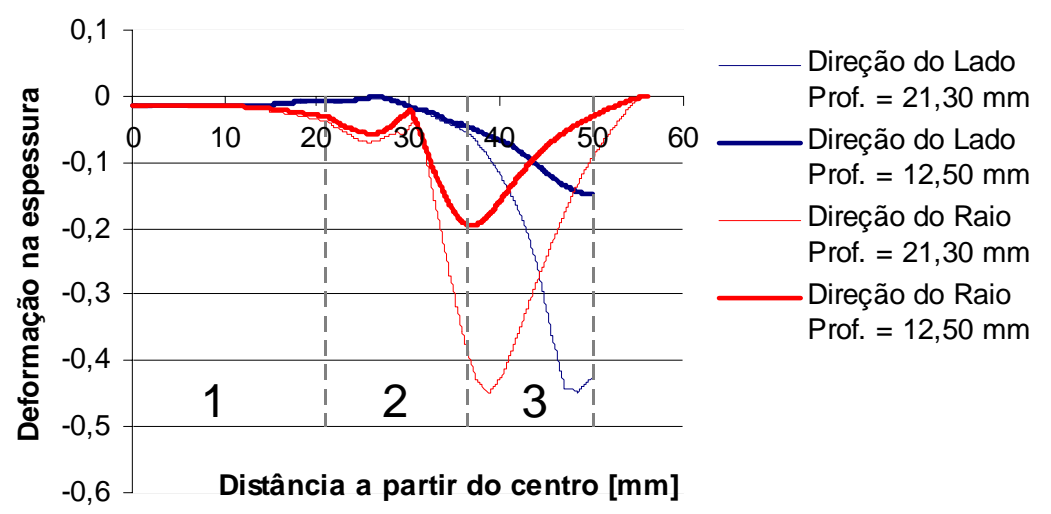

FIGURA 5.3.15 : Variação da deformação na direção principal 3 (espessura da chapa) .

Pela fig. (5.3.15) a redução na profundidade de estampagem de 8,80 mm (de 21,30 para 12,50 mm ou -41,31 \%) possibilitou-se uma redução de 55,5\% no módulo das deformações máximas de espessura para a linha de nós direcionada para o canto 
arredondado. Para a linha cujo final é a borda da peça com lado reto, a redução no módulo das deformações máximas de espessura foi de $66,7 \%$.

Para a tolerância na espessura da peça final, dentro das condições estudadas, tem-se :
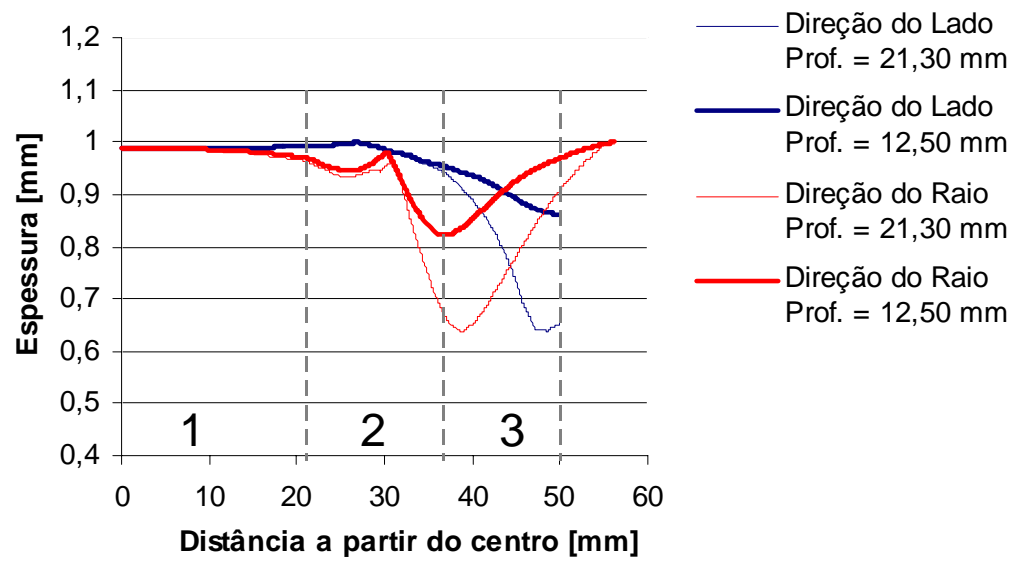

FIGURA 5.3.16 : Variação da espessura da chapa na direção principal 3.

Com estes procedimentos limita-se a variação máxima na espessura da chapa de 0,20 mm (mínimo de 0,8 $\mathrm{mm}$ a 1,00 mm, com espessura inicial de 1,00 mm) para o substep 58 da solução .

Os dois casos de estampagem aqui analisados podem ser comparados diretamente, uma vez que as dimensões dos problemas 1 e 2 são muito similares e sendo que a diferença principal está no perfil axissimétrico ou quadrado com raios de canto. Considerando-se os substeps críticos nos dois casos (passo 76 para o caso 1 e passo 58 para o caso 2) e as linhas de nós das malhas construídas apresentadas anteriormente, apresentam-se as comparações na fig. (5.3.17) .

Assim : 


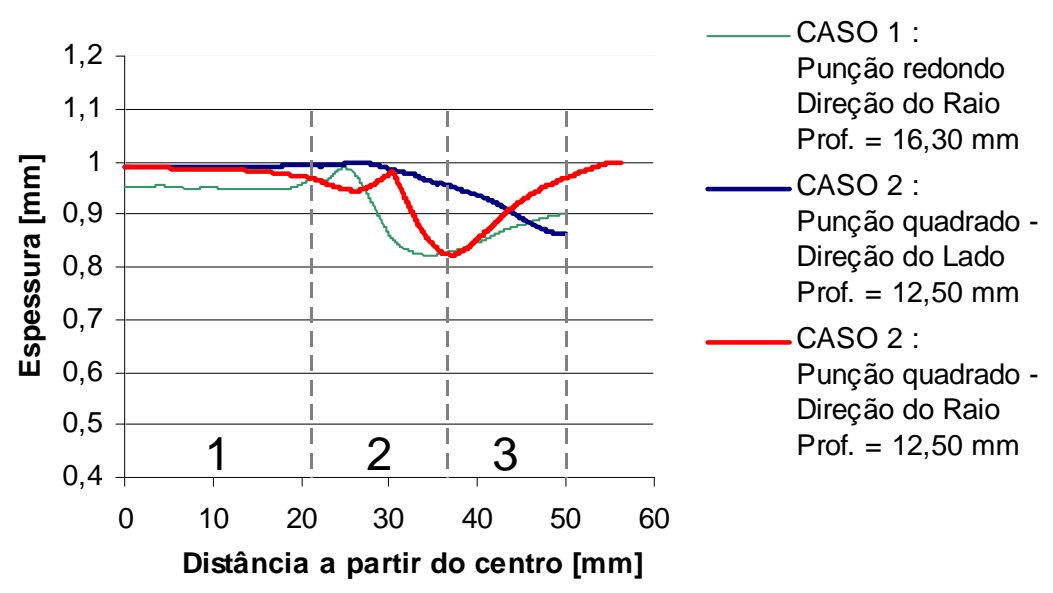

FIGURA 5.3.17 : Comparação da variação da espessura da chapa na direção principal 3, casos 1 e 2 .

Um requisito para os processos de conformação é dado pela distribuição uniforme de deformações na espessura da peça. Assim, a chapa vista no caso 1 (punção redondo) apresenta maior regularidade que no caso 2 (direção do raio) nas regiões 2 e 3 em que há melhor escoamento de material.

No caso 2 o trecho da chapa que encerra-se no lado reto apresenta melhor distribuição de deformações que na borda com raio de arredondamento. Isto é devido a que o trecho reto apresenta um volume menor de material na entrada da matriz do que o trecho arredondado. Assim facilitou-se o fluxo de material e conseqüentemente a distribuição de deformações, principalmente nas regiões 2 e 3 . A concentração de deformações de espessura no trecho de borda arredondada e na região 2 é confirmada pelas figs (5.3.10) através do path do nó 129 e das figs. (5.3.12) e (5.3.14).

Assim, pode-se evitar ou reduzir a estricção através de procedimentos que visem favorecer o fluxo do material nas diversas partes e no andamento do processo.

\subsubsection{Considerações para o diagrama de limite de tensões de conformação}

Apesar de os diversos diagramas de limite conformação converterem-se para aproximadamente uma função linear no espaço de tensões, como visto no cap. 4, o mapeamento de paths de pontos $\left(\sigma_{1}, \sigma_{2}\right)$ no diagrama de limite de tensões de 
conformação não apresentou resultados satisfatórios. No caso 1, para os mesmos nós escolhidos anteriormente, obteve-se para o mapa de tensões :

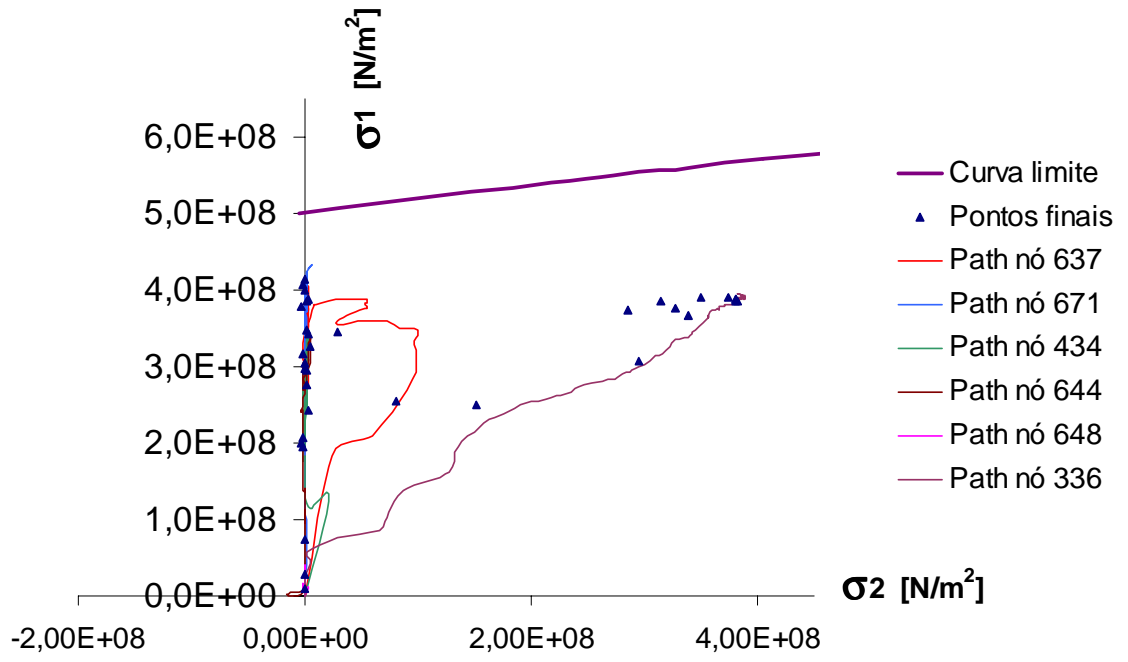

FIGURA 5.3.18 : Diagrama de tensões de conformação, curva limite e paths, caso 1 .

O comportamento irregular dos paths neste caso não permite predições razoáveis do comportamento do processo quando comparado ao comportamento dos paths de deformações, embora os resultados visuais e finais da solução ao longo da chapa apresentem para as tensões uma distribuição tão regular quanto aquelas observadas anteriormente para o caso axissimétrico, como na fig. (5.3.19) .

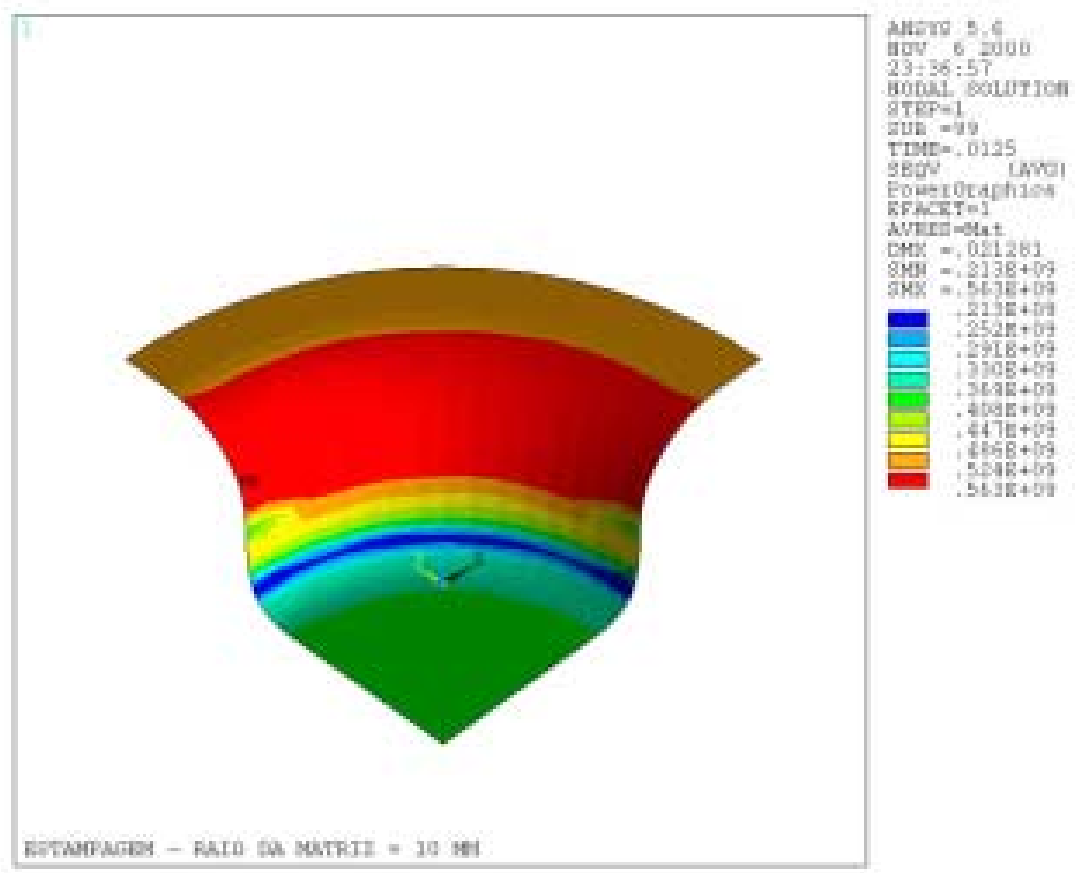

FIGURA 5.3.19: Diagrama de tensões de von Mises, caso 1 . 
São necessários assim estudos posteriores a respeito destes paths de tensões no sentido de verificar-se a influência de aspectos do método de elementos finitos tais como a malha aplicada ao problema, a questão dos parâmetros de contato, a influência do aumento da velocidade de processo em 100 vezes, entre outros.

\subsection{Variáveis para otimização do projeto de estampos}

Apresentou-se uma metodologia para o projeto e reforma de estampos de repuxo, exemplificada através da determinação da profundidade máxima de processo pelo critério da estricção na chapa.

Este método é aplicável para o estudo de outras variáveis do projeto ou processo, entre elas :

- Variáveis geométricas : raios do punção, raios da matriz, dimensões exteriores do blank, dimensões lineares, espessura da chapa, etc.

- Variáveis de processo : velocidade do punção, atrito e controle do prensa-chapas, drawbeads, etc.

- Outras variáveis : Parâmetros de anisotropia, espessura da chapa, expoente de encruamento e de sensibilidade à taxa de deformação, etc

Seguem-se procedimentos análogos aos descritos neste capítulo para a otimização de uma variável relevante, mantendo-se constantes os demais fatores influentes. O cálculo e avaliação em relação aos diagramas de limite de conformação são realizados a partir dos valores iniciais obtidos com uma variável de análise préestipulada. A partir disto, realizam-se novas análises por elementos finitos com modificações desta variável dentro dos limites aceitáveis, de modo a obter um conjunto de resultados a ser verificado e estudado para o próximo passo de otimização. 


\section{6 . Conclusões e sugestões para trabalhos futuros}

Este trabalho alcançou os objetivos previstos inicialmente, dentro das circunstâncias especificadas. O cálculo dos diagramas de limite de conformação foi obtido com adaptações ao método $M K$ visando a implementação por elementos finitos no software ANSYS. Com isto obtiveram-se curvas próximas porém mais conservadoras e de concavidade invertida em relação às curvas citadas e propostas na literatura . Por outro lado, o comportamento destas curvas é coerente com as propriedades de material utilizadas, uma vez adequados os parâmetros $f_{0}$ para o defeito induzido do material. Ressalta-se porém que a forma de utilização destes parâmetros $\left(f_{0}=K_{B} / K_{A}\right)$ encontra-se sugerida em autores citados, mas não utilizada. A sua utilização neste trabalho deveu-se à facilidade de implementação junto ao método de Elementos Finitos. O critério utilizado para a estricção (expressões 4.2 .9 e 4.2.13) é de fácil implementação através de programas associados ao software ANSYS tais como macros e permite também futuros aperfeiçoamentos.

As análises por elementos finitos dos dois casos de estampagem apresentados também foram coerentes entre si e com resultados próximos aos encontrados na literatura para geometrias e materiais similares aos utilizados. A metodologia de avaliação e otimização apresentada torna-se útil para aplicações industriais em estampagem pois apresenta diretrizes para o projeto do estampo de repuxo . Assim pode-se minimizar o tempo gasto no desenvolvimento do ferramental e podem-se minimizar-se também os custos relacionados aos try-outs, contribuindo para um número menor de reformas no ferramental até a liberação final do estampo. 
Sugestões para trabalhos futuros:

Posteriormente pode-se aprimorar o cálculo dos diagramas através do refinamento do algorítimo apresentado, enfocando-se os parâmetros $f_{0}$, os próprios critérios de estricção e os incrementos de carga dados aos seus loops .

Por outro lado pode-se incluir defeitos de processo tais como enrugamentos e fraturas sob enfoques como Mecânica do Dano e da Fratura.

Sob os aspectos da implementação do algorítimo junto ao Método dos Elementos Finitos e do software utilizado, merecem futuras considerações a influência dos contatos e raios de curvatura para o cálculo das deformações no limite de estricção bem como na inclusão de parâmetros como a anisotropia e encruamento prévio e modificações nas direções principais, dentre outros.

Pode-se estender as análises por elementos finitos apresentadas para outros processos de conformação, seguindo-se a mesma metodologia estudada. Merecem também outros estudos o enfoque dinâmico explícito e os algorítimos de contato aplicados aos processos de conformação de chapas. 


\section{Referências Bibliográficas}

AGELET DE SARACIBAR, C.; OÑATE, E. (1991) Modelado Numérico de Procesos de Conformado de Láminas Metálicas. Barcelona, Centro Internacional de Métodos Numéricos en Ingeniería. Cap.5, p.5.1-5.80. /Monografia ${ }^{\circ}$ 8/

ALTAN, T.; OH, S. I.; GEGEL, H. L. (1983) Metal forming: fundamentals and applications. Ohio, American Society for Metals - ASM, 353p.

ANSYS User's Manual. Theory manual. 1995. ANSYS revision 5.2. v.4. p. 3.1-4.57.

ARRIEUX, R. (1995). Determination and use of the forming limit stress diagrams in sheet metal forming. Journal of Materials Processing Technology. v. 53, n. 1-2, p. 47-56, aug.

ARRIEUX, R.; BRUNET, M.; VACHER, P.; NHAT, T.N. (1996). A method to predict the onset of necking in numerical simulation of deep drawing operations. Ann. CIRP. v. 45, p. 255-258.

ASSOCIAÇÃO BRASILEIRA DE NORMAS TÉCNICAS (1979). NBR-MB362/79

Determinação do índice de embutimento em chapas de aço pelo método

Erichsen modificado . Rio de Janeiro .

ASSOCIAÇÃO BRASILEIRA DOS METAIS. (1971). Estampagem dos aços. São Paulo.

BANABIC, D. (1999). Limit strains in the sheet metals by using the new hill's yield criterion (1993). Journal of Materials Processing Technology. v. 92-93, p.429432.

BATHE, K. J. (1996). Finite element procedures. New Jersey, Prentice Hall, p.485641.

BLECK, W.; DENG, Z.; PAPAMANTEllOS, K.; GUSEK, C.O. (1998). Comparative study of the forming-limit diagram models for sheet steels. Journal of Materials Processing Technology. v. 83, n. 1-3, p. 223-230, nov. 
CHAN, K.C.; GAO, L. (1996). On the susceptibility to localized necking of defectfree metal sheets under biaxial stretching. Journal of Materials Processing Technology. v. 58, n. 2-3, p. 251-255, mar.

DEEP drawing. In: AMERICAN SOCIETY FOR METALS. Metals handbook : forming and forging. 9.ed. Metals Park, Ohio, 1988. v.14, p. 575-590.

DOEGE, E.; DRÖDER, K.; GRIESBACH, B. (1997). On the development of new characteristics values for the evaluation of sheet metal formability. Journal of Materials Processing Technology. v. 72, p.152-159.

FERNANDEZ, F.F.; AL-QURESHI, H.A. (1999). Desenvolvimento de novo teste para ensaio de estiramento in-plane de chapas metálicas. In : CONFERÊNCIA NACIONAL DE CHAPAS, 2., Porto Alegre, 1999. Anais. Porto Alegre, UFRGS., p. 97-106.

FERRON, G.; MAKINDE, A. (1988). Design and Development of a Biaxial Strength Testing Device. Journal of Testing and Evaluation. v. 16, n. 3, p. 253256, may.

GRAF, A.; HOSFORD, W.F. (1990). Calculations of forming limit diagrams. Metallurgical Transactions. v. 21A, p. 87-94.

HALLQUIST, J.O. (1993). LS-DYNA-3D Theoretical Manual. 2.ed. Livermore, USA. Livermore Software.

HILL, R. (1950) The mathematical theory of plasticity. London, Oxford University Press.

HOFFMAN, O.; SACHS, G. (1953) Introduction to the theory of plasticity for engineers. New York, McGraw-Hill.

HUEBNER, K.H.; THORNTON, E.A. (1982). The Finite Element Method for Engineers. 2. ed. John Wiley \& Sons.

KOBAYASHI, S.; OH, S.I.; ALTAN, T. (1989). Metal Forming and the FiniteElement Method. Oxford University Press.

LANGE, K. (1997). Modern metal forming technology for industrial production. Journal of Materials Processing Technology. v. 71, p.2-13.

LEE, D.; MAJLESSI, S.A.; VOGEL, J.H. Process modeling and simulation for sheet forming. In: AMERICAN SOCIETY FOR METALS. Metals handbook : forming and forging. 9.ed. Metals Park, Ohio, 1988. v.14, p. 911-927. 
LIRANI, J. (1978). Substructuring techniques in the analysis of partially coated structures. Manchester. 177p. Tese (Doutorado) - Institute of Science and Technology, The University of Manchester.

MAKINOUCHI, A. (1996). Sheet metal forming simulation in industry. Journal of Materials Processing Technology, v.60, p.19-26.

MAMALIS, A.G.; MANOLAKOS, D.E.; BALDOUKAS, A.K. (1996). Simulation of sheet metal forming using explicit finite element techniques: effect of material and forming characteristics Part 1. Deep-drawing of cylindrical cups. Journal of Materials Processing Technology. v. 58, p.48-60.

MAMALIS, A.G.; MANOLAKOS, D.E.; BALDOUKAS, A.K. (1996). Simulation of sheet metal forming using explicit finite element techniques: effect of material and forming characteristics Part 2. Deep-drawing of square cups. Journal of Materials Processing Technology. v. 58, p.110-116.

MAMALIS, A.G.; MANOLAKOS, D.E.; BALDOUKAS, A.K. (1996). On the finite-element modelling of deep-drawing of square sections of coated steels. Journal of Materials Processing Technology. v. 58, p.153-159.

MAMALIS, A.G.; MANOLAKOS, D.E.; BALDOUKAS, A.K.(1997). FiniteElement Modelling of Stretch Forming of Coated Steels. Journal of Materials Processing Technology. v. 68, p.71-75.

MARCINIAK, Z.; DUNCAN, J.L. (1992). The Mechanics of Sheet Metal Forming. Edward Arnold.

MENDELSON, A. (1983).Plasticity: theory and application. Malabar, Robert E. Krieger Publishing Company.

MORENO, M.E.; CARVALHO, J.; LIRANI, J.(1999). Desenvolvimento de uma Metodologia de Otimização do Perfil do Blank em Processos de Conformação de Chapas Metálicas. . In : CONFERÊNCIA NACIONAL DE CHAPAS, 2., Porto Alegre, 1999. Anais. Porto Alegre, UFRGS., p. 7-16.

MORENO, M.E. (2000). Desenvolvimento e implementação de metodologia de otimização da geometria do blank em processos de conformação de chapas metálicas. São Carlos. 88p. Dissertação (Mestrado) - Escola de Engenharia de São Carlos, Universidade de São Paulo. 
NARASIMHAN, K.; MILES, M.P.; WAGONER, R.H. (1995). A better sheet formability test. Journal of Materials Processing Technology. v. 50, p.385-394.

OWEN, D. R. J.; HINTON, E. (1986). Finite Elements in plasticity: theory and practice. Swansea, Pineridge Press.

RASMUSSEN,S.N. (1981) Theoretical Prediction of Strainpath Dependence of Limit Strains in Sheet Metals. Ann. CIRP. v. 30, p. 179-184.

SIEGERT, K.; ZIEGLER, M.; WAGNER, S. (1997). Closed loop controle of the friction force. Deep drawing process. Journal of Materials Processing Technology. v. 71, p.126-133.

SING, W.M.; RAO, K.P. (1997). Role of strain-hardening laws in the prediction of forming limit curves. Journal of Materials Processing Technology. v. 63, p.105110.

STOUGHTON, T.B. (2000). A general forming limit criterion for sheet metal forming. International Journal of Mechanical Sciences. v. 42 2000, p.1-27.

TAYLOR, B. Formability testing of sheet metals. In: AMERICAN SOCIETY FOR METALS. Metals handbook : forming and forging. 9.ed. Metals Park, Ohio, 1988. v.14, p. 877-899.

VACHER, P.; ARRIEUX, R.; TABOUROT, L.(1998). Analysis of Criterion of Deep Drawing Operation Capability for Thin Orthotropic Sheets. Journal of Materials Processing Technology. v. 78, p.190-197.

ZHAO, L.; SOWERBY,R. ; SKLAD,M.P. (1996). Theoretical and experimental investigation of limit strains in sheet metal forming. International Journal of Mechanical Sciences. v. 38, n. 12, p. 1307-1317, dec.

ZIENKIEWICZ, O C. (1977) The Finite Element Method. London, McGraw-Hill. $787 \mathrm{p}$. 


\section{Apêndice I - Descrição dos tipos de elementos utilizados nas simulações}

\section{SOLID45 : Elemento sólido estrutural 3-D implícito}

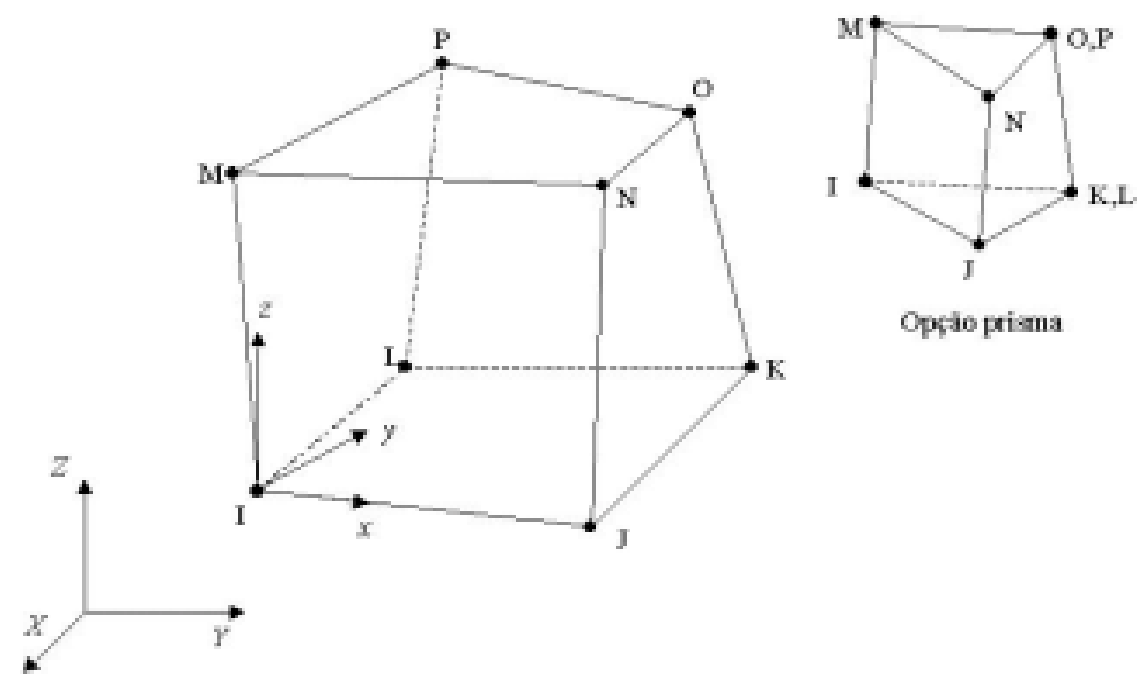

FIGURA I-1 : Elemento SOLID45

Elemento de 8 nós utilizado em modelagens tridimensionais de estruturas sólidas. Para cada nó são definidos os graus de liberdade de translação nodal nas direções $x, y, \mathrm{e} z$.

Neste tipo de elemento, pode-se aplicar forças e deslocamentos nodais como condições externas ao problema. Pressões podem ser aplicadas nas superfícies do elemento, sendo adotada a convenção que uma pressão positiva atua sobre o elemento.

Para as propriedades do material, devem ser fornecidos os valores de módulo de Young, coeficiente de Poisson e densidade. O material pode ser definido como ortotrópico. Alguns modelos de material para este elemento são listados a seguir, sendo que eventualmente são exigidos valores específicos de propriedades : 
- Bilinear e Multilinear cinemático

- Bilinear e Multilinear isotrópico

- Anisotrópico

- Hiperelástico

- Definido pelo usuário através de curva específica de material ( opção utilizada )

- Outros.

O elemento SOLID45 foi utilizado para modelagem da chapa de teste para o cálculo dos diagramas de limite de conformação.

Para o elemento existe também as opções prisma e tetraedro. Na modelagem do problema de estudo dos diagramas foram utilizados apenas elementos hexaédricos.

\section{SHELL 163: Elemento shell estrutural explícito}

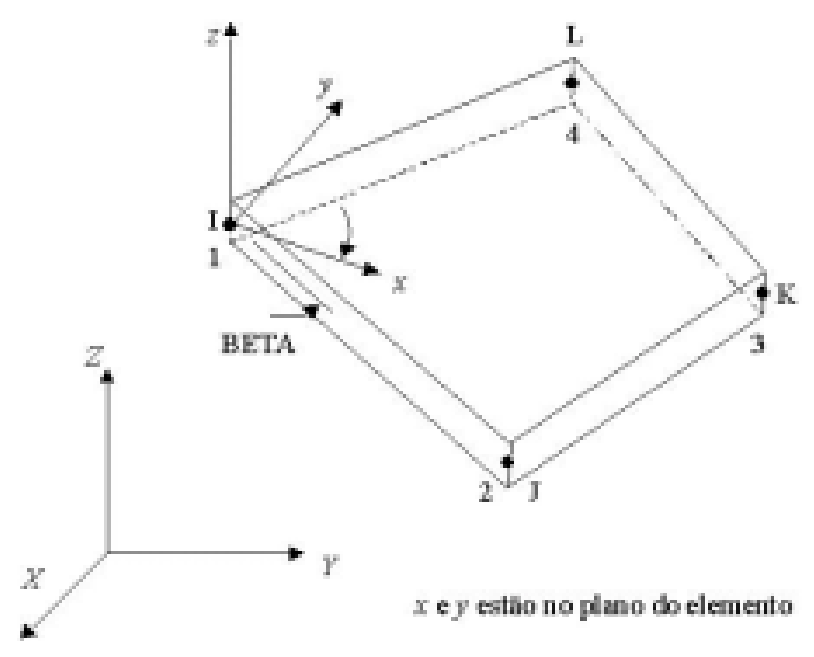

FIGURA I-2 : Elemento SHELL163

O elemento SHELL163 foi utilizado para a modelagem do chapa nos casos 1 e 2 . Possui 4 nós com propriedades de dobramento (bending) e membrana, e aceita carregamentos em seu plano e normais a ele. Possui 12 graus de liberdade por nó: translação, aceleração e velocidade nas direções nodais $x, y$, e $z$ e rotação em torno 
dos eixos nodais $x, y$, e $z$. (ANSYS User's Manual, 1995 e HALLQUIST, 1993). São utilizados apenas para análises dinâmico-explícitas.

$\mathrm{O}$ número de pontos de integração adotado foi o valor padrão estabelecido pelo programa, 2. A espessura solicitada para o elemento shell foi adotada como a espessura da chapa, 1,00 mm, constante em todo o elemento. Foi escolhida como superfície de referência o plano médio do elemento.

Para as propriedades do material, devem ser fornecidos os valores de módulo de Young, coeficiente de Poisson e densidade. O material pode ser definido como rígido e também como ortotrópico (este apenas para simulações com linearidade de material).

Para o comportamento de material, podem ser escolhidos entre outros:

- Elástico e Elástico ortotrópico;

- Bilinear cinemático e Bilinear isotrópico;

- Plástico cinemático (dependente da taxa de deformação);

- Plasticidade por lei de potência;

- Plasticidade dependente da taxa de deformação (opção utilizada).

Nas simulações apresentadas foram utilizados materiais com formulação de plasticidade considerando por lei de potência.

Pressão pode ser aplicada a este elemento, sendo considerada atuando na superfície intermediária do elemento. Não são aceitos como carregamentos forças de campo. Nas simulações os carregamentos foram aplicados aos componentes modelados com elemento SOLID164 (HALLQUIST ,1993) e as forças aplicadas ao elemento shell devem-se ao contato entre os componentes.

São especificados onze tipos de formulação para o elemento SHELL163, e detalhes podem ser obtidos em HALLQUIST (1993). Dentre as formulações permitidas, foi escolhida a formulação de Hughes-Liu, que resulta em maiores custos computacionais, mas é a mais eficiente quando se espera grandes deformações na peça. 